\title{
Predicting Solvation Thermodynamics in Water and Ionic Liquids Using the Multi-Scale Solvation-Layer Interface Condition (SLIC) Continuum Model
}

\author{
Ali Mehdizadeh Rahimi and Safa Jamali \\ Department of Mechanical and Industrial Engineering, \\ Northeastern University, Boston MA 02115 \\ Jaydeep P. Bardhan \\ Pacific Northwest National Laboratory, Richland WA 99354 \\ Steven R. Lustig* \\ Department of Chemical Engineering, Northeastern University, Boston MA 02115
}

(Dated: September 14, 2021)

\begin{abstract}
We highlight the most recent developments of the solvation-layer interface condition (SLIC) continuum dielectric model in predicting solvation thermodynamics of neutral small molecules in water and multiple ionic liquids. We demonstrate that a simple temperature-dependent solventaccessible-surface-area (SASA) correlation and a cavity-dispersion-combinatorial (CDC) theory, combined with the SLIC electrostatics model, provide highly accurate predictions of Gibbs solvation energies, solvation entropies, and solvation heat capacities. The SLIC/SASA model parameters are temperature dependent, whereas the SLIC/CDC parameters are constant. Compared to experimental data, the SLIC/SASA and SLIC/CDC models, respectively, achieve an RMS error 1.25 (1.24) and $0.98(1.76) \mathrm{kcal} / \mathrm{mol}$ for hydration Gibbs energy (hydration entropy) predictions. Solvation heat capacities are predicted with RMS errors 24.42 and $46.17 \mathrm{cal} / \mathrm{mol} / \mathrm{K}$. Most remarkably, the SLIC/CDC predictions of solvation entropies and heat capacities are made without apriori knowledge of experimental solvation entropies. In addition, the SLIC/SASA predictions of Gibbs solvation energies (solvation entropies) of 12 amino acid side-chain analogs in seven (three) ionic liquids are compared to the available explicit-solvent simulation data from Paluch et al. 74 and Latif 54 et al.
\end{abstract}

\footnotetext{
${ }^{*}$ Corresponding Author
} 


\section{INTRODUCTION}

Implicit solvent models can be solved orders of magnitude faster than atomistic, explicitsolvent models to compute comparably accurate thermodynamic properties. They replace detailed statistical sampling of solvent molecular positions and orientations with continuum electrostatics. The starting point for standard continuum electrostatics models is almost always the Poisson or Poisson-Boltzmann partial differential equations that couple a microscopic description of solute to a macroscopic representation of the solvent, 7, 41, 22. Solutes have been described using different levels of granularity; from an electronic structure level, as in polarizable continnum model $(\mathrm{PCM})^{62,63}$ up to coarse-grained models for DNA 52,87 and large macromolecules 24,81. Even though the continuum description of solvent significantly reduces the complexities involved in statistical modelling, some of the continuum electrostatics approximations breakdown in systems at atomistic length scales, that in turn can lead to serious errors in predictions when compared with experimental data 17, 37, 50,56, 34, 88, 91 . This work presents two significantly improved implicit solvent models that remedy these inaccuracies by making two simple modifications to the standard continuum electrostatics theory.

Many prior investigators have taken different approaches to address the inaccuracies of the standard continuum electrostatics theory. Several models use a non-linear function to describe the dielectric properties of solvent molecules. Sandbergs's Langevin-Debye model $^{79}$ characterizes water polarizbility using the variation of water's relative permittivity with the local electric field. Warshel's Langevin dipoles solvation model uses a nonlinear, electrostatic potential-dependent surface area model to improve the accuracy of standard continuum model in predicting hydration entropies, enthalpies, and Gibbs energies of small molecules 32 . Gong et al. used a nonlinear function to describe the solvent permittivity that depends on the solute-solvent boundary distance to the solute center of mass $\frac{36}{3}$. Numerous models address the deviations from linear-response theory using a non-local theory. Non-local theories replace the governing partial differential equations by partial integrodifferential equations to take into account the near-interface correlations between solvent molecules 29,40,51. Many models address both non-linearity and non-locality of the solvent response. For instance, by including the dipole degrees of freedom for the solvent molecules, Orland and co-workers derived a mean-field level Poisson model that can capture some 
molecular-level characteristics of the solvent molecules, e.g., the organization of solvent molecules around biomolecules, 3, , 18, 19. Additional models that are both non-linear and nonlocal include density-functional theory (DFT)-based approaches ${ }^{34}$, variational approaches $\frac{31}{}$, and statistical-mechanical integral equations 101,102 . Our work differs from previous work in the literature in that we address different sources of inaccuracy in conventional continuum methods, the neglect of charge-sign asymmetry $(\mathrm{CHA}) \underline{38,55,61,69,76}$ and liquid-vapor interface potential20.

Standard continuum models are charge-sign symmetric, meaning that they predict the same solvation Gibbs energy for an ion of charge magnitude $q$, regardless of its sign. In reality, ions of equal size but opposite valence have very different solvation Gibbs energies that may differ as much as $40 \mathrm{kcal} / \mathrm{mol}$ in the same solvent. This effect is known as charge-hydration asymmetry. The two major underlying mechanisms of CHA include steric asymmetry and liquid-vapor interface potential. In water, the steric asymmetry is due to the size difference between the hydrogen and oxygen atoms. Electropositive hydrogens can approach a negative ion more closely than the electronegative oxygens can approach a positive ion of the same radius ${ }^{\mathrm{B}}$. The liquid-vapor interface potential, hereafter called the static potential, emerges due to the highly ordered first solvation shell and has been thoroughly studied using atomistic simulations 5 , 20, 77. The static potential field is approximately constant in the solute interior 20 . Our previous work showed that accounting for the static potential as well as the solvent-steric component significantly improves the accuracy of the solvation Gibbs energy predictions 5 , 75 .

Fitting atomic radii $13,14,55,70$ and using empirical corrections to the first solvation shell 15, 16, 26, 27, $, 99,103$ are popular approaches to address the CHA in aqueous solvation. For example, Purisima et al. 99 used surface charge density on the solute-solvent interface to adjust the Born radius of each solute atom to solve the inaccuracies due to charge asymmetry. Parameter-fitting approaches have some fundamental problems. First, the adjusted atomic radii often exhibit unphysical trends in size, for example, radius of hydrogen may end up becoming larger than that of fluorine $\underline{38}$. Second, other thermodynamic properties are inaccurate. When radii are fitted to reproduce experimental solvation Gibbs energies using the Born expression, the Born model ends up severely overestimating the transfer Gibbs energies and pKa shifts 30,35 . Third, training-set and test-set compounds must have homologous structures $19,71,104,105$.

We have previously introduced an accurate solvation electrostatics model that includes 
the physical mechanisms underlying CHA. The model supplements the classical continuum model with a non-linear boundary condition at the solute-solvent dielectric interface. The new boundary condition accounts for molecular ordering in the solvation shell, and hence we call it the solvation-layer interface condition (SLIC) model $9,65,66,75$. The SLIC model also includes the effect of static potential, that is especially important for solvation thermodynamics calculations of charged species. The SLIC model provides improved predictions of solvation properties while using standard classical force-field atomic radii, with a constant scaling factor for all atom-types ${ }^{9}$. This simple model accurately predicts monovalent ion hydration Gibbs energies ${ }^{9}$. The SLIC model was then extended to solvation calculations in pure solvents and ionic solutions via the linear Poisson-Boltzmann equation 65 . The SLIC model with temperature-dependent parameters can accurately correlate the ion solvation Gibbs energies, entropies, and heat capacities in various polar solvents 56,67 . Another remarkable accomplishment is the ability to reproduce positive charging Gibbs energies for atoms that are hydrophobic 6 . This was a significant outcome considering that the standard PB theories can not reproduce positive charging Gibbs energies. The SLIC model also self-consistently correlates ion transfer Gibbs energies in mixtures ${ }^{66}$. With temperature-dependent SLIC parameters and temperature-dependent parameters for the solvent-accessible surface area (SASA), the combined model can accurately predict hydration Gibbs energies and entropies 75 . This SLIC/SASA model exhibits significant weaknesses in predicting solvation heat capacity and the nonpolar component of the solvation Gibbs energy for small molecules.

The present work combines the SLIC model with statistical descriptions of cavitydispersion-combinatorial molecular thermodynamics, hereafter called the SLIC/CDC model, to address weakness in the SLIC/SASA model. The reference experimental data in this work is far more comprehensive than the previous work ${ }^{75}$. The new reference data improves the quality of model assessment which was a major bottleneck in our previous work 66,75 . The SLIC/SASA and SLIC/CDC models to our knowledge, are the first implicit-solvation model capable of predicting hydration heat capacities. Prompted by the challenges involved in performing molecular simulations in ionic liquids $\frac{73}{100}$, we test the performance of SLIC/SASA in predicting solvation Gibbs energies and entropies. The following section introduces the theory behind the SLIC/SASA and SLIC/CDC solvation models. Section III describes the numerical methods and optimization scheme used in this work. Section IV demonstrates the accuracies of these models to predict experimental solvation thermodynamic properties. 


\section{THEORY}

We model the solvation Gibbs energy per mole of a mixture $\Delta_{\text {solv }} G$ as a sum of independent energy modes

$$
\Delta_{\text {solv }} G=\Delta_{\text {solv }} G^{\mathrm{es}}+\Delta_{\text {solv }} G^{\mathrm{np}}+\Delta_{\text {solv }} G^{\mathrm{hb}}
$$

where $\Delta_{\text {solv }} G^{\text {es }}$ is the electrostatic contribution, $\Delta_{\text {solv }} G^{\text {np }}$ is the nonpolar contribution, and $\Delta_{\text {solv }} G^{\mathrm{hb}}$ describes the contribution of hydrogen bonding. We propose two implicit solvent models based on the contributions that are outlined in the Introduction. The SLIC/SASA model comprises the SLIC electrostatic theory and the empirical solvent-accessible surfacearea (SASA) nonpolar correction as

$$
\Delta_{\text {solv }} G^{\mathrm{SLIC} / \mathrm{SASA}}=\Delta_{\text {solv }} G^{\mathrm{SLIC}, \mathrm{es}}+\Delta_{\text {solv }} G^{\mathrm{SASA}, \mathrm{np}} .
$$

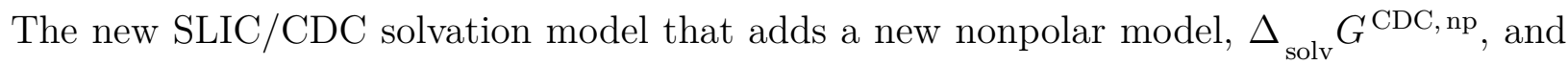
the hydrogen bonding model, $\Delta_{\text {solv }} G^{\text {CDC, np }}$, to the SLIC electrostatic model has the form

$$
\Delta_{\text {solv }} G^{\mathrm{SLIC} / \mathrm{CDC}}=\Delta_{\text {solv }} G^{\mathrm{SLIC}, \mathrm{es}}+\Delta_{\text {solv }} G^{\mathrm{hb}}+\Delta_{\text {solv }} G^{\mathrm{CDC}, \mathrm{np}} .
$$

We begin by summarizing the SLIC electrostatic model, and then we describe two different approaches to treat the nonpolar solvation contribution. The solvent-accessible surface area approach is an empirical correlation determined by the solute surface area. The cavitydispersion-combinatorial (CDC) theory describes the nonpolar contribution from statistical thermodynamics models. In the SLIC/SASA model, we fit the SLIC and SASA parameters at each temperature. In the SLIC/CDC model, all parameters are fixed constants, independent of temperature.

\section{A. SLIC Electrostatics Theory}

Figure 1 illustrates a schematic of the electrostatics problem. The solute is a dielectric medium with relative permittivity $\varepsilon_{\Omega}$ in region $\Omega$, bounded by dielectric boundary $\Gamma_{\mathrm{D}}$. The solute charge distribution, $\rho(\mathbf{r})$, contains $N_{c}$ discrete point charges. The $i$-th charge is located at $\mathbf{r}_{i}$ and has value $q_{i}$. The Poisson equation governs the electrostatic potential in the solute $\varphi_{\Omega}(\mathbf{r})$ :

$$
\nabla^{2} \varphi_{\Omega}(\mathbf{r})=-\frac{\rho(\mathbf{r})}{\varepsilon_{\Omega}} \quad \mathbf{r} \in \Omega
$$


The solvent region $\Sigma$ is a homogeneous medium with relative permittivity $\varepsilon_{\Sigma}$. The linearized Poisson-Boltzmann equation governs the electrostatic potential in the solvent $\varphi_{\Sigma}(\mathbf{r})$

$$
\nabla^{2} \varphi_{\Sigma}(\mathbf{r})=\kappa^{2} \varphi_{\Sigma}(\mathbf{r}) \quad \mathbf{r} \in \Sigma
$$

where $\kappa$ is the inverse Debye screening length, defined in terms of ionic strength 28 . The dielectric region $\Omega$ is separated from the solvent region $\Sigma$ by a thin, uncharged region $\Sigma_{\mathrm{s}}$ known as Stern layer, or ion-exclusion layer. The potential in the Stern layer satisfies the Laplace equation, the Poisson-Boltamann equation in the absence of free charges,

$$
\nabla^{2} \varphi_{\Sigma_{\mathbf{s}}}(\mathbf{r})=0 \quad \mathbf{r} \in \Sigma_{\mathbf{s}}
$$

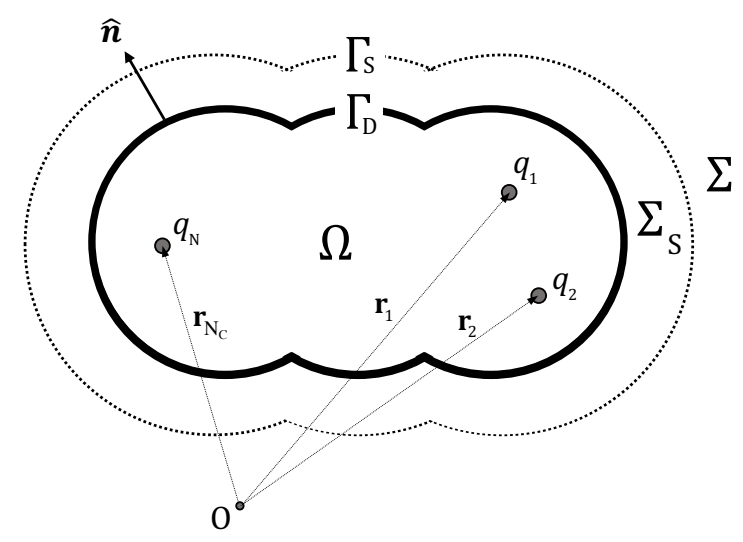

FIG. 1. Schematic of the continuum electrostatic problem. The solute interior region $\Omega$ contains point charges $q_{i}$ at locations $\mathbf{r}_{i}$ and is surrounded by an ion-exclusion region $\Sigma_{\mathrm{S}}$, which in turn is surrounded by the solvent region $\Sigma$. The ion-exclusion region is bounded by the dielectric surface $\Gamma_{\mathrm{D}}$ and the Stern surface $\Gamma_{\mathrm{S}}$ and is charge-depleted. The outward unit normal on the dielectric surface $\Gamma_{\mathrm{D}}$ is denoted by $\hat{\mathbf{n}}$.

Boundary conditions are specified on the dielectric and Stern surfaces. The standard continuum model enforces the classical Maxwell boundary conditions on both interfaces, 
namely, continuity of electrostatic potential and electric displacement field, as follows

$$
\begin{array}{ll}
\varphi_{\Omega}(\mathbf{r})=\varphi_{\Sigma_{\mathrm{S}}}(\mathbf{r}) & \text { (a) } \\
\varepsilon_{\Omega} \frac{\partial \varphi_{\Omega}(\mathbf{r})}{\partial \mathbf{n}(\mathbf{r})}=\varepsilon_{\Sigma_{\mathrm{S}}} \frac{\partial \varphi_{\Sigma_{\mathrm{S}}}(\mathbf{r})}{\partial \mathbf{n}(\mathbf{r})} & \text { (b) } \mathbf{r} \in \Gamma_{\mathrm{D}} \\
\varphi_{\Sigma_{\mathrm{S}}}(\mathbf{r})=\varphi_{\Sigma}(\mathbf{r}) & \text { (c) } \\
\varepsilon_{\Sigma} \frac{\partial \varphi_{\Sigma}(\mathbf{r})}{\partial \mathbf{n}(\mathbf{r})}=\varepsilon_{\Sigma_{\mathrm{S}}} \frac{\partial \varphi_{\Sigma}(\mathbf{r})}{\partial \mathbf{n}(\mathbf{r})} & \text { (d) } \mathbf{r} \in \Gamma_{\mathrm{S}} .
\end{array}
$$

Boundary conditions in the SLIC models differ from the standard continuum models in two ways. First, the continuity of the displacement boundary condition on the dielectric interface (Equation - b) is replaced with a new displacement boundary condition that captures charge hydration asymmetry $65,66,75$

$$
\left[\varepsilon_{\Omega}-\varepsilon_{\Delta} h\left(E_{n}\left(\mathbf{r}^{-}\right)\right)\right] \frac{\partial \varphi_{\Omega}\left(\mathbf{r}^{-}\right)}{\partial \mathbf{n}(\mathbf{r})}=\left[\varepsilon_{\Sigma}-\varepsilon_{\Delta} h\left(E_{n}\left(\mathbf{r}^{+}\right)\right)\right] \frac{\partial \varphi_{\Sigma_{\mathrm{S}}}\left(\mathbf{r}^{+}\right)}{\partial \mathbf{n}(\mathbf{r})}, \quad \mathbf{r} \in \Gamma_{\mathrm{D}},
$$

where

$$
h\left(E_{n}(\mathbf{r})\right)=\alpha \tanh \left(\beta E_{n}(\mathbf{r})-\gamma\right)+\mu,
$$

$\varepsilon_{\Delta}=\varepsilon_{\Sigma}-\varepsilon_{\Omega}$, and $E_{n}\left(\mathbf{r}^{-}\right)$and $E_{n}\left(\mathbf{r}^{+}\right)$are the normal electric field just inside and outside the dielectric interface, respectively. Parameters $\alpha, \beta, \gamma$ and $\mu$ are unique to the SLIC model. Figure 2 shows a schematic plot of $h\left(E_{n}\right)$ in Equation 9. Parameter $\alpha$ corresponds to the magnitude of asymmetry in dielectric response, i.e., it characterizes the difference between the two response regimes. Response regimes correspond to $E_{n}>>0$ and $E_{n}<<0$ limits of $h\left(E_{n}\right)$ as shown in Figure 2. Parameter $\beta$ captures the minimum variation in the local, normal electric field that is required to change the dielectric response from one mode to another. Parameter $\gamma$ determines the critical electric field where the transition between the two modes occurs, i.e., the dielectric response adopts the negative mode if $E_{n}>\gamma / \beta$ and vice versa. Parameter $\mu$ detemines the asymmetry of the two response modes with respect to the bulk response. The second difference between the SLIC and standard continuum model boundary condition is that the SLIC model replaces Equation 8 - $d$ with a nonlinear 
electric displacement field boundary condition

$$
\left[-\frac{q_{\mathrm{tot}}}{\varepsilon_{\Sigma}}\right] \frac{\partial \varphi_{\Sigma_{\mathrm{s}}}(\mathbf{r})}{\partial \mathbf{n}(\mathbf{r})}=\left[\oiint_{\Gamma_{\mathrm{S}}} \frac{\partial \varphi_{\Sigma_{\mathrm{s}}}\left(\mathbf{r}^{\prime}\right)}{\partial \mathbf{n}\left(\mathbf{r}^{\prime}\right)} \mathrm{d} \mathbf{r}^{\prime}\right] \frac{\partial \varphi_{\Sigma}(\mathbf{r})}{\partial \mathbf{n}(\mathbf{r})}, \quad \mathbf{r} \in \Gamma_{\mathrm{S}}
$$

This ensures that Gauss's law is satisfied outside the Stern surface $\Gamma_{S}, \sqrt{55}, 75$. The Supporting Information section presents the numerical solution of the coupled system of partial differential equations (PDEs) 46 with the SLIC model boundary conditions using the boundary element method.

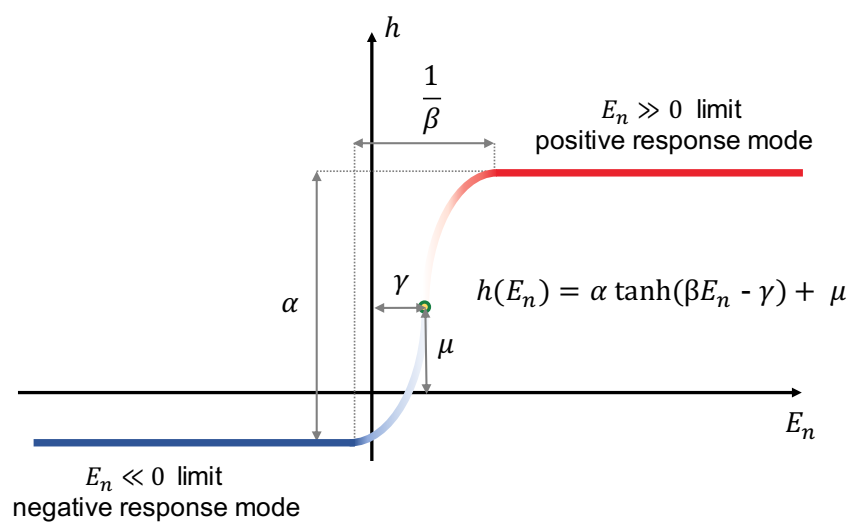

FIG. 2. Schematic of the nonlinear perturbation funtion presented in Equation 9 .

The SLIC model for the electrostatic Gibbs energy of solvation comprises reaction and static potential contributes as

$$
\Delta_{\text {solv }} G^{\text {SLIC, es }}=\Delta_{\text {solv }} G^{\text {reac }}+\Delta_{\text {solv }} G^{\text {static }}=\frac{1}{2} \sum_{i=1}^{N_{c}} q_{i} \varphi_{\text {reac }}\left(\mathbf{r}_{i}\right)+\varphi_{\text {static }} q_{\text {tot }} .
$$

where $q_{\text {tot }}=\sum_{i=1}^{N_{c}} q_{i}\left(\mathbf{r}_{i}\right)$. The reaction potential contribution, $\varphi_{\text {reac }}$, is due to the solvent polarization response to the fixed solute charges. It can be calculated using the superposition principle for electric potentials:

$$
\varphi_{\Omega}=\varphi_{\text {Coul }}+\varphi_{\text {reac }}
$$

where $\varphi_{\text {Coul }}$ is the electrostatic potential calculated from Coulomb's law considering the fixed charges in the solute region and $\varphi_{\Omega}$ is the electrostatic potential in the solute region calculated from solving the system of governing PDEs with suitable boundary conditions. The static potential, $\varphi_{\text {static }}$, is induced by the complex structuring of the solvent molecules 
around a fully uncharged solute molecule. Atomistic simulations have shown that the static potential is nearly constant in the solute region 20 . Similar to our previous work ${ }^{75}$, the static potential is assumed to be constant and is regarded as a fitting parameter. The contribution to solvation Gibbs energy due to static potential is zero for neutral small molecules because the net electrostatic charge $q_{\text {tot }}$ is zero.

\section{B. Hydrogen Bond Model}

A simple two energy level system describes the solute and solvent in unbonded and hydrogen bonded microstates. The hydrogen bond canonical partition function takes the form of a two-state system

$$
q^{\mathrm{hb}}=e^{-\beta \varepsilon_{0}}\left(1+e^{-\beta \varepsilon}\right) \text { where } \varepsilon<0
$$

where $\varepsilon_{0}$ and $\varepsilon_{0}+\varepsilon$ denote the energy in unbonded and hydrogen-bonded states, respectively, and $\beta$ is the reciprocal of $k_{B} T$. We use the canonical ensemble average energy to define the average hydrogen bonding energy $\varepsilon_{i}^{\text {hb }}$ for a hydrogen bond acceptor-donor system of type $i$,

$$
\varepsilon_{i}^{\mathrm{hb}}=-\frac{\partial \ln q^{\mathrm{hb}}}{\partial \beta}=\frac{\varepsilon_{i} e^{-\beta \varepsilon_{i}}}{1+e^{-\beta \varepsilon_{i}}}
$$

where $\varepsilon_{i}$ is the hydrogen-bond energy difference $\varepsilon$ for the hydrogen bond type $i$. The Gibbs energy term for the sum over all interactions between the hydrogen-bonding sites between the solute and solvent can be written as

$$
\Delta G^{\mathrm{hb}}=\sum_{j}^{\text {hbtypes }} n_{j} \varepsilon_{j}^{\mathrm{hb}},
$$

where $n_{j}$ denotes the number of all possible hydrogen-bond types $j$ between the solute and solvent. The hydrogen bond energy controbution $\varepsilon_{j}^{\mathrm{hb}}$ can be computed or experimentally measured independently. For the scope of the current work, values are calculated via parameterization of the solvation energy functional (Equation 3) against the experimental values. These coefficients are independent of temperature and depend only upon chemical group. Table SI-1 in Supporting Information shows the hydrogen bonding atom-types used in this work. This pre-averaging the energy states comprises a statistical approximation that neglects longer range interactions. More formal speciation methods $s 0$ are fundamentally correct. 


\section{SASA Nonpolar Model}

The SASA nonpolar model estimates the nonpolar contribution to solvation using the linear equation

$$
\Delta_{\mathrm{solv}} G^{\mathrm{SASA}, \mathrm{np}}=\gamma_{A} A_{\mathrm{SASA}}+\gamma_{B}
$$

where $A_{\mathrm{SASA}}$ is the solvent-accessible surface area of the solute. This area depends on the solute conformation and is independent of temperature. Multiple conformations can be considered in this model using a speciation approach $\underline{60}$. Parameters $\gamma_{A}$ and $\gamma_{B}$ describe the effective surface tension, and the energy required to create an infinitesimally small vacuum cavity in the solvent, respectively ${ }^{85}$. Both parameters are fit to data at each temperature of interest, and they are assumed to be independent of solute and depend only on the solvent.

\section{CDC Nonpolar Model}

The CDC nonpolar model is an extension of the nonpolar model that has been successfully used in COSMO-SAC solvation models. $.59,97,98$

$$
\Delta_{\mathrm{solv}} G^{\mathrm{CDC}, \mathrm{np}}=\Delta_{\mathrm{solv}} G^{\mathrm{cav}}+\Delta_{\mathrm{solv}} G^{\mathrm{disp}}+\Delta_{\mathrm{solv}} G^{\mathrm{comb}}
$$

where $\Delta_{\text {solv }} G^{\text {cav }}, \Delta_{\text {solv }} G^{\text {disp }}$, and $\Delta_{\text {solv }} G^{\text {comb }}$ are the cavity formation, dispersion, and combinatorial energy mode contributions to the nonpolar solvation Gibbs energy, respectively.

The cavity contribution is the Gibbs energy required to create a hole space in the pure solute with the solute's shape and size. Thermodynamic perturbation theory for molecules with fused cores, 94 provides

$$
\Delta_{\mathrm{solv}} G^{\mathrm{cav}}=R T\left(\left(\alpha_{c}-1\right) \frac{\eta(4-3 \eta)}{(1-\eta)^{2}}-\left(2 \alpha_{c}-2\right) \ln \left[\frac{1-(\eta / 2)}{(1-\eta)^{3}}\right]\right),
$$

where $\alpha_{c}$ is the inverse of sphericity parameter, and $\eta$ is the packing fraction of the solute 59 . In this work, the two parameters are calculated as

$$
\alpha_{c}=\frac{A_{\mathrm{vdw}}}{\left(6 \sqrt{\pi} V_{\mathrm{vdw}}\right)^{\frac{2}{3}}} \quad \text { and } \quad \eta=\frac{\sum_{i}^{n_{a}}(4 / 3) \pi r_{i}^{3}-V_{\mathrm{vdw}}}{\sum_{i}^{n_{a}}(4 / 3) \pi r_{i}^{3}}
$$

where $n_{a}$ is the number of atoms, $r_{i}$ is the radius of atom $i$, and $A_{\mathrm{vdw}}$ and $V_{\mathrm{vdw}}$ are the Van der Waals surface area and volume of the solute, respectively. Note that cavity formation 
energy is considered for the pure solute. The combinatorial term accounts for the differences in size and shape of the solute and solvent molecules. The combinatorial contribution to nonpolar solvation Gibbs energy is calculated using the Stavermann-Guggenheim 39,86 model for a binary mixture of a solute $i$ and a solvent $S$. The infinite-dilution limit can be expressed as:

$$
\Delta_{\mathrm{solv}} G_{i, S}^{c o m b}=-R T\left[1-\frac{V_{\mathrm{vdw}, i}}{V_{\mathrm{vdw}, S}}\left(1-\frac{z}{2}\right)+\ln \frac{V_{\mathrm{vdw}, i}}{V_{\mathrm{vdw}, S}}-\frac{z}{2} \frac{A_{\mathrm{vdw}, i}}{A_{\mathrm{vdw}, S}}\left(1+\ln \left[\frac{A_{\mathrm{vdw}, S} V_{\mathrm{vdw}, i}}{A_{\mathrm{vdw}, i} V_{\mathrm{vdw}, S}}\right]\right)\right],
$$

where $z$ is the coordination number, i.e., the average number of the neighboring solvent molecules around the solute. Parameter $z$ is commonly taken to be a number in the range $10-12^{57,58,97}$ but in this work, it was empirically fit to data.

The dispersion contribution to the solvation Gibbs energy is calculated using a mean-field model that accounts for all possible pairwise interatomic contacts between the solute and solvent molecules $\frac{98}{}$. The infinite-dilution limit of the dispersion interaction energy for a binary mixture of a solute $i$ and a solvent $S$ can be written in terms of the Helmholtz energy as:

$$
\Delta_{\text {solv }} A_{i / S}^{\text {disp }}=\frac{\bar{V}_{i / L}}{\bar{V}_{S}} \sum_{\tau}^{n_{a}, S} \sum_{\omega}^{n_{a}, S} m_{\tau}^{S} m_{\omega}^{S} \varepsilon_{\tau \omega}-2 \sum_{\tau}^{n_{a},_{i}} \sum_{\omega}^{n_{a}, S} m_{\tau}^{i} m_{\omega}^{S} \varepsilon_{\tau \omega}
$$

where $n_{a}, x$ is the total number of atom types in the species $x, \bar{V}_{i / L}$ is the partial molar volume of the solute $i$, and $\bar{V}_{S}$ is the partial molar volume of the solvent $S$. The variable $m_{\tau}^{i}$ is the effective number of atom-types $\tau$ of species $i$ defined as

$$
m_{\tau}^{i}=\sum_{a \in i}\left(\frac{S_{a}}{S_{a 0}}\right)^{q_{s}}
$$

where $S_{a}$ is the solvent-accessible surface area of atom $a$ of species $i, S_{a 0}$ is the surface area of the atom $a$, and $q_{s}$ is a fitting parameter in the range 0-1. Surface area fractions of different atom types for dispersion calculations are calculated using their COSMO radii. Table SI-4 in Supporting Information contains the COSMO radii 98 for different atom types, defined by element and electronic hybridization only. The parameter $\varepsilon_{\tau \omega}$ in Equation 21 is the pairinteraction energy between atom types $\tau$ and $\omega$ which is correlated using Lorentz-Berthelot combinig rule as $\varepsilon_{\tau \omega}=\sqrt{\varepsilon_{\tau} \varepsilon_{\omega}}$, where $\varepsilon_{\tau}$ is the dispersion energy-coefficient of atom-type $\tau$, obtained by fitting to data. Since solutions are regarded largely as incompressible, the dispersion contribution to solvation Gibbs energy can be calculated from Equation 21 as $\frac{98}{9}$

$$
\Delta_{\text {solv }} G^{\text {disp }}=\Delta_{\text {solv }} A_{i / S}^{\text {disp }}
$$


The original dispersion model ${ }^{98}$ assumes the atom-specific energy coefficients in Equation 21 to be universal constants that are fit to experimental data. We use a simple squarewell potential to describe the temperature-dependent inter-molecular dispersion interactions. The average energy accounts for all two-body interactions resulting from the second virial coefficient. Thus the interaction between atom-types $\tau$ and $\omega$ can be written as

$$
\varepsilon_{\tau \omega}^{\mathrm{d}}=\langle E\rangle_{\tau \omega}=-\frac{2 \pi \rho_{n} \sigma_{\tau \omega}^{3}}{3}\left[\varepsilon_{\tau \omega} e^{\beta \varepsilon_{\tau \omega}}\left(\lambda_{\tau \omega}^{3}-1\right)\right]
$$

Parameter $\sigma_{\tau \omega}=R_{\tau}+R_{\omega}$, where $R_{i}$ denotes the atom radius for atom-type $i$. Parameter $\rho_{n}$ is the average number density of the species in the mixture and parameter $\lambda_{\tau \omega}=r_{\tau \omega} / \sigma_{\tau \omega}$ is the square-well range, where $r_{\tau \omega}$ is the center-to-center distance between the atom-types $\tau$ and $\omega$. The parameter $\rho_{n}$ approaches the number density of pure water in the infinite dilution limit, i.e., $\rho_{n}=N / V_{\text {mix }}$. The parameter $\lambda_{\tau \omega}$ was taken to be constant, equal to 2 , to reduce the complexity of the model. Setting $\lambda_{\tau \omega}$ to this value incorporates the width of the Lennard-Jones potential between the close range abscissa and $94.3 \%$ of the attraction energy well. The only temperature dependence in Equation 24 is from $\beta$ which is the reciprocal of $k_{\mathrm{B}} T$. Using Equation 23, the final expression for the dispersion component of the infinite dilution solvation Gibbs energy can be written as

$$
\Delta_{\text {solv }} G_{i / S}^{\text {disp }}=\frac{V_{i}}{V_{S}} \sum_{\tau}^{n_{a}, S} \sum_{\omega}^{n_{a}, S} m_{\tau}^{S} m_{\omega}^{S} \varepsilon_{\tau \omega}^{\mathrm{d}}-2 \sum_{\tau}^{n_{a}, i} \sum_{\omega}^{n_{a}, S} m_{\tau}^{i} m_{\omega}^{S} \varepsilon_{\tau \omega}^{\mathrm{d}}
$$

We note that all the fitting parameters in the CDC nonpolar model are temperatureindependent.

\section{COMPUTATIONAL METHODS}

Experimental assessment of the SLIC/CDC and SLIC/SASA models requires determination of parameters from training data. Parameters are estimated by minimizing the objective function defined by the Mean-Squared Error (MSE)

$$
\mathrm{MSE}=\frac{1}{N_{\text {train }}} \sum_{i=1}^{N_{\text {train }}}\left[\Delta_{\text {solv }} G_{\text {ref, } \mathrm{i}}-\Delta_{\text {solv }} G_{\text {calc }, \mathrm{i}}\right]^{2}
$$

where $\Delta_{\text {solv }} G_{\text {ref,i }}$ is the reference Gibbs solvation energy of the solute $i$ obtained from experimental data or explicit-solvent simulations, $\Delta_{\text {solv }} G_{\text {calc, i }}$ is the model-predicted solvation 
Gibbs energy of the solute, and $N_{\text {train }}$ is the number of the solutes in the training-set. We used lsqnonlin, the nonlinear least-squares solver of MATLAB ${ }^{\mathbb{1}}$, with constraints on all parameters. Parameter optimization is difficult since several parameter values evaluate to local MSE minima. The optimization procedure used in our previous work ${ }^{75}$ fit the electrostatic and nonpolar parameters simultaneously. Considering that the nonpolar component of the solvation Gibbs energy was available from the explicit-solvent MD simulations of Mobley et al. .64 , we used a 2-step optimization scheme in this work. First, the electrostatic parameters are obtained by optimizing the SLIC electrostatic model against the explicitsolvent MD electrostatic charging energies. Then, the total solvation model is optimized against the experimental solvation Gibbs energies, where the electrostatic parameters are fixed at their optimal values obtained in the first step. Our results show that this approach increases the accuracy of the model predictions with the attainment of the lower MSE minima. The system of PDEs in Equations 4-6 with the SLIC model boundary conditions in Equations $\mathbb{6}(\mathrm{a}), \mathrm{Z}(\mathrm{c}), 8$, and 10 are recast into boundary-integral equations (BIEs) and solved numerically using boundary element method (BEM). The boundary integrals and BEM derivations are provided in the Supporting Information. The first step in implementing the BEM is discretizing the solute surfaces. Figure 3 provides a schematic of the molecular surfaces used in the SLIC model. The dielectric boundary $\Gamma_{\mathrm{D}}$ is the solvent excluded surface (SES) formed by rolling a solvent probe sphere, representing a solvent molecule, over the solute Van der Waals surface and tracing the interior surface, having a surface area $A_{\mathrm{SES}}$. Solvent-accessible surface (SAS) is formed by tracing the center of the solvent probe as it spans the solute Van der Waals surface and has a surface area $A_{\mathrm{SAS}}$. Similar to the dielectric boundary, the Stern surface $\Gamma_{S}$ is formed by tracing the interior of the solvent probe sphere rolling on a hypothetical Van der Waals surface that is created by adding $2 \AA$ to the atomistic Van der Waals radii. All the surfaces and surface areas are computed using the MSMS software $\underline{80}$, with vertex density and solvent probe radius set to 2 vertices $/ \AA^{2}$ and $1.4 \AA$, respectively. The second step is solving the system of BIEs. We used a standard panel-based BEM using triangular panels with piecewise-constant basis functions and centroid collocation 9,65 , where the electrostatic potential and its normal derivative are computed at the element centroids using Picard iteration. The system of BIEs is documented in the Supporting Information (See Equation B-15). Let this system of equations be $A X=b$, where some elements of matrix $A$ depend on the unknown electro- 
static potential and its normal derivative in vector $X$ and vector $b$ is constant. Let vector $X_{(i)}$ represent the unknowns at the centroids of surface elements at the $i$ th iteration. A self-consistent solution for $X_{(i)}$ is obtained by evaluating matrix elements $A_{(i)}$ for the $i$ th iteration in terms of the unknowns from previous iteration $X_{(i-1)}$, and solving the linear system of equations $A_{(i)} X_{(i)}=b$. The iterations are continued until the convergence criteria are met. We used a generalized minimal residual method (GMRES) with preconditioning, to a tolerance of $10^{-5}$ and maximum 100 iterations to solve the linear system of equations. The BEM solution convergence was achieved within the first 20 iterations for most cases 65 . In contrast to our previous work 6 , 75 , we terminated Picard iterations after 20 loops instead of 5 as we observed a few small-molecule calculations require more iterations to converge 75 . A rigorous analysis of the solution convergence, existence, and uniqueness can be found in the work by Klotz $\underline{47}$.

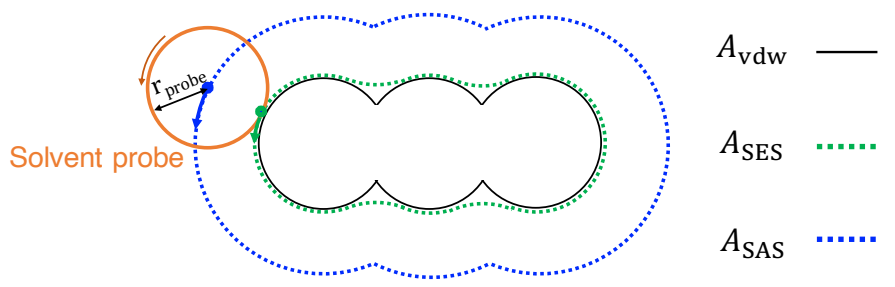

FIG. 3. Schematic of the solvent excluded surface (SES), solvent accessible surface (SAS), and Van der Waals (VdW) surface of a solute molecule. The SES is formed by tracing the inward part of the solvent probe as it rolls on the solute Van der Waals surface. The SAS is formed by tracing the center of the solvent probe. $A_{\mathrm{S}}$ denotes the surface are of the surface S.

\section{RESULTS}

This section demonstrates the accuracy of the SLIC/SASA and SLIC/CDC solvation models. Part IV A demonstrates the predicted solvation thermodynamics of small molecules in water versus experimental data. Part IVC presents the SLIC/SASA model predictions of solvation Gibbs energies and solvation entropies of 12 amino-acid sidechain analogs in seven ionic liquids compared with that of the molecular dynamics (MD) simulations from Latif et al. and Paluch et al 74 . 


\section{A. SOLVATION IN WATER}

We assess the accuracy of the SLIC/SASA and SLIC/CDC models for predicting solvation Gibbs energy for a subset of 502 neutral small molecules in water from the data of Mobley et al. $\underline{64}$, hereafter called Mobley test-set. The data contain 504 molecules but two of the molecules (ammonia and 4-methoxy-N,N-dimethyl-benzamide) were excluded in this work because our meshing software failed to generate discretized surfaces for them. The Mobley test-set comprises experimental measurements. Mobley also provides explicitsolvent molecular dynamics (MD) calculations that are helpful to benchmark our results.
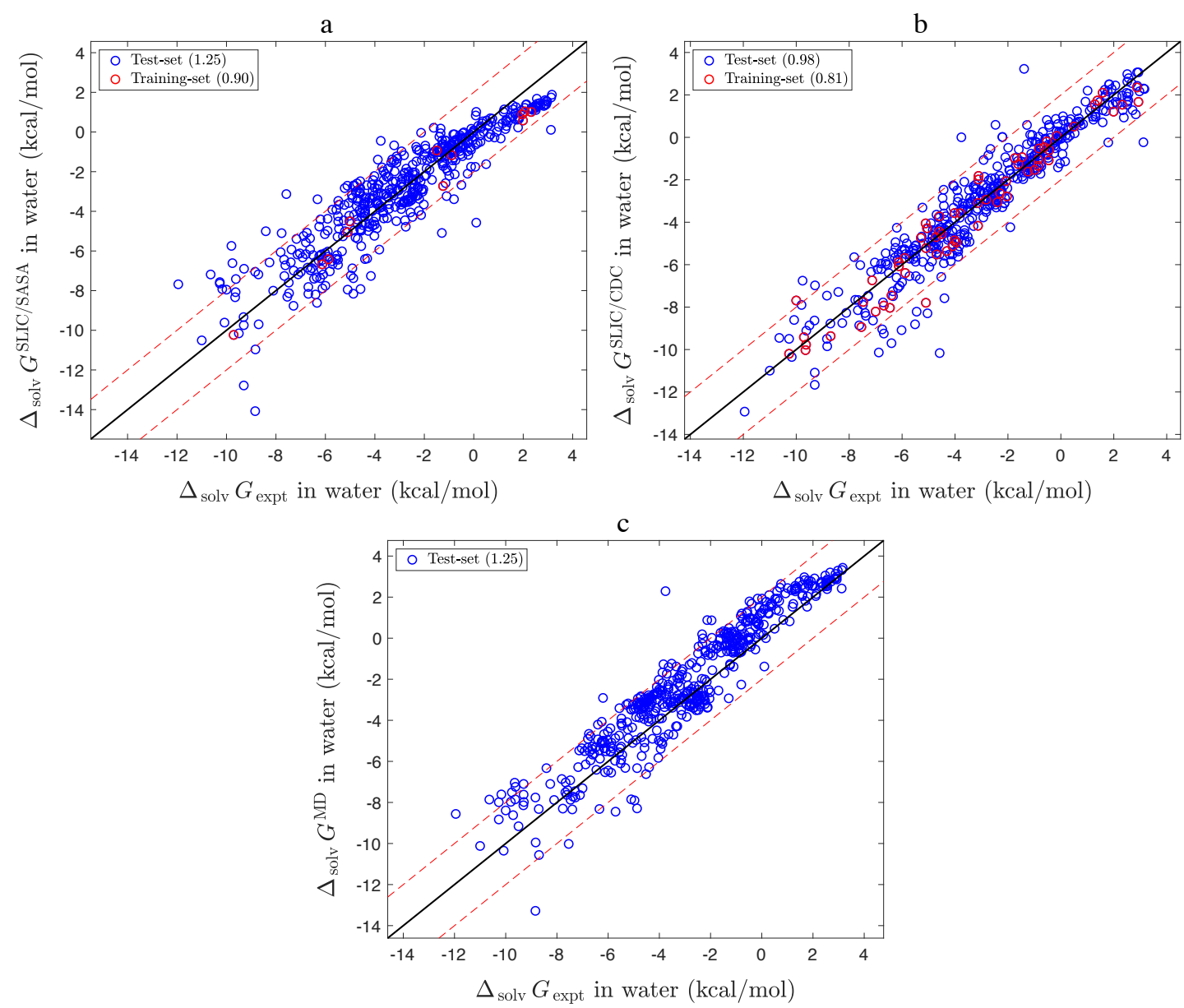

FIG. 4. SLIC/SASA (a), SLIC/CDC (b), and MD (c) predictions of solvation Gibbs energy (vertical axis) for the Mobley test-set compared with experiments (horizontal axis). Blue and red circles denote the model predictions for the test-set and training-set, respectively, at $25^{\circ} \mathrm{C}$. Red dashed lines show the $\pm 2 \mathrm{kcal} / \mathrm{mol}$ error margin. The numbers in parentheses are the RMS errors in $\mathrm{kcal} / \mathrm{mol}$. 
Figure 4 illustrates the SLIC/SASA and SLIC/CDC solvation Gibbs enegy predictions at $25^{\circ} \mathrm{C}$, compared to experimental values. The results in Figure 4 illustrate that both the SLIC/SASA and SLIC/CDC models accurately reproduce the experimental solvation Gibbs energies of small molecules in water. Predictions of the SLIC/SASA model show 0.3 kcal/mol improvement compared to our previous work ${ }^{75}$. The SLIC/CDC model exhibits a remarkable accuracy in predicting solvation Gibbs energies. With an RMS error of 0.98 $\mathrm{kcal} / \mathrm{mol}$ compared to experiments, only about $4 \%$ of the 502 small molecules have an error larger than $2 \mathrm{kcal} / \mathrm{mol}$. Furthermore, the errror is sensibly random in both the SLIC/CDC and SLIC/SASA models. There is no observable bias for solutes having either positive (weakly solvated solute) or negative (strongly solvated solute) solvation Gibbs energy. In contrast, there are two modes of apparent bias in the MD calculations of solvation Gibbs energy, as illustrated in Figure 4-c. First, the MD calculations systematically over-estimate experimental solvation Gibbs energy. Second, the MD calculation errors are systematically smaller in magnitude for weakly solvated solutes and grow in magnitude for more strongly solvated solutes.

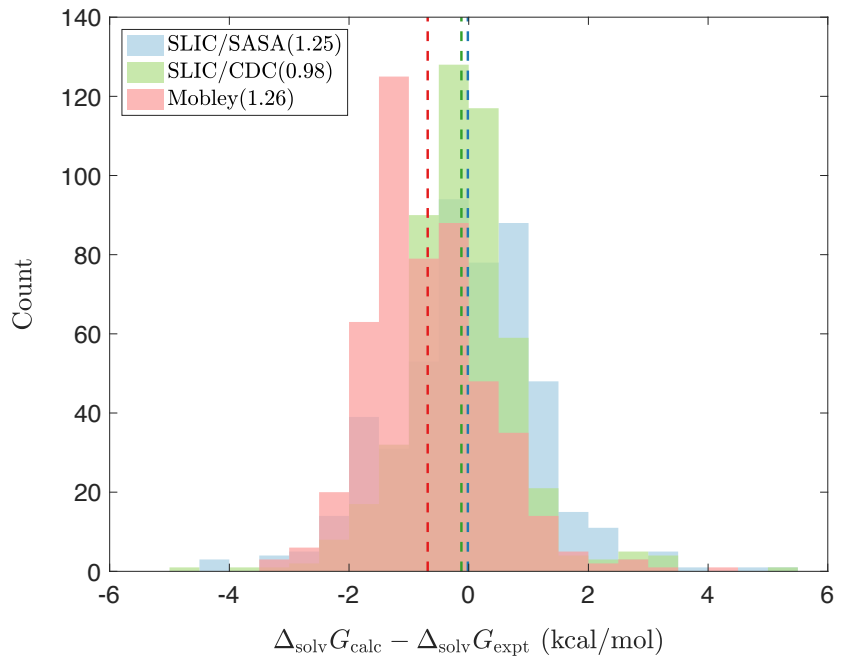

FIG. 5. Histogram of errors relative to experiment, for neutral small-molecule solvation Gibbs energies using SLIC/SASA, SLIC/CDC, and explicit-solvent MD results $\underline{64}$. The numbers in parentheses indicate the RMS errors in $\mathrm{kcal} / \mathrm{mol}$. Dashed lines show the means of the corresponding populations.

Figure 5 shows histograms of the errors relative to experimental solvation Gibbs energies for the two models along with those from Mobley's explicit-solvent MD results $\underline{64}$. Mobley's 
MD simulations were performed in GROMACS ${ }^{96}$ using the GAFF small molecule parameters as assigned by Antechamber 95 where partial charges were assigned using Merck-Frosst implementation of AM1-BCC 15,46 . Mobley's calculations tend to slightly overestimate the solvation Gibbs energies with an average error $(\hat{x})$ and standard deviation $\left(S_{x}\right)$ of -0.68 and $1.05 \mathrm{kcal} / \mathrm{mol}$, respectively. The SLIC/SASA and SLIC/CDC models do not exhibit a bias in over- or under-prediction with average errors equal to $-0.01\left(S_{x}=1.25\right)$ and 0.03 $\left(S_{x}=1.00\right) \mathrm{kcal} / \mathrm{mol}$, respectively. Particularly remarkable in this regard is the SLIC/SASA model's consistency considering that it uses only 6 free parameters and a training-set of 12 solutes.

TABLE 1: Accuracy of SLIC/SASA, SLIC/CDC, and MD in making predictions of solvation Gibbs energies for hydrogen-bonding and non-hydrogen-bonding compounds. Ref column shows the reference data that was used to parameterize the model. No HB denotes that the Hydrogen bonding term was not included in the model. RMSE is reported in $\mathrm{kcal} / \mathrm{mol}$. Separate parameterizations are run for each row.

\begin{tabular}{|c|c|c|c|c|}
\hline \multirow[b]{2}{*}{ Model } & \multirow[b]{2}{*}{$\operatorname{Ref} 64$} & \multicolumn{3}{|c|}{ RMSE w.r.t. $\Delta_{\text {solv }} G_{\text {Ref }}^{\text {tot }}$} \\
\hline & & All & $\mathrm{HB}$ & non-HB \\
\hline SLIC/SASA & $\overline{\text { expt. }}$ & 1.25 & 1.47 & 0.79 \\
\hline $\mathrm{SLIC} / \mathrm{CDC}$ & expt. & 0.98 & 1.12 & 0.73 \\
\hline MD & expt. & 1.26 & 1.33 & 1.22 \\
\hline SLIC/SASA & MD & 0.95 & 1.00 & 0.85 \\
\hline SLIC/CDC(No HB) & MD & 0.77 & 0.91 & 0.47 \\
\hline
\end{tabular}

Next, we compare the performance of the SLIC models and explicit-solvent molecular dynamics, contrasting accuracy over all test data and between solute-solvent systems with and without hydrogen bonding. Table 1 summarizes the statistical results. Separate parameterizations are derived for two types of reference and test data sets, as indicated in the Ref column. Parameterizations indicated by expt use the experimental data from Mobley et al. $\underline{64}$ as the reference. Parameterizations indicated by MD use the explicit-solvent molecular dynamics calculations of Mobley $\underline{64}$ as the reference. The statistical performance measured by RMSE (in each column) is provided for the entire test set (All), for only systems with hydrogen bonds (HB), and for systems without hydrogen bonds (non-HB) in columns 3, 4, and 5, respectively. First, consider the results pertaining to the experimental reference and test data. Overall, the performance of the SLIC/SASA model (RMSE=1.25) and MD simu- 
lations $(\mathrm{RMSE}=1.26)$ are comparable and quantitatively accurate. Overall, the SLIC/CDC model $(\mathrm{RMSE}=0.98)$ is most accurate. Hydrogen bonding systems are more accurately described by the MD forcefield (RMSE $=1.33$ ) than by SLIC/SASA (RMSE=1.47). The effects of hydrogen bonding are successfully correlated using the simple, two-state bonding model in equations 13 - IIB, as the SLIC/CDC model $(\mathrm{RMSE}=1.12)$ is the most accurate for these systems. Systems without hydrogen bonds are more accurately described by the SLIC/SASA model $(\mathrm{RMSE}=0.79)$ and the SLIC/CDC model $(\mathrm{RMSE}=0.73)$, than by MD simulations (RMSE=1.22). Second, consider the results for SLIC parameterizations when explicit solvent molecular dynamics simulations are used for reference and test data. We note that the MD forcefield does not include an explicit energy contribution for the existence of hydrogen bonds. Instead, the structural and thermodynamic effects of hydrogen bonds are parameterized using constant, atom-centered charges. Therefore, the two-state hydrogen bonding model is not included in this separate parameterization of the SLIC/CDC(no HB) model. The SLIC/CDC(no HB) model $(\mathrm{RMSE}=0.77)$ is more accurate than the SLIC/SASA model $(\mathrm{RMSE}=0.95)$, but their accuracies are comparable for polar systems in which hydrogen bonding occurs in the experimental systems, $(\mathrm{RMSE}=0.91)$ and $(\mathrm{RMSE}=1.00)$ respectively. The non-polar contribution to the SLIC/CDC(no HB) model (RMSE=0.47) markedly improves the accuracy describing the simulations of systems in which hydrogen bonding does not occur over the SLIC/SASA model (RMSE=0.85) using the linear SASA non-polar contribution.

A more detailed statistical analysis further supports this assessment. Figure 6 presents histogram distributions for the signed errors of the SLIC/SASA and SLIC/CDC models as parameterized the first two rows of Table 11. There are slight differences in performance between the RMSE metric and the mean absolute error metric due to the use of equation (26) for parameterization, but the numerical comparisons are qualitatively similar. Error distribution functions for the SLIC/CDC model are roughly normally distributed while centered at zero for both hydrogen bonding and non-hydrogen bonding compounds, the former are slightly wider. Error distributions for the SLIC/SASA model are slightly skewed. Systems with hydrogen bonds are slightly over-estimated and systems without hydrogen bonds are slightly underestimated. We conclude that the two-state hydrogen bonding description in the SLIC/CDC model improves the overall accuracy of the model in predicting solvation Gibbs energies. 

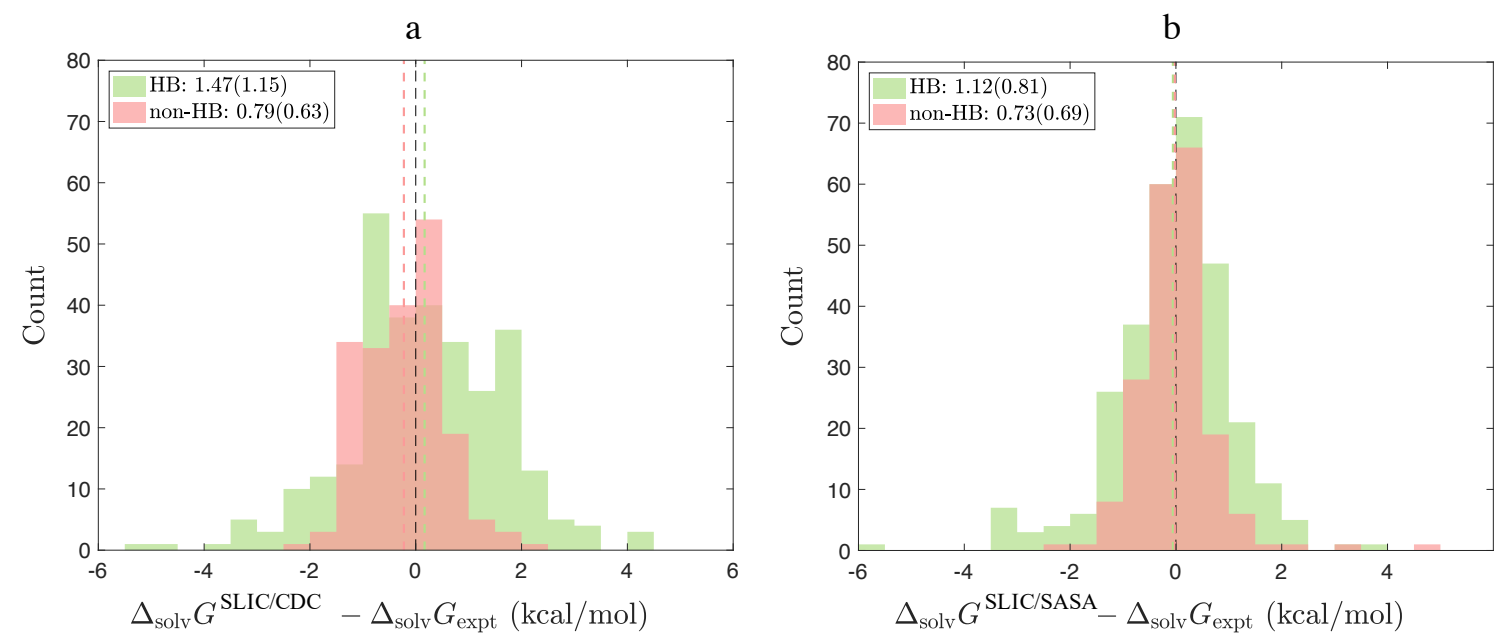

FIG. 6. Histogram of errors relative to experiment, for neutral small-molecule solvation Gibbs energies using the SLIC/SASA (a) and SLIC/CDC (b) models. The HB and non-HB denote the hydrogen bonding and non-hydrogen bonding compounds, respectively. The numbers in the legends indicate RMS (and mean absolute) errors in kcal/mol. Dashed lines show the means of the corresponding populations. These lines are visually indistinguishable in graph (a).

The solvation entropy and heat capacity properties are temperature derivatives of the solvation Gibbs energy that provide additional diagnostic assessments of solvation models. Methods to calculate these properties for the SLIC/SASA and SLIC/CDC models are described in Appendix V of the Supporting Information. The Supporting Information also indicates how these properties were determined from an experimental data set comprising 159 small molecular weight solutes. Because the experimental data is obtained from the work of multiple research groups that use different experimental techniques for measuring solvation enthalpies $\Delta_{\text {solv }} H$, we assess the precision of the experimental data for solvation entropies as $1 \mathrm{kcal} / \mathrm{mol}$. Figure 7 illustrates comparisons of the experimental solvation entropies with the predictions of the SLIC/SASA model, the SLIC/CDC model, and MD simulations. The latter predictions were computed by Florian and Warshel ${ }^{32}$ using a Langevin dipole method. Here we include their results for 25 solutes for which we have experimental measurements. All methods are generally accurate to within about $+3 \mathrm{kcal} / \mathrm{mol}$ absolute error. The SLIC/CDC model has no temperature-dependent fitting parameters and performs with $1.76 \mathrm{kcal} / \mathrm{mol}$ RMS error. The square well model approximating the dispersion energy has the greatest contribution to the solvation entropy. The experimental, 
temperature-dependent density of water contributes to the model ${ }^{\mathbb{2}}$. The Langevin dipole method performs with $1.13 \mathrm{kcal} /$ ol RMS error. The SLIC/SASA method has temperature dependent parameters and performs with $1.23 \mathrm{kcal} / \mathrm{mol}$ RMS error with respect to experimental data and $0.94 \mathrm{kcal} / \mathrm{mol}$ RMS error for the compounds that could be compared to the Langevin dipole method.

a

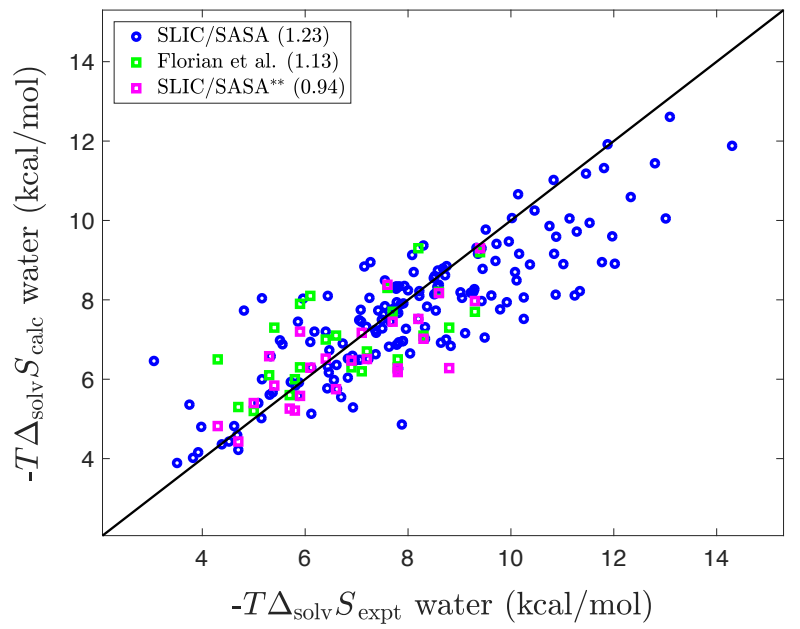

b

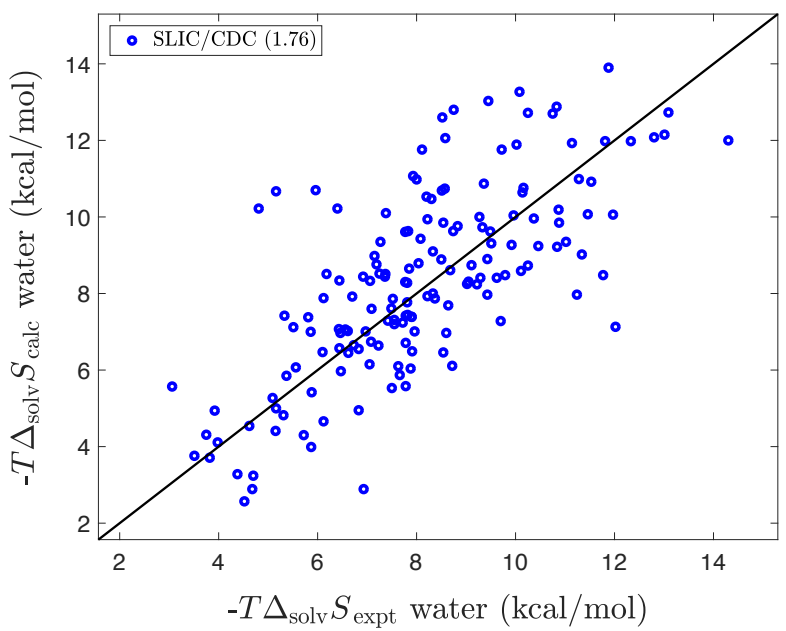

FIG. 7. SLIC/SASA (a - Blue circles, 159 data points), Florian et al. 32 (a - green squares, 25 data points), and SLIC/CDC (b - Blue circles, 159 data points) predictions of solvation entropies (vertical axis) compared with experimental data (horizontal axis). In (a), magenta squares denote the SLIC/SASA model results for the compounds in Florian et al.'s work. The numbers in parentheses are the RMS errors in $\mathrm{kcal} / \mathrm{mol}$.

Table 2 shows the temperature dependence of the electrostatic and nonpolar parameters of the SLIC/SASA solvation model. The electrostatic parameters and the nonpolar offset parameter $\gamma_{B}$ show no significant change with the temperature. The nonpolar surfacetension parameter $\gamma_{A}$ exhibits a linear increase with the temperature as $7 \times 10^{-5} T(K)$ $2.03 \times 10^{-2} \mathrm{kcal} / \mathrm{mol} / \AA^{2}$ with Pearson correlation coefficient of 0.93 . The SLIC/SASA model essentially predicts the solvation entropy to have a linear correlation with the molecular surface area where the linear coefficient is equal to the rate which $\gamma_{\mathrm{A}}$ changes with the temperature, i.e., $\Delta S \propto \frac{\partial \gamma_{A}}{\partial T} A_{\mathrm{SASA}}$. Figure SI-1 in the Supporting Information illustrates that solvation entropy is strongly correlated with SAS. 
TABLE 2: Optimized SLIC/SASA parameters as temperature varies.

\begin{tabular}{|c|c|c|c|c|c|c|}
\hline \multirow[b]{2}{*}{$T(K)$} & \multicolumn{4}{|c|}{ electrostatic } & \multicolumn{2}{|c|}{ nonpolar } \\
\hline & $\alpha$ & $\beta(*)$ & $\gamma$ & $\mu$ & $\gamma_{A}\left(\mathrm{kcal} / \mathrm{mol} / \AA^{2}\right)$ & $\overline{\gamma_{B}(\mathrm{kcal} / \mathrm{mol})}$ \\
\hline 278 & 0.41 & -200.00 & -0.95 & -0.43 & 0.0006 & 1.63 \\
\hline 288 & 0.42 & -200.00 & -1.02 & -0.44 & 0.0005 & 1.63 \\
\hline 298 & 0.43 & -195.95 & -1.11 & -0.45 & 0.0016 & 1.61 \\
\hline 308 & 0.44 & -200.00 & -1.29 & -0.46 & 0.0027 & 1.59 \\
\hline 318 & 0.45 & -199.75 & -1.26 & -0.46 & 0.0032 & 1.64 \\
\hline
\end{tabular}

Figure 8 shows the histogram of errors in SLIC/SASA, SLIC/CDC and our former model predictions of solvation entropies relative to experimental data. The current SLIC/SASA model is more accurate than the previous published model ${ }^{75}$ in predicting solvation entropies of neutral small molecules. The previous model exhibits a systematic under prediction of solvation entropies $(T \Delta S)$ with a mean error of $0.92 \mathrm{kcal} / \mathrm{mol}$. The new SLIC/SASA and the SLIC/CDC models demonstrate mean errors of 0.38 and $-0.22 \mathrm{kcal} / \mathrm{mol}$, respectively.

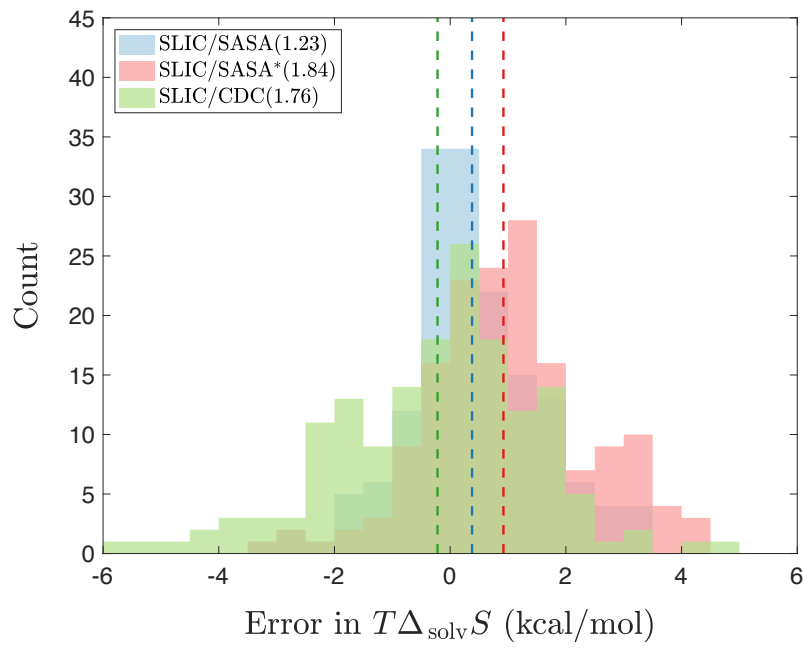

FIG. 8. Histogram of errors relative to experiment, for solvation entropies using SLIC/SASA, SLIC/CDC, and our previous SLIC/SASA model 75 . The numbers in parentheses are the RMS errors in $\mathrm{kcal} / \mathrm{mol}$. Dashed lines indicate the distribution mean for the three models.

Lastly, we demonstrate the performance of the SLIC/SASA model in making predictions of solvation heat capacities. Figure 9 shows these predictions for 123 neutral small molecules, 
hereafter called $H C$ test-set, compared with experimental measurements. Heat capacity predictions of the SLIC/SASA model are substantially more accurate when compared with our previous results 55 . The previous model failed to provide meaningful predictions of solvation heat capacities with a correlation coefficient of -0.43 and an RMS error of $217.98 \mathrm{cal} / \mathrm{mol} / \mathrm{K}$ (we reported a different correlation coefficient and RMS error in our previous work because only 20 experimental heat capacities were available at the time). The new SLIC/SASA model achieves a correlation coefficient of 0.69 and an RMS error of $24.42 \mathrm{cal} / \mathrm{mol} / \mathrm{K}$ in comparison with experimental solvation heat capacities. This level of accuracy is quite surprising because solvation heat capacity is a second derivative property; therefore, one would expect accurate predictions of this quantity to require more sophisticated physics and molecular details than the present model.

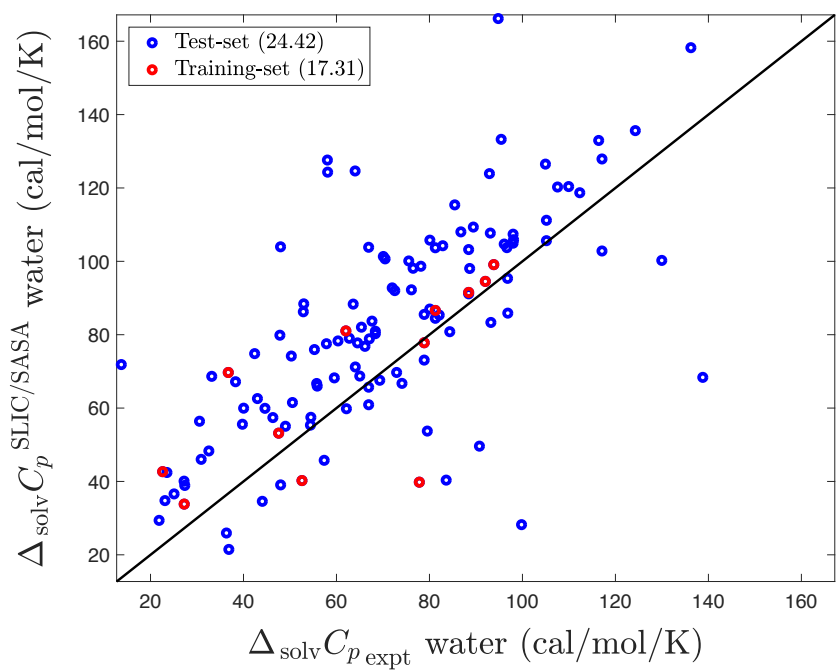

FIG. 9. SLIC/SASA predictions of solvation heat capacities (vertical axis) for the HC test-set compared with experimental data (horizontal axis). Blue and red circles denote the predictions for the test-set and training-set, respectively. The numbers in parentheses are the RMS errors in $\mathrm{cal} / \mathrm{mol} / \mathrm{K}$. 


\section{B. DETAILED COMPARISON OF THE PREDICTED SOLVATION GIBBS ENERGY COMPONENTS TO FEP CALCULATIONS}

In the first study of the SLIC solvation models in section IV A, we parameterized the models using experimental data for solvation Gibbs energies, entropies, and heat capacities. However, to assess the SLIC/SASA and SLIC/CDC in more details, we re-parameterized them using explicit-solvent FEP results of Mobley et al $[4$. Mobley's work provides a breakdown of the change in Gibbs solvation energy to electrostatics and nonpolar components as well as the breakdown of the nonpolar component into cavity and dispersion components. The FEP data of Mobley et al. 64 motivated us to illustrate the separate performance of the nonpolar and electrostatic models when comapred to Mobley's explicit-solvent results. In addition, we compare the performace of the SLIC/CDC models' cavity and dispersion components with that of the FEP data. Lastly, we present two sets of predictions for each thermodynamic property. One where the 2-step optimization scheme that we introduced in Section III is used (hereafter called 2-step scheme) and one where all the model parameters are optimized in a single calculation (hereafter called 1-step scheme). We used Mobley's FEP data for solvation Gibbs energies of small molecules $\underline{64}$ to parameterize the SLIC/SASA and SLIC/CDC models. Figure 10 shows the predictions for the two mdoels where the first row denotes the predictions made using the 1-step scheme and the second row shows the predictions made using the 2-step scheme. Predictions of the two models are in very good agreement with the reference data and the quality of predictions for both models is improved when compared to the results of the previous section where the two models were parameterized against the experimental data. This is intuitive because both the SLIC models and the FEP calculations can not reproduce the solvation events that are beyond the scope of atomistic simulations. Finally, optimization using the 2-step scheme does not demonstrate a significant improvement over the 1 -step scheme for the SLIC/SASA model $(0.03 \mathrm{kcal} / \mathrm{mol}$ improvement in RMS error), however, for the SLIC/CDC model, the improvement in the RMS is $0.18 \mathrm{kcal} / \mathrm{mol}$.

As we mentioned in the beginning of this section, to assess how well the SLIC/SASA and SLIC/CDC models reproduce different contributions to solvation Gibbs eneriges, we compared the model-predicted electrostatic component of the solvation Gibbs energies with that

of the FEP data for the Mobley test-set. Figure 11 illustrates the outcome of this comparison 
a

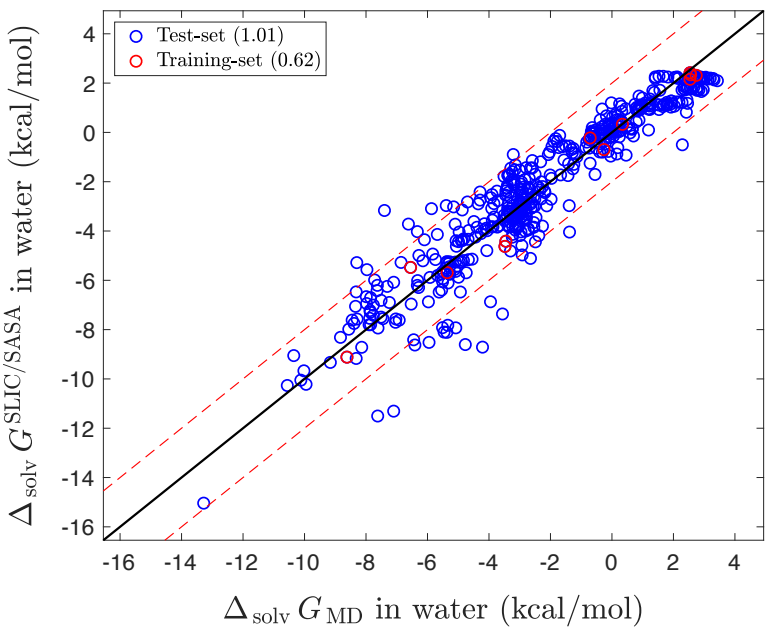

C

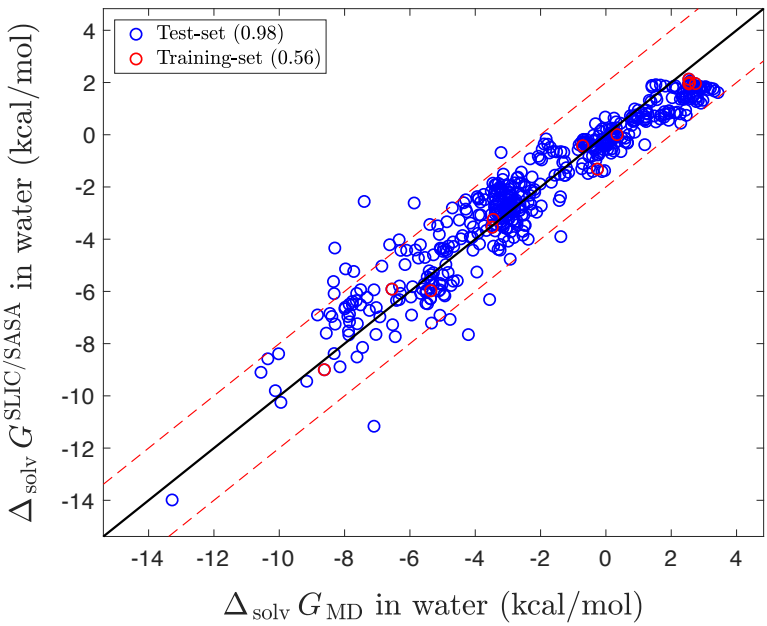

$\mathrm{b}$

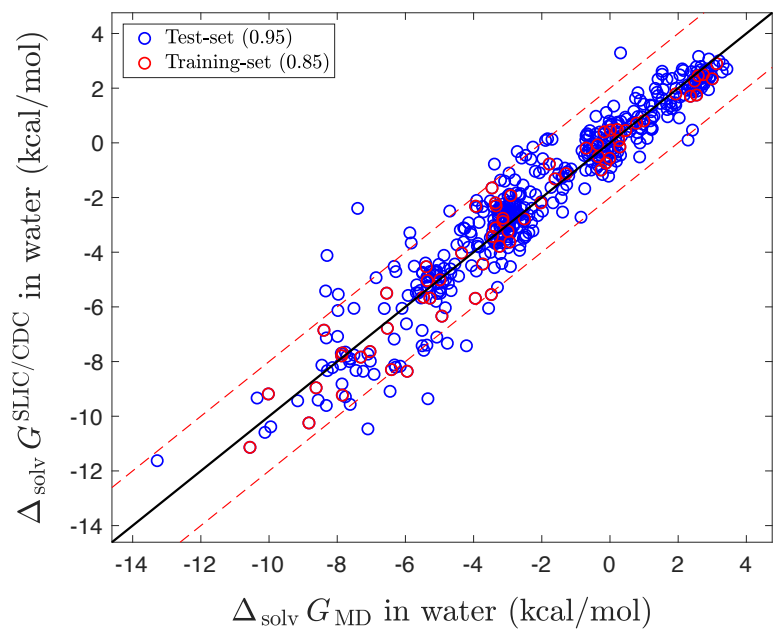

d

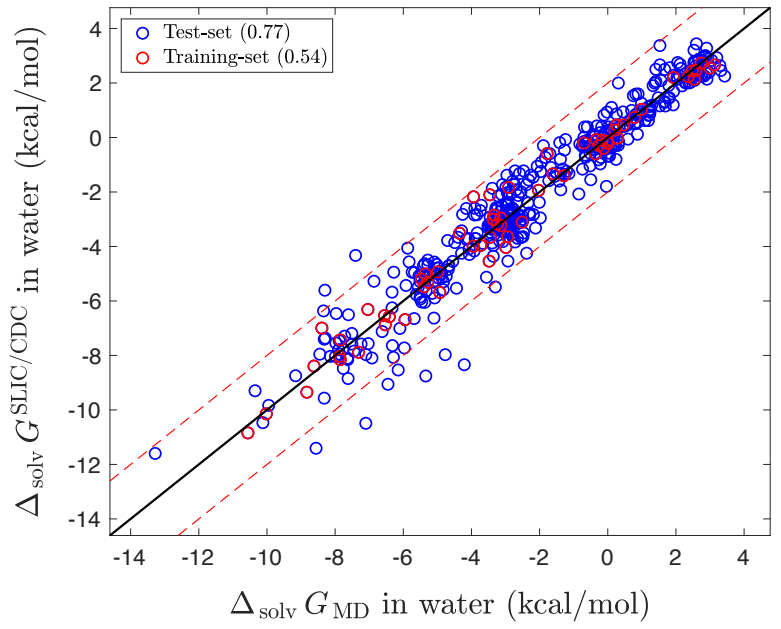

FIG. 10. SLIC/SASA and SLIC/CDC predictions of the solvation Gibbs energies (vertical axis) for the Mobley test-set compared with the FEP results (horizontal axis) $\underline{64}$ of Mobley et al. First row $(\mathrm{a}, \mathrm{b})$ denotes the predictions made using the 1-step scheme and second row $(\mathrm{c}, \mathrm{d})$ denotes the predictions made using the 2-step scheme. Blue and red circles denote the model predictions for the test-set and training-set, respectively. Red dashed lines show the $\pm 2 \mathrm{kcal} / \mathrm{mol}$ error margin. The numbers in parentheses indicate the RMS errors in $\mathrm{kcal} / \mathrm{mol}$.

where the first and second rows show the model predictions made using the 1-step scheme and 2-step scheme, respectively. In Mobley's work, the electrostatic component of solvation Gibbs energy was calculated as the Gibbs energy of charging the solute in water. SLIC/SASA and SLIC/CDC predictions of the electrostatic component of solvation Gibbs energies are in good agreement with Mobley's explicit-solvent results. The Pearson correlation coef- 
ficient $(\rho)$ between SLIC/SASA-predicted electrostatic energies and Mobley's data using 2-step scheme (1-step scheme) is 0.959 (0.960) with an RMS error of 0.80 (1.01) kcal/mol. Similarly, SLIC/CDC predictions gives $\rho=0.969(0.975)$ and RMSE=0.69(1.40) kcal $/ \mathrm{mol}$. By looking at Figures 11-c and 11-d, we notice that using a larger training-set lead to a higher accuracy in predictions made using the SLIC electrostatics model. This is most likely due to the fact that a larger training-set provides an opportunity to include chemical groups that might not be well represented when using a small training-set.

To illustrate the separate performance of the nonpolar models, Figure 12 presents the SLIC/SASA and SLIC/CDC models' predictions of the nonpolar contribution, compared to Mobley's FEP results ${ }^{64}$. In Mobley's work, the nonpolar component was computed as the free energy of turning on the Lennard-Jones interactions between the uncharged solute and water. Alternative ways of defining or computing the nonpolar component are possible and can lead to different results $\underline{64}$. Notice that using the 2-step scheme significantly improves the performance of the SLIC/CDC model in predicting the nonpolar component (Figure 12-d). This is a promising result considering that the surface-area dependent models are known to fail to reproduce the nonpolar energies from simulations. The SLIC/SASA model on the other hand exhibits poor accuracy in predicting the nonpolar component of solvation Gibbs energies when compared with the FEP calculations of Mobley $\underline{64}$, regardless of the optimization scheme used.

We also sought to assess the SLIC/CDC models' preidctions of the cavity and dispersion energies with the explicit-solvent results of Mobley ${ }^{64}$, as plotted in Figure 13. The sum of cavity and combinatorial energy components is considered as the cavity energy. The resulting RMS errors of the cavity and dispersion energy components using 2-step scheme (1-step scheme) are 4.58 (4.61) and 4.64 (7.10) kcal/mol, respectively. The Pearson correlation coefficients between the model predictions and the explicit-solvent results are 0.914 (0.912) and 0.863 (0.854), respectively, for cavity and dispersion components. Cavity and dispersion energies have readily been shown to strongly correlate with molecular surface areas and volumes $33,64,90$. The SLIC/CDC model and MD correlations with the molecular volumes and surface areas are presented in Table SI-9. The correlation plots can be found in Supporting Information (Figures SI-2 to SI-5). The 502 molecules in the Mobley testset are small enough that surface areas and volumes are highly correlated $\left(R^{2}=0.995\right)$. Our analysis confirms that both the dispersion and cavity components from explicit-solvent 
a

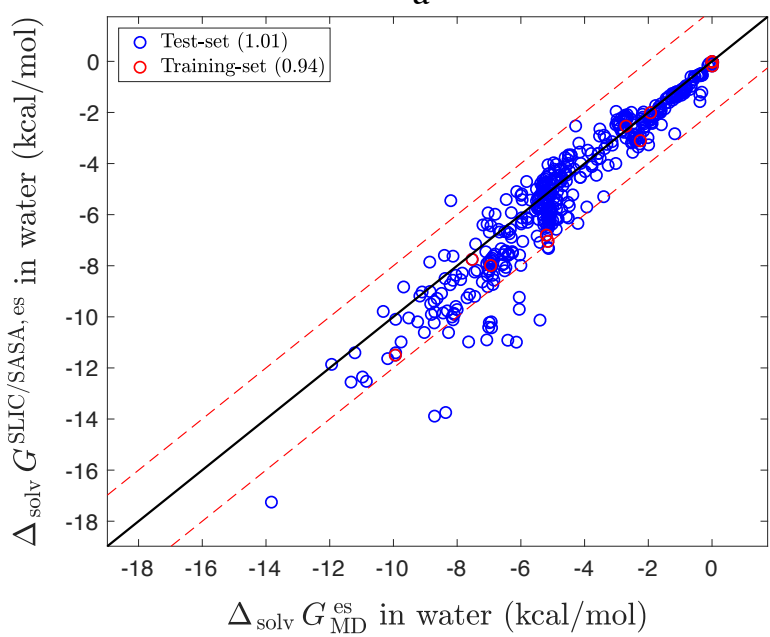

c

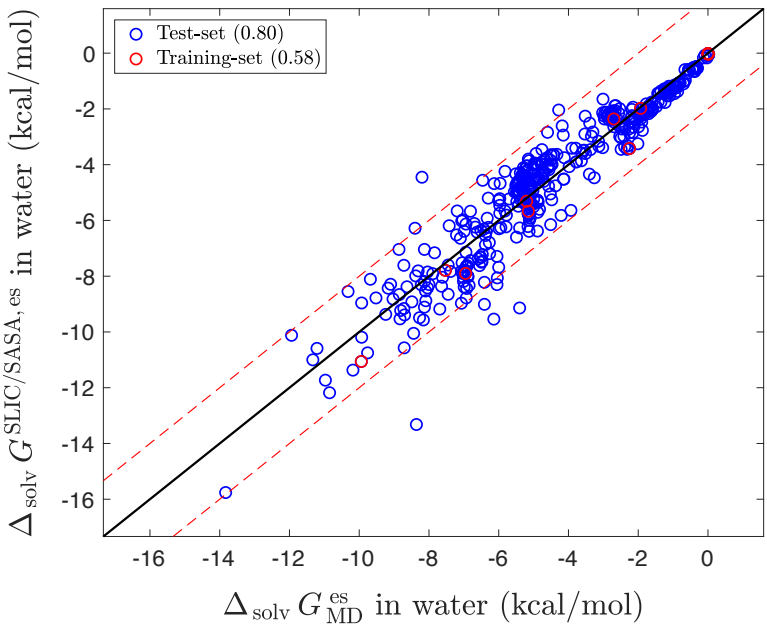

b

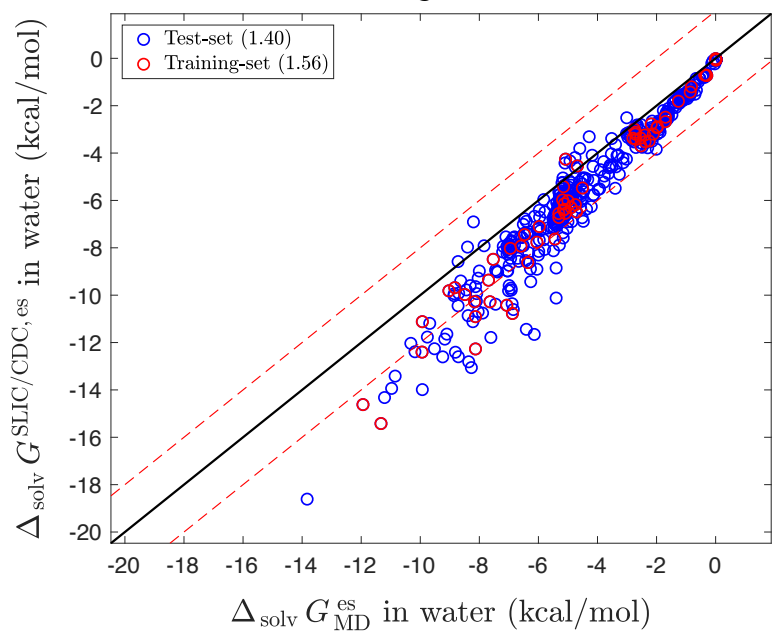

d

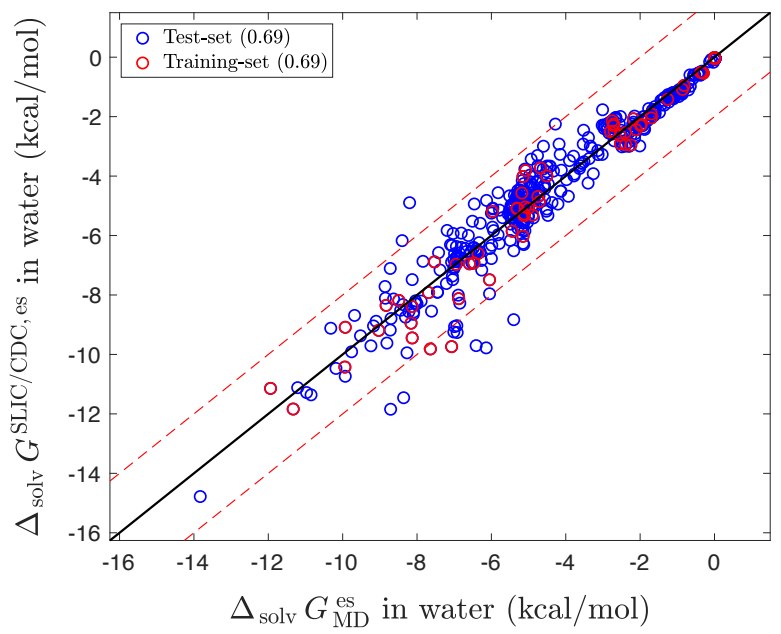

FIG. 11. SLIC/SASA and SLIC/CDC predictions of the electrostatic component of solvation Gibbs energies (vertical axis) for the Mobley test-set compared with the FEP results (horizontal axis) of Mobley et al ${ }^{64}$. First row $(\mathrm{a}, \mathrm{b})$ denotes the predictions made using the 1-step scheme and second row $(\mathrm{c}, \mathrm{d})$ denotes the predictions made using the 2-step scheme. Blue and red circles denote the model predictions for the test-set and training-set, respectively. Red dashed lines show the $\pm 2 \mathrm{kcal} / \mathrm{mol}$ error margin. The numbers in parentheses indicate the RMS errors in kcal/mol.

simulations and from the model predictions highly correlate with molecular surface area and volume. Table SI-9 in Supporting Information contains the correlation coefficients for molecular surface area and volume as estimators of the cavity and dispersion energies. 
a

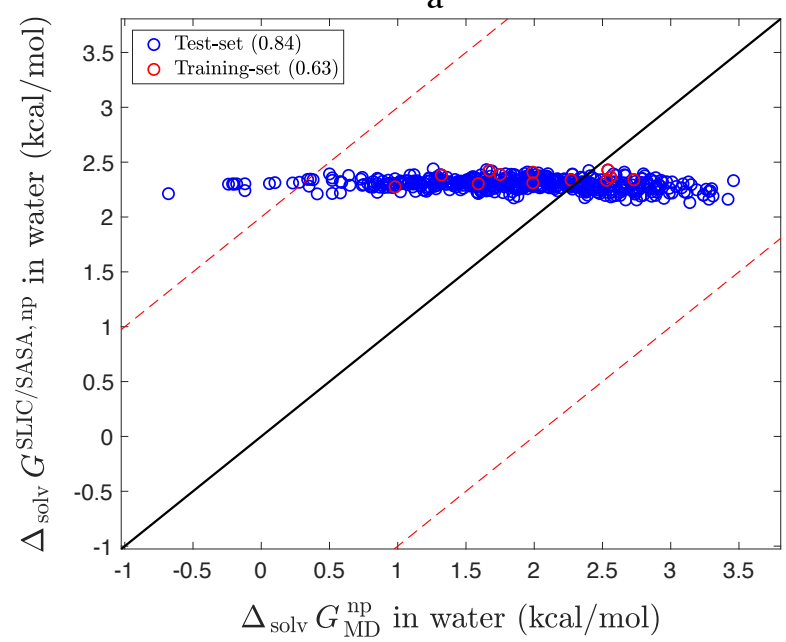

C

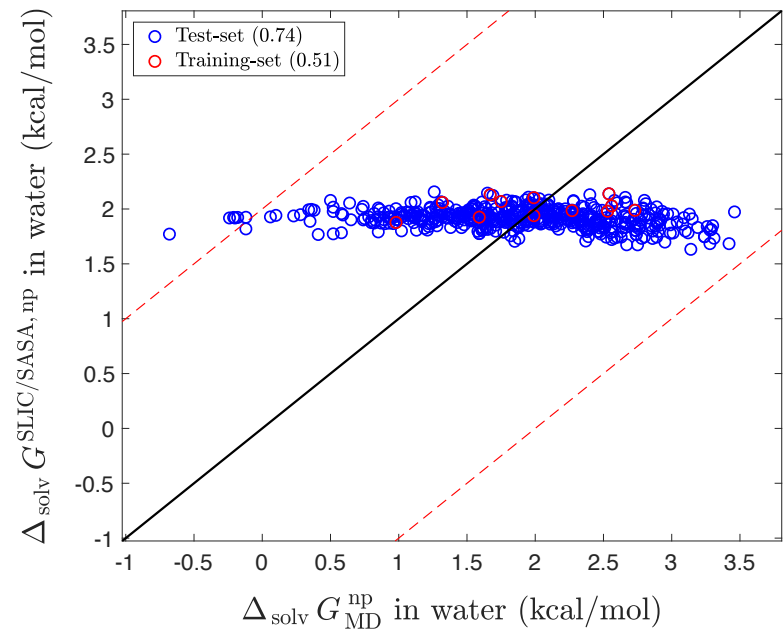

$\mathrm{b}$

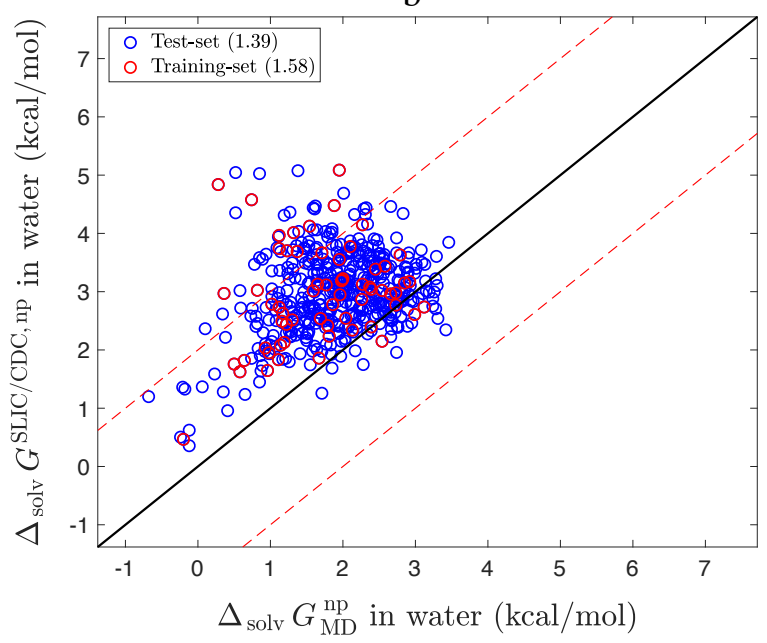

d

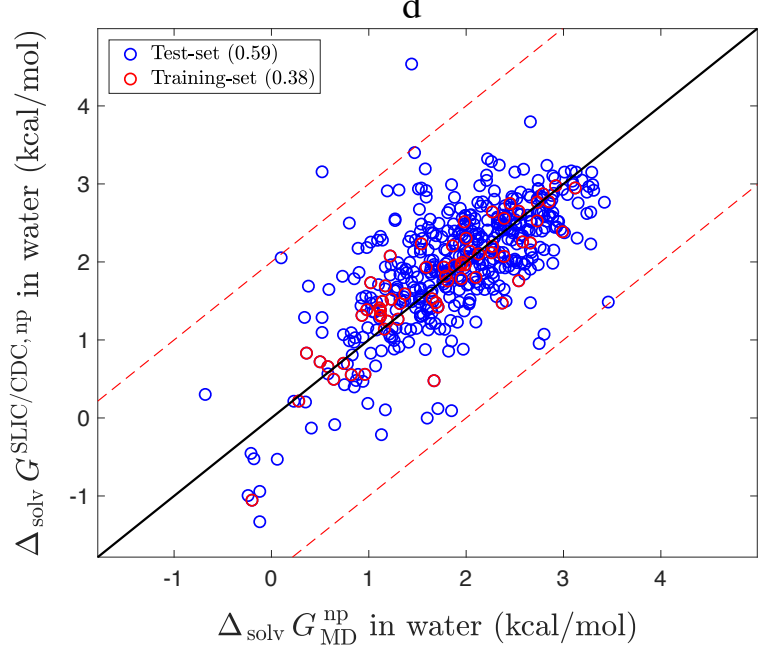

FIG. 12. SLIC/SASA (a) and SLIC/CDC (b) predictions of the nonpolar component of solvation Gibbs energies (vertical axis) for the Mobley test-set compared with the FEP results (horizontal axis) of Mobley et al ${ }^{64}$. First row $(a, b)$ denotes the predictions made using the 1-step scheme and second row $(\mathrm{c}, \mathrm{d})$ denotes the predictions made using the 2-step scheme. Blue and red circles denote the model predictions for the test-set and training-set, respectively. Red dashed lines show the $\pm 2 \mathrm{kcal} / \mathrm{mol}$ error margin. The numbers in parentheses indicate the RMS errors in $\mathrm{kcal} / \mathrm{mol}$. 
a

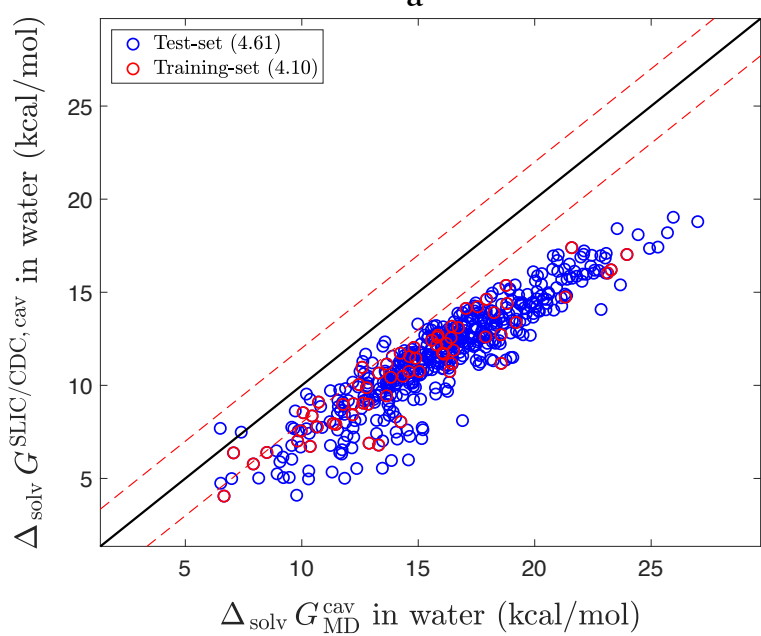

$\mathrm{c}$

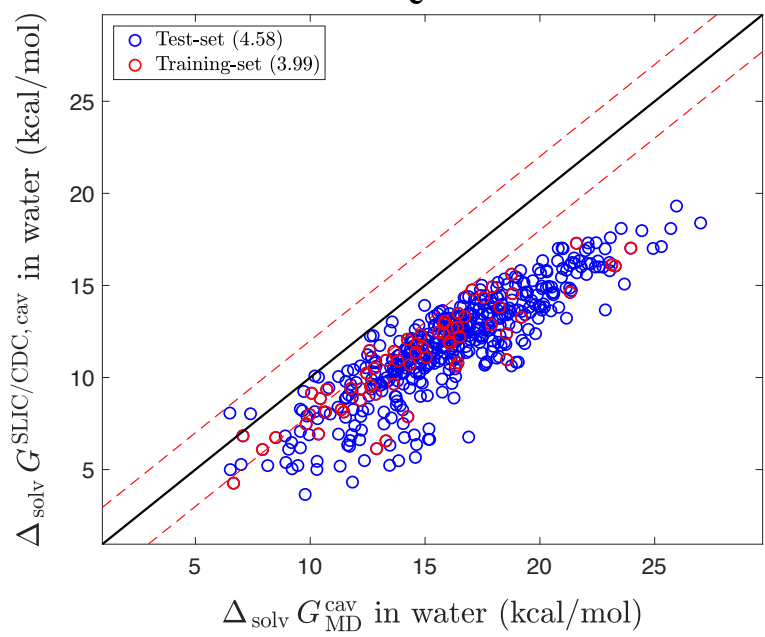

b

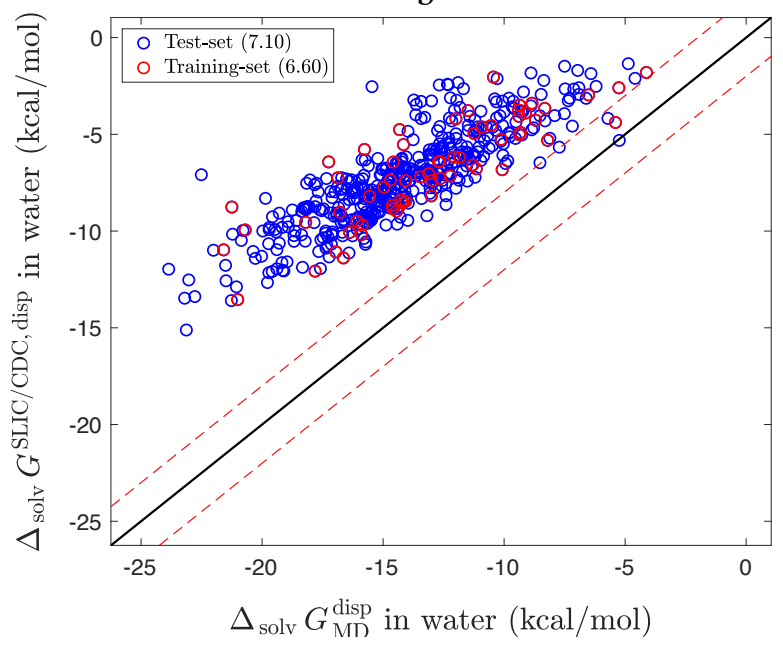

$\mathrm{d}$

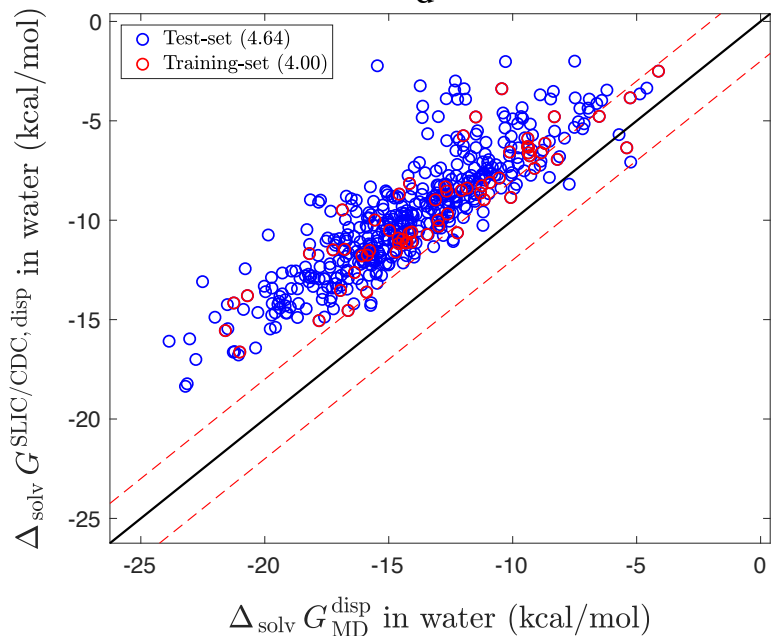

FIG. 13. SLIC/CDC predictions of the cavity (a) and dispersion (b) components of solvation Gibbs energies (vertical axis) for the Mobley test-set compared with the FEP results (horizontal axis) of Mobley et al $\underline{64}$. First row $(\mathrm{a}, \mathrm{b})$ denotes the predictions made using the 1-step scheme and second row $(\mathrm{c}, \mathrm{d})$ denotes the predictions made using the 2-step scheme. Blue and red circles denote the model predictions for the test-set and training-set, respectively. Red dashed lines show the $\pm 2 \mathrm{kcal} / \mathrm{mol}$ error margin. The numbers in parentheses indicate the RMS errors in $\mathrm{kcal} / \mathrm{mol}$. 


\section{SOLVATION THERMODYNAMICS IN IONIC LIQUIDS}

This section presents the performance of SLIC/SASA in predicting solvation thermodynamics in seven ionic liquids. Experimental measurements for solvation thermodynamics are not available for a wide range of small molecules in ionic liquids. Instead, to test the SLIC/SASA implicit-solvent model on ionic liquids, we used as reference solvation Gibbs energies the results of explicit-solvent FEP calculations on amino-acid sidechain analogs by Latif et al. .54 and Paluch et al.74. Solvation free energy calculations for amino-acid sidechain analogs in ionic liquids with $[\mathrm{BMIM}]^{+}$cations were performed by Latif et al. $\underline{54}$ at a temperature of $298.15 \mathrm{~K}$ and in ionic liquids with [Tf2N $]^{-}$anions were performed by Paluch et al. $\frac{74}{8}$ at temperatures 298, 328, and $358 \mathrm{~K}$. We first present the model predictions of solvation Gibbs energies for 12 amino-acid sidechain analogs, hereafter called $A A$ test-set, in seven ionic liquids at $298 \mathrm{~K}$. Table SI-3 in Supporting Information presents the 12 amino-acids and corresponding sidechain analogs. The seven ionic liquids are [EMIM][Tf2N], [BMIM][Tf2N], $[\mathrm{OMIM}][\mathrm{Tf} 2 \mathrm{~N}]$, [BMIM] $[\mathrm{BF} 4], \quad[\mathrm{BMIM}][\mathrm{Cl}], \quad[\mathrm{BMIM}][\mathrm{PF} 6]$, and [BMIM] $][\mathrm{TfO}]$. Next, we present the model predictions of solvation entropies in [EMIM] [Tf2N], and [BMIM] [Tf2N], $[\mathrm{OMIM}][\mathrm{Tf} 2 \mathrm{~N}]$ at $328 \mathrm{~K}$.

TABLE 3: Dielectric constants of seven ionic liquids at $298 \mathrm{~K}$

\begin{tabular}{|c|c|c|c|}
\hline Solvent & Dielectric constant & Solvent & Dielectric constant \\
\hline$[\mathrm{EMIM}][\mathrm{Tf} 2 \mathrm{~N}]$ & $15.2^{\frac{93}{3}}, 12^{42}$ & {$[\mathrm{BMIM}][\mathrm{PF} 6]$} & $11.4^{93}, 13.57^{78}, 17.2^{42}$ \\
\hline$[\mathrm{BMIM}][\mathrm{Tf} 2 \mathrm{~N}]$ & $11.6^{\underline{93}}, 13.85^{78}$ & {$[\mathrm{BMIM}][\mathrm{TfO}]$} & $14.34^{78}, 12.942$ \\
\hline$[\mathrm{BMIM}][\mathrm{BF} 4]$ & $11.7^{93}, 13.57^{78}, 14.6^{43}$ & {$[\mathrm{BMIM}][\mathrm{Cl}]$} & $12.68^{78}$ \\
\hline
\end{tabular}

One of the challenges in making predictions of solvation thermodynamics in ionic liquids was obtaining credible dielectric constants from the literature. Most ionic liquids exhibit a dielectric constant in the range of 10-15 which classifies them as moderately polar solvents 93 . The static dielectric constant of ionic liquids can not be determined by conventional methods and require special measurement techniques 78 . Because the reported dielectric constants for ionic liquids that we found in the literature are sometimes very different (e.g. $11.4^{93}$ and $17.2^{43}$ for $[\mathrm{BMIM}][\mathrm{PF} 6]$ ), for each ionic liquid, we parameterized SLIC/SASA using multiple dielectric constants (unless, of course, there is a single reported value). The dielectric constant(s) and the corresponding reference(s) that we used to parameterize the 
SLIC/SASA model for ionic liquid calculations are shown in Table 3. Regardless of the dielectric constant that was used to parameterize the model, SLIC/SASA predictions of solvation Gibbs energies are in good agreement with the explicit-solvent counterparts. Figure 14 shows the SLIC/SASA models' predictions of solvation Gibbs energies for the AA test-set in $[\mathrm{BMIM}][\mathrm{BF} 4]$ and $[\mathrm{EMIM}][\mathrm{Tf} 2 \mathrm{~N}]$. One reason behind the accurate SLIC/SASA predictions when paramaterized using different values of dielectric constants is that the optimizer can minimize the error relative to the reference data by tuning the SLIC electrostatic parameters. The model predictions for the rest of the ionic liquids can be found in Table 4 and Supporting Information.

TABLE 4: Performance of the SLIC/SASA model in prediction solvation Gibbs energies of the AA test-set in seven ionic liquids at $298 \mathrm{~K} . \varepsilon$ and $\rho$ denote dielectric constant and Pearson correlation coefficient, respectively. Subscripts denote the reference that the explicit-solvent data was obtained; L: Latif et al. 54 and P: Paluch et al. 74

\begin{tabular}{lccclccc}
\hline Ionic liquid & $\varepsilon$ & RMSE & $\rho$ & Ionic liquid & $\varepsilon$ & RMSE & $\rho$ \\
\hline$[$ EMIM $][\text { Tf2N }]_{\mathrm{P}}$ & 15.2 & 0.66 & 0.981 & {$[\mathrm{BMIM}][\mathrm{BF} 4]_{\mathrm{L}}$} & 14.6 & 0.45 & 0.995 \\
{$[\mathrm{EMIM}][\mathrm{Tf} 2 \mathrm{~N}]_{\mathrm{P}}$} & 15.3 & 0.66 & 0.981 & {$[\mathrm{BMIM}][\mathrm{PF} 6]_{\mathrm{L}}$} & 11.4 & 0.50 & 0.993 \\
{$[\mathrm{EMIM}][\mathrm{Tf} 2 \mathrm{~N}]_{\mathrm{P}}$} & 12 & 0.78 & 0.974 & {$[\mathrm{BMIM}][\mathrm{PF} 6]_{\mathrm{L}}$} & 13.57 & 0.62 & 0.991 \\
{$[\mathrm{BMIM}][\mathrm{Tf} 2 \mathrm{~N}]_{\mathrm{P}}$} & 11.6 & 0.55 & 0.986 & {$[\mathrm{BMIM}][\mathrm{PF}]_{\mathrm{L}}$} & 17.2 & 0.53 & 0.993 \\
{$[\mathrm{BMIM}][\mathrm{Tf} 2 \mathrm{~N}]_{\mathrm{P}}$} & 13.85 & 0.56 & 0.986 & {$[\mathrm{BMIM}][\mathrm{TfO}]_{\mathrm{L}}$} & 14.34 & 0.56 & 0.993 \\
{$[\mathrm{BMIM}][\mathrm{Tf} 2 \mathrm{~N}]_{\mathrm{L}}$} & 11.6 & 0.58 & 0.990 & {$[\mathrm{BMIM}][\mathrm{TfO}]_{\mathrm{L}}$} & 12.9 & 0.61 & 0.992 \\
{$[\mathrm{BMIM}][\mathrm{Tf} 2 \mathrm{~N}]_{\mathrm{L}}$} & 13.85 & 0.58 & 0.990 & {$[\mathrm{BMIM}][\mathrm{Cl}]_{\mathrm{L}}$} & 12.68 & 0.88 & 0.991 \\
{$[\mathrm{BMIM}][\mathrm{BF} 4]_{\mathrm{L}}$} & 11.7 & 0.54 & 0.992 & {$[\mathrm{OMIM}][\mathrm{Tf} 2 \mathrm{~N}]_{\mathrm{P}}$} & 12.85 & 0.52 & 0.987 \\
{$[\mathrm{BMIM}][\mathrm{BF} 4]_{\mathrm{L}}$} & 13.57 & 0.49 & 0.994 & {$[\mathrm{OMIM}][\mathrm{Tf} 2 \mathrm{~N}]_{\mathrm{P}}$} & 16.8 & 0.53 & 0.987 \\
\hline \hline
\end{tabular}

We also tested SLIC against the results of Paluch and Maginn et al., who have performed solvation FEP calculations at multiple temperatures in water and octanol as well as three ionic liquids containing anion $[\mathrm{Tf} 2 \mathrm{~N}]^{-}$which allows estimation of solvation entropies 74 . Figure 15 plots the SLIC/SASA-predicted solvation entropies for [EMIM][Tf2N], and [OMIM][Tf2N], compared to Paluch's 74 explicit-solvent results. We used a temperaturedependent dielectric constant for [EMIM] [Tf2N] and [BMIM] [Tf2N] from a work by Krossing et al. where the dielectric constant for $[\mathrm{BMIM}][\mathrm{Tf} 2 \mathrm{~N}]$ was extrapolated for $\mathrm{T}>328 \mathrm{~K} \underline{53}$. No temperature-dependent permittivity was available for [OMIM][Tf2N] and for consistency, 
we used the same permittivity $\underline{78}$ at multiple temperatures. SLIC/SASA predictions of ionic liquids are in good agreement with reference data. All entropy calculation started from the same initial guess (see Numerical Methods and Supporting Information for more details). Table 5 summarizes the SLIC/SASA models' performance in predicting solvation entropies of the AA test-set in three ionic liquids.
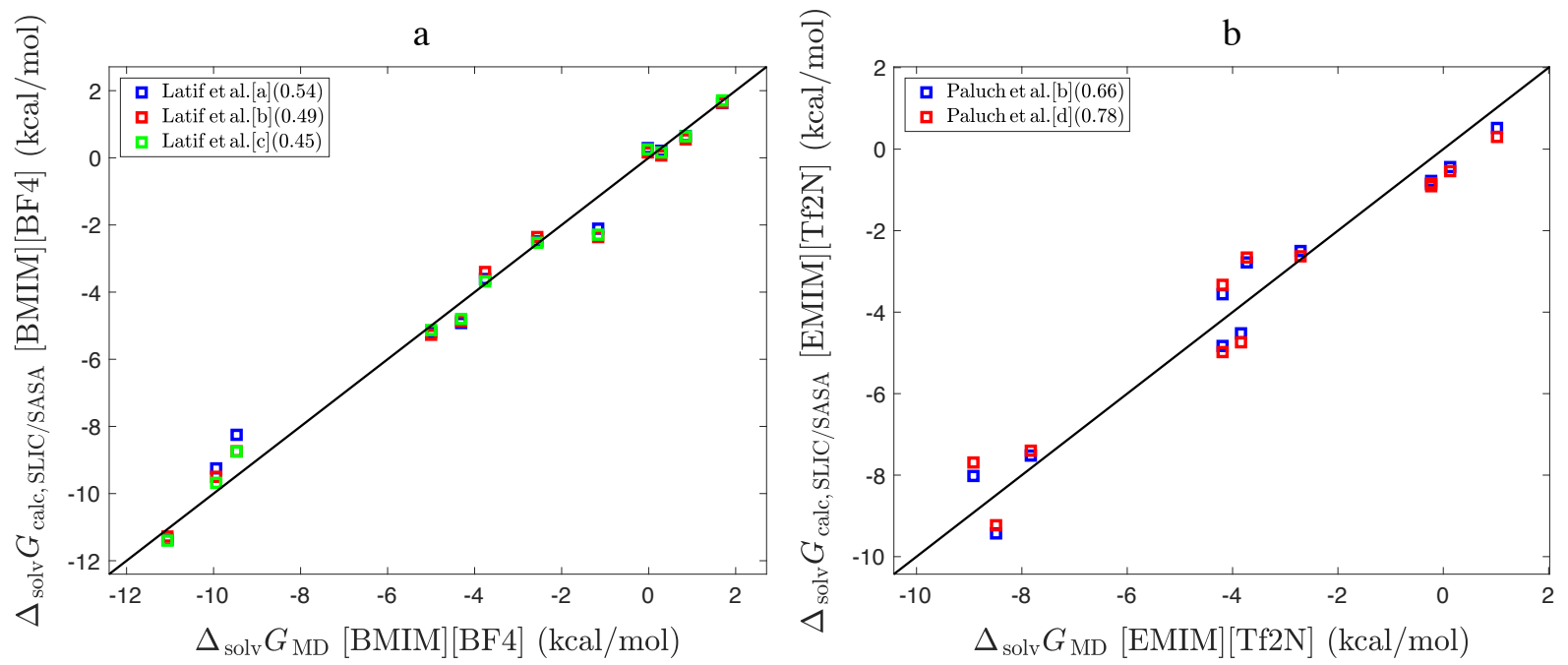

FIG. 14. Solvation Gibbs energies for the AA test-set in [BMIM][BF4] (a) and [EMIM][Tf2N] (b) calculated using the SLIC/SASA model (vertical axis), compared to the explicit-solvent MD results (horizontal axis) 54,74. The reference data that is used to parameterize the model is denoted in the legend. The letters in brackets denote the dielectric constant that was used; a:Reference 93 , b:Reference $\underline{78}$, c:Reference $\underline{43}$, and d:Reference $\underline{42}$. The numbers in parentheses are the RMS errors in $\mathrm{kcal} / \mathrm{mol}$.

TABLE 5: Performance of the SLIC/SASA model in predicting solvation Gibbs energies of the AA test-set in seven ionic liquids at $328 \mathrm{~K}$. RMSE is reported in in $\mathrm{kcal} / \mathrm{mol}$ and $\rho$ denotes Pearson correlation coefficient.

\begin{tabular}{lcc}
\hline Ionic liquid & RMSE & $\rho$ \\
\hline$[$ EMIM] $[$ Tf2N] & 1.30 & 0.963 \\
{$[$ BMIM] $[$ Tf2N] } & 1.59 & 0.951 \\
{$[$ OMOM][Tf2N] } & 1.37 & 0.947 \\
\hline \hline
\end{tabular}




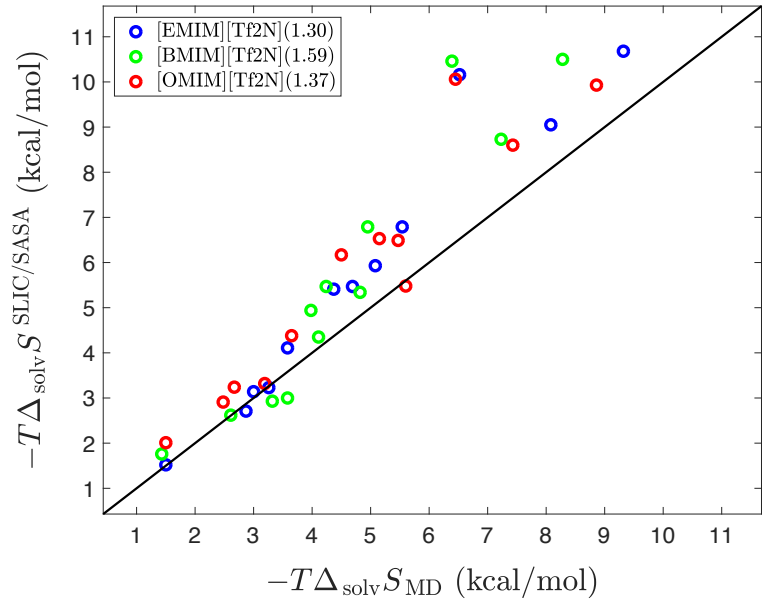

FIG. 15. Solvation entropies for AA test-set in octanol, [EMIM][Tf2N], [BMIM][Tf2N], and [OMIM] [Tf2N] at $328 \mathrm{~K}$ calculated using SLIC/SASA (vertical axis), compared to the explicitsolvent MD results of Paluch at al. as reference $\underline{74}$. The numbers in parentheses are the RMS errors in $\mathrm{kcal} / \mathrm{mol}$.

\section{DISCUSSION}

In this work, we tested the performance of two implicit-solvent models that both use the SLIC electrostatics model for electrostatic calculations. The first model is the SLIC/SASA model that combines SLIC with a simple SASA-proportional nonpolar correlation. The second model is the SLIC/CDC model that combines SLIC with a more sophisticated nonpolar model from COSMO-SAC studies and a hydrogen-bonding correlation that explicitly accounts for the hydrogen bond energies. We demonstrated that both models predict hydration Gibbs energies, entropies, and heat capacities with surprising accuracy compared to experiments. We assessed the accuracy of the two models' predictions of hydration Gibbs energies, entropies, and heat capacities by comparing them with experimental data for 502, 159, and 123 neutral small molecules, respectively. We also tested the performance of SLIC/SASA in making predictions of solvation Gibbs energies and entropies for 12 amino-acid sidechain analogs in seven ionic liquids and octanol. Our results show that 
the SLIC/SASA model's accuracy is not limited to aqueous solvents, and the model can be successfully used to predict solvation properties in more complex solvents.

SLIC/SASA achieves high accuracy in predicting solvation properties using only six free parameters and a training-set of only 12 small molecules. The small number of free parameters made it possible to fit the nonpolar and electrostatic parameters simultaneously. We also tested a two-step optimization procedure. First, we obtained the electrostatic parameters by parameterizing the SLIC electrostatics model against Mobley's explicit-solvent electrostatic free energies. Next, we optimized the SLIC/SASA model against the experimental hydration Gibbs energies, where we kept the electrostatic parameters found in the first step fixed. The two-step optimization procedure lead to a slight increase in the accuracy of predictions $(\approx 0.1 \mathrm{kcal} / \mathrm{mol})$. The SLIC/CDC model achieved higher accuracy than the explicit-solvent simulations of Mobley in predicting hydration Gibbs energies. Compared to the SLIC/SASA model, SLIC/CDC requires a higher number of small molecules in the training set (63 rather than 12). This large training-set is required to ensure the training-set's adequately diverse to represent the various atom-specific dispersion and hydrogen-bonding parameters.

Both models demonstrate high accuracy in predicting hydration entropies and heat capacities. Compared to our previous study, the new implementation of SLIC/SASA was shown to be more accurate in predicting solvation entropies of small molecules. The new SLIC/SASA implementation differs from our previous work in two ways. First, the number of Picard iterations was increased from 5 to 10 because we realized that 5 iterations do not guarantee the solution convergence for a few compounds. Second, we used the optimal electrostatic parameters from hydration Gibbs energy calculations at $298 \mathrm{~K}$ as the initial guesses for the entropy calculations at all temperatures. This ensures that the optimization at all temperatures starts from a local minimum. This was in contrast to our previous work, where the initial guesses at all temperatures were also the same but not a local minimum. These two changes also significantly improved the accuracy of SLIC/SASA in predicting hydration heat capacities, where we achieved a 10-fold increase in accuracy compared to our previous work ${ }^{75}$. One of the most remarkable outcomes of this work was the SLIC/CDC model's high accuracy in predicting hydration entropies and heat capacities for small molecules. This was very surprising for two reasons; First, the SLIC/CDC model does not require to be parameterized at different temperatures to make accurate predictions. 
In other words, the model does not need prior knowledge of the experimental hydration entropies and heat capacities for the training-set compounds. This was in stark contrast to the SLIC/SASA calculations, where the model uses temperature-dependent parameters to predict hydration thermodynamics. Second, because hydration entropies are higher-order derivative quantities of hydration Gibbs energies, one would not naturally expect to obtain accurate predictions of hydration entropies with the same level of accuracy as solvation free energies. This highlighted the value of a robust statistical-mechanics-based model, where meeting the thermodynamic consistency conditions was shown to boost the accuracy of the model significantly.

We find that when compared with the explicit-solvent results of Mobley, SLIC/CDC can provide accurate predictions of the cavity and dispersion components of the nonpolar hydration Gibbs energies. We noticed that the cavity and dispersion components are strongly correlated and anti-correlated, respectively, with molecule's size (volume or area.) Despite this good correlation, the sum of the cavity and dispersion energy that gives the nonpolar component of solvation Gibbs energy neither correlates with the molecular size nor the explicit-solvent results. The reason is that the nonpolar component of solvation is the sum of two anti-correlated quantities of the same order of magnitude. Therefore, the nonpolar solvation energy is dominated by the noise in the model's predictions of the two quantities, namely, the cavity and dispersion energies. In other words, the deviations of model predictions from a perfect correlation (for the cavity term) or anti-correlation (for the dispersion term) with the size of small molecules are in the same order of magnitude as the nonpolar energies. Similarly, the SLIC/SASA predictions of nonpolar hydration are inaccurate and poorly correlated with the explicit-solvent data. This poor performance suggests that implicit nonpolar models that solely incorporate area or volume dependant descriptors are insufficient to capture nonpolar solvation. Other 21,23, 72, 90,92. Cooper and Bardhan have recently proposed an auspicious approach where they use a simple model to make accurate predictions of nonpolar solvation for small molecules of arbitrary shapes 25 .

Ionic liquid solvation study demonstrated SLIC/SASA's ability to make accurate predictions of solvation Gibbs energies and entropies in complex solvents. Accurate predictions of solvation properties, significantly lower computational cost in comparison to explicitsolvent simulations, and the challenges associated with the slow dynamics of solvation in explicit-solvent simulations in ionic liquids 73,100 make the SLIC/SASA model a very ap- 


\section{REFERENCES}

1 Matlab v.6. Mathworks, Inc.

2 CRC handbook of chemistry and physics, volume 85. CRC Press, 2004.

3 A. Abrashkin, D. Andelman, and H. Orland. Dipolar Poisson-Boltzmann equation: ions and dipoles close to charge interfaces. Phys. Rev. Lett., 99:077801, 2007.

4 J. Alejandre, S. E. Martinez-Casas, and G. A. Chapela. On the calculation of the sphericity factor for fused hard sphere molecules. Mol. Phys., 65(5):1185-1193, 1988.

5 J. Åqvist and T. Hansson. On the validity of electrostatic linear response in polar solvents. J. Phys. Chem., 100:9512-9521, 1996.

6 C. Azuara, H. Orland, M. Bon, P. Koehl, and M. Delarue. Incorporating dipolar solvents with variable density in Poisson-Boltzmann electrostatics. Biophys. J., 95:5587-5605, 2008.

7 J. P. Bardhan. Biomolecular electrostatics - I want your solvation (model). Comput. Sci. Discov., 5:013001, 2012.

8 J. P. Bardhan, P. Jungwirth, and L. Makowski. Affine-response model of molecular solvation of ions: Accurate predictions of asymmetric charging free energies. J. Chem. Phys., 137:124101, 2012.

9 J. P. Bardhan and M. G. Knepley. Modeling charge-sign asymmetric solvation free energies with nonlinear boundary conditions. J. Chem. Phys., 141:131103, 2014.

10 A. Ben-Naim. Solvation thermodynamics. Springer, 1987.

11 A. Ben-Naim and Y. Marcus. Standard thermodynamics of transfer. uses and misuses. J. Phys. Chem., 82(7):792-803, 1978.

12 A. Ben-Naim and Y. Marcus. Solvation thermodynamics of nonionic solutes. J. Chem. Phys., 81(4):2016-2027, 1984

13 L. Blum. Mean spherical model for asymmetric electrolytes: I. method of solution. Mol. Phys., 30(5):1529-1535, 1975.

14 L. Blum and W. R. Fawcett. Application of the mean spherical approximation to describe the Gibbs solvation energies of monovalent monoatomic ions in polar solvents. J. Phys. Chem., 96(1):408-414, 1992.

15 J. O’M. Bockris, M. A. V. Devanathan, and K. Müller. On the structure of charged interfaces. Proc. Royal Soc. London. A: Math. and Phys. Sci., 274:55-79, 1963. 
D. J. Bonthuis and R. R. Netz. Beyond the continuum: how molecular solvent structure affects electrostatics and hydrodynamics at solid-electrolyte interfaces. J. Phys. Chem. B, 117:1139711413, 2013.

17 I. Borukhov, D. Andelman, and H. Orland. Steric effects in electrolytes: a modified PoissonBoltzmann equation. Phys. Rev. Lett., 79:435-438, 1997.

18 T. Boublík. Equation of state of linear fused hard-sphere models. Mol. Phys., 68(1):191-198, 1989.

19 B. D. Bursulaya and C. L. Brooks III. Comparative study of the folding free energy landscape of a three-stranded $\beta$-sheet protein with explicit and implict solvent models. J. Phys. Chem. $B, 104: 12378-12383,2000$.

D. S. Cerutti, N. A. Baker, and J. A. McCammon. Solvent reaction field potential inside an uncharged globular protein: a bridge between implicit and explicit solvent models? J. Chem. Phys., 127:155101, 2007.

21 A. Chakravorty, E. Gallicchio, and E. Alexov. A grid-based algorithm in conjunction with a gaussian-based model of atoms for describing molecular geometry. J. Comput. Chem., 40(12):1290-1304, 2019.

22 A. C. Chamberlin, C. J. Cramer, and D. G. Truhlar. Extension of a temperature-dependent aqueous solvation model to compounds containing nitrogen, fluorine, chlorine, bromine, and sulfur. J. Phys. Chem. B, 112:3024-3039, 2008.

23 M. Chen, B. Tu, and B. Lu. Triangulated manifold meshing method preserving molecular surface topology. J. Mol. Graphics Modeling, 2012.

24 I.-L. Chern, J.-G. Liu, and W.-C. Wang. Accurate evaluation of electrostatics for macromolecules in solution. Methods Appl. Anal., 10:309-328, 2003.

25 C. Cooper and J. P. Bardhan. A simple electrostatic model for the hard-sphere solute component of nonpolar solvation. arXiv preprint arXiv:2005.13019, 2020.

26 C. R. Corbeil, T. Sulea, and E. O. Purisima. Rapid prediction of solvation free energy. 2. The first-shell hydration (FiSH) continuum model. J. Chem. Theory Comput., 6:1622-1637, 2010.

27 S. Das, S. Chakraborty, and S. K. Mitra. Redefining electrical double layer thickness in narrow confinements: effect of solvent polarization. Phys. Rev. E, 85:051508, 2012.

28 P. Debye and E. Huückel. Zur theorie der elektrolyte ii. das grenzgesetz für die elektrische leitfähigkeit (theory of electrolytes-limiting law for electrical conductivity). Physik Z, 24:305- 
$325,1923$.

29 R. R. Dogonadze and A. A. Kornyshev. Polar solvent structure in the theory of ionic solvation. J. Chem. Soc. Faraday Trans. 2, 70:1121-1132, 1974.

30 J. J. Dwyer, A. G. Gittis, D. A. Karp, E. E. Lattman, D. S. Spencer, W. E. Stites, and B. García Moreno E. High apparent dielectric constants in the interior of a protein reflect water penetration. Biophys. J., 79:1610-1620, 2000.

31 J. Dzubiella, J. M. J. Swanson, and J. A. McCammon. Coupling hydrophobicity, dispersion, and electrostatics in continuum solvent models. Phys. Rev. Lett., 96:087802, 2006.

32 J. Florián and A. Warshel. Calculations of hydration entropies of hydrophobic, polar, and ionic solutes in the framework of the Langevin dipoles solvation model. J. Phys. Chem. B, 103:10282-10288, 1999.

33 E. Gallicchio, M. M. Kubo, and R. M. Levy. Enthalpy-entropy and cavity decomposition of alkane hydration free energies: numerical results and implications for theories of hydrophobic solvation. J. Phys. Chem. B, 104(26):6271-6285, 2000.

34 V. Gavini, K. Bhattacharya, and M. Ortiz. Quasi-continuum orbital-free density-functional theory: a route to multi-million atom non-periodic DFT calculation. Journal of the Mechanics and Physics of Solids, 55:697-718, 2007.

35 H. Gong and K. F. Freed. Langevin-Debye model for nonlinear electrostatic screening of solvated ions. Phys. Rev. Lett., 102(057603), 2009.

36 H. Gong and K. F. Freed. Electrostatic solvation energy for two oppositely charged ions in a solvated protein system: Salt bridges can stabilize proteins. Biophys. J., 98(3):470-477, Feb 2010.

37 P. Grochowski and J. Trylska. Continuum molecular electrostatics, salt effects, and counterion binding - a review of the Poisson-Boltzmann theory and its modifications. Biopolymers, 89:93$113,2007$.

38 A. Grossfield. Dependence of ion hydration on the sign of the ion's charge. J. Chem. Phys., 122:024506, 2005

39 E. A. Guggenheim. Mixtures: the theory of the equilibrium properties of some simple classes of mixtures, solutions and alloys. Clarendon Press, 1952.

40 A. Hildebrandt. Biomolecules in a structured solvent: A novel formulation of nonlocal electrostatics and its numerical solution. PhD thesis, Universität des Saarlandes, 2005. 
41 B. Honig and A. Nicholls. Classical electrostatics in biology and chemistry. Science, 268:11441149, 1995.

42 M. M. Huang, Y. Jiang, P. Sasisanker, G. W. Driver, and H. Weingärtner. Static relative dielectric permittivities of ionic liquids at 25 c. J. Chem. Eng. Data, 56(4):1494-1499, 2011.

43 J. Hunger, A. Stoppa, S. Schrödle, G. Hefter, R., and Buchner. Temperature dependence of the dielectric properties and dynamics of ionic liquids. ChemPhysChem, 10(4):723-733, 2011.

44 J. D. Jackson. Classical Electrodynamics. Wiley, New York, $3^{\text {rd }}$ edition, 1998.

45 A. Jakalian, B. L. Bush, D. B. Jack, and C. I. Bayly. Fast, efficient generation of high-quality atomic charges. am1-bcc model: I. method. J. Comput. Chem., 21(2):132-146, 2000.

46 A. Jakalian, D. B. Jack, and C. I. Bayly. Fast, efficient generation of high-quality atomic charges. am1-bcc model: Ii. parameterization and validation. J. Comput. Chem., 23(16):1623$1641,2002$.

47 T. S. Klotz. Numerical Analysis of Nonlinear Boundary Integral Equations Arising in Molecular Biology. PhD thesis, Rice University, 2019.

48 P. Koehl, H. Orland, and M. Delarue. Beyond the Poisson-Boltzmann: modeling biomoleculewater and water-water interactions. Phys. Rev. Lett., 102:087801, 2009.

49 P. Koehl, H. Orland, and M. Delarue. Adapting Poisson-Boltzmann to the self-consistent mean field theory: application to protein side-chain modeling. J. Chem. Phys., 135:055104, 2011.

50 P. Kollman. Free energy calculations: Applications to chemical and biochemical phenomena. Chem. Rev., 93:2395-2417, 1993.

51 A. A. Kornyshev and G. Sutmann. The shape of the nonlocal dielectric function of polar liquids and the implications for thermodynamic properties of electrolytes: A comparative study. J. Chem. Phys., 104:1524, 1996.

52 N. Korolev, A. P. Lyubartsev, A. Rupprecht, and L. Nordenskiöld. Competitive binding of $\mathrm{Mg} 2+, \mathrm{Ca} 2+, \mathrm{Na}+$, and $\mathrm{K}+$ ions to DNA in oriented DNA fibers: experimental and Monte Carlo simulation results. Biophys. J., 77:2736-2749, 1999.

53 I. Krossing, J. M. Slattery, C. Daguenet, P. J. Dyson, A. Oleinikova, and H. Weingärtner. Why are ionic liquids liquid? a simple explanation based on lattice and solvation energies. J. Phys. Chem., 128(41):13427-13434, 2006.

54 M. A. M. Latif, N. Micaêlo, and M. B. A. Rahman. Solvation free energies in [bmim]-based ionic liquids: anion effect toward solvation of amino acid side chain analogues. Chem. Phys. 
Lett., 615:69-74, 2014.

55 W. M. Latimer, K. S. Pitzer, and C. M. Slansky. The free energy of hydration of gaseous ions, and the absolute potential of the normal calomel electrode. J. Chem. Phys., 7:108-112, 1939.

56 R. M. Levy and E. Gallicchio. Computer simulations with explicit solvent: recent progress in the thermodynamic decomposition of free energies and in modeling electrostatic effects. Annu. Rev. Phys. Chem., 49(1):531-567, 1998.

57 S. T. Lin and S. I. Sandler. Infinite dilution activity coefficients from ab initio solvation calculations. AIChE Journal, 45:2606-2618, 1999.

58 S. T. Lin and S. I. Sandler. A priori phase equilibrium prediction from a segment contribution solvation model. Ind. Eng. Chem. Res., 41:899-913, 2002.

59 Shiang-Tai Lin, Jaeeon Chang, Shu Wang, William A Goddard, and Stanley I Sandler. Prediction of vapor pressures and enthalpies of vaporization using a cosmo solvation model. jphyschema, 108(36):7429-7439, 2004.

60 S. R. Lustig. Speciation in electrolytes using the cosmo-rs solution model. Fluid Ph. Equilibria, 521:112717, 2020.

61 R. M. Lynden-Bell, J. C. Rasaiah, and J. P. Noworyta. Using simulation to study solvation in water. Pure Appl. Chem., 73:1721-1731, 2001.

62 B. Mennucci. Continuum solvation models: what else can we learn from them? J. Phys. Chem. Lett., 1:1666-1674, 2010.

63 S. Miertus, E. Scrocco, and J. Tomasi. Electrostatic interactions of a solute with a continuum - a direct utilization of $a b$ initio molecular potentials for the prevision of solvent effects. Chem. Phys., 55(1):117-129, 1981.

64 D. L. Mobley, C. I. Bayly, M. D. Cooper, M. R. Shirts, and K. A. Dill. Small molecule hydration free energies in explicit solvent: an extensive test of fixed-charge atomistic simulations. J. Chem. Theory Comput., 5(2):350-358, 2009.

65 A. Molavi Tabrizi, S. Goossens, A. Mehdizadeh Rahimi, C. D. Cooper, M. G. Knepley, and J. P. Bardhan. Extending the solvation-layer interface condition (SLIC) continuum electrostatic model to linearized Poisson-Boltzmann solvent. J. Chem. Theory Comput., 13:2897-2914, 2017.

66 A. Molavi Tabrizi, S. Goossens, A. Mehdizadeh Rahimi, M. Knepley, and J. P. Bardhan. Predicting solvation thermodynamics with dielectric continuum theory and a solvation-layer interface condition (SLIC). J. Chem. Phys., 146(094103), 2017. 
67 A. Molavi Tabrizi, M. Knepley, and J. P. Bardhan. Generalizing the mean spherical approximation as a multiscale, nonlinear boundary condition at the solute-solvent interface. Mol. Phys., 114:2558-2567, 2016.

68 A. Mukhopadhyay, B. H. Aguilar, I. S. Tolokh, and A. V. Onufriev. Introducing charge hydration asymmetry into the Generalized Born model. J. Chem. Theory Comput., 10:1788-1794, 2014.

69 A. Mukhopadhyay, A. T. Fenley, I. S. Tolokh, and A. V. Onufriev. Charge hydration asymmetry: the basic principle and how to use it to test and improve water models. J. Phys. Chem. B, 116:9776â€"9783, 2012.

70 M. Nina, D. Beglov, and B. Roux. Atomic radii for continuum electrostatics calculations based on molecular dynamics free energy simulations. J. Phys. Chem. B, 101:5239-5248, 1997.

71 H. Nymeyer and A. E. García. Simulation of the folding equilibrium of $\alpha$-helical peptides: a comparison of the generalized Born approximation with explicit solvent. PNAS, 100(24):1393413939, 2003.

72 S. Ou, J. A. Drake, and B. M. Pettitt. Nonpolar solvation free energy from proximal distribution functions. J. Phys. Chem. B, 121(15):3555-3564, 2017.

73 T. Pal and R. Biswas. Slow solvation in ionic liquids: Connections to non-gaussian moves and multi-point correlations. J. Chem. Phys., 141(10):p104501, 2019.

74 A. S. Paluch, C. A. Vitter, J. K. Shah, and E. J. Maginn. A comparison of the solvation thermodynamics of amino acid analogues in water, 1-octanol and 1-n-alkyl-3-methylimidazolium bis(trifluormethylsulfonyl)imide ionic liquids by molecular simulation. J. Chem. Phys., 137(18):184504, 2012.

75 A. Mehdizadeh Rahimi, A. Molavi Tabrizi, S. Goossens, M. G. Knepley, and J. P. Bardhan. Solvation thermodynamics of neutral and charged solutes using the solvation--layer interface condition continuum dielectric model. Int. J. Quantum Chem, 119(1):e25771, 2019.

76 S. Rajamani, T. Ghosh, and S. Garde. Size dependent ion hydration, its asymmetry, and convergence to macroscopic behavior. J. Chem. Phys., 120:4457, 2004.

77 M. M. Reif and P. H. Hünenberger. Origin of asymmetric solvation effects for ions in water and organic solvents investigated using molecular dynamics simulations: the Swain acity-basity scale revisited. J. Phys. Chem. B, 120:8485-8517, 2016. 
78 A. Rybinska-Fryca, A. Sosnowska, and T. Puzyn. Prediction of dielectric constant of ionic liquids. J. Mol. Liq, 260:57-64, 2018.

79 L. Sandberg, R. Casemyr, and O. Edholm. Calculated hydration free energies of small organic molecules using a nonlinear dielectric continuum model. J. Phys. Chem. B, 106:7889-7897, 2002.

80 M. Sanner, A. J. Olson, and J. C. Spehner. Reduced surface: An efficient way to compute molecular surfaces. Biopolymers, 38:305-320, 1996.

81 M. Schaefer and C. Froemmel. A precise analytical method for calculating the electrostatic energy of macromolecules in aqueous solution. J. Mol. Biol., 216:1045-1066, 1990.

82 K. A. Sharp and B. Honig. Electrostatic interactions in macromolecules: Theory and applications. Annu. Rev. Biophys. Bio., 19:301-332, 1990.

83 M. R. Shirts and V. S. Pande. Solvation free energies of amino acid side chain analogs for common molecular mechanics water models. J. Chem. Phys., 122(134508), 2005.

84 T. Simonson. Macromolecular electrostatics: Continuum models and their growing pains. Curr. Opin. Struc. Biol., 11:243-252, 2001.

85 D. Sitkoff, K. A. Sharp, and B. Honig. Accurate calculation of hydration free energies using macroscopic solvent models. J. Phys. Chem. B, 98:1978-1988, 1994.

86 A. Staverman. The entropy of high polymer solutions. generalization of formulae. Trav. Chim. Pays-Bas, 69:163-174, 1950.

87 D. Stigter. Interactions of highly charged colloidal cylinders with applications to doublestranded DNA. Biopolymers, 16:1435-1448, 1977.

88 C. M. Stultz. An assessment of potential of mean force calculations with implicit solvent models. J. Phys. Chem. B, 108:16525-16532, 2004.

89 T. Sulea and E. O. Purisima. Optimizing ligand charges for maximum binding affinity. A solvated interaction energy approach. J. Phys. Chem. B, 105(4):889-899, 2001.

90 C. Tan, Y. Tan, and R. Luo. Implicit nonpolar solvent models. J. Phys. Chem. B, 111(42):12263$12274,2007$.

91 V. Vlachy. Ionic effects beyond Poisson-Boltzmann theory. Annu. Rev. Phys. Chem., 50:145$165,1999$.

92 J. A. Wagoner and N. A. Baker. Assessing implicit models for nonpolar mean solvation forces: The importance of dispersion and volume terms. Proc. Natl. Acad. Sci. USA, 103(22):8331- 
$8336,2006$.

93 C. Wakai, A. Oleinikova, M. Ott, and H. Weingärtner. How polar are ionic liquids? determination of the static dielectric constant of an imidazolium-based ionic liquid by microwave dielectric spectroscopy. J. Phys. Chem. B, 109:17028-17030, 2005.

94 J. M. Walsh and K. E. Gubbins. A modified thermodynamic perturbation theory equation for molecules with fused hard sphere cores. jphyschem, 94(12):5115-5120, 1988.

95 J. Wang, W. Wang, P. A. Kollman, and D. A. Case. Automatic atom type and bond type perception in molecular mechanical calculations. J. Mol. Graph. Model., 25(2):247-260, 2006.

96 J. Wang, R. M. Wolf, J. W. Caldwell, P. A. Kollman, and D. A. Case. Development and testing of a general AMBER force field. J. Comput. Chem., 25:1157-1174, 2004.

97 Shu Wang, Stanley I Sandler, and Chau-Chyun Chen. Refinement of cosmo- sac and the applications. Ind. Eng. Chem. Res., 46(22):7275-7288, 2007.

98 R. Xiong, S. I. Sandler, and R. I. Burnett. An improvement to cosmo-sac for predicting thermodynamic properties. Ind. Eng. Chem. Res., 53:8265-8278, 2014.

99 Y. K. Yang, G. Némethy, and H. A. Scheraga. Free energies of hydration of solute molecules. 1. improvement of the hydration shell model by exact computations of overlapping volumes. $J$. Phys. Chem., 91:4105-4109, 1987.

100 Y. Yasaka, M. L. Klein, M. Nakahara, and N. Matubayasi. Communication: Exploring the reorientation of benzene in an ionic liquid via molecular dynamics: Effect of temperature and solvent effective charge on the slow dynamics. J. Chem. Phys., 134:191101, 2011.

101 D. Yokogawa, H. Sato, T. Imai, and S. Sakaki. A highly parallelizable integral equation theory for three dimensional solvent distribution function: Application to biomolecules. J. Chem. Phys., 130:064111, 2009.

102 N. Yoshida, T. Imai, S. Phongphanphanee, A. Kovalenko, and F. Hirata. Molecular recognition in biomolecules studied by statistical-mechanical integral-equation theory of liquids. J. Phys. Chem. B, 113:873-886, 2009.

103 Z. Yu, M. P. Jacobson, J. Josovitz, C. S. Rapp, and R. A. Friesner. First-shell solvation of ion pairs: Correction of systematic errors in implicit solvent models. J. Phys. Chem. B, 108:6643-6654, 2004.

104 R. Zhou. Free energy landscape of protein folding in water: explicit vs. implicit solvent. Proteins, 53:148-161, 2003. 
105 R. Zhou and B. J. Berne. Can a continuum solvent model reproduce the free energy landscape of a $\beta$-hairpin folding in water? Proc. Natl. Acad. Sci. USA, 99(20):12777-12782, 2002. 


\section{APPENDIX A: RELATIONSHIP BETWEEN THE CHANGE IN GIBBS EN- ERGIES AND THE ELECTROSTATIC CHARGING ENERGIES IN SOLVATION PROCESS}

Solvation Gibbs energy is a thermodynamic property that is perhaps best defined by Ben-Naim as the energy change during the process of introducing a solute to a solution at a given absolute temperature $T$ and pressure $P$. Solvation Gibbs energy is a measure of the solute's affinity for the solvent and can be directly determined by experimental measurements. Standard solvation Gibbs energies $\left(\Delta_{\text {solv }} G^{0}\right)$ are often described as the Gibbs energy change in the process of transferring a solute from a gas-phase at 1 atm to a solution-phase at $1 \mathrm{~mol} / \mathrm{L}$ concentration. Ben-Naim proposed an alternative process where the solute is transferred from a gas-phase at $1 \mathrm{~mol} / \mathrm{L}$ concentration to a solution-phase at $1 \mathrm{~mol} / \mathrm{L}$ concentration. We denote the solvation Gibbs energy change in this process by $\Delta_{\text {solv }} G^{*}$. For a solute $\mathrm{A}$ in a solution $\mathrm{S}$, the two definitions are related through the expression

$$
\Delta_{\text {solv }} G_{\mathrm{A}}^{0}=\left[\Delta_{\text {solv }} G_{\mathrm{A}}^{*}+k_{B} T \ln \left(\rho_{\mathrm{A}}^{\mathrm{sol}} / \rho_{\mathrm{A}}^{\mathrm{g}}\right)\right]_{\substack{P_{\mathrm{A}}=1 \mathrm{~atm} \\ x_{\mathrm{A}}=1}}
$$

where $\rho_{\mathrm{A}}^{\mathrm{sol}}$ and $\rho_{\mathrm{A}}^{\mathrm{g}}$ are the solution-phase and gas-phase number densities, respectively. We adopt the definition of Ben-Naim for the rest of this section and we refer to $\Delta_{\text {solv }} G^{*}$ as solvation Gibbs energy. Consider a gas-phase and a solution-phase where species A are distributed

$$
[A]_{\mathrm{g}} \Longleftrightarrow[A]_{\mathrm{sol}} \text {. }
$$

At equilibrium where the two phases are at the same pressure and temperature we have

$$
\mu_{\mathrm{A}}^{\mathrm{sol}}=\mu_{\mathrm{A}}^{\mathrm{g}}
$$

where $\mu_{\mathrm{A}}^{\mathrm{i}}$ is the chemical potential of species A at phase i. Statistical thermodynamics provides a useful relationship for the chemical potential of the solute as (following the work of Ben-Naim 11, 12, 83 )

$$
\mu_{\mathrm{A}}=\mu_{\mathrm{A}}^{*}+k_{B} T \ln \rho_{\mathrm{A}} \Lambda_{\mathrm{A}}^{3},
$$

where $\Lambda_{\mathrm{A}}$ is the momentum partition function and $\mu_{\mathrm{A}}^{*}$ is referred to as the pseudochemical potential of species A and can be interpreted as the Gibbs energy change for adding a species 
A with the constraint that its center of mass is fixed (internal and translational degrees of freedom do not change). No constraints are imposed on the other degrees of freedom of A. The second term on the RHS is due to the removal of the fixed-position constraint and is referred to as the liberation Gibbs energy ${ }^{10}$. Using Equation A-4, chemical potential of the solute in each phase can be obtained as

$$
\begin{gathered}
\mu_{\mathrm{A}}^{\text {sol }}=\mu_{\mathrm{A}}^{* \text { sol }}+k_{B} T \ln \rho_{\mathrm{A}}^{\mathrm{sol}} \Lambda_{\mathrm{A}}^{3} \\
\mu_{\mathrm{A}}^{\mathrm{g}}=\mu_{\mathrm{A}}^{* \mathrm{~g}}+k_{B} T \ln \rho_{\mathrm{A}}^{\mathrm{g}} \Lambda_{\mathrm{A}}^{3} .
\end{gathered}
$$

Finally, solvation Gibbs energy can be calculated as

$$
\Delta_{\text {solv }} G_{\mathrm{A}}^{*}=\mu_{\mathrm{A}}^{* \mathrm{sol}}-\mu_{\mathrm{A}}^{* \mathrm{~g}} .
$$

Note that the standard solvation Gibbs energy can also be calculated as

$$
\begin{aligned}
\Delta_{\text {solv }} G_{\mathrm{A}}^{0} & =\mu_{\mathrm{A}}^{\text {sol }}-\mu_{\mathrm{A}}^{\mathrm{g}}=\mu_{\mathrm{A}}^{* \mathrm{sol}}+k_{B} T \ln \rho_{\mathrm{A}}^{\mathrm{sol}} \Lambda_{\mathrm{A}}^{3}-\mu_{\mathrm{A}}^{* \mathrm{~g}}-k_{B} T \ln \rho_{\mathrm{A}}^{\mathrm{g}} \Lambda_{\mathrm{A}}^{3} \\
& =\Delta_{\text {solv }} G_{\mathrm{A}}^{*}+k_{B} T \ln \left(\rho_{\mathrm{A}}^{\mathrm{sol}} / \rho_{\mathrm{A}}^{\mathrm{g}}\right),
\end{aligned}
$$

which recovers Equation A-1. Equation 11 provided an expression for the electrostatic interaction energy between the solvated solute and solvent. We now provide a relationship between Gibbs solvation energy in Equation A-6 and electrostatic work in Equation 11. Consider the reversible process of transferring the solute from a fixed position in the gas phase to a fixed position in solution. The Gibbs energy change in the process $\left(\Delta_{\text {solv }} G\right)$ is equal to the difference in standard chemical potentials between the solution and gas phases, and also equal to the work performed on the system during the transfer, that is:

$$
\Delta_{\text {solv }} G=\Delta_{\text {solv }} G_{\mathrm{A}}^{*}=\mu_{\mathrm{A}}^{* \mathrm{sol}}-\mu_{\mathrm{A}}^{* \mathrm{~g}}=W .
$$

Because we are only considering the electrostatic interactions during the transfer process, the work required for the transfer can be interpreted as the difference between the work required to discharge the solute in the gas phase and the work required to charge it in solution. Note that we are disregarding the contribution of nonpolar solvation and will focus on the electrostatic component for the rest of this section. We denote the electrostatic component of the solvation Gibbs energy by $\Delta_{\text {solv }} G^{* e s}$ and for the sake of simplicity will refer to it as solvation Gibbs energy. We define the process of charging the solute as a 
function of a charging parameter $\lambda$, ranging from 0 (uncharged) to 1 , where the molecular charge density reaches its final value $\rho(\mathbf{r})$ at any point $\mathbf{r}$ in the dielectric region. Defining the charge density in terms of the charging variable as $\rho(\mathbf{r} ; \lambda)=\lambda \rho(\mathbf{r})$ and knowing from the linear-response theory that the total potential field is a linear function of the charge distribution, we can write

$$
\varphi(\mathbf{r} ; \lambda)=\lambda \varphi(\mathbf{r})
$$

Note that in the solution phase, an extra term due to the contribution of static potential is added to the total potential field which is independent of the internal charge distribution of the solute 20,65 , i.e.

$$
\varphi^{\mathrm{sol}}(\mathbf{r} ; \lambda)=\lambda \varphi(\mathbf{r})+\varphi_{\text {static }}
$$

Variation in charge for a volume element $\mathrm{d} V(\mathbf{r})$ in the solute region during a variation $\mathrm{d} \lambda$ in charging parameter can then be written as

$$
\mathrm{d} q=[\rho(\mathbf{r}) \mathrm{d} V(\mathbf{r})] \mathrm{d} \lambda .
$$

The electrostatic potential energy, $U^{\mathrm{es}}$, of a point charge $q$ at position $\mathbf{r}$ in the presence of an electric potential $\varphi$ is defined as

$$
U^{\mathrm{es}}(\mathbf{r})=q \varphi(\mathbf{r})
$$

The work performed on the system during the variation $\mathrm{d} \lambda$ can be obtined by integrating over the dielectric region $\Omega$

$$
\mathrm{d} U^{\mathrm{es}}(\mathbf{r})=\int \varphi \mathrm{d} q=\int_{\Omega} \varphi\left(\mathbf{r}^{\prime} ; \lambda\right)\left[\rho\left(\mathbf{r}^{\prime}\right) \mathrm{d} V\left(\mathbf{r}^{\prime}\right)\right] \mathrm{d} \lambda
$$

Finally, substituting $\varphi(\mathbf{r} ; \lambda)$ from Equation A-9 to Equation A-13 and integrating $\lambda$ from 0 to 1 gives the charging work in the gas and solution phases as

$$
\begin{aligned}
\mathrm{d} U^{\mathrm{es}, \mathrm{g}} & =\int_{0}^{1} \lambda \mathrm{d} \lambda \int_{\Omega} \varphi^{\mathrm{g}}\left(\mathbf{r}^{\prime}\right) \rho\left(\mathbf{r}^{\prime}\right) \mathrm{d} V\left(\mathbf{r}^{\prime}\right)=\frac{1}{2} \int_{\Omega} \varphi^{\mathrm{g}}\left(\mathbf{r}^{\prime}\right) \rho\left(\mathbf{r}^{\prime}\right) \mathrm{d} V\left(\mathbf{r}^{\prime}\right) \\
\mathrm{d} U^{\mathrm{es}, \text { sol }} & =\int_{0}^{1} \lambda \mathrm{d} \lambda \int_{\Omega} \varphi^{\mathrm{sol}}\left(\mathbf{r}^{\prime}\right) \rho\left(\mathbf{r}^{\prime}\right) \mathrm{d} V\left(\mathbf{r}^{\prime}\right)+\varphi^{\text {static }} \int_{0}^{1} \mathrm{~d} \lambda \int_{\Omega} \rho\left(\mathbf{r}^{\prime}\right) \mathrm{d} V\left(\mathbf{r}^{\prime}\right) \\
& =\frac{1}{2} \int_{\Omega} \varphi^{\mathrm{sol}}\left(\mathbf{r}^{\prime}\right) \rho\left(\mathbf{r}^{\prime}\right) \mathrm{d} V\left(\mathbf{r}^{\prime}\right)+\varphi^{\text {static }} \int_{\Omega} \rho\left(\mathbf{r}^{\prime}\right) \mathrm{d} V\left(\mathbf{r}^{\prime}\right) .
\end{aligned}
$$


where $\varphi^{\mathrm{g}}=\varphi_{\mathrm{Coul}}$ and $\varphi^{\mathrm{g}}=\varphi_{\mathrm{Coul}}+\varphi_{\text {reac }}$. Solvation Gibbs energy can now be calculated using Equation A-14 as the sum of the uncharging work in a gas phase and the charging work in a solution phase

$$
\Delta_{\text {solv }} G^{* \mathrm{es}}=\Delta_{\text {solv }} U^{\mathrm{es}}=\overbrace{U^{\mathrm{es}, \text { sol }}}^{\begin{array}{c}
\text { charging } \\
\text { in solution }
\end{array}}+\overbrace{\left(-U^{\mathrm{es}, \mathrm{g}}\right)}^{\begin{array}{c}
\text { uncharging } \\
\text { in gas }
\end{array}}
$$

Using this equation and plugging the expressions for $\varphi^{\mathrm{g}}$ and $\varphi^{\text {sol }}$ into Equation A-14, we obtain

$$
\begin{aligned}
\Delta_{\text {solv }} G^{* \mathrm{es}} & =\frac{1}{2} \int_{\Omega}\left(\varphi^{\text {sol }}-\varphi^{\mathrm{g}}\right)\left(\mathbf{r}^{\prime}\right) \rho\left(\mathbf{r}^{\prime}\right) \mathrm{d} V\left(\mathbf{r}^{\prime}\right)+\varphi^{\text {static }} \int_{\Omega} \rho\left(\mathbf{r}^{\prime}\right) \mathrm{d} V\left(\mathbf{r}^{\prime}\right) \\
& =\frac{1}{2} \int_{\Omega} \varphi_{\text {reac }}\left(\mathbf{r}^{\prime}\right) \rho\left(\mathbf{r}^{\prime}\right) \mathrm{d} V\left(\mathbf{r}^{\prime}\right)+\varphi^{\text {static }} \int_{\Omega} \rho\left(\mathbf{r}^{\prime}\right) \mathrm{d} V\left(\mathbf{r}^{\prime}\right)
\end{aligned}
$$

Considering the solute charge distribution to be $N_{c}$ discrete point-charges where the $i-$ th charge is located at $\mathbf{r}_{i}$ with a value value $q_{i}$, Equation A-17 reproduces what we presented in Equation 11

$$
\Delta_{\text {solv }} G^{* \mathrm{es}}=\frac{1}{2} \sum_{i=1}^{N_{c}} q_{i} \varphi_{\text {reac }}\left(\mathbf{r}_{i}\right)+\varphi_{\text {static }} \sum_{i=1}^{N_{c}} q_{i}\left(\mathbf{r}_{i}\right)
$$

\section{APPENDIX B: BOUNDARY ELEMENT METHOD FOR CONTINUUM ELEC-} TROSTATICS

Continuum electrostatics theory provides a mathematical model for the solvation electrostatics problem by describing the behavior of the electrostatic potential in different domains using a system of coupled PDEs. Each PDE corresponds to a domain and mimics the spatial evolution of the electrostatic potential in that domain as seen in Equations 4 to ??. Boundary element methods reformulates the system of coupled PDEs as a system of boundary integral equations (BIEs). It then approximates the solution by finding the unknowns on the boundaries separating the domains and then use that information to find the solution at regions of interest. BEM is a powerful method especially for the problems with large domains where other numerical methods such as FEM or FVM would have too many elements to be practical. Another advantage of BEM is accurate treatment of the boundary conditions which is extremely important in molecular electrostatics. Furthermore, by oviating the 
need to solve the unknown function (electrostatic potential and its normal derivative) on the separating boundaries only (and not the entire domain), it offers a significant computational advantage. There are numerous approaches that use BEM for solving the problem but here here we are interested only in introducing the formulation originally proposed by Yoon and Lenhoff. We encourage the interested reader to take a look at our previous work which describes the polarizable continuum model (PCM) formulation.

The Yoon-Lenhoff formulation uses Green's second theorem, which says for two scalar fields $\Phi(\mathbf{r})$ and $\Psi(\mathbf{r})$, both twice continuously differentiable in a domain $\Omega$ that is enclosed

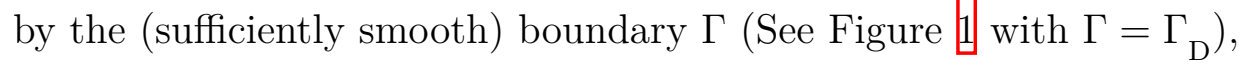

$$
\int_{\Omega}\left[\Phi\left(\mathbf{r}^{\prime}\right) \nabla^{2} \Psi\left(\mathbf{r}^{\prime}\right)-\Phi\left(\mathbf{r}^{\prime}\right) \nabla^{2} \Psi\left(\mathbf{r}^{\prime}\right)\right] \mathrm{d} \mathbf{r}^{\prime}=\oiint_{\Gamma}\left[\Phi\left(\mathbf{r}^{\prime}\right) \frac{\partial \Psi\left(\mathbf{r}^{\prime}\right)}{\partial \mathbf{n}\left(\mathbf{r}^{\prime}\right)}-\Psi\left(\mathbf{r}^{\prime}\right) \frac{\partial \Phi\left(\mathbf{r}^{\prime}\right)}{\partial \mathbf{n}\left(\mathbf{r}^{\prime}\right)}\right] \mathrm{d} \mathbf{r}^{\prime},
$$

where $\mathbf{n}$ points outward from $\Omega$. Assuming $\Phi\left(\mathbf{r}^{\prime}\right)$ to be the electrostatic potential, Equation B-1 allows the calculation of the $\Phi$ at any point in $\Omega$ directly from $\Phi$ and $\partial \Phi / \partial \mathbf{n}$ on $\Gamma$. For instance, consider $\Phi(\mathbf{r})$ to be the electrostatic potential in the solute region $\varphi_{\Omega}(\mathbf{r})$ from Equation 4 (where $\left.\nabla^{2} \varphi_{\Omega}(\mathbf{r})=-\rho(\mathbf{r}) / \varepsilon_{\Omega}\right)$. Setting $\Phi(\mathbf{r})=G_{\mathrm{L}}\left(\mathbf{r}, \mathbf{r}^{\prime}\right)$, where $G_{\mathrm{L}}\left(\mathbf{r}, \mathbf{r}^{\prime}\right)=1 / 4 \pi\left|\mathbf{r}-\mathbf{r}^{\prime}\right|$ is the free-space Green's function for the Laplace equation in threedimension,

$$
\nabla^{2} G_{\mathrm{L}}\left(\mathbf{r}, \mathbf{r}^{\prime}\right)=-\delta\left(\mathbf{r}-\mathbf{r}^{\prime}\right)
$$

and plugging $\Phi(\mathbf{r})$ into Equation B-1, we obtain

$$
\varphi_{\Omega}(\mathbf{r})=\frac{1}{\varepsilon_{\Omega}} \sum_{i=1}^{N_{c}} q_{i} G_{\mathrm{L}}\left(\mathbf{r}, \mathbf{r}_{i}\right)-\oiint_{\Gamma} \varphi_{\Omega}\left(\mathbf{r}^{\prime}\right) \frac{\partial G_{\mathrm{L}}\left(\mathbf{r}, \mathbf{r}^{\prime}\right)}{\partial \mathbf{n}\left(\mathbf{r}^{\prime}\right)} \mathrm{d} \mathbf{r}^{\prime}+\oiint_{\Gamma} G_{\mathrm{L}}\left(\mathbf{r}, \mathbf{r}^{\prime}\right) \frac{\partial \varphi_{\Omega}\left(\mathbf{r}^{\prime}\right)}{\partial \mathbf{n}\left(\mathbf{r}^{\prime}\right)} \mathrm{d} \mathbf{r}^{\prime}
$$

where we described the solute charge distribution as a set of $N_{c}$ point charges, the $i$ th of which is located at $\mathbf{r}_{i}$ with value $q_{i}$

$$
\rho(\mathbf{r})=\sum_{i=1}^{N_{c}} q_{i} \delta\left(\mathbf{r}-\mathbf{r}_{i}\right)
$$

The unknown functions on the boundary can be obtained by letting $\mathbf{r}$ approach the boundary $\Gamma$ but both integral terms in Equation B-3 become singular at $\mathbf{r}=\mathbf{r}_{\Gamma}$. We can remove the singularity by defining a sphere centered at $\mathbf{r}_{\Gamma}$ and calculate the integrals as its radius vanishes. Figure 16 shows a schematic of this procedure. 


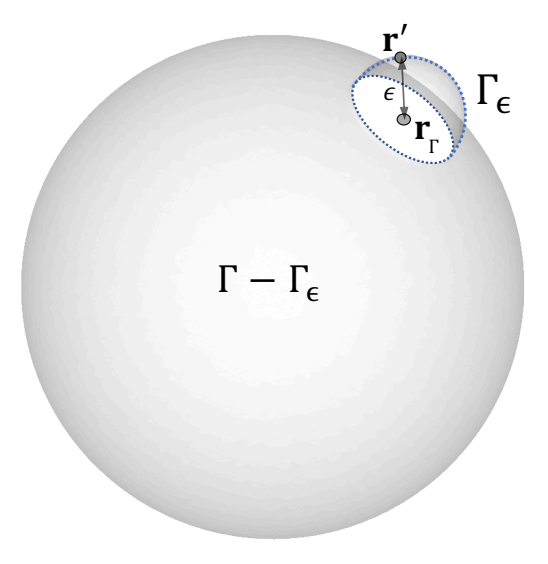

FIG. 16. Schematic of the limiting process to remove singularities in Equation B-3 as $\mathbf{r}^{\prime} \rightarrow \mathbf{r}_{\Gamma}$.

We divide the boundary $\Gamma$ to two regions as shown in the figure and calculate the surface integrals in spherical coordinate system on the singular region $\Gamma_{\epsilon}$ and as the sphere radius $\epsilon$ vanishes

$$
\begin{aligned}
& \lim _{\epsilon \rightarrow 0}\left[\oiint_{\Gamma_{\epsilon}} \varphi_{\Omega}\left(\mathbf{r}^{\prime}\right) \frac{1}{4 \pi\left|\mathbf{r}-\mathbf{r}^{\prime}\right|^{2}} \mathrm{~d} \mathbf{r}^{\prime}+\oiint_{\Gamma_{\epsilon}} \frac{\partial \varphi_{\Omega}\left(\mathbf{r}^{\prime}\right)}{\partial \mathbf{n}\left(\mathbf{r}^{\prime}\right)} \frac{1}{4 \pi\left|\mathbf{r}-\mathbf{r}^{\prime}\right|} \mathrm{d} \mathbf{r}^{\prime}\right] \\
= & \int_{\phi=0}^{\phi=2 \pi} \int_{\theta=0}^{\theta=\frac{\pi}{2}} \varphi_{\Omega}(\mathbf{r}) \frac{1}{4 \pi \ell^{\ell^{\prime}}} \not^{2} \sin \theta \mathrm{d} \theta \mathrm{d} \phi+\int_{\phi=0}^{\phi=2 \pi} \int_{\theta=0}^{\theta=\frac{\pi}{2}} \frac{\partial \varphi_{\Omega}(\mathbf{r})}{\partial \mathbf{n}(\mathbf{r})} \frac{1}{4 \pi \phi^{2}} \not^{2} \sin \theta \mathrm{d} \theta \mathrm{d} \varphi \\
= & \frac{1}{4 \pi}\left(\int_{\phi=0}^{\phi=2 \pi} \mathrm{d} \phi \int_{\theta=0}^{\theta=\frac{\pi}{2}} \sin \theta \mathrm{d} \theta\right)\left[\varphi\left(\mathbf{r}_{\Gamma}\right)+\frac{\partial \varphi_{\Omega}\left(\mathbf{r}_{X}\right)}{\partial \mathbf{n}\left(\mathbf{r}_{\Gamma}\right)} \epsilon\right]=\frac{1}{2} \varphi_{\Omega}\left(\mathbf{r}_{\Gamma}\right),
\end{aligned}
$$

where we assumed the unknown functions to remain constant on $\Gamma_{\epsilon}$ as $\epsilon \rightarrow 0$. We can now use this result to find the unknown functions on the boundary as

$$
\begin{aligned}
\varphi_{\Omega}\left(\mathbf{r}_{\Gamma}\right) & =\lim _{\mathbf{r} \rightarrow \mathbf{r}_{\Gamma}} \varphi_{\Omega}(\mathbf{r}) \\
& =\frac{1}{\varepsilon_{\Omega}} \sum_{i=1}^{N_{c}} q_{i} G_{\mathrm{L}}\left(\mathbf{r}_{\Gamma}, \mathbf{r}_{i}\right) \\
& +\frac{1}{2} \varphi_{\Omega}\left(\mathbf{r}_{\Gamma}\right)-\oiint_{\Gamma} \varphi_{\Omega}\left(\mathbf{r}^{\prime}\right) \frac{\partial G_{\mathrm{L}}\left(\mathbf{r}_{\Gamma}, \mathbf{r}^{\prime}\right)}{\partial \mathbf{n}\left(\mathbf{r}^{\prime}\right)} \mathrm{d} \mathbf{r}^{\prime}+\oiint_{\Gamma} G_{\mathrm{L}}\left(\mathbf{r}_{\Gamma}, \mathbf{r}^{\prime}\right) \frac{\partial \varphi_{\Omega}\left(\mathbf{r}^{\prime}\right)}{\partial \mathbf{n}\left(\mathbf{r}^{\prime}\right)} \mathrm{d} \mathbf{r}^{\prime}
\end{aligned}
$$

The term $\varphi_{\Omega}\left(\mathbf{r}_{\Gamma}\right) / 2$ on the right-hand side which we obtained in Equation B-5 is a consequence of the discontinuity discontinuity in the dipole potential (first surface integral in Equation B-1] across the interface ${ }^{44}$. Equation B-6 can be written more simply by defin- 
ing the Laplace single-layer and double-layer potential operators. The Laplace single-layer potential operator is defined as

$$
\mathcal{V}_{\mathrm{L}, \Gamma}^{\Upsilon} \frac{\partial \varphi}{\partial \mathbf{n}}=\oiint_{\Gamma} G_{\mathrm{L}}\left(\mathbf{r}_{\Upsilon}, \mathbf{r}^{\prime}\right) \frac{\partial \varphi\left(\mathbf{r}^{\prime}\right)}{\partial \mathbf{n}\left(\mathbf{r}^{\prime}\right)} \mathrm{d} \mathbf{r}^{\prime}
$$

which computes the potential induced at the interface $\Upsilon$ due to a single-layer of charge (monopole charge distribution) on the interface $\Gamma$. Similarly, the Laplace double-layer potential operator calculates the potential at the interface $\Upsilon$ due to a double-layer of charge (dipole charge density) on the interface $\Gamma$

$$
\mathcal{K}_{\mathrm{L}, \Gamma}^{\Upsilon} \varphi=\oiint_{\Gamma} \frac{\partial G_{\mathrm{L}}\left(\mathbf{r}_{\Upsilon}, \mathbf{r}^{\prime}\right)}{\partial \mathbf{n}\left(\mathbf{r}^{\prime}\right)} \varphi\left(\mathbf{r}^{\prime}\right) \mathrm{d} \mathbf{r}^{\prime}
$$

Equation B-6 can then be rearranged and written using the operator definitions as

$$
\frac{1}{2} \varphi_{\Omega}(\mathbf{r})=\frac{1}{\varepsilon_{\Omega}} \sum_{i=1}^{N_{c}} q_{i} G_{\mathrm{L}}\left(\mathbf{r}, \mathbf{r}_{i}\right)+\mathcal{V}_{\mathrm{L}, \Gamma_{\mathrm{D}}}^{\Gamma_{\mathrm{D}}} \frac{\partial \varphi_{\Omega}(\mathbf{r})}{\partial \mathbf{n}(\mathbf{r})}-\mathcal{K}_{\mathrm{L}, \Gamma_{\mathrm{D}}}^{\Gamma_{\mathrm{D}}} \varphi_{\Omega}(\mathbf{r}) \quad \mathbf{r} \in \Gamma_{\mathrm{D}}
$$

where we substituted $\Gamma$ with $\Gamma_{\mathrm{D}}$ in accordance with the schematic of the problem in Figure 1. A similar limiting process for the governing PDE in the Stern layer gives the BIE for the potential in that region as

$$
\frac{1}{2} \varphi_{\Sigma_{\mathrm{S}}}(\mathbf{r})=\mathcal{K}_{\mathrm{L}, \Gamma_{\mathrm{D}}}^{\Gamma_{\mathrm{D}}} \varphi_{\Sigma_{\mathrm{S}}}(\mathbf{r})-\mathcal{V}_{\mathrm{L}, \Gamma_{\mathrm{D}}}^{\Gamma_{\mathrm{D}}} \frac{\partial \varphi_{\Sigma_{\mathrm{S}}}(\mathbf{r})}{\partial \mathbf{n}(\mathbf{r})} \quad \mathbf{r} \in \Gamma_{\mathrm{D}}
$$

Note that the signs of the two surface-integral terms are flipped compared to Equation B9 because the normal-to-interface vector $\mathbf{n}$ now points into the region of intereset $\left(\Sigma_{S}\right)$, in contrast to the previous case. Using the dielectric interface boundary conditions ((a) and (b) in Equation 7), we obtain the coupled system of BIEs known as the Yoon--Lenhoff formulation

$$
\left[\begin{array}{cc}
\frac{1}{2} \mathcal{I}+\mathcal{K}_{\mathrm{L}, \Gamma_{\mathrm{D}}}^{\Gamma_{\mathrm{D}}} & -\mathcal{V}_{\mathrm{L}, \Gamma_{\mathrm{D}}}^{\Gamma_{\mathrm{D}}} \\
\frac{1}{2} \mathcal{I}-\mathcal{K}_{\mathrm{L}, \Gamma_{\mathrm{D}}}^{\Gamma_{\mathrm{D}}} & \frac{\varepsilon_{\Omega}}{\varepsilon_{\Sigma}} \mathcal{K}_{\mathrm{L}, \Gamma_{\mathrm{D}}}^{\Gamma_{\mathrm{D}}}
\end{array}\right]\left[\begin{array}{c}
\varphi_{\Omega}\left(\mathbf{r}_{\Gamma_{\mathrm{D}}}\right) \\
\frac{\partial \varphi_{\Omega}\left(\mathbf{r}_{\Gamma_{\mathrm{D}}}\right)}{\partial \mathbf{n}\left(\mathbf{r}_{\Gamma_{\mathrm{D}}}\right)}
\end{array}\right]\left[\begin{array}{c}
\sum_{j=1}^{N_{c}} q_{j} G_{\mathrm{L}}\left(\mathbf{r}_{\Gamma_{\mathrm{D}}}, \mathbf{r}_{j}\right) \\
0
\end{array}\right],
$$

where $\mathcal{I}$ is the identity operator. Continuum electrostatic model that we illustrated in Figure 1 consists of multiple embedded regions with different dielectric properties and governing BIEs. Electrostatic potential in a region that is defined by multiple interfaces e.g. $\Sigma_{\mathrm{S}}$ can be obtained by finding the electrostatic potential and its normol derivative on the 
bounding interfaces. For example, using Green's second theorem to find the electrostatic potential in $\Sigma_{\mathrm{S}}$ gives

$$
\begin{aligned}
\varphi_{\Sigma_{\mathrm{S}}}(\mathbf{r})= & -\oiint_{\Gamma_{\mathrm{D}}} \varphi_{\Sigma_{\mathrm{S}}}\left(\mathbf{r}^{\prime}\right) \frac{\partial G_{\mathrm{L}}\left(\mathbf{r}, \mathbf{r}^{\prime}\right)}{\partial \mathbf{n}\left(\mathbf{r}^{\prime}\right)} \mathrm{d} \mathbf{r}^{\prime}+\oiint_{\Gamma_{\mathrm{D}}} G_{\mathrm{L}}\left(\mathbf{r}, \mathbf{r}^{\prime}\right) \frac{\partial \varphi_{\Sigma_{\mathrm{S}}}\left(\mathbf{r}^{\prime}\right)}{\partial \mathbf{n}\left(\mathbf{r}^{\prime}\right)} \mathrm{d} \mathbf{r}^{\prime} \\
& +\oiint_{\Gamma_{\mathrm{S}}} \varphi_{\Sigma_{\mathrm{S}}}\left(\mathbf{r}^{\prime}\right) \frac{\partial G_{\mathrm{L}}\left(\mathbf{r}, \mathbf{r}^{\prime}\right)}{\partial \mathbf{n}\left(\mathbf{r}^{\prime}\right)} \mathrm{d} \mathbf{r}^{\prime}-\oiint_{\Gamma_{\mathrm{S}}} G_{\mathrm{L}}\left(\mathbf{r}, \mathbf{r}^{\prime}\right) \frac{\partial \varphi_{\Sigma_{\mathrm{S}}}\left(\mathbf{r}^{\prime}\right)}{\partial \mathbf{n}\left(\mathbf{r}^{\prime}\right)} \mathrm{d} \mathbf{r}^{\prime}
\end{aligned}
$$

where the surface integrals in (B-12a) and (B-12b) correspond to the contributions from $\Gamma_{\mathrm{D}}$ and $\Gamma_{\mathrm{S}}$, respectively. Similarly for $\Sigma$ region one finds

$$
\varphi_{\Sigma}(\mathbf{r})=\oiint_{\Gamma_{\mathrm{S}}} \varphi_{\Sigma}\left(\mathbf{r}^{\prime}\right) \frac{\partial G_{\mathrm{L}}\left(\mathbf{r}, \mathbf{r}^{\prime}\right)}{\partial \mathbf{n}\left(\mathbf{r}^{\prime}\right)} \mathrm{d} \mathbf{r}^{\prime}-\oiint_{\Gamma_{\mathrm{S}}} G_{\mathrm{L}}\left(\mathbf{r}, \mathbf{r}^{\prime}\right) \frac{\partial \varphi_{\Sigma}\left(\mathbf{r}^{\prime}\right)}{\partial \mathbf{n}\left(\mathbf{r}^{\prime}\right)} \mathrm{d} \mathbf{r}^{\prime}
$$

A limiting process on Equations B-12 and B-13 followed by imposing the boundary conditions of Equation 7 is required to find the unknowns on $\Gamma_{\mathrm{S}}$. Note that for a region like $\Sigma_{\mathrm{S}}$ that is bounded by more than one interface, the limiting process as a point $\mathbf{r} \in \Sigma_{\mathrm{S}}$ moves towards an interface results in one equation per interface. For example in the electrostatic problem that we described, presence of the two interfaces $\Sigma_{\mathrm{D}}$ and $\Sigma_{\mathrm{S}}$ leads to a system of four coupled BIEs as

$$
\left[\begin{array}{cc|cc}
\frac{1}{2} \mathcal{I}+\mathcal{K}_{\mathrm{L}, \Gamma_{\mathrm{D}}}^{\Gamma_{\mathrm{D}}} & -\mathcal{V}_{\mathrm{L}, \Gamma_{\mathrm{D}}}^{\Gamma_{\mathrm{D}}} & & \\
\frac{1}{2} \mathcal{I}-\mathcal{K}_{\mathrm{L}, \Gamma_{\mathrm{D}}}^{\Gamma_{\mathrm{D}}} & \frac{\varepsilon_{\Omega}}{\varepsilon_{\Sigma}} \mathcal{V}_{\mathrm{L}, \Gamma_{\mathrm{D}}}^{\Gamma_{\mathrm{D}}} & \mathcal{K}_{\mathrm{L}, \Gamma_{\mathrm{S}}}^{\Gamma_{\mathrm{D}}} & -\mathcal{V}_{\mathrm{L}, \Gamma_{\mathrm{S}}}^{\Gamma_{\mathrm{D}}} \\
\hline-\mathcal{K}_{\mathrm{L}, \Gamma_{\mathrm{D}}}^{\Gamma_{\mathrm{S}}} & \frac{\varepsilon_{\Omega}}{\varepsilon_{\Sigma}} \mathcal{V}_{\mathrm{L}, \Gamma_{\mathrm{D}}}^{\Gamma_{\mathrm{S}}} & \frac{1}{2} \mathcal{I}+\mathcal{K}_{\mathrm{L}, \Gamma_{\mathrm{S}}}^{\Gamma_{\mathrm{S}}} & -\mathcal{V}_{\mathrm{L}, \Gamma_{\mathrm{S}}}^{\Gamma_{\mathrm{S}}} \\
& & \frac{1}{2} \mathcal{I}-\mathcal{K}_{\mathrm{L}, \Gamma_{\mathrm{S}}}^{\Gamma_{\mathrm{S}}} & \frac{\varepsilon_{\Sigma_{\mathrm{S}}}}{\varepsilon_{\Sigma}} \mathcal{V}_{\mathrm{L}, \Gamma_{\mathrm{S}}}^{\Gamma_{\mathrm{S}}}
\end{array}\right]\left[\begin{array}{c}
\varphi_{\Omega}\left(\mathbf{r}_{\Gamma_{\mathrm{D}}}\right) \\
\frac{\partial \varphi_{\Omega}\left(\mathbf{r}_{\Gamma_{\mathrm{D}}}\right)}{\partial \mathbf{n}\left(\mathbf{r}_{\Gamma_{\mathrm{D}}}\right)} \\
\varphi_{\Sigma}\left(\mathbf{r}_{\Gamma_{\mathrm{S}}}\right) \\
\frac{\partial \varphi_{\Sigma_{\mathrm{S}}}\left(\mathbf{r}_{\Gamma_{\mathrm{S}}}\right)}{\partial \mathbf{n}\left(\mathbf{r}_{\Gamma_{\mathrm{S}}}\right)}
\end{array}\right]=\left[\begin{array}{c}
\sum_{j=1}^{N_{c}} q_{j} G_{\mathrm{L}}\left(\mathbf{r}_{\Gamma_{\mathrm{D}}}, \mathbf{r}_{j}\right) \\
0 \\
0 \\
0 \\
0 \\
0
\end{array}\right]
$$

The system of BIEs in Eqution B-14 was obtained using the standard continuum theory boundary conditions from Equation 6. Similarly, using SLIC boundary condition results in 
a block system of the form $A x=b$ as

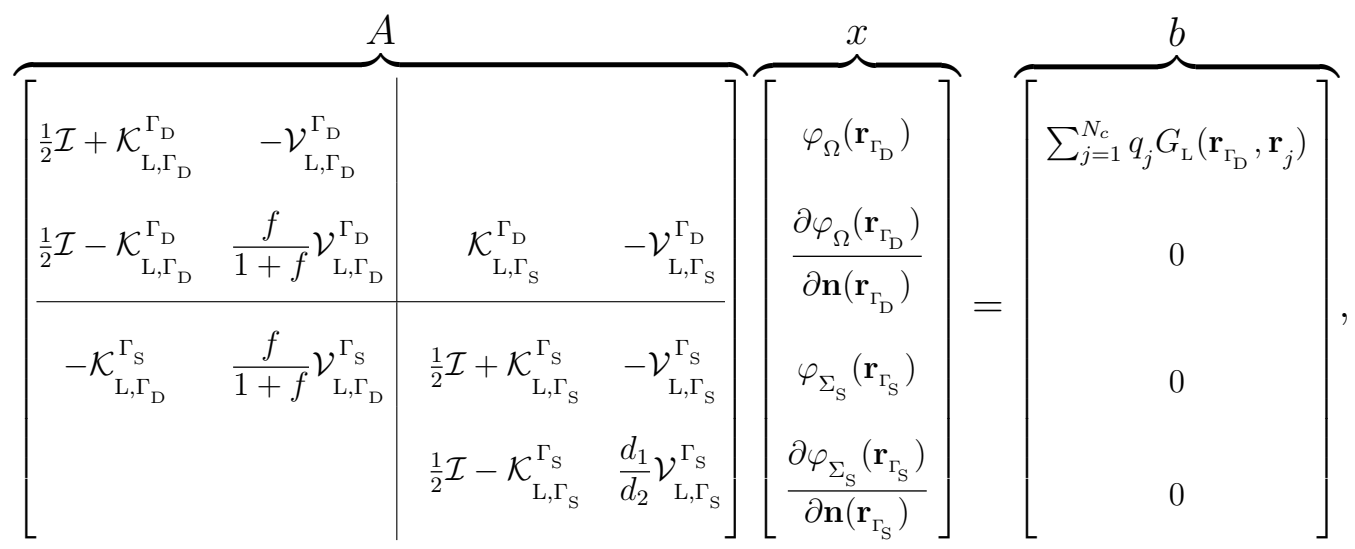

where $f=f\left(E_{n}\right)=\left[\varepsilon_{\Omega} /\left(\varepsilon_{\Sigma_{\mathrm{S}}}-\varepsilon_{\Omega}\right)\right]+h\left(E_{n}\right), h\left(E_{n}\right)=\alpha \tanh \left(\beta E_{n}-\gamma\right)+\mu, d_{1}=-q_{\mathrm{total}} / \varepsilon_{\Sigma_{\mathrm{S}}}$, and $d_{2}=\oiint_{\Gamma_{\mathrm{S}}}\left[\partial \varphi_{\Sigma_{\mathrm{S}}}\left(\mathbf{r}^{\prime}\right) / \partial \mathbf{n}\left(\mathbf{r}^{\prime}\right)\right] \mathrm{d} \mathbf{r}^{\prime}$. Note that the knowledge of $x$ and also the electrosttic parameters $\alpha, \beta, \gamma$, and $\mu$ are required to calculate $A_{22}, A_{32}$, and $A_{44}$ in Equation B-15).

Boundary element method descritizes the molecular surface to a set of $N$ non-overlapping boundary elements as shown in Figure 17.
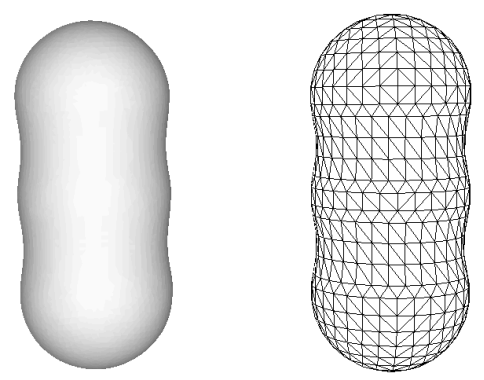

FIG. 17. Schematic of a boundary discretization: the boundary elements approximate the solutesolvent interface.

BEM then approximates the unknown surface variables $\varphi$ and $\partial \varphi / \partial \mathbf{n}$ as weighted combinations of a set of $N$ basis functions as

$$
\begin{gathered}
\varphi_{\Omega}\left(\mathbf{r}_{\Gamma}\right) \approx \sum_{i=1}^{N} w_{i, \varphi} \mathbf{e}_{i}\left(\mathbf{r}_{\Gamma}\right) \\
\frac{\partial \varphi_{\Omega}\left(\mathbf{r}_{\Gamma}\right)}{\partial \mathbf{n}\left(\mathbf{r}_{\Gamma}\right)} \approx \sum_{i=1}^{N} w_{i, \varphi_{\mathbf{n}}} \mathbf{e}_{i}\left(\mathbf{r}_{\Gamma}\right),
\end{gathered}
$$

such that the $i$ th basis function $\mathbf{e}_{i}$ equals 1 if $\mathbf{r}$ is on the $i$ th element, and 0 otherwise. The unknown weights $w_{i}$ and $w_{i, \varphi_{\mathbf{n}}}$ are then found by forcing Equation B-15 to be satisfied 
(see Section [II). After determining the basis-function weights $w_{i}$ and $w_{i, \varphi_{\mathbf{n}}}$, the reaction potential at the charge locations $\mathbf{r}_{i}$ that are induced in the solute can be calculated using Green's theorem. Note that $\varphi_{\Omega}\left(\mathbf{r}_{\Gamma}\right)$ in Equation B-16a is sum of the Coulombic potential and the reaction potential as $\varphi_{\Omega}=\varphi_{\text {Coul }}+\varphi_{\text {reac }}$. The reactional potential can then be used to predict solvation Gibbs energies using Equation 11 .

\section{APPENDIX C: ADDING TEMPERATURE DEPENDENCE TO THE DISPER- SION MODEL}

The canonical partition function which is a measure of the number of microstates available to the system can be written as

$$
\begin{aligned}
& Q^{\operatorname{disp}}(N, V, T)= \\
& C_{N} \int\left[e^{-\beta \sum_{j=1}^{N}\left(\mathbf{p}_{j}^{2} / 2 m\right)}\right] \mathrm{d} \mathbf{p}_{1} \mathrm{~d} \mathbf{p}_{2} \ldots \mathrm{d} \mathbf{p}_{N} \int\left[e^{-\beta U^{\operatorname{disp}}\left(\mathbf{r}_{1}, \mathbf{r}_{2}, \ldots, \mathbf{r}_{N}\right)}\right] \mathrm{d} \mathbf{r}_{1} \mathrm{~d} \mathbf{r}_{2} \ldots \mathrm{d} \mathbf{r}_{\mathrm{N}}
\end{aligned}
$$

where $\beta=\frac{1}{k_{B} T}$ is the Boltzmann constant, $\mathbf{p}=m \mathbf{v}, C_{N}$ is the normalization constant $\left(C_{N}=1 / h^{3 N}\right.$ if all the particles are distinguishable, otherwise $\left.C_{N}=1 /\left(N ! h^{3 N}\right)\right)$, and $U^{\text {disp }}$ is the dispersion energy of the system with $N$ particles. Note that the first integral is always the same for any system $(U=0)$, and in fact, is the ideal-gas partition function (assuming the particles to be indistinguishable):

$$
\begin{aligned}
Q^{\operatorname{disp}}(N, V, T)_{\mathrm{ig}} & =\frac{1}{N ! h^{3 N}} \int\left[e^{-\beta \sum_{j=1}^{N}\left(\mathbf{p}_{j}^{2} / 2 m\right)}\right] \mathrm{d} \mathbf{p}_{1} \mathrm{~d} \mathbf{p}_{2} \ldots \mathrm{d} \mathbf{p}_{N} \mathrm{~d} \mathbf{r}_{1} \mathrm{~d} \mathbf{r}_{2} \ldots \mathrm{d} \mathbf{r}_{\mathrm{N}} \\
& =\frac{V^{N}}{N ! h^{3 N}} \int\left[e^{-\beta \sum_{j=1}^{N}\left(\mathbf{p}_{j}^{2} / 2 m\right)}\right] \mathrm{d} \mathbf{p}_{1} \mathrm{~d} \mathbf{p}_{2} \ldots \mathrm{d} \mathbf{p}_{N}=\frac{V^{N}}{N ! \Lambda^{3 N}},
\end{aligned}
$$

where $\Lambda=h /\left(\sqrt{2 \pi m k_{B} T}\right)$ is the thermal de Broglie wavelength. The second part of the Equation $\mathrm{C}-2$ is particular to each individual system and gives rise to the particular properties of different systems and is called configuration integral (some references call this integral partition function rather than Equation C-2

$$
Z^{\operatorname{disp}}(N, V, T)=\int \ldots \int e^{-\beta U\left(\mathbf{r}_{1}, \mathbf{r}_{2}, \ldots, \mathbf{r}_{\mathrm{N}}\right)} \mathrm{d} \mathbf{r}_{1} \mathrm{~d} \mathbf{r}_{2} \ldots \mathrm{d} \mathbf{r}_{\mathrm{N}} .
$$

The Helmholtz free energy of dispersion can be written as

$$
A^{\operatorname{disp}}(N, V, T)=-k_{B} T \ln Q^{\operatorname{disp}}(N, V, T)
$$


where

$$
Q^{\text {disp }}(N, V, T)=\frac{1}{N ! \Lambda^{3 N}} Z^{\text {disp }}(N, V, T),
$$

The potential energy, $U^{\text {disp }}$, can be expressed as a sum of intermolecular pair potentials, $u_{i j}$, of all the particle pairs $(i, j)$, triplet potentials (given by the difference of the interaction energy of a triplet system $u_{i j k}$ and sum of the three pair potentials $u_{i j}, u_{i k}$, and $u_{j k}$ ), and so on. Higher order potentials and quite often also triplet interaction potentials are neglected and only pair potentials $u_{i j}$ are considered. Assuming the potential energy $U^{\text {disp }}$ to be additive, it can be approximated using:

$$
U^{\text {disp }}\left(\mathbf{r}_{1}, \mathbf{r}_{2}, \ldots, \mathbf{r}_{\mathrm{N}}\right) \approx \sum_{\substack{j \leq N \\ 1 \leq i \leq j}} u_{\mathrm{disp}}\left(\mathbf{r}_{\mathrm{ij}}\right),
$$

where $r_{i j}=\left|\mathbf{r}_{i}-\mathbf{r}_{j}\right|$ and $u_{\text {disp }}\left(r_{i j}\right)$ describes the dispersion interaction energy between two particles as a function of their separation distance. Typically, $u_{\text {disp }}\left(r_{i j}\right) \rightarrow \infty$ as $r \rightarrow 0$, $u_{\text {disp }}\left(r_{i j}\right) \rightarrow 0$ as $r \rightarrow \infty$, and $u_{\text {disp }}\left(r_{i j}\right)$ exhibits a minimum between the two limits. The assumption above makes it much easier to calculate the configurational integral, $Z$. Another reasonable assumption for this system is that the pair potential depends only on the particle center-to-center distance of particles $i$ and $j$ (simple fluid)

$$
Z^{\mathrm{disp}}(N, V, T)=\int e^{-\beta U} \mathrm{~d} \mathbf{r}_{1} \mathrm{~d} \mathbf{r}_{2} \ldots \mathrm{d} \mathbf{r}_{\mathrm{N}}
$$

where

$$
e^{-\beta U}=\prod_{i<j} e^{-\beta u_{\text {disp }}\left(\mathbf{r}_{i j}\right)}=\prod_{i<j}\left(1+f\left(\mathbf{r}_{i j}\right)\right),
$$

and $f\left(\mathbf{r}_{i j}\right)=e^{-\beta u\left(\mathbf{r}_{i j}\right)}-1$. Expanding the product and writing all the terms gives

$$
\prod_{i<j}\left(1+f\left(\mathbf{r}_{i j}\right)\right)=1+\sum_{i<j} f\left(\mathbf{r}_{i j}\right)+\sum_{i<j} \sum_{k<l} f\left(\mathbf{r}_{i j}\right) f\left(\mathbf{r}_{k l}\right)+\ldots,
$$

therefore, $Z^{\text {disp }}$ can be re-written as

$$
\begin{aligned}
Z^{\mathrm{disp}}(N, V, T) & =\int(1) \cdot \mathrm{d} \mathbf{r}_{1} \mathrm{~d} \mathbf{r}_{2} \ldots \mathrm{d} \mathbf{r}_{\mathrm{N}}+\int\left[\sum_{i<j} f\left(\mathbf{r}_{i j}\right)\right] \mathrm{d} \mathbf{r}_{1} \mathrm{~d} \mathbf{r}_{2} \ldots \mathrm{d} \mathbf{r}_{\mathrm{N}} \\
& +\int\left[\sum_{i<j} \sum_{k<l} f\left(\mathbf{r}_{i j}\right) f\left(\mathbf{r}_{k l}\right)\right] \mathrm{d} \mathbf{r}_{1} \mathrm{~d} \mathbf{r}_{2} \ldots \mathrm{d} \mathbf{r}_{\mathrm{N}}+\ldots \\
& \approx V^{N}+\frac{N(N-1) V^{N-2}}{2} \int f\left(\mathbf{r}_{i j}\right) \mathrm{d} \mathbf{r}_{1} \mathrm{~d} \mathbf{r}_{2} .
\end{aligned}
$$


By making a change of variables as follows

$$
\mathbf{R}=\frac{\mathbf{r}_{1}+\mathbf{r}_{2}}{2}, \quad \mathbf{r}=\mathbf{r}_{1}-\mathbf{r}_{2}
$$

which gives $\mathrm{d} \mathbf{r}_{1} \mathrm{~d} \mathbf{r}_{2}=\mathrm{d} \mathbf{R} \mathrm{d} \mathbf{r}$, and substituting in Equation C-10, $Z^{\text {disp }}$ can be found as

$Z^{\operatorname{disp}}(N, V, T) \approx V^{N}+\frac{N(N-1)}{2} \int f(\mathbf{r}) \mathrm{d} \mathbf{r} \mathrm{d} \mathbf{R}=V^{N}+\frac{N(N-1) V^{N-1}}{2} \int f(\mathbf{r}) \mathrm{d} \mathbf{r}$.

Writing $Z^{\text {disp }}$ in spherical polar coordinates gives

$$
\begin{aligned}
Z^{\operatorname{disp}}(N, V, T) & =V^{N}+\frac{N(N-1) V^{N-1}}{2} \int_{0}^{2 \pi} \int_{0}^{\pi} \int_{0}^{\infty} r^{2} f(\mathbf{r}) \sin \theta \mathrm{d} \mathbf{r} \mathrm{d} \theta \mathrm{d} \varphi \\
& =V^{N}+\frac{N(N-1) V^{N-1}}{2} \int_{0}^{\infty} 4 \pi r^{2} f(\mathbf{r}) \mathrm{d} r \\
N \stackrel{N-1 \approx N}{\longrightarrow} \infty & \approx V^{N}+N^{2} V^{N-1} \int_{0}^{\infty} 2 \pi r^{2} f(\mathbf{r}) \mathrm{d} \mathbf{r} .
\end{aligned}
$$

Finally, substituting the results to the partition function in Equation C-1

$$
\begin{aligned}
Q^{\operatorname{disp}}(N, V, T) & =\frac{1}{N ! \Lambda^{3 N}}\left(V^{N}+N^{2} V^{N-1} \int_{0}^{\infty} 2 \pi r^{2} f(\mathbf{r}) \mathrm{d} \mathbf{r}\right) \\
& =Q^{\operatorname{disp}}(N, V, T)_{\operatorname{ig}}\left(1+N \rho_{n} \int_{0}^{\infty} 2 \pi r^{2} f(\mathbf{r}) \mathrm{d} \mathbf{r}\right)
\end{aligned}
$$

where $\rho_{n}=N / V$ is the particle density of the system where for the infinitely dilute solutions is assumed to be the number density of the solvent. This gives the change in Helmholtz energy with respect to the ideal gas state from Equation C-4 to be

$$
\begin{aligned}
A^{\operatorname{disp}}(N, V, T) & =-k_{B} T \ln Q^{\operatorname{disp}}(N, V, T), \Delta A=A-A_{\mathrm{ig}} \\
\rightarrow \Delta A^{\operatorname{disp}}(N, V, T) & =-k_{B} T \ln \frac{Q^{\text {disp }}}{Q_{\text {ig }}^{\text {disp }}}=-k_{B} T \ln \left(1+N \rho_{n} \int_{0}^{\infty} 2 \pi r^{2} f(\mathbf{r}) \mathrm{d} \mathbf{r}\right) \\
\stackrel{\text { Taylor expansion of } \ln (1+x)}{\longrightarrow} & \approx-k_{B} T N \rho_{n}\left(\int_{0}^{\infty} 2 \pi r^{2}\left(e^{-\beta u(\mathbf{r})}-1\right) \mathrm{d} \mathbf{r}\right)
\end{aligned}
$$

Finding an appropriate pair potential leads to an expression for the change in the Helmholtz energy of the system. A great variety of pair potentials have been proposed to this date. To keep the model as simple as possible, a square-well potential is used to describe the dispersion interactions in the system 18 .

$$
u(r)= \begin{cases}\infty & r \leq \sigma \\ -\epsilon & \sigma \leq r \leq \lambda \sigma \text { where } \lambda>1 \\ 0 & r>\lambda \sigma\end{cases}
$$


where the pair potential has a short-range constant attractive potential $\epsilon$ with a squarewell shape. The parameter $\lambda$ determines the range of the square well. Plugging the square well potential function to Equation $\mathrm{C}$-15 gives

$$
\begin{aligned}
\frac{\Delta A^{\operatorname{disp}}(N, V, T)^{O(1)}}{2 \pi k_{B} T N \rho_{n}}= & -\left[\int_{0}^{\sigma}\left(e^{-\beta \infty}-1\right) r^{2} \mathrm{~d} r\right. \\
& \left.+\int_{\sigma}^{\lambda \sigma}\left(e^{\beta \epsilon}-1\right) r^{2} \mathrm{~d} r+\int_{\lambda \sigma}^{\infty}\left(e^{-\beta \cdot 0}-1\right) r^{2} \mathrm{~d} r\right] \\
= & -\left[-\int_{0}^{\sigma} r^{2} \mathrm{~d} r+\left(e^{\beta \epsilon}-1\right) \int_{\sigma}^{\lambda \sigma} r^{2} \mathrm{~d} r\right] \\
= & -\left[-\frac{\sigma^{3}}{3}+\left.\left(e^{\beta \epsilon}-1\right) \frac{r^{3}}{3}\right|_{\sigma} ^{\lambda \sigma}\right] \\
= & \frac{\sigma^{3}}{3}\left[1-\left(e^{\beta \epsilon}-1\right)\left(\lambda^{3}-1\right)\right] \\
\rightarrow \frac{\Delta A^{\operatorname{disp}}(N, V, T)^{O(1)}}{N k_{B} T}= & \frac{2 \pi \rho_{n} \sigma^{3}}{3}\left[1-\left(e^{\beta \epsilon}-1\right)\left(\lambda^{3}-1\right)\right]=\rho_{n} B_{2}(T) .
\end{aligned}
$$

where $B_{2}(T)$ is called the second virial coefficient and $O(1)$ denotes the first order approximation of the Helmholtz energy. Using Equation C-4, the average change in internal energy $\langle E\rangle$ in a canonical distribution can be obtained as

$$
\begin{aligned}
\langle E\rangle=-\left(\frac{\partial \ln Q^{\mathrm{disp}}}{\partial \beta}-\frac{\partial \ln Q_{\mathrm{ig}}^{\mathrm{disp}}}{\partial \beta}\right)=-\left(\frac{\partial\left(\ln Q_{\mathrm{ig}}^{\mathrm{disp}}+\ln Z\right)}{\partial \beta}-\frac{\partial \ln Q_{\mathrm{ig}}^{\mathrm{disp}}}{\partial \beta}\right) \\
\stackrel{\text { square-well potential }}{\longrightarrow} \ln Z=-\frac{2 \pi \rho_{n} \sigma^{3} N}{3}\left[1-\left(e^{\beta \epsilon}-1\right)\left(\lambda^{3}-1\right)\right] \\
\rightarrow\langle E\rangle=-\frac{\partial \ln Z}{\partial \beta}=-\frac{1}{Z} \frac{\partial Z}{\partial \beta}=-\frac{2 \pi \rho_{n} \sigma^{3} N}{3}\left[\epsilon e^{\beta \epsilon}\left(\lambda^{3}-1\right)\right]
\end{aligned}
$$

Using this form of average energy as the atom-specific energy coefficients in Equation 21 implicitly adds the temperature dependence to the dispersion model without needing to explicitly parameterizing energy coefficients at different temperatures.

\section{APPENDIX D: CALCULATION OF SOLVATION ENTROPIES AND SOLVA- TION HEAT CAPACITIES}

SLIC/CDC uses the adjustable parameters that are obtained in the optimization process of solvation Gibbs energies to find solvation entropies. This is due to the fact that the 
temperature dependence of solvation Gibbs energy is naturally incorporated in the model as explained previously. One can simply calculate the solvation entropies by differentiating solvation Gibbs energies with respect to temperature as

$$
\Delta_{\text {solv }} S_{\text {calc, SLIC } / \mathrm{CDC}}=-\frac{\partial\left(\Delta_{\text {solv }} G_{\text {calc, SLIC } / \mathrm{CDC}}\right)}{\partial T} .
$$

This is extremely attractive from the computational cost stand point as solvation Gibbs energies and entropies can simultaneously be calculated in a single optimization run. SLIC/SASA on the other hand needs to be parameterized at multiple temperatures as we explain in the following: First, solvation Gibbs energies are calculated at five temperatures, linearly spaced between $278 \mathrm{~K}$ and $318 \mathrm{~K}$. We use the standard-state temperature dependence of the Gibbs energy of solvation 22 to find solvation Gibbs energies and subsequently, the optimized SLIC/SASA model parameters at each temperature. The starting initial guess at each temperature was set to the optimized parameters at $298 \mathrm{~K}$. Finally we computed the Gibbs solvation energies at each temperature and used a nonlinear least square fit to determine entropy and heat capacity for each solute using

$$
\Delta_{\text {solv }} G_{\text {calc }}(T)=\Delta_{\text {solv }} G_{\text {calc }}\left(T_{0}\right)-\Delta_{\text {solv }} S_{\text {calc }}\left[T-T_{0}\right]+\Delta_{\text {solv }} C_{p_{\text {calc }}}\left(T_{0}\right)\left[\left(T-T_{0}\right)-\ln \frac{T}{T_{0}}\right]
$$

TABLE D-1: Optimized SLIC/SASA parameters as temperature varies.

\begin{tabular}{lccc}
\hline Model & $\Delta G$ & $\Delta S$ & $\Delta C_{p}$ \\
\hline SLIC/SASA & 6 & $30^{*}$ & $30^{*}$ \\
SLIC/CDC & 38 & 38 & 38 \\
SLIC/CDC (No-HB) & 26 & 26 & 26 \\
$* 6$ parameters per temperature at 5 temperatures & & \\
\hline \hline
\end{tabular}

This limits the impact of numerical errors (due to poor discretization and optimization termination) on calculation of the derivative quantities (entropies and heat capacities). Table D-1 summarizes the number of parameters used in this work by the SLIC/SASA and SLIC/CDC models to calculate different thermodynamic properties. 


\section{APPENDIX E: REFERENCE DATA COLLECTION AND TRAINING-SET SE-}

\section{LECTION}

As discussed in the introduction, our earlier work failed to fully explore the performance of SLIC/SASA and address its potential issues in predicting solvation entropies due to the lack

of experimental data ${ }^{75}$. This motivated us to carry out a broader search in the literature to obtain credible experimental measurements of entropy and heat capacity of solvation. Due to the way the SLIC/SASA model predicts solvation entropies and heat capacities, one major restriction is that the experimental data is only valuable if the small molecule belongs to the subset of 502 small molecules of Mobley et al., where the molecular structures with accurate charge locations and partial charges are readily available. Table E-1 presents the number experimental data points and the number references that the data are gathered from compared with the previous work.

TABLE E-1: Number of reference data for small molecule solvation calculations.

\begin{tabular}{lcc}
\hline Thermodynamic variable & Present work & Mehdizadeh et al. 75 \\
\hline$\Delta_{\text {solv }} G$ & 502 & 502 \\
$\Delta_{\text {solv }} S$ & 159 & 25 \\
$\Delta_{\text {solv }} C_{p}$ & 123 & 18 \\
\hline \hline
\end{tabular}

Our training-set for SLIC/SASA calculations is composed of 12 neutral amino-acid sidechain analogues as shown in Table SI-3 in Supporting Information. Our results suggest that SLIC/SASA achieves a surprising accuracy even with such a small training-set. While a training set of this size is adequate for parameterizing SLIC/SASA models, SLIC/CDC model requires a larger training set due to the larger number of free parameters. For the SLIC/CDC model, we used a training set with 65 neutral compounds to make sure that it covers the wide variety of dispersion and hydrogen bonding specific atom types. This training-set is presented in Table SI-2 in Supporting Information. 


\section{TABLES}

TABLE SI-1: Hydrogen bond atom types

\begin{tabular}{llllllllll}
\hline Acceptors & $\mathrm{N}_{\text {Amine }}$ & $\mathrm{N}_{\text {Amide }}$ & $\mathrm{N}_{\mathrm{NO} 2}$ & $\mathrm{~N}_{\text {other }}$ & $\mathrm{F}$ & $\mathrm{O}_{\text {Ester }}$ & $\mathrm{O}_{\mathrm{NO} 2}$ & $\mathrm{O}_{\mathrm{OH}}$ & $\mathrm{O}_{\text {Carbonyl }}$ \\
Donors & $\mathrm{H}_{\mathrm{OH}}$ & $\mathrm{H}_{\mathrm{NH}}$ & $\mathrm{H}_{\text {other }}$ & & & & & & \\
\hline \hline
\end{tabular}

TABLE SI-2: Training-set used in SLIC/CDC calculations

\begin{tabular}{lll}
\hline 2-nitropropane & methyl-octanoate & hex-1-ene \\
triethyl-phosphate & 1-nitropentane & 4-bromophenol \\
2,6-dimethylpyridine & n-octane & n-butanethiol \\
trimethyl-phosphate & 3-cyanophenol & ethanamide \\
benzene & n-propylbenzene & naphthalene \\
methanethiol & pyridine & teflurane \\
but-1-ene & p-cresol & 3,3-dimethylbutan-2-one \\
dimethyl-sulfate & 4-nitroaniline & 4-chloroaniline \\
but-1-yne & propanoic-acid & $3,3,3$-trimethoxypropionitrile \\
piperidine & 1,4-dioxane & 2-methylpropane \\
m-xylene & tetrahydropyran & chloroethane \\
ethylamine & acetic-acid & $2,2,2$-trifluoroethanol \\
methane & trichloroethene & diethyl-sulfide \\
N-methylacetamide & butan-1-ol & 2-fluorophenol \\
n-pentylamine & 2-methoxyaniline & ethene \\
nitromethane & methyl-acetate & 2-iodopropane \\
p-dibromobenzene & 2-methylhexane & imidazole \\
nonanal & propanone & iodobenzene \\
benzaldehyde & methanol & 3 -methyl-1h-indole \\
anthracene & 1,2,4-trimethylbenzene & 2-naphthylamine \\
4-formylpyridine & cyclohexylamine & dimethyl-sulfide \\
\hline \hline
\end{tabular}


TABLE SI-3: The experimental data of solvation heat capacities of 12 amino acids (AAs) and their analogues in $\left[\frac{\mathrm{cal}}{\mathrm{mol} . \mathrm{K}}\right]$.

\begin{tabular}{|c|c|c|c|c|}
\hline Amino-acid (abbv.) & $\Delta C_{p}^{\mathrm{a}}$ & Analogue & $\Delta C_{p}$ & $\Delta C_{p}^{\mathrm{AA}}-\Delta C_{p}^{\text {Analogue }}$ \\
\hline alanine(Ala) & 33.9 & methane & $52.6^{\mathrm{b}}$ & 18.7 \\
\hline asparagine(Asn) & 6.0 & ethanamide & $26.0^{\mathrm{d}}$ & 20.0 \\
\hline isoleucine(Ile) & 74.1 & n-butane & $92.0^{\mathrm{b}}$ & 17.9 \\
\hline leucine(Leu) & 69.3 & 2-methylpropane & $88.6^{\mathrm{b}}$ & 19.3 \\
\hline phenylalanine(Phe) & 68.1 & toluene & $85.8^{\mathrm{e}}$ & 17.7 \\
\hline serine(Ser) & 10.5 & methanol & $27.3^{\mathrm{d}}$ & 16.8 \\
\hline threonine(Thr) & 29.2 & ethanol & $47.6^{\mathrm{b}}$ & 18.4 \\
\hline tyrosine(Tyr) & 41.6 & p-cresol & $62.0^{\mathrm{c}}$ & 20.4 \\
\hline valine(Val) & 58.8 & propane & $78.9^{\mathrm{b}}$ & 20.1 \\
\hline cysteine(Cys) & 50.9 & methanethiol & $60.7^{*}$ & 18.8 \\
\hline methionine(Met) & 20.6 & methyl-ethyl-sulfide & $39.4^{*}$ & 18.8 \\
\hline tryptophane(Trp) & 80.3 & 3-methyl-1h-indole & $99.1^{*}$ & 18.8 \\
\hline${ }^{a}$ Reference ${ }^{6}$ & & & \multicolumn{2}{|c|}{${ }^{\mathrm{d}}$ Reference 10} \\
\hline${ }^{\mathrm{b}}$ Reference ${ }^{14}$ & & & \multicolumn{2}{|c|}{${ }^{\mathrm{e}}$ Reference ${ }^{9}$} \\
\hline \multicolumn{5}{|l|}{${ }^{\mathrm{c}}$ Reference ${ }^{3}$} \\
\hline \multicolumn{5}{|c|}{$\begin{array}{l}{ }^{*} \text { The difference between solvation heat capacity of the AA and its analogue }\left(\Delta C_{p}^{\mathrm{AA}}-\Delta C_{p}^{\text {Analogue }}\right. \\
\text { does not vary significantly }\left(\mu=18.8 \text { and } \sigma=1.16 \frac{\mathrm{cal}}{\mathrm{mol.K}}\right) \text { for the amino acid side-chain analogues } \\
\text { with known experimental solvation heat capacities. }\end{array}$} \\
\hline \multicolumn{5}{|c|}{ Borrowing from this, the missing experimental solvation heat capacities were approximated using } \\
\hline \multicolumn{5}{|c|}{$\Delta C_{p}^{\text {Analogue }}=\Delta C_{p}^{\mathrm{AA}}+18.8 \frac{\mathrm{cal}}{\mathrm{mol} . \mathrm{K}}$} \\
\hline
\end{tabular}


TABLE SI-4: Dispersion interaction atom types, radii, and the optimal dispersion energy coefficients. Energy coefficients are reported in $\mathrm{kcal} / \mathrm{mol}$. The optimized value for the parameter $q_{s}$ was found to be 0.37

\begin{tabular}{lclclc}
\hline Atom type & $\mathrm{R}(\AA)$ & Atom type & $\mathrm{R}(\AA)$ & Atom type & $\mathrm{R}(\AA)$ \\
\hline $\mathrm{C}(\mathrm{sp} 3)$ & 2 & $\mathrm{H}$ & 1.3 & $\mathrm{P}$ & 2.12 \\
$\mathrm{C}(\mathrm{sp} 2)$ & 2 & $\mathrm{O}(\mathrm{sp} 3-\mathrm{H})$ & 1.72 & $\mathrm{~S}$ & 2.16 \\
$\mathrm{C}(\mathrm{sp})$ & 2 & $\mathrm{O}(\mathrm{sp} 3)$ & 1.72 & $\mathrm{Cl}$ & 2.05 \\
$\mathrm{~N}(\mathrm{sp} 3)$ & 1.83 & $\mathrm{O}(\mathrm{sp} 2)$ & 1.72 & $\mathrm{Br}$ & 2.16 \\
$\mathrm{~N}(\mathrm{sp} 2)$ & 1.83 & $\mathrm{O}(\mathrm{sp} 2-\mathrm{N})$ & 1.72 & $\mathrm{I}$ & 2.32 \\
$\mathrm{~N}(\mathrm{sp})$ & 1.83 & $\mathrm{~F}$ & 1.72 & & \\
\hline \hline
\end{tabular}

TABLE SI-5: Optimized SLIC/SASA (SS) and SLIC/CDC (SC) model parameters used in this work

\begin{tabular}{|c|c|c|c|c|c|}
\hline \multirow[b]{3}{*}{ Reference data 64} & \multicolumn{5}{|c|}{ Model } \\
\hline & $\mathrm{SS}$ & $\mathrm{SC}$ & $\mathrm{SC}(\mathrm{No} \mathrm{HB})$ & $\mathrm{SS}$ & $\mathrm{SC}\left(\mathrm{No}_{\mathrm{HB}}\right)$ \\
\hline & expt. & expt. & expt. & $\mathrm{MD}$ & MD \\
\hline \multicolumn{6}{|l|}{ Parameter - type* } \\
\hline$\alpha-\mathrm{ES}$ & 0.43 & 1.93 & 1.90 & 0.45 & 0.88 \\
\hline$\beta-\mathrm{ES}$ & 195.95 & -198.59 & -191.13 & -48.81 & -46.11 \\
\hline$\gamma-\mathrm{ES}$ & -1.11 & -1.03 & -0.55 & -0.54 & -1.05 \\
\hline$\mu-\mathrm{ES}$ & -0.45 & -2.24 & -1.70 & -0.55 & -0.77 \\
\hline$\phi_{\text {static }}-\mathrm{ES}$ & 0.1 & -0.10 & -0.10 & -0.06 & -0.10 \\
\hline$\gamma_{A}-\mathrm{SA}$ & 0.0016 & - & - & -0.0017 & - \\
\hline$\gamma_{B}-\mathrm{SA}$ & 1.61 & - & - & 2.38 & - \\
\hline $\mathrm{Br}-\mathrm{D}$ & - & 0.5 & 0.50 & - & 0.16 \\
\hline $\mathrm{C}_{\mathrm{sp}}-\mathrm{D}$ & - & 0.48 & 0.30 & - & 0.14 \\
\hline $\mathrm{C}_{\mathrm{sp} 2}-\mathrm{D}$ & - & 0.48 & 0.22 & - & 0.25 \\
\hline $\mathrm{C}_{\mathrm{sp} 3}-\mathrm{D}$ & - & 0.61 & 0.22 & - & 0.35 \\
\hline $\mathrm{Cl}-\mathrm{D}$ & - & 0.31 & 0.40 & - & 0.14 \\
\hline $\mathrm{F}-\mathrm{D}$ & - & 0.24 & 0.32 & - & 0.07 \\
\hline $\mathrm{H}-\mathrm{D}$ & - & 0.18 & 0.04 & - & 0.02 \\
\hline $\mathrm{I}-\mathrm{D}$ & - & 0.35 & 0.40 & - & 0.11 \\
\hline
\end{tabular}


Table SI-5 (Continued)

\begin{tabular}{|c|c|c|c|c|c|}
\hline \multirow[b]{3}{*}{ Reference data 64} & \multicolumn{5}{|c|}{ Model } \\
\hline & SS & $\mathrm{SC}$ & $\mathrm{SC}(\mathrm{No} H B)$ & SS & $\mathrm{SC}(\mathrm{No} H B)$ \\
\hline & expt. & expt. & expt. & $\mathrm{MD}$ & MD \\
\hline \multicolumn{6}{|l|}{ Parameter - type* } \\
\hline $\mathrm{N}_{\mathrm{sp}}-\mathrm{D}$ & - & 0.65 & 0.54 & - & 0.00 \\
\hline $\mathrm{N}_{\mathrm{sp} 2}-\mathrm{D}$ & - & 0.58 & 0.41 & - & 0.51 \\
\hline $\mathrm{N}_{\mathrm{sp} 3}-\mathrm{D}$ & - & 0.70 & 0.39 & - & 0.30 \\
\hline $\mathrm{O}_{\mathrm{sp} 2}-\mathrm{D}$ & - & 0.09 & 0.06 & - & 0.02 \\
\hline $\mathrm{O}_{\mathrm{sp} 2 \mathrm{~N}}-\mathrm{D}$ & - & 0.52 & 0.44 & - & 0.19 \\
\hline $\mathrm{O}_{\mathrm{sp} 3}-\mathrm{D}$ & - & 0.23 & 0.37 & - & 0.23 \\
\hline $\mathrm{O}_{\mathrm{sp} 3 \mathrm{H}}-\mathrm{D}$ & - & 0.45 & 0.16 & - & 0.18 \\
\hline $\mathrm{P}-\mathrm{D}$ & - & 0.45 & 0.00 & - & 0.00 \\
\hline $\mathrm{S}-\mathrm{D}$ & - & 0.49 & 0.34 & - & 0.17 \\
\hline$q_{s}-\mathrm{D}$ & - & 0.39 & 0.27 & - & 0.37 \\
\hline $\mathrm{z}-\mathrm{C}$ & - & 2.33 & 2.82 & - & 6.91 \\
\hline $\mathrm{N}_{\text {Amine }}-\mathrm{H}_{\mathrm{OH}}$ & - & 0.00 & - & - & - \\
\hline $\mathrm{N}_{\text {Amide }}-\mathrm{H}_{\mathrm{OH}}$ & - & 0.34 & - & - & - \\
\hline $\mathrm{N}_{\text {Nitro }}-\mathrm{H}_{\mathrm{OH}}$ & - & 0.00 & - & - & - \\
\hline $\mathrm{N}_{\text {other }}-\mathrm{H}_{\mathrm{OH}}$ & - & 0.00 & - & - & - \\
\hline $\mathrm{O}_{\text {Carbonyl }}-\mathrm{H}_{\mathrm{OH}}$ & - & 0.00 & - & - & - \\
\hline $\mathrm{O}_{\text {Ester }}-\mathrm{H}_{\mathrm{OH}}$ & - & 0.17 & - & - & - \\
\hline $\mathrm{O}_{\text {Nitro }}-\mathrm{H}_{\mathrm{OH}}$ & - & 0.00 & - & - & - \\
\hline $\mathrm{O}_{\text {Hydroxyl }}-\mathrm{H}_{\mathrm{OH}}$ & - & 0.49 & - & - & - \\
\hline $\mathrm{O}_{\text {Hydroxyl }}-\mathrm{H}_{\mathrm{NH}}$ & - & 0.12 & - & - & - \\
\hline Fluorine $-\mathrm{H}_{\mathrm{OH}}$ & - & 0.00 & - & - & - \\
\hline
\end{tabular}

* ES: electrostatic, SA: surface area, D: dispersion, C: combinatorial, H: hydrogen bonding 
TABLE SI-6: SLIC/SASA (SS) and SLIC/CDC (SC) predictions of hydration Gibbs energies, solvation entropies and solvation heat capacities of 109 neutral compounds compared with experimental measurements. This subset of small molecules was the biggest set that was found in the literature where for all the compounds, the experimental values of hydration thermodynamics $\left(\Delta G^{\text {expt }}, \Delta S^{\text {expt }}\right.$, and $\left.\Delta C_{p}^{\text {expt }}\right)$ were available.

\begin{tabular}{|c|c|c|c|c|c|c|c|c|c|}
\hline \multirow[b]{2}{*}{ Neutral compound } & \multicolumn{3}{|c|}{$\Delta G\left[\frac{\mathrm{kcal}}{\mathrm{mol}}\right]$} & \multicolumn{2}{|c|}{$-T \Delta S^{*}$} & $\left.\frac{\mathrm{kcal}}{\mathrm{mol}}\right]$ & $\Delta C_{p}$ & \multicolumn{2}{|c|}{$\left[\frac{\mathrm{cal}}{\mathrm{mol} . \mathrm{K}}\right]$} \\
\hline & expt. $^{\mathrm{a}}$ & SS & $\mathrm{SC}$ & expt. & SS & $\mathrm{SC}$ & expt. & SS & $\mathrm{SC}$ \\
\hline 1,2-diacetoxyethane & -6.34 & -10.61 & -7.47 & $10.25^{\mathrm{b}}$ & 8.06 & 12.72 & $96.85^{\mathrm{b}}$ & 85.88 & 113.70 \\
\hline 1,2-dimethoxyethane & -4.84 & -5.27 & -3.21 & $8.74^{\mathrm{b}}$ & 7.00 & 9.63 & $57.84^{\mathrm{b}}$ & 77.54 & 46.15 \\
\hline 1,2-ethanediol & -9.3 & -11.77 & -11.12 & $7.38^{\mathrm{b}}$ & 7.17 & 10.10 & $27.22^{\mathrm{b}}$ & 40.08 & 86.19 \\
\hline 1,4-dioxane & -5.06 & -4.00 & -4.34 & $5.81^{\mathrm{b}}$ & 5.84 & 7.38 & $30.54^{\mathrm{b}}$ & 56.41 & 40.48 \\
\hline 2,2-dimethylpropane & -6.25 & -4.63 & -4.14 & $10.75^{\mathrm{b}}$ & 9.86 & 12.70 & $92.90^{\mathrm{b}}$ & 123.91 & 141.89 \\
\hline 2,4-dimethylpentan-3-one & -6.69 & -9.67 & -8.27 & $8.57^{\mathrm{b}}$ & 8.33 & 10.74 & $62.76^{\mathrm{b}}$ & 79.03 & 106.09 \\
\hline 2,6-dimethylpyridine & -6.76 & -9.44 & -5.42 & $7.09^{\mathrm{b}}$ & 7.45 & 7.60 & $44.62^{\mathrm{b}}$ & 59.93 & 88.59 \\
\hline 2-butoxyethanol & -4.43 & -2.73 & -3.15 & $11.34^{\mathrm{c}}$ & 8.22 & 9.02 & $96.80^{\mathrm{c}}$ & 95.36 & 68.59 \\
\hline 2-ethoxyethanol & -4.5 & -4.17 & -4.34 & $9.29^{\mathrm{c}}$ & 8.27 & 8.41 & $78.87^{\mathrm{c}}$ & 85.53 & 106.14 \\
\hline 2-methoxyethanol & -4.47 & -3.45 & -3.09 & $10.25^{\mathrm{c}}$ & 7.52 & 8.73 & $84.37^{\mathrm{c}}$ & 80.82 & 79.71 \\
\hline 2-methylbutan-2-ol & 2.32 & 2.00 & 1.31 & $7.50^{\mathrm{c}}$ & 7.28 & 5.53 & $88.43^{\mathrm{c}}$ & 91.52 & 39.50 \\
\hline 2-methylpropan-1-ol & -4.63 & -3.35 & -4.84 & $7.82^{\mathrm{d}}$ & 6.93 & 7.44 & $64.53^{\mathrm{b}}$ & 77.77 & 143.72 \\
\hline 2-methylpropan-2-ol & -6.4 & -9.67 & -8.39 & $9.72^{\mathrm{b}}$ & 9.41 & 11.76 & $78.15^{\mathrm{b}}$ & 98.66 & 46.61 \\
\hline 2-methylpropane & 2.51 & 2.03 & 2.31 & $7.91^{\mathrm{c}}$ & 7.91 & 6.49 & $117.11^{\mathrm{c}}$ & 102.82 & 53.33 \\
\hline 2-methylpyridine & -2.74 & -3.13 & -1.39 & $9.33^{\mathrm{b}}$ & 9.31 & 9.73 & $58.10^{\mathrm{b}}$ & 124.31 & 87.33 \\
\hline 2-propoxyethanol & -4.59 & -2.92 & -4.29 & $9.62^{\mathrm{d}}$ & 8.11 & 8.41 & $75.55^{\mathrm{b}}$ & 100.10 & 44.36 \\
\hline 3-methyl-1h-indole & -5.88 & -6.17 & -7.15 & $8.58^{\dagger}$ & 8.74 & 12.06 & $99.10^{\ddagger}$ & 99.10 & 65.78 \\
\hline 3-methylpyridine & -4.77 & -3.37 & -4.92 & $7.90^{\mathrm{d}}$ & 6.96 & 7.39 & $67.07^{\mathrm{b}}$ & 78.87 & 117.98 \\
\hline 3-nitrophenol & -9.62 & -6.50 & -10.04 & $5.96^{\mathrm{b}}$ & 8.03 & 10.70 & $59.54^{\mathrm{b}}$ & 68.23 & 67.32 \\
\hline 4-methylpentan-2-one & -3.00 & -3.52 & -3.00 & $7.77^{\mathrm{d}}$ & 8.28 & 8.30 & $66.92^{\mathrm{b}}$ & 103.83 & 56.58 \\
\hline 4-methylpyridine & -4.93 & -3.54 & -5.02 & $7.78^{\mathrm{d}}$ & 6.87 & 7.42 & $66.13^{\mathrm{b}}$ & 76.83 & 78.88 \\
\hline 4-nitrophenol & -10.64 & -6.98 & -10.40 & $5.16^{\mathrm{b}}$ & 8.04 & 10.67 & $55.74^{\mathrm{b}}$ & 66.70 & 67.15 \\
\hline acenaphthene & -3.15 & -3.12 & -3.76 & $8.11^{\mathrm{b}}$ & 8.70 & 11.76 & $93.09^{\mathrm{b}}$ & 107.70 & 54.72 \\
\hline acetic-acid & -6.69 & -9.16 & -8.15 & $5.33^{\mathrm{d}}$ & 6.58 & 7.42 & $23.54^{\mathrm{b}}$ & 42.44 & 131.69 \\
\hline
\end{tabular}


Table SI-6. (Continued)

\begin{tabular}{|c|c|c|c|c|c|c|c|c|c|}
\hline \multirow[b]{2}{*}{ Neutral compound } & \multicolumn{3}{|c|}{$\Delta G\left[\frac{\mathrm{kcal}}{\mathrm{mol}}\right]$} & \multicolumn{2}{|c|}{$-T \Delta S^{*}$} & $\left.\frac{\mathrm{rcal}}{\mathrm{mol}}\right]$ & $\Delta C_{p}$ & \multicolumn{2}{|c|}{$\left[\frac{\mathrm{cal}}{\mathrm{mol} . \mathrm{K}}\right]$} \\
\hline & expt. $^{a}$ & SS & $\mathrm{SC}$ & expt. & SS & $\mathrm{SC}$ & expt. & SS & $\mathrm{SC}$ \\
\hline anthracene & -3.95 & -4.47 & -5.39 & $9.45^{\mathrm{b}}$ & 8.78 & 13.03 & $47.97^{\mathrm{b}}$ & 103.96 & 111.09 \\
\hline benzene & -0.86 & -1.21 & -0.66 & $6.12^{\mathrm{c}}$ & 6.29 & 7.88 & $69.31^{\mathrm{c}}$ & 67.58 & 52.16 \\
\hline bromomethane & -0.82 & 0.45 & -1.06 & $4.68^{\mathrm{b}}$ & 4.59 & 2.89 & $47.99^{\mathrm{b}}$ & 39.06 & 139.32 \\
\hline but-1-ene & 1.38 & 1.34 & 2.10 & $6.73^{\mathrm{c}}$ & 6.90 & 6.65 & $93.21^{\mathrm{c}}$ & 83.34 & 207.52 \\
\hline buta-1,3-diene & 0.61 & 0.44 & 1.85 & $6.46^{\mathrm{c}}$ & 6.17 & 6.97 & $138.79^{\mathrm{b}}$ & 68.37 & 167.09 \\
\hline butan-1-ol & -4.72 & -3.92 & -4.41 & $9.43^{\mathrm{c}}$ & 7.97 & 8.90 & $80.07^{\mathrm{c}}$ & 86.99 & 121.79 \\
\hline butan-2-ol & -4.62 & -3.22 & -3.87 & $9.79^{\mathrm{c}}$ & 7.76 & 8.48 & $81.26^{\mathrm{c}}$ & 84.47 & 70.56 \\
\hline butanoic-acid & -6.35 & -8.52 & -7.42 & $7.27^{\mathrm{d}}$ & 8.95 & 9.35 & $52.87^{\mathrm{b}}$ & 86.25 & 98.67 \\
\hline butanone & -3.71 & -3.99 & -3.19 & $6.61^{\mathrm{b}}$ & 6.36 & 7.02 & $55.86^{\mathrm{b}}$ & 65.99 & 50.69 \\
\hline chlorodifluoromethane & -0.5 & -0.81 & -2.17 & $6.93^{\mathrm{b}}$ & 5.29 & 2.89 & $83.60^{\mathrm{b}}$ & 40.36 & 29.83 \\
\hline chloroethylene & -0.59 & 0.40 & 0.15 & $5.15^{\mathrm{b}}$ & 5.02 & 4.41 & $30.90^{\mathrm{b}}$ & 46.02 & 101.38 \\
\hline chlorofluoromethane & -0.77 & -0.90 & -1.61 & $3.82^{\mathrm{b}}$ & 4.02 & 3.71 & $36.85^{\mathrm{b}}$ & 21.47 & 103.76 \\
\hline chloromethane & -0.55 & 0.22 & -0.46 & $4.38^{\mathrm{b}}$ & 4.36 & 3.28 & $44.05^{\mathrm{b}}$ & 34.58 & 82.12 \\
\hline cycloheptanol & -5.48 & -3.67 & -7.46 & $11.77^{\mathrm{c}}$ & 8.95 & 8.48 & $105.16^{\mathrm{c}}$ & 105.63 & 68.06 \\
\hline cyclohexane & 1.23 & 2.04 & 0.21 & $8.54^{\mathrm{c}}$ & 8.17 & 6.46 & $97.99^{\mathrm{c}}$ & 107.40 & 46.74 \\
\hline cyclohexanol & -5.46 & -4.21 & -5.63 & $10.84^{\mathrm{c}}$ & 9.16 & 9.22 & $81.26^{\mathrm{c}}$ & 103.70 & 139.88 \\
\hline cyclopentanol & -5.49 & -4.05 & -5.32 & $10.11^{\mathrm{c}}$ & 8.49 & 8.59 & $88.43^{\mathrm{c}}$ & 91.14 & 151.10 \\
\hline cyclopropane & 0.75 & 1.73 & 0.43 & $5.72^{\mathrm{c}}$ & 5.93 & 4.30 & $74.09^{c}$ & 66.73 & 64.72 \\
\hline di-n-butylamine & -3.24 & -1.81 & -2.00 & $14.30^{\mathrm{d}}$ & 11.88 & 12.00 & $94.79^{\mathrm{b}}$ & 166.18 & 117.06 \\
\hline di-n-propyl-sulfide & -1.28 & -0.36 & -0.46 & $9.51^{\mathrm{e}}$ & 9.77 & 9.31 & $116.40^{\mathrm{e}}$ & 132.95 & 48.84 \\
\hline di-n-propylamine & -3.65 & -1.89 & -2.71 & $13.01^{\mathrm{d}}$ & 10.05 & 12.15 & $95.43^{\mathrm{b}}$ & 133.25 & 87.06 \\
\hline diethyl-disulfide & -1.64 & -0.97 & -2.55 & $7.55^{\mathrm{e}}$ & 8.49 & 7.31 & $86.76^{\mathrm{e}}$ & 108.03 & 16.89 \\
\hline diethyl-sulfide & -1.46 & -0.59 & -0.92 & $7.55^{\mathrm{e}}$ & 7.84 & 7.20 & $76.48^{\mathrm{e}}$ & 98.11 & 19.11 \\
\hline diethylamine & -4.07 & -2.15 & -2.91 & $10.87^{\mathrm{d}}$ & 8.13 & 10.19 & $88.65^{\mathrm{b}}$ & 98.05 & 131.28 \\
\hline dimethyl-disulfide & -1.83 & 0.98 & -1.23 & $5.86^{\mathrm{e}}$ & 7.45 & 7.00 & $68.36^{\mathrm{e}}$ & 80.28 & 64.39 \\
\hline dimethyl-sulfide & -1.61 & -0.44 & -1.27 & $5.31^{\mathrm{e}}$ & 5.61 & 4.82 & $54.49^{\mathrm{e}}$ & 57.48 & 34.72 \\
\hline dimethyl-sulfoxide & -8.71 & -8.40 & -8.24 & $7.88^{\mathrm{d}}$ & 4.86 & 6.04 & $23.11^{\mathrm{b}}$ & 34.78 & 66.09 \\
\hline ethanamide & -9.71 & -9.80 & -10.95 & $6.56^{\mathrm{g}}$ & 5.98 & 7.06 & $22.61^{\mathrm{b}}$ & 42.67 & 38.74 \\
\hline
\end{tabular}


Table SI-6. (Continued)

\begin{tabular}{|c|c|c|c|c|c|c|c|c|c|}
\hline \multirow[b]{2}{*}{ Neutral compound } & \multicolumn{3}{|c|}{$\Delta G\left[\frac{\mathrm{kcal}}{\mathrm{mol}}\right]$} & \multicolumn{2}{|c|}{$-T \Delta S^{*}$} & $\left.\frac{\mathrm{kcal}}{\mathrm{mol}}\right]$ & $\Delta C_{p}$ & {$\left[\frac{\mathrm{cal}}{\mathrm{mol} \cdot \mathrm{K}}\right.$} & \\
\hline & expt. $^{a}$ & SS & $\mathrm{SC}$ & expt. & SS & $\mathrm{SC}$ & expt. & SS & $\mathrm{SC}$ \\
\hline ethane & 1.83 & 1.91 & 1.67 & $5.87^{\mathrm{c}}$ & 5.58 & 3.99 & $66.92^{\mathrm{c}}$ & 60.91 & 50.08 \\
\hline ethanol & -5 & -4.74 & -4.56 & $6.97^{\mathrm{c}}$ & 6.47 & 7.01 & $47.56^{\mathrm{c}}$ & 53.16 & 92.97 \\
\hline ethene & 1.28 & 1.20 & 2.02 & $4.62^{\mathrm{c}}$ & 4.82 & 4.54 & $57.36^{\mathrm{c}}$ & 45.76 & 70.52 \\
\hline ethyl-acetate & -2.94 & -4.22 & -2.66 & $7.36^{\mathrm{b}}$ & 7.24 & 8.44 & $67.64^{\mathrm{b}}$ & 83.70 & 103.67 \\
\hline ethylbenzene & -0.79 & -0.95 & -0.15 & $8.22^{\mathrm{c}}$ & 8.22 & 9.94 & $88.43^{\mathrm{c}}$ & 103.21 & 98.06 \\
\hline fluoromethane & -0.22 & -0.26 & 0.13 & $3.51^{\mathrm{b}}$ & 3.89 & 3.76 & $36.33^{\mathrm{b}}$ & 25.94 & 40.51 \\
\hline heptan-1-ol & -4.21 & -3.65 & -3.87 & $12.33^{\mathrm{c}}$ & 10.59 & 11.98 & $124.28^{\mathrm{c}}$ & 135.63 & 95.55 \\
\hline heptan-2-one & -3.04 & -3.64 & -2.56 & $9.96^{\mathrm{d}}$ & 9.47 & 10.04 & $64.01^{\mathrm{b}}$ & 124.63 & 38.13 \\
\hline heptan-4-one & -2.92 & -3.21 & -2.50 & $10.88^{\mathrm{d}}$ & 9.59 & 9.85 & $58.05^{\mathrm{b}}$ & 127.61 & 53.14 \\
\hline hexan-1-ol & -4.4 & -3.62 & -3.96 & $11.28^{\mathrm{c}}$ & 9.72 & 10.99 & $109.94^{\mathrm{c}}$ & 120.38 & 106.80 \\
\hline hexan-3-ol & -4.06 & -2.76 & -3.83 & $11.97^{\mathrm{c}}$ & 9.60 & 10.06 & $112.33^{\mathrm{c}}$ & 118.70 & 76.68 \\
\hline iodomethane & -0.89 & -0.86 & -1.64 & $4.70^{\mathrm{b}}$ & 4.22 & 3.24 & $99.81^{\mathrm{b}}$ & 28.22 & 134.18 \\
\hline m-xylene & -0.83 & -0.86 & -0.44 & $7.77^{\mathrm{c}}$ & 8.34 & 9.61 & $98.09^{\mathrm{b}}$ & 105.89 & 52.12 \\
\hline methane & 1.99 & 1.86 & 1.33 & $4.52^{\mathrm{c}}$ & 4.43 & 2.57 & $52.58^{\mathrm{c}}$ & 40.24 & 18.37 \\
\hline methanethiol & -1.24 & -1.49 & -1.72 & $3.98^{\mathrm{c}}$ & 4.80 & 4.11 & $69.70^{\ddagger}$ & 69.70 & 72.98 \\
\hline methanol & -5.1 & -5.08 & -6.60 & $5.09^{\mathrm{c}}$ & 5.40 & 5.27 & $27.25^{\mathrm{c}}$ & 33.82 & 158.07 \\
\hline methyl-acetate & -3.13 & -5.04 & -3.97 & $6.43^{\mathrm{b}}$ & 5.77 & 7.07 & $49.02^{\mathrm{b}}$ & 55.04 & 85.60 \\
\hline methyl-ethyl-sulfide & -1.5 & -0.54 & -1.14 & $6.47^{\S}$ & 6.73 & 5.97 & $39.80^{\ddagger}$ & 39.80 & 81.31 \\
\hline morpholine & -7.17 & -5.16 & -7.06 & $8.83^{\mathrm{b}}$ & 6.84 & 9.76 & $33.17^{\mathrm{b}}$ & 68.65 & 146.46 \\
\hline n-butane & 2.07 & 2.00 & 1.60 & $7.66^{\mathrm{c}}$ & 7.45 & 5.87 & $92.02^{\mathrm{c}}$ & 94.53 & 40.62 \\
\hline n-butylacetamide & -9.31 & -9.17 & -10.07 & $11.53^{\mathrm{d}}$ & 9.94 & 10.92 & $85.44^{\mathrm{b}}$ & 115.39 & 59.87 \\
\hline n-butylamine & -4.24 & -3.89 & -4.48 & $9.27^{\mathrm{d}}$ & 8.20 & 10.00 & $72.54^{\mathrm{b}}$ & 92.02 & 56.81 \\
\hline n-hexane & 2.48 & 2.10 & 1.93 & $9.43^{\mathrm{c}}$ & 9.30 & 7.97 & $117.11^{\mathrm{c}}$ & 127.90 & 25.03 \\
\hline n-hexylamine & -3.95 & -3.45 & -4.14 & $11.14^{\mathrm{d}}$ & 10.05 & 11.93 & $104.95^{\mathrm{b}}$ & 126.50 & 46.90 \\
\hline N-methylacetamide & -10 & -8.58 & -9.29 & $6.92^{\mathrm{g}}$ & 6.59 & 8.44 & $40.03^{\mathrm{b}}$ & 59.97 & 30.42 \\
\hline N-methylmorpholine & -6.32 & -4.17 & -4.31 & $9.49^{\mathrm{b}}$ & 7.05 & 9.62 & $47.83^{\mathrm{b}}$ & 79.86 & 46.96 \\
\hline N-methylpiperidine & -3.88 & -1.64 & -3.94 & $11.24^{\mathrm{b}}$ & 8.11 & 7.97 & $96.65^{\mathrm{b}}$ & 103.73 & 32.79 \\
\hline n-pentane & 2.32 & 2.05 & 1.84 & $8.60^{\mathrm{c}}$ & 8.38 & 6.97 & $105.16^{\mathrm{c}}$ & 111.19 & 19.30 \\
\hline
\end{tabular}


Table SI-6. (Continued)

\begin{tabular}{|c|c|c|c|c|c|c|c|c|c|}
\hline \multirow[b]{2}{*}{ Neutral compound } & \multicolumn{3}{|c|}{$\Delta G\left[\frac{\mathrm{kcal}}{\mathrm{mol}}\right]$} & \multicolumn{3}{|c|}{$-T \Delta S^{*}\left[\frac{\mathrm{kcal}}{\mathrm{mol}}\right]$} & \multicolumn{3}{|c|}{$\Delta C_{p}\left[\frac{\mathrm{cal}}{\mathrm{mol} . \mathrm{K}}\right]$} \\
\hline & expt. $^{a}$ & $\mathrm{SS}$ & $\mathrm{SC}$ & expt. & SS & $\mathrm{SC}$ & expt. & SS & $\mathrm{SC}$ \\
\hline n-pentylamine & -4.09 & -3.99 & -4.91 & $10.16^{\mathrm{d}}$ & 9.16 & 10.76 & $89.44^{\mathrm{b}}$ & 109.34 & 44.29 \\
\hline n-propanethiol & -1.06 & -1.47 & -1.54 & $5.56^{\mathrm{e}}$ & 6.88 & 6.07 & $78.87^{\mathrm{e}}$ & 73.08 & 35.33 \\
\hline n-propylamine & -4.39 & -3.74 & -4.25 & $8.33^{\mathrm{d}}$ & 7.31 & 9.10 & $55.26^{\mathrm{b}}$ & 75.95 & 58.43 \\
\hline n-propylbenzene & -0.53 & -0.86 & -0.10 & $9.36^{\mathrm{c}}$ & 9.16 & 10.87 & $107.55^{\mathrm{c}}$ & 120.26 & 85.01 \\
\hline naphthalene & -2.4 & -3.05 & -3.15 & $8.20^{\mathrm{b}}$ & 7.52 & 10.53 & $82.10^{\mathrm{b}}$ & 85.35 & 108.97 \\
\hline N,N-dimethylformamide & -7.81 & -6.81 & -4.99 & $6.70^{\mathrm{g}}$ & 5.55 & 7.92 & $32.55^{\mathrm{b}}$ & 48.31 & 29.75 \\
\hline octan-1-ol & -4.09 & -5.07 & -4.80 & $13.09^{\mathrm{c}}$ & 12.61 & 12.73 & $136.23^{\mathrm{c}}$ & 158.24 & 80.27 \\
\hline p-cresol & -6.13 & -6.00 & -6.16 & $8.00^{\mathrm{d}}$ & 8.24 & 10.98 & $62.02^{\mathrm{b}}$ & 81.03 & 67.12 \\
\hline p-xylene & -0.8 & -0.88 & -0.44 & $7.83^{\mathrm{c}}$ & 8.34 & 9.63 & $80.09^{\mathrm{b}}$ & 105.77 & 45.03 \\
\hline pentan-1-ol & -4.57 & -3.69 & -3.95 & $10.37^{\mathrm{c}}$ & 8.89 & 9.96 & $96.08^{c}$ & 104.71 & 164.29 \\
\hline pentan-3-ol & -4.35 & -3.22 & -3.86 & $11.02^{\mathrm{c}}$ & 8.90 & 9.35 & $97.99^{\mathrm{c}}$ & 104.95 & 94.97 \\
\hline pentan-3-one & -3.41 & -3.42 & -2.90 & $7.81^{\mathrm{d}}$ & 7.67 & 7.77 & $71.99^{\mathrm{b}}$ & 92.76 & 52.08 \\
\hline phenol & -6.61 & -6.20 & -6.16 & $6.40^{\mathrm{d}}$ & 7.20 & 10.22 & $50.53^{\mathrm{b}}$ & 61.51 & 51.12 \\
\hline piperidine & -5.11 & -2.42 & -4.98 & $9.92^{\mathrm{b}}$ & 7.94 & 9.27 & $76.12^{\mathrm{b}}$ & 92.24 & 41.75 \\
\hline prop-2-en-1-ol & -5.03 & -4.32 & -3.63 & $7.37^{\mathrm{c}}$ & 6.63 & 8.51 & $62.14^{\mathrm{c}}$ & 59.82 & 76.51 \\
\hline propan-1-ol & -4.85 & -3.76 & -4.36 & $8.33^{\mathrm{c}}$ & 7.02 & 8.00 & $64.05^{\mathrm{c}}$ & 71.20 & 77.11 \\
\hline propan-2-ol & -4.74 & -3.78 & -4.33 & $8.64^{c}$ & 6.92 & 7.69 & $65.01^{\mathrm{c}}$ & 68.73 & 83.73 \\
\hline propane & 1.96 & 1.96 & 1.63 & $6.83^{c}$ & 6.52 & 4.95 & $78.87^{\mathrm{c}}$ & 77.81 & 49.10 \\
\hline propanoic-acid & -6.46 & -9.23 & -8.12 & $6.44^{\mathrm{d}}$ & 8.10 & 8.34 & $38.29^{\mathrm{b}}$ & 67.18 & 127.71 \\
\hline propanone & -3.8 & -4.15 & -3.49 & $5.37^{\mathrm{b}}$ & 5.67 & 5.85 & $39.77^{\mathrm{b}}$ & 55.59 & 55.11 \\
\hline propene & 1.32 & 1.22 & 1.71 & $5.88^{c}$ & 5.92 & 5.42 & $66.92^{\mathrm{c}}$ & 65.69 & 111.90 \\
\hline propyne & -0.48 & 0.50 & -0.39 & $3.75^{c}$ & 5.36 & 4.31 & $79.54^{\mathrm{b}}$ & 53.73 & 89.20 \\
\hline pyrene & -4.52 & -5.39 & -7.64 & $10.08^{b}$ & 8.70 & 13.27 & $129.97^{\mathrm{b}}$ & 100.25 & 171.82 \\
\hline pyridine & -4.69 & -3.70 & -5.24 & $6.62^{\mathrm{d}}$ & 5.75 & 6.45 & $54.40^{\mathrm{b}}$ & 55.35 & 28.56 \\
\hline pyrrolidine & -5.48 & -3.12 & -5.48 & $9.11^{\mathrm{b}}$ & 7.16 & 8.74 & $60.33^{\mathrm{b}}$ & 78.30 & 89.07 \\
\hline tetrafluoromethane & 3.12 & 1.25 & 1.77 & $6.12^{\mathrm{b}}$ & 5.13 & 4.66 & $90.75^{\mathrm{b}}$ & 49.62 & 177.44 \\
\hline tetrahydrofuran & -3.47 & -1.83 & -2.24 & $7.23^{\mathrm{b}}$ & 6.51 & 6.64 & $50.29^{\mathrm{b}}$ & 74.18 & 90.77 \\
\hline tetrahydropyran & -3.12 & -1.13 & -2.09 & $7.96^{\mathrm{b}}$ & 7.27 & 7.01 & $63.60^{\mathrm{b}}$ & 88.34 & 96.18 \\
\hline
\end{tabular}


Table SI-6. (Continued)

\begin{tabular}{|c|c|c|c|c|c|c|c|c|c|}
\hline \multirow[b]{2}{*}{ Neutral compound } & \multicolumn{2}{|c|}{$\Delta G\left[\frac{\mathrm{k}}{\mathrm{r}}\right.$} & {$\left[\frac{\mathrm{kcal}}{\mathrm{mol}}\right]$} & \multicolumn{2}{|c|}{$-T \Delta S^{*}$} & {$\left[\frac{\mathrm{kcal}}{\mathrm{mol}}\right]$} & $\Delta C_{p}$ & \multicolumn{2}{|c|}{$\left[\frac{\mathrm{cal}}{\mathrm{mol} . \mathrm{K}}\right]$} \\
\hline & expt. $^{a}$ & SS & $\mathrm{SC}$ & expt. & SS & $\mathrm{SC}$ & expt. & SS & $\mathrm{SC}$ \\
\hline toluene & -0.89 & -1.06 & -0.55 & $7.19^{\mathrm{c}}$ & 7.32 & 8.76 & $81.26^{\mathrm{g}}$ & 86.61 & 89.80 \\
\hline RMSE & & 1.37 & 0.95 & & 1.29 & 1.71 & & 24.23 & 45.91 \\
\hline MAE & & 1.02 & 0.74 & & 0.98 & 1.33 & & 18.12 & 36.61 \\
\hline
\end{tabular}

a Reference $\underline{64 .} \quad$ eReference 15.

${ }^{\mathrm{b}}$ Reference $\underline{3}$. $\quad{ }^{\mathrm{f}}$ Reference ${ }^{\underline{1}}$.

${ }^{\mathrm{c}}$ Reference ${ }^{14}$. $\quad$ 'Reference ${ }^{\mathrm{g}}$.

${ }^{\mathrm{d}}$ Reference 10 .

*Calculated using:

$$
-T \Delta S=\Delta G-\Delta H
$$

${ }^{\dagger}$ Approximated using the difference between $\Delta H$ of Tyr and p-cresol:

$$
\Delta H(3 \text {-methyl-1h-indole }) \approx \Delta H(\operatorname{Trp})+\Delta H(\mathrm{p} \text {-cresol })-\Delta H(\mathrm{Tyr})
$$

$\ddagger$ Approximated using the average of $\left|\Delta C_{p}^{\mathrm{AA}}-\Delta C_{p}^{\text {Analogue }}\right|$ (See Table SI-3)

§Interpolated from the experimental values of $\Delta H$ for dimethyl-sulfide and diethyl-sulfide.

Experimental solvation enthalpies were transformed to the $1 \mathrm{M}$ gas standard state:

$$
\Delta H_{1 M}=\Delta H_{\mathrm{ref}}+0.6 \frac{\mathrm{kcal}}{\mathrm{mol}} .(\text { See References } 12,32,33 \text { ) }
$$


TABLE SI-7: The experimental data and SLIC/SASA predictions of hydration Gibbs energies, entropies, and heat capacities of 502 neutral compounds.

\begin{tabular}{|c|c|c|c|c|c|c|c|c|}
\hline \multirow[b]{3}{*}{ Neutral compound } & \multicolumn{3}{|c|}{$\Delta G\left[\frac{\mathrm{kcal}}{\mathrm{mol}}\right]$} & \multirow{3}{*}{\multicolumn{2}{|c|}{$\frac{-T \Delta S^{*}}{\text { expt. }}$}} & \multirow{3}{*}{$\frac{\left[\frac{\mathrm{kcal}}{\mathrm{mol}}\right]}{\text { calc. }}$} & \multirow{3}{*}{$\begin{array}{r}\Delta C_{p}[\overline{]} \\
\text { expt. }\end{array}$} & \multirow{3}{*}{$\frac{\left.\frac{\mathrm{cal}}{\mathrm{mol} . \mathrm{K}}\right]}{\text { calc. }}$} \\
\hline & \multirow[t]{2}{*}{ expt. $^{a}$} & \multicolumn{2}{|r|}{ calc. } & & & & & \\
\hline & & tot & es & & & & & \\
\hline 1-bromo-2-chloroethane & -1.95 & -0.02 & -2.03 & 2.01 & & 5.81 & & 58.13 \\
\hline 1-bromo-2-methylpropane & -0.03 & 0.66 & -1.41 & 2.06 & & 7.33 & & 89.49 \\
\hline 1-bromobutane & -0.40 & 0.63 & -1.46 & 2.09 & & 7.72 & & 96.58 \\
\hline 1-bromoheptane & 0.34 & 0.79 & -1.46 & 2.25 & & 10.52 & & 147.02 \\
\hline 1-bromohexane & 0.18 & 0.76 & -1.43 & 2.19 & & 9.60 & & 130.54 \\
\hline 1-bromooctane & 0.52 & 0.85 & -1.45 & 2.30 & & 11.46 & & 163.91 \\
\hline 1-bromopentane & -0.10 & 0.71 & -1.43 & 2.14 & & 8.68 & & 113.83 \\
\hline 1-bromopropane & -0.56 & 0.58 & -1.46 & 2.03 & & 6.80 & & 79.94 \\
\hline 1-chloro-2,2,2-trifluoroethane & 0.06 & -0.72 & -2.73 & 2.01 & & 5.27 & & 43.94 \\
\hline 1-chlorobutane & -0.16 & 0.46 & -1.61 & 2.08 & & 7.55 & & 93.49 \\
\hline 1-chloroheptane & 0.29 & 0.62 & -1.62 & 2.24 & & 10.35 & & 143.81 \\
\hline 1-chlorohexane & 0.00 & 0.52 & -1.66 & 2.18 & & 9.25 & & 123.74 \\
\hline 1-chloropentane & -0.07 & 0.45 & -1.67 & 2.13 & & 8.35 & & 107.50 \\
\hline 1-chloropropane & -0.33 & 0.47 & -1.55 & 2.02 & & 6.44 & & 72.99 \\
\hline 1-ethylnaphthalene & -2.40 & -2.73 & -4.97 & 2.24 & & 9.21 & & 116.87 \\
\hline 1-iodobutane & -0.25 & -0.52 & -2.62 & 2.10 & & 7.57 & & 91.32 \\
\hline 1-iodoheptane & 0.27 & -0.32 & -2.58 & 2.26 & & 10.39 & & 142.04 \\
\hline 1-iodohexane & 0.08 & -0.36 & -2.57 & 2.21 & & 9.45 & & 125.26 \\
\hline 1-iodopentane & -0.14 & -0.43 & -2.58 & 2.16 & & 8.53 & & 108.65 \\
\hline 1-iodopropane & -0.53 & -0.58 & -2.63 & 2.05 & & 6.65 & & 74.78 \\
\hline 1-methyl-imidazole & -8.41 & -5.62 & -7.65 & 2.03 & & 5.71 & & 52.37 \\
\hline 1-methyl-pyrrole & -2.89 & -2.38 & -4.43 & 2.04 & & 6.32 & & 66.77 \\
\hline 1-methylcyclohexene & 0.67 & 1.29 & -0.83 & 2.12 & & 8.62 & & 114.46 \\
\hline 1-methylnaphthalene & -2.44 & -2.86 & -5.05 & 2.19 & & 8.36 & & 101.30 \\
\hline
\end{tabular}


Table SI-7. (Continued)

\begin{tabular}{|c|c|c|c|c|c|c|c|c|}
\hline \multirow[b]{3}{*}{ Neutral compound } & & $\Delta G[$ & \multicolumn{2}{|l|}{$\left.\frac{\mathrm{kcal}}{\mathrm{mol}}\right]$} & $-T \Delta S^{*}$ & {$\left[\frac{\mathrm{kcal}}{\mathrm{mol}}\right]$} & $\Delta C_{p}[$ & $\left.\frac{\mathrm{cal}}{\mathrm{mol} . \mathrm{K}}\right]$ \\
\hline & & & calc. & & expt. & calc. & expt. & calc. \\
\hline & & tot & es & np & & & & \\
\hline 1-naphthol & -7.67 & -8.23 & -10.39 & 2.16 & & 9.37 & & 89.79 \\
\hline 1-naphthylamine & -7.28 & -7.52 & -9.68 & 2.16 & & 9.07 & & 90.07 \\
\hline 1-nitrobutane & -3.09 & -1.04 & -3.15 & 2.10 & & 7.62 & & 92.14 \\
\hline 1-nitropentane & -2.82 & -0.94 & -3.10 & 2.16 & & 8.56 & & 109.00 \\
\hline 1-nitropropane & -3.34 & -1.14 & -3.19 & 2.05 & & 6.68 & & 74.95 \\
\hline 1,1-diacetoxyethane & -4.97 & -9.18 & -11.40 & 2.22 & & 8.69 & & 102.90 \\
\hline 1,1-dichloroethane & -0.84 & -0.14 & -2.15 & 2.00 & & 5.82 & & 58.26 \\
\hline 1,1-dichloroethene & 0.25 & 0.85 & -1.14 & 1.99 & & 5.77 & & 59.76 \\
\hline 1,1-diethoxyethane & -3.28 & -3.47 & -5.69 & 2.21 & & 9.43 & & 123.75 \\
\hline 1,1-difluoroethane & -0.11 & -1.02 & -2.98 & 1.96 & & 4.89 & & 40.85 \\
\hline 1,1,1-trichloroethane & -0.19 & 0.60 & -1.44 & 2.04 & & 6.55 & & 73.28 \\
\hline 1,1,1-trifluoro-2,2,2-trimethoxyethane & e -0.80 & -3.71 & -5.87 & 2.16 & & 7.33 & & 78.83 \\
\hline 1,1,1-trifluoropropan-2-ol & -4.16 & -6.86 & -8.90 & 2.04 & $8.04^{\mathrm{b}}$ & 6.65 & & 44.29 \\
\hline 1,1,1-trimethoxyethane & -4.42 & -4.60 & -6.73 & 2.13 & & 7.75 & & 91.42 \\
\hline 1,1,1,2-tetrachloroethane & -1.28 & 0.32 & -1.75 & 2.07 & & 6.62 & & 71.52 \\
\hline 1,1,2-trichloro-1,2,2-trifluoroethane & 1.77 & 1.47 & -0.60 & 2.07 & & 7.54 & & 94.07 \\
\hline 1,1,2-trichloroethane & -1.99 & -1.25 & -3.29 & 2.03 & & 5.29 & & 41.40 \\
\hline 1,1,2,2-tetrachloroethane & -2.47 & -0.39 & -2.46 & 2.06 & & 6.52 & & 64.17 \\
\hline 1,2-diacetoxyethane & -6.34 & -10.61 & -12.84 & 2.23 & $10.25^{\mathrm{b}}$ & 8.06 & $96.85^{\mathrm{b}}$ & 85.88 \\
\hline 1,2-dibromoethane & -2.33 & 0.08 & -1.94 & 2.02 & & 5.99 & & 61.42 \\
\hline 1,2-dichlorobenzene & -1.36 & -0.39 & -2.50 & 2.10 & & 7.07 & & 79.03 \\
\hline 1,2-dichloroethane & -1.79 & -1.22 & -3.22 & 2.00 & & 5.00 & & 39.99 \\
\hline 1,2-dichloropropane & -1.27 & -1.07 & -3.11 & 2.05 & & 6.08 & & 61.01 \\
\hline 1,2-diethoxyethane & -3.54 & -4.36 & -6.58 & 2.22 & & 9.49 & & 124.15 \\
\hline 1,2-dimethoxyethane & -4.84 & -5.27 & -7.36 & 2.09 & $8.74^{\mathrm{b}}$ & 7.00 & $57.84^{\mathrm{b}}$ & 77.54 \\
\hline
\end{tabular}


Table SI-7. (Continued)

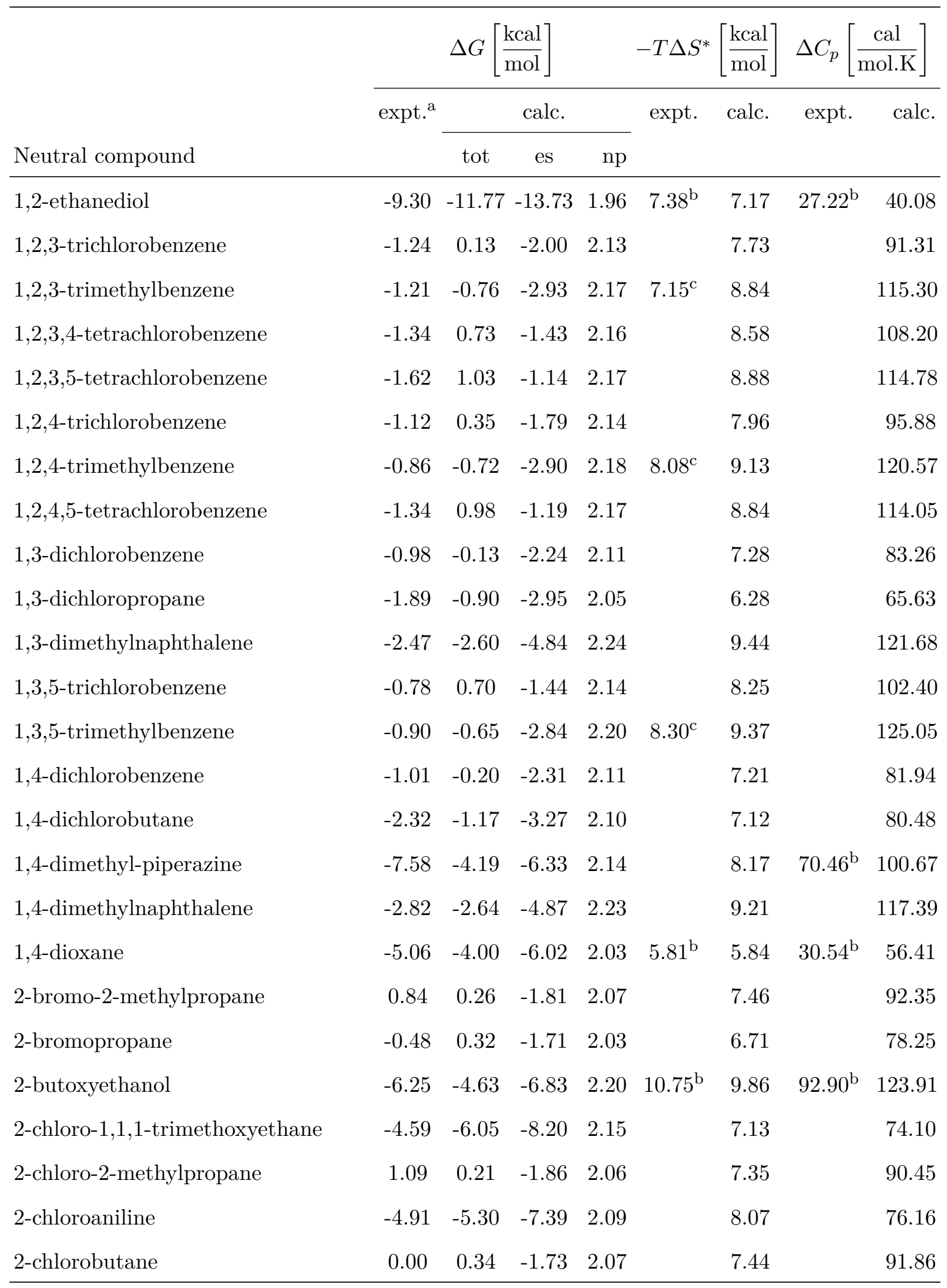


Table SI-7. (Continued)

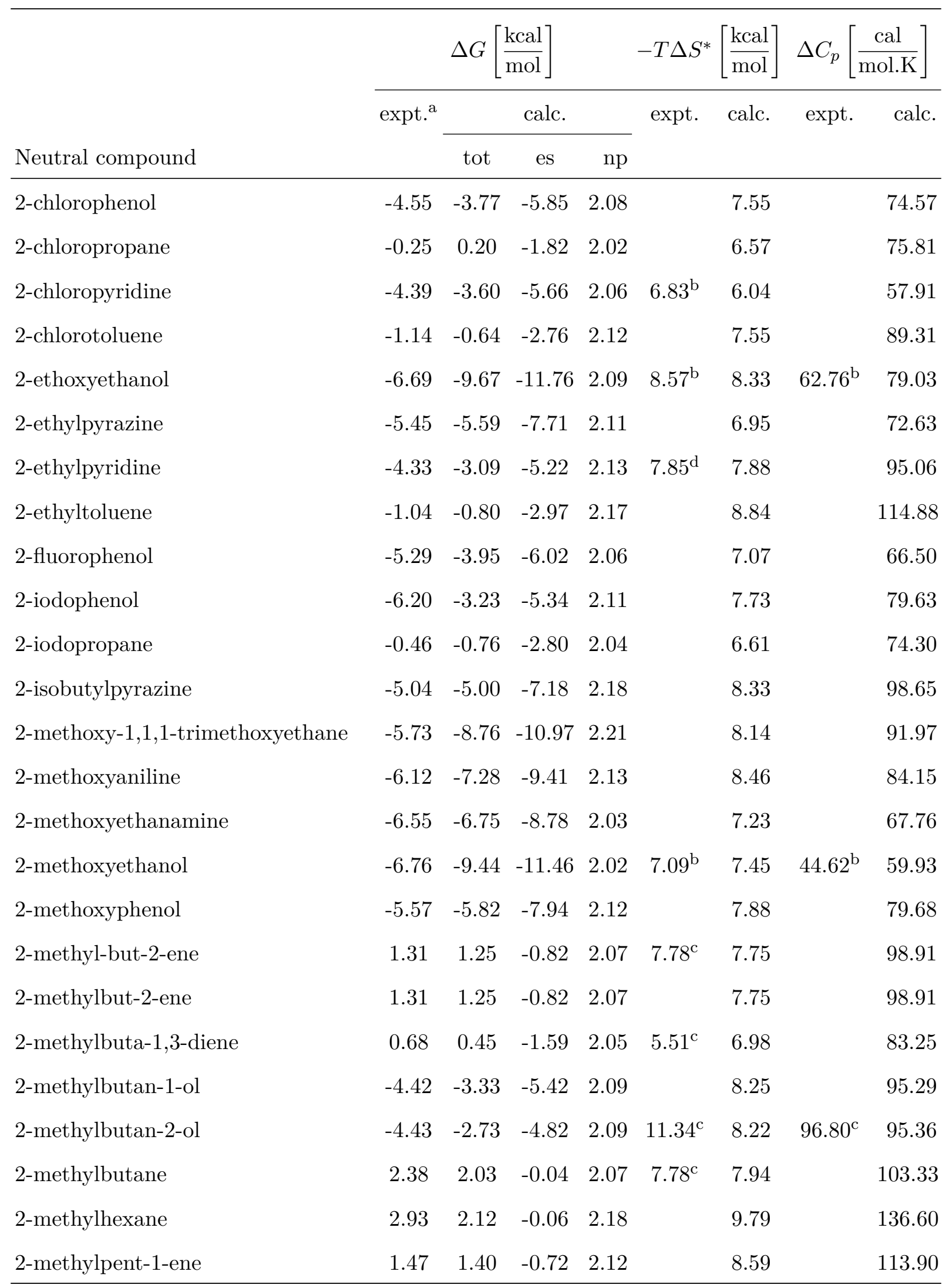


Table SI-7. (Continued)

\begin{tabular}{|c|c|c|c|c|c|c|c|c|}
\hline \multirow[b]{3}{*}{ Neutral compound } & & $\Delta G[$ & $\left.\frac{\mathrm{kcal}}{\mathrm{mol}}\right]$ & & \multirow{3}{*}{$\frac{-T \Delta S^{*}}{\text { expt. }}$} & \multirow{3}{*}{$\frac{\left[\frac{\mathrm{kcal}}{\mathrm{mol}}\right]}{\text { calc. }}$} & \multirow{3}{*}{$\frac{\Delta C_{p}\left[\frac{1}{\mathrm{r}}\right.}{\text { expt. }}$} & $\left.\frac{\mathrm{cal}}{\mathrm{mol} . \mathrm{K}}\right]$ \\
\hline & & & calc. & & & & & calc. \\
\hline & & tot & es & $\mathrm{np}$ & & & & \\
\hline 2-methylpentan-2-ol & -3.92 & -3.25 & -5.39 & 2.14 & & 9.27 & & 112.31 \\
\hline 2-methylpentan-3-ol & -3.88 & -2.11 & -4.25 & 2.14 & & 8.98 & & 112.45 \\
\hline 2-methylpentane & 2.51 & 2.08 & -0.05 & 2.13 & $9.70^{\mathrm{c}}$ & 8.98 & & 122.03 \\
\hline 2-methylpropan-1-ol & -4.50 & -4.17 & -6.21 & 2.04 & $9.29^{\mathrm{c}}$ & 8.27 & $78.87^{\mathrm{c}}$ & 85.53 \\
\hline 2-methylpropan-2-ol & -4.47 & -3.45 & -5.49 & 2.05 & $10.25^{\mathrm{c}}$ & 7.52 & $84.37^{\mathrm{c}}$ & 80.82 \\
\hline 2-methylpropane & 2.32 & 2.00 & -0.04 & 2.04 & $7.50^{\mathrm{c}}$ & 7.28 & $88.43^{\mathrm{c}}$ & 91.52 \\
\hline 2-methylpropene & 1.16 & 1.25 & -0.77 & 2.02 & & 6.82 & $65.37^{\mathrm{b}}$ & 82.05 \\
\hline 2-methylpyrazine & -5.51 & -5.90 & -7.96 & 2.06 & & 5.88 & & 52.34 \\
\hline 2-methylpyridine & -4.63 & -3.35 & -5.43 & 2.08 & $7.82^{\mathrm{d}}$ & 6.93 & $64.53^{\mathrm{b}}$ & 77.77 \\
\hline 2-methyltetrahydrofuran & -3.30 & -1.39 & -3.45 & 2.07 & & 7.43 & & 91.35 \\
\hline 2-methylthiophene & -1.38 & -0.46 & -2.52 & 2.06 & & 6.87 & & 78.37 \\
\hline 2-naphthol & -8.11 & -8.26 & -10.42 & 2.16 & & 9.09 & & 87.52 \\
\hline 2-naphthylamine & -7.47 & -7.85 & -10.02 & 2.17 & & 9.17 & & 92.42 \\
\hline 2-nitroaniline & -7.37 & -5.76 & -7.86 & 2.10 & & 7.66 & & 68.18 \\
\hline 2-nitrophenol & -4.58 & -7.78 & -9.88 & 2.10 & & 7.53 & & 58.84 \\
\hline 2-nitropropane & -3.13 & -1.22 & -3.26 & 2.04 & & 6.62 & & 74.24 \\
\hline 2-nitrotoluene & -3.58 & -1.94 & -4.07 & 2.13 & & 7.35 & & 82.74 \\
\hline 2-phenylethanol & -6.79 & -6.53 & -8.68 & 2.15 & & 8.63 & & 91.98 \\
\hline 2-propoxyethanol & -6.40 & -9.67 & -11.82 & 2.15 & $9.72^{\mathrm{b}}$ & 9.41 & $78.15^{\mathrm{b}}$ & 98.66 \\
\hline 2,2-dimethylbutane & 2.51 & 2.07 & -0.04 & 2.11 & & 8.58 & & 114.83 \\
\hline 2,2-dimethylpentane & 2.88 & 2.11 & -0.05 & 2.16 & & 9.51 & & 131.68 \\
\hline 2,2-dimethylpropane & 2.51 & 2.03 & -0.04 & 2.07 & $7.91^{\mathrm{c}}$ & 7.91 & $117.11^{\mathrm{c}}$ & 102.82 \\
\hline 2,2,2-trifluoroethanol & -4.31 & -6.34 & -8.33 & 1.99 & $7.06^{\mathrm{b}}$ & 6.49 & & 38.21 \\
\hline 2,2,4-trimethylpentane & 2.89 & 2.13 & -0.05 & 2.18 & & 9.88 & & 138.34 \\
\hline 2,2,5-trimethylhexane & 2.93 & 2.18 & -0.06 & 2.24 & & 10.88 & & 156.20 \\
\hline
\end{tabular}


Table SI-7. (Continued)

\begin{tabular}{|c|c|c|c|c|c|c|c|c|}
\hline \multirow[b]{3}{*}{ Neutral compound } & \multicolumn{3}{|c|}{$\Delta G\left[\frac{\mathrm{kcal}}{\mathrm{mol}}\right]$} & \multicolumn{2}{|r|}{$-T \Delta S^{*}$} & {$\left[\frac{\mathrm{kcal}}{\mathrm{mol}}\right]$} & $\Delta C_{p}[$ & $\left.\frac{\mathrm{cal}}{\mathrm{mol} . \mathrm{K}}\right]$ \\
\hline & expt. $^{a}$ & & calc. & & expt. & calc. & expt. & calc. \\
\hline & & tot & es & np & & & & \\
\hline 2,3-dimethylbuta-1,3-diene & 0.40 & 0.46 & -1.63 & 2.09 & & 7.76 & & 97.43 \\
\hline 2,3-dimethylbutane & 2.34 & 2.07 & -0.04 & 2.11 & $8.72^{\mathrm{c}}$ & 8.62 & & 115.59 \\
\hline 2,3-dimethylnaphthalene & -2.78 & -2.60 & -4.84 & 2.24 & & 9.38 & & 120.51 \\
\hline 2,3-dimethylpentane & 2.52 & 2.11 & -0.05 & 2.16 & & 9.38 & & 129.35 \\
\hline 2,3-dimethylphenol & -6.16 & -5.38 & -7.52 & 2.14 & & 8.95 & & 95.82 \\
\hline 2,3-dimethylpyridine & -4.82 & -3.13 & -5.25 & 2.12 & $8.37^{\mathrm{d}}$ & 7.83 & & 94.97 \\
\hline 2,3,4-trimethylpentane & 2.56 & 2.14 & -0.05 & 2.19 & & 9.95 & & 139.51 \\
\hline 2,4-dimethylpentan-3-one & -2.74 & -3.13 & -5.31 & 2.18 & $9.33^{\mathrm{b}}$ & 9.31 & $58.10^{\mathrm{b}}$ & 124.31 \\
\hline 2,4-dimethylpentane & 2.83 & 2.10 & -0.05 & 2.15 & & 9.26 & & 127.17 \\
\hline 2,4-dimethylphenol & -6.01 & -5.33 & -7.48 & 2.15 & & 9.19 & & 100.06 \\
\hline 2,4-dimethylpyridine & -4.86 & -3.19 & -5.32 & 2.13 & $9.05^{\mathrm{d}}$ & 8.05 & & 99.02 \\
\hline 2,5-dimethylphenol & -5.91 & -3.92 & -6.07 & 2.15 & & 8.72 & & 101.37 \\
\hline 2,5-dimethylpyridine & -4.72 & -3.07 & -5.20 & 2.13 & $9.22^{\mathrm{d}}$ & 8.18 & & 101.88 \\
\hline 2,5-dimethyltetrahydrofuran & -2.92 & -1.07 & -3.20 & 2.12 & & 8.52 & & 111.38 \\
\hline 2,6-dimethylaniline & -5.21 & -4.46 & -6.61 & 2.15 & & 8.80 & & 99.60 \\
\hline 2,6-dimethylnaphthalene & -2.63 & -2.59 & -4.85 & 2.25 & & 9.63 & & 125.17 \\
\hline 2,6-dimethylphenol & -5.26 & -3.98 & -6.13 & 2.15 & & 8.58 & & 98.23 \\
\hline 2,6-dimethylpyridine & -4.59 & -2.92 & -5.06 & 2.14 & $9.62^{\mathrm{d}}$ & 8.11 & $75.55^{\mathrm{b}}$ & 100.10 \\
\hline 3-acetylpyridine & -8.26 & -7.66 & -9.78 & 2.12 & & 6.57 & & 62.45 \\
\hline 3-chloroaniline & -5.82 & -5.27 & -7.36 & 2.09 & & 8.54 & & 82.68 \\
\hline 3-chlorophenol & -6.62 & -5.19 & -7.28 & 2.09 & $4.81^{\mathrm{b}}$ & 7.73 & & 68.91 \\
\hline 3-chloroprop-1-ene & -0.57 & -0.23 & -2.24 & 2.00 & & 5.74 & & 57.49 \\
\hline 3-chloropyridine & -4.01 & -2.73 & -4.78 & 2.05 & $6.44^{\mathrm{b}}$ & 6.32 & & 65.09 \\
\hline 3-cyanophenol & -9.65 & -7.80 & -9.91 & 2.11 & & 7.84 & & 65.28 \\
\hline 3-cyanopyridine & -6.75 & -5.31 & -7.39 & 2.08 & & 5.83 & & 50.05 \\
\hline
\end{tabular}


Table SI-7. (Continued)

\begin{tabular}{|c|c|c|c|c|c|c|c|c|}
\hline \multirow[b]{3}{*}{ Neutral compound } & & $\Delta G\left[\begin{array}{l}l \\
1\end{array}\right.$ & \multicolumn{2}{|l|}{$\left.\frac{\mathrm{kcal}}{\mathrm{mol}}\right]$} & $-T \Delta S^{*}$ & {$\left[\frac{\mathrm{kcal}}{\mathrm{mol}}\right]$} & $\Delta C_{p}[$ & $\left.\frac{\mathrm{cal}}{\mathrm{mol} \cdot \mathrm{K}}\right]$ \\
\hline & & & calc. & & expt. & calc. & expt. & calc. \\
\hline & & tot & es & $\mathrm{np}$ & & & & \\
\hline 3-ethylphenol & -6.25 & -5.62 & -7.77 & 2.15 & & 9.25 & & 100.77 \\
\hline 3-ethylpyridine & -4.59 & -3.24 & -5.37 & 2.12 & & 7.91 & & 96.39 \\
\hline 3-formylpyridine & -7.10 & -8.00 & -10.07 & 2.07 & & 5.51 & & 41.11 \\
\hline 3-hydroxybenzaldehyde & -9.50 & -9.81 & -11.91 & 2.10 & & 7.45 & & 58.29 \\
\hline 3-methoxyaniline & -7.29 & -7.95 & -10.08 & 2.12 & & 8.60 & & 82.70 \\
\hline 3-methoxyphenol & -7.66 & -7.87 & -9.99 & 2.12 & & 7.76 & & 66.59 \\
\hline 3-methyl-1h-indole & -5.88 & -6.17 & -8.32 & 2.16 & & 8.74 & & 93.83 \\
\hline 3-methyl-but-1-ene & 1.83 & 1.44 & -0.63 & 2.07 & & 7.75 & & 98.71 \\
\hline 3-methylbut-1-ene & 1.82 & 1.44 & -0.63 & 2.07 & & 7.75 & & 98.71 \\
\hline 3-methylbutan-1-ol & -4.42 & -5.19 & -7.28 & 2.09 & & 9.56 & & 102.82 \\
\hline 3-methylbutan-2-one & -3.24 & -3.73 & -5.82 & 2.09 & $7.49^{\mathrm{d}}$ & 7.50 & & 90.06 \\
\hline 3-methylbutanoic-acid & -6.09 & -8.28 & -10.38 & 2.09 & & 9.42 & & 96.87 \\
\hline 3-methylheptane & 2.97 & 2.17 & -0.07 & 2.23 & & 10.70 & & 152.93 \\
\hline 3-methylhexane & 2.71 & 2.12 & -0.05 & 2.17 & & 9.63 & & 133.76 \\
\hline 3-methylpentane & 2.51 & 2.08 & -0.05 & 2.13 & & 8.85 & & 119.79 \\
\hline 3-methylpyridine & -4.77 & -3.37 & -5.44 & 2.07 & $7.90^{\mathrm{d}}$ & 6.96 & $67.07^{\mathrm{b}}$ & 78.87 \\
\hline 3-nitroaniline & -8.84 & -7.34 & -9.45 & 2.11 & & 8.26 & & 70.24 \\
\hline 3-nitrophenol & -9.62 & -6.50 & -8.61 & 2.11 & $5.96^{\mathrm{b}}$ & 8.03 & $59.54^{\mathrm{b}}$ & 68.23 \\
\hline 3-nitrotoluene & -3.45 & -2.13 & -4.28 & 2.14 & & 7.64 & & 87.76 \\
\hline 3-phenylpropanol & -6.92 & -6.29 & -8.50 & 2.20 & & 9.32 & & 107.54 \\
\hline 3,3-dimethylbutan-2-one & -3.11 & -3.51 & -5.62 & 2.11 & $8.22^{\mathrm{d}}$ & 8.10 & & 101.59 \\
\hline 3,3-dimethylpentane & 2.56 & 2.10 & -0.04 & 2.15 & & 9.23 & & 126.64 \\
\hline 3,3,3-trimethoxypropionitrile & -6.40 & -7.81 & -10.00 & 2.19 & & 6.85 & & 63.73 \\
\hline 3,4-dimethylphenol & -6.50 & -5.54 & -7.68 & 2.14 & & 9.09 & & 98.38 \\
\hline 3,4-dimethylpyridine & -5.22 & -3.28 & -5.39 & 2.11 & $7.72^{\mathrm{d}}$ & 7.78 & & 94.52 \\
\hline
\end{tabular}


Table SI-7. (Continued)

\begin{tabular}{|c|c|c|c|c|c|c|c|c|}
\hline \multirow[b]{3}{*}{ Neutral compound } & \multicolumn{3}{|c|}{$\Delta G\left[\frac{\mathrm{kcal}}{\mathrm{mol}}\right]$} & \multicolumn{2}{|r|}{$-T \Delta S^{*}$} & {$\left[\frac{\mathrm{kcal}}{\mathrm{mol}}\right]$} & $\Delta C_{p}[$ & $\left.\frac{\mathrm{cal}}{\mathrm{mol} . \mathrm{K}}\right]$ \\
\hline & expt. $^{a}$ & & calc. & & expt. & calc. & expt. & calc. \\
\hline & & tot & es & np & & & & \\
\hline 3,5-dimethylphenol & -6.27 & -5.77 & -7.92 & 2.16 & & 9.36 & & 102.72 \\
\hline 3,5-dimethylpyridine & -4.84 & -3.17 & -5.30 & 2.13 & $9.02^{\mathrm{d}}$ & 8.19 & & 102.50 \\
\hline 4-acetylpyridine & -7.62 & -7.86 & -9.98 & 2.12 & & 6.43 & & 59.37 \\
\hline 4-bromophenol & -7.13 & -5.61 & -7.70 & 2.09 & $8.54^{\mathrm{b}}$ & 7.73 & & 67.53 \\
\hline 4-bromotoluene & -1.39 & -0.69 & -2.83 & 2.13 & & 7.83 & & 94.14 \\
\hline 4-chloro-3-methylphenol & -6.79 & -5.15 & -7.28 & 2.13 & & 8.56 & & 85.24 \\
\hline 4-chloroaniline & -5.90 & -5.90 & -7.99 & 2.09 & & 8.23 & & 74.92 \\
\hline 4-chlorophenol & -7.03 & -5.57 & -7.66 & 2.09 & & 7.59 & & 65.77 \\
\hline 4-cyanophenol & -10.17 & -8.10 & -10.21 & 2.11 & & 7.96 & & 67.05 \\
\hline 4-cyanopyridine & -6.02 & -5.38 & -7.46 & 2.07 & & 5.74 & & 47.91 \\
\hline 4-ethylphenol & -6.13 & -5.88 & -8.03 & 2.15 & & 9.15 & & 97.72 \\
\hline 4-ethylpyridine & -4.73 & -3.40 & -5.53 & 2.12 & & 7.80 & & 93.94 \\
\hline 4-ethyltoluene & -0.95 & -0.77 & -2.96 & 2.19 & & 9.24 & & 122.20 \\
\hline 4-fluorophenol & -6.19 & -5.63 & -7.69 & 2.07 & & 7.27 & & 60.27 \\
\hline 4-formylpyridine & -7.00 & -7.78 & -9.85 & 2.07 & & 5.34 & & 37.21 \\
\hline 4-hydroxybenzaldehyde & -8.83 & -10.83 & -12.93 & 2.10 & & 7.28 & & 52.05 \\
\hline 4-isopropyltoluene & -0.68 & -0.43 & -2.66 & 2.23 & & 9.87 & & 133.05 \\
\hline 4-methoxyacetophenone & -4.40 & -7.75 & -9.96 & 2.20 & & 7.75 & & 82.79 \\
\hline 4-methoxyaniline & -7.48 & -8.12 & -10.24 & 2.12 & & 8.33 & & 77.61 \\
\hline 4-methyl-1h-imidazole & -10.27 & -7.26 & -9.29 & 2.03 & & 6.78 & & 60.03 \\
\hline 4-methylacetophenone & -4.70 & -5.69 & -7.88 & 2.19 & & 8.39 & & 100.62 \\
\hline 4-methylbenzaldehyde & -4.27 & -5.71 & -7.85 & 2.14 & & 7.32 & & 78.89 \\
\hline 4-methylpentan-2-ol & -3.73 & -2.21 & -4.34 & 2.13 & & 9.11 & & 111.64 \\
\hline 4-methylpentan-2-one & -3.05 & -3.52 & -5.65 & 2.14 & $7.77^{\mathrm{d}}$ & 8.28 & $66.92^{\mathrm{b}}$ & 103.83 \\
\hline 4-methylpyridine & -4.93 & -3.54 & -5.61 & 2.07 & $7.78^{\mathrm{d}}$ & 6.87 & $66.13^{\mathrm{b}}$ & 76.83 \\
\hline
\end{tabular}


Table SI-7. (Continued)

\begin{tabular}{|c|c|c|c|c|c|c|c|c|}
\hline \multirow[b]{3}{*}{ Neutral compound } & \multicolumn{2}{|r|}{$\Delta G$} & \multicolumn{2}{|l|}{$\left.\frac{\mathrm{kcal}}{\mathrm{mol}}\right]$} & $-T \Delta S^{*}$ & {$\left[\frac{\mathrm{kcal}}{\mathrm{mol}}\right]$} & $\Delta C_{p}$ & $\left.\frac{\mathrm{cal}}{\mathrm{mol} . \mathrm{K}}\right]$ \\
\hline & expt. $^{a}$ & & calc. & & expt. & calc. & expt. & calc. \\
\hline & & tot & es & $\mathrm{np}$ & & & & \\
\hline 4-n-propylphenol & -5.90 & -5.79 & -8.00 & 2.21 & & 10.09 & & 114.69 \\
\hline 4-nitroaniline & -10.27 & -8.31 & -10.42 & 2.11 & & 8.44 & & 69.19 \\
\hline 4-nitrophenol & -10.64 & -6.98 & -9.09 & 2.11 & $5.16^{\mathrm{b}}$ & 8.04 & $55.74^{\mathrm{b}}$ & 66.70 \\
\hline 4-tert-butylphenol & -5.91 & -6.77 & -8.99 & 2.22 & & 10.77 & & 119.45 \\
\hline acenaphthene & -3.15 & -3.12 & -5.32 & 2.21 & $8.11^{\mathrm{b}}$ & 8.70 & $93.09^{\mathrm{b}}$ & 107.70 \\
\hline acetaldehyde & -3.50 & -4.31 & -6.25 & 1.93 & & 4.37 & $21.85^{\mathrm{b}}$ & 29.39 \\
\hline acetic-acid & -6.69 & -9.16 & -11.11 & 1.95 & $5.33^{\mathrm{d}}$ & 6.58 & $23.54^{\mathrm{b}}$ & 42.44 \\
\hline acetonitrile & -3.88 & -2.81 & -4.74 & 1.93 & & 4.24 & & 28.10 \\
\hline acetophenone & -4.58 & -5.83 & -7.96 & 2.13 & & 7.29 & & 79.66 \\
\hline alpha-methylstyrene & -1.24 & -1.70 & -3.86 & 2.16 & & 8.28 & & 102.59 \\
\hline aniline & -5.49 & -6.39 & -8.45 & 2.06 & & 7.73 & & 69.75 \\
\hline anisole & -2.45 & -3.12 & -5.23 & 2.10 & & 6.89 & & 74.51 \\
\hline anthracene & -3.95 & -4.47 & -6.73 & 2.26 & $9.45^{\mathrm{b}}$ & 8.78 & $47.97^{\mathrm{b}}$ & 103.96 \\
\hline azetidine & -5.56 & -3.51 & -5.48 & 1.98 & & 6.21 & & 61.72 \\
\hline benzaldehyde & -4.02 & -5.81 & -7.89 & 2.08 & & 6.19 & & 57.56 \\
\hline benzamide & -11.00 & -10.70 & -12.80 & 2.10 & & 7.53 & & 67.36 \\
\hline benzene & -0.86 & -1.21 & -3.25 & 2.03 & $6.12^{\mathrm{c}}$ & 6.29 & $69.31^{\mathrm{c}}$ & 67.58 \\
\hline benzonitrile & -4.21 & -3.31 & -5.40 & 2.09 & & 6.60 & & 68.43 \\
\hline benzotrifluoride & -0.25 & -1.79 & -3.92 & 2.12 & & 7.10 & & 77.01 \\
\hline benzyl-alcohol & -6.62 & -5.87 & -7.97 & 2.10 & & 7.83 & & 79.40 \\
\hline benzyl-bromide & -2.38 & -2.01 & -4.14 & 2.13 & & 7.25 & & 80.57 \\
\hline benzyl-chloride & -1.93 & -2.19 & -4.31 & 2.12 & & 7.09 & & 77.70 \\
\hline biphenyl & -2.66 & -2.93 & -5.18 & 2.24 & & 9.35 & & 119.28 \\
\hline 1-chloro-2-(2-chloroethoxy)ethane & -4.23 & -4.28 & -6.41 & 2.14 & & 6.48 & & 61.11 \\
\hline bromobenzene & -1.46 & -0.86 & -2.94 & 2.08 & & 6.74 & & 73.55 \\
\hline
\end{tabular}


Table SI-7. (Continued)

\begin{tabular}{|c|c|c|c|c|c|c|c|c|}
\hline \multirow[b]{3}{*}{ Neutral compound } & \multicolumn{3}{|c|}{$\Delta G\left[\frac{\mathrm{kcal}}{\mathrm{mol}}\right]$} & \multicolumn{2}{|r|}{$-T \Delta S^{*}$} & {$\left[\frac{\mathrm{kcal}}{\mathrm{mol}}\right]$} & $\Delta C_{p}$ & {$\left[\frac{\mathrm{cal}}{\mathrm{mol} . \mathrm{K}}\right]$} \\
\hline & expt. $^{\mathrm{a}}$ & & calc. & & expt. & calc. & expt. & calc. \\
\hline & & tot & es & np & & & & \\
\hline bromoethane & -0.74 & 0.43 & -1.55 & 1.98 & & 5.77 & & 60.91 \\
\hline bromomethane & -0.82 & 0.45 & -1.46 & 1.92 & $4.68^{\mathrm{b}}$ & 4.59 & $47.99^{\mathrm{b}}$ & 39.06 \\
\hline bromotrifluoromethane & 1.79 & 1.28 & -0.69 & 1.97 & & 5.70 & & 60.18 \\
\hline but-1-ene & 1.38 & 1.34 & -0.68 & 2.02 & $6.73^{\mathrm{c}}$ & 6.90 & & 83.34 \\
\hline but-1-yne & -0.16 & 0.65 & -1.36 & 2.01 & $3.06^{\mathrm{c}}$ & 6.46 & $-29.47^{\mathrm{b}}$ & 73.97 \\
\hline buta-1,3-diene & 0.61 & 0.44 & -1.56 & 2.00 & $6.46^{\mathrm{c}}$ & 6.17 & $138.79^{\mathrm{b}}$ & 68.37 \\
\hline butan-1-ol & -4.72 & -3.92 & -5.98 & 2.06 & $9.43^{\mathrm{c}}$ & 7.97 & $80.07^{\mathrm{c}}$ & 86.99 \\
\hline butan-2-ol & -4.62 & -3.22 & -5.27 & 2.05 & $9.79^{\mathrm{c}}$ & 7.76 & $81.26^{\mathrm{c}}$ & 84.47 \\
\hline butanenitrile & -3.64 & -2.31 & -4.36 & 2.05 & & 6.66 & & 74.64 \\
\hline butanoic-acid & -6.35 & -8.52 & -10.58 & 2.06 & $7.27^{\mathrm{d}}$ & 8.95 & $52.87^{\mathrm{b}}$ & 86.25 \\
\hline butanone & -3.71 & -3.99 & -6.03 & 2.04 & $6.61^{\mathrm{b}}$ & 6.36 & $55.86^{\mathrm{b}}$ & 65.99 \\
\hline butyraldehyde & -3.18 & -3.99 & -6.03 & 2.04 & & 6.36 & & 65.99 \\
\hline chlorobenzene & -1.12 & -0.78 & -2.85 & 2.07 & & 6.64 & & 72.08 \\
\hline chlorodifluoromethane & -0.50 & -0.81 & -2.75 & 1.94 & $6.93^{\mathrm{b}}$ & 5.29 & $83.60^{\mathrm{b}}$ & 40.36 \\
\hline chloroethane & -0.63 & 0.22 & -1.75 & 1.97 & & 5.58 & & 57.43 \\
\hline chloroethylene & -0.59 & 0.40 & -1.54 & 1.95 & $5.15^{\mathrm{b}}$ & 5.02 & $30.90^{\mathrm{b}}$ & 46.02 \\
\hline chlorofluoromethane & -0.77 & -0.90 & -2.82 & 1.92 & $3.82^{\mathrm{b}}$ & 4.02 & $36.85^{\mathrm{b}}$ & 21.47 \\
\hline chloromethane & -0.55 & 0.22 & -1.69 & 1.91 & $4.38^{\mathrm{b}}$ & 4.36 & $44.05^{\mathrm{b}}$ & 34.58 \\
\hline cis-1,2-dimethylcyclohexane & 1.58 & 2.10 & -0.05 & 2.16 & & 9.40 & & 129.68 \\
\hline cyanobenzene & -4.10 & -3.31 & -5.40 & 2.09 & & 6.60 & & 68.43 \\
\hline cyclohepta-1,3,5-triene & -0.99 & -0.98 & -3.06 & 2.08 & $6.18^{\mathrm{c}}$ & 7.20 & & 84.68 \\
\hline cycloheptanol & -5.48 & -3.67 & -5.80 & 2.13 & $11.77^{\mathrm{c}}$ & 8.95 & $105.16^{\mathrm{c}}$ & 105.63 \\
\hline cyclohexane & 1.23 & 2.04 & -0.05 & 2.09 & $8.54^{\mathrm{c}}$ & 8.17 & $97.99^{\mathrm{c}}$ & 107.40 \\
\hline cyclohexanol & -5.46 & -4.21 & -6.31 & 2.10 & $10.84^{\mathrm{c}}$ & 9.16 & $81.26^{\mathrm{c}}$ & 103.70 \\
\hline cyclohexanone & -4.91 & -3.86 & -5.95 & 2.09 & & 7.70 & & 94.40 \\
\hline
\end{tabular}


Table SI-7. (Continued)

\begin{tabular}{|c|c|c|c|c|c|c|c|c|}
\hline \multirow[b]{3}{*}{ Neutral compound } & \multicolumn{3}{|c|}{$\Delta G\left[\frac{\mathrm{kcal}}{\mathrm{mol}}\right]$} & \multicolumn{2}{|r|}{$-T \Delta S^{*}$} & {$\left[\frac{\mathrm{kcal}}{\mathrm{mol}}\right]$} & $\Delta C_{p}$ & $\left.\frac{\mathrm{cal}}{\mathrm{mol} . \mathrm{K}}\right]$ \\
\hline & expt. $^{a}$ & & calc. & & expt. & calc. & expt. & calc. \\
\hline & & tot & es & np & & & & \\
\hline cyclohexene & 0.37 & 1.25 & -0.82 & 2.07 & $7.42^{\mathrm{c}}$ & 7.73 & & 98.15 \\
\hline cyclohexylamine & -4.59 & -2.30 & -4.40 & 2.10 & & 8.86 & $82.86^{\mathrm{b}}$ & 104.25 \\
\hline cyclopentane & 1.20 & 1.97 & -0.08 & 2.05 & $7.05^{\mathrm{c}}$ & 7.49 & & 95.21 \\
\hline cyclopentanol & -5.49 & -4.05 & -6.11 & 2.06 & $10.11^{\mathrm{c}}$ & 8.49 & $88.43^{c}$ & 91.14 \\
\hline cyclopentanone & -4.70 & -3.77 & -5.82 & 2.05 & & 6.99 & & 81.33 \\
\hline cyclopentene & 0.56 & 1.09 & -0.94 & 2.03 & $6.10^{\mathrm{c}}$ & 6.94 & & 83.59 \\
\hline cyclopropane & 0.75 & 1.73 & -0.23 & 1.96 & $5.72^{\mathrm{c}}$ & 5.93 & $74.09^{\mathrm{c}}$ & 66.73 \\
\hline decan-1-ol & -3.64 & -4.06 & -6.44 & 2.38 & & 14.02 & & 190.91 \\
\hline decan-2-one & -2.34 & -3.41 & -5.78 & 2.37 & & 12.25 & & 174.83 \\
\hline di-isopropyl-sulfide & -1.21 & -0.78 & -2.95 & 2.17 & & 9.15 & & 122.36 \\
\hline di-n-butyl-ether & -0.83 & -0.37 & -2.66 & 2.30 & & 11.60 & & 167.37 \\
\hline di-n-butylamine & -3.24 & -1.81 & -4.11 & 2.30 & $14.30^{\mathrm{d}}$ & 11.88 & $94.79^{\mathrm{b}}$ & 166.18 \\
\hline di-n-propyl-ether & -1.16 & -0.49 & -2.69 & 2.19 & & 9.73 & & 133.66 \\
\hline di-n-propyl-sulfide & -1.28 & -0.36 & -2.57 & 2.21 & $9.51^{\mathrm{e}}$ & 9.77 & $116.40^{\mathrm{e}}$ & 132.95 \\
\hline di-n-propylamine & -3.65 & -1.89 & -4.08 & 2.19 & $13.01^{\mathrm{d}}$ & 10.05 & $95.43^{\mathrm{b}}$ & 133.25 \\
\hline dibromomethane & -1.96 & 0.45 & -1.51 & 1.96 & & 5.15 & & 46.51 \\
\hline dichloromethane & -1.31 & -0.10 & -2.04 & 1.94 & & 4.56 & & 34.07 \\
\hline diethoxymethoxybenzene & -5.23 & -5.11 & -7.49 & 2.38 & & 11.56 & & 157.16 \\
\hline diethyl-disulfide & -1.64 & -0.97 & -3.13 & 2.15 & $7.55^{\mathrm{e}}$ & 8.49 & $86.76^{\mathrm{e}}$ & 108.03 \\
\hline diethyl-ether & -1.59 & -0.92 & -3.00 & 2.08 & & 7.62 & & 94.40 \\
\hline diethyl-malonate & -6.00 & -9.66 & -11.95 & 2.29 & & 9.57 & & 115.25 \\
\hline diethyl-succinate & -5.71 & -8.76 & -11.10 & 2.34 & & 10.74 & & 139.50 \\
\hline diethyl-sulfide & -1.46 & -0.59 & -2.69 & 2.10 & $7.55^{\mathrm{e}}$ & 7.84 & $76.48^{\mathrm{e}}$ & 98.11 \\
\hline diethylamine & -4.07 & -2.15 & -4.24 & 2.08 & $10.87^{\mathrm{d}}$ & 8.13 & $88.65^{\mathrm{b}}$ & 98.05 \\
\hline diiodomethane & -2.49 & -1.10 & -3.09 & 1.99 & & 5.17 & & 38.96 \\
\hline
\end{tabular}


Table SI-7. (Continued)

\begin{tabular}{|c|c|c|c|c|c|c|c|c|}
\hline \multirow[b]{3}{*}{ Neutral compound } & \multicolumn{3}{|c|}{$\Delta G\left[\frac{\mathrm{kcal}}{\mathrm{mol}}\right]$} & \multicolumn{2}{|r|}{$-T \Delta S^{*}$} & {$\left[\frac{\mathrm{kcal}}{\mathrm{mol}}\right]$} & $\Delta C_{p}$ & $\left.\frac{\mathrm{cal}}{\mathrm{mol} . \mathrm{K}}\right]$ \\
\hline & expt. $^{a}$ & & calc. & & expt. & calc. & expt. & calc. \\
\hline & & tot & es & np & & & & \\
\hline diisopropyl-ether & -0.53 & -0.23 & -2.39 & 2.16 & & 9.10 & & 122.27 \\
\hline diisopropylamine & -3.22 & -1.62 & -3.78 & 2.16 & & 9.32 & & 120.63 \\
\hline dimethoxymethane & -2.93 & -2.75 & -4.77 & 2.02 & & 6.04 & $43.00^{\mathrm{b}}$ & 62.59 \\
\hline dimethyl-disulfide & -1.83 & 0.98 & -1.05 & 2.03 & $5.86^{\mathrm{e}}$ & 6.79 & $68.36^{\mathrm{e}}$ & 80.28 \\
\hline dimethyl-ether & -1.91 & -1.59 & -3.54 & 1.95 & & 5.21 & & 50.09 \\
\hline dimethyl-sulfate & -5.10 & -8.96 & -11.04 & 2.08 & & 5.62 & & 41.70 \\
\hline dimethyl-sulfide & -1.61 & -0.44 & -2.42 & 1.98 & $5.31^{\mathrm{e}}$ & 5.61 & $54.49^{\mathrm{e}}$ & 57.48 \\
\hline dimethyl-sulfone & -10.08 & -10.88 & -12.89 & 2.01 & & 4.24 & & 15.25 \\
\hline dimethyl-sulfoxide & -8.71 & -8.40 & -10.39 & 1.99 & $7.88^{\mathrm{d}}$ & 4.86 & $23.11^{\mathrm{b}}$ & 34.78 \\
\hline dimethylamine & -4.29 & -3.59 & -5.55 & 1.95 & & 6.18 & $46.32^{\mathrm{b}}$ & 57.41 \\
\hline E-1,2-dichloroethene & -0.78 & 0.66 & -1.32 & 1.99 & & 5.70 & & 57.12 \\
\hline E-but-2-enal & -4.22 & -5.05 & -7.08 & 2.03 & & 6.00 & & 59.05 \\
\hline E-hept-2-ene & 1.68 & 1.48 & -0.71 & 2.20 & & 9.90 & & 137.50 \\
\hline E-hex-2-enal & -3.68 & -4.53 & -6.67 & 2.14 & & 8.06 & & 97.12 \\
\hline E-oct-2-enal & -3.43 & -4.30 & -6.55 & 2.25 & & 9.93 & & 130.79 \\
\hline ethanamide & -9.71 & -9.80 & -11.76 & 1.96 & $6.56^{\mathrm{f}}$ & 5.98 & $22.61^{\mathrm{b}}$ & 42.67 \\
\hline ethane & 1.83 & 1.91 & -0.02 & 1.94 & $5.87^{\mathrm{c}}$ & 5.58 & $66.92^{\mathrm{c}}$ & 60.91 \\
\hline ethanethiol & -1.14 & -1.56 & -3.53 & 1.97 & $5.16^{\mathrm{e}}$ & 6.00 & & 59.05 \\
\hline ethanol & -5.00 & -4.74 & -6.69 & 1.95 & $6.97^{\mathrm{c}}$ & 6.47 & $47.56^{\mathrm{c}}$ & 53.16 \\
\hline ethene & 1.28 & 1.20 & -0.70 & 1.91 & $4.62^{\mathrm{c}}$ & 4.82 & $57.36^{\mathrm{c}}$ & 45.76 \\
\hline ethyl-acetate & -2.94 & -4.22 & -6.30 & 2.09 & $7.36^{\mathrm{b}}$ & 7.24 & $67.64^{\mathrm{b}}$ & 83.70 \\
\hline ethyl-benzoate & -3.64 & -5.39 & -7.62 & 2.23 & & 9.13 & & 114.40 \\
\hline ethyl-butanoate & -2.49 & -3.86 & -6.05 & 2.19 & & 9.31 & & 122.35 \\
\hline ethyl-formate & -2.56 & -4.00 & -6.02 & 2.02 & & 6.02 & & 57.89 \\
\hline ethyl-hexanoate & -2.23 & -3.80 & -6.10 & 2.30 & & 11.20 & & 156.52 \\
\hline
\end{tabular}


Table SI-7. (Continued)

\begin{tabular}{|c|c|c|c|c|c|c|c|c|}
\hline \multirow[b]{3}{*}{ Neutral compound } & & $\Delta G[$ & $\left.\frac{\mathrm{kcal}}{\mathrm{mol}}\right]$ & & \multirow{3}{*}{$\frac{-T \Delta S^{*}}{\text { expt. }}$} & \multirow{3}{*}{$\frac{\left[\frac{\mathrm{kcal}}{\mathrm{mol}}\right]}{\text { calc. }}$} & \multirow{3}{*}{$\frac{\Delta C_{p}\left[\frac{1}{\mathrm{r}}\right.}{\text { expt. }}$} & \multirow{3}{*}{$\begin{array}{r}\left.\frac{\mathrm{cal}}{\mathrm{mol} . \mathrm{K}}\right] \\
\text { calc. }\end{array}$} \\
\hline & & \multicolumn{3}{|c|}{ calc. } & & & & \\
\hline & & tot & es & $\mathrm{np}$ & & & & \\
\hline ethyl-pentanoate & -2.49 & -3.94 & -6.19 & 2.25 & & 10.24 & & 139.08 \\
\hline ethyl-phenyl-ether & -2.22 & -2.73 & -4.90 & 2.17 & & 8.28 & & 100.95 \\
\hline ethyl-propanoate & -2.68 & -4.17 & -6.31 & 2.14 & & 8.34 & & 104.45 \\
\hline ethylamine & -4.50 & -3.86 & -5.81 & 1.95 & $7.81^{\mathrm{d}}$ & 6.27 & & 57.65 \\
\hline ethylbenzene & -0.79 & -0.95 & -3.09 & 2.14 & $8.22^{\mathrm{c}}$ & 8.22 & $88.43^{\mathrm{c}}$ & 103.21 \\
\hline fluorene & -3.35 & -3.83 & -6.06 & 2.24 & $8.75^{\mathrm{b}}$ & 8.85 & $256.00^{\mathrm{b}}$ & 107.58 \\
\hline fluorobenzene & -0.80 & -0.81 & -2.86 & 2.05 & & 6.33 & & 66.81 \\
\hline fluoromethane & -0.22 & -0.26 & -2.14 & 1.88 & $3.51^{\mathrm{b}}$ & 3.89 & $36.33^{\mathrm{b}}$ & 25.94 \\
\hline formaldehyde & -2.75 & -4.25 & -6.11 & 1.86 & & 3.19 & & 5.16 \\
\hline halothane & -0.11 & 0.22 & -1.82 & 2.05 & & 6.64 & & 71.22 \\
\hline hept-1-ene & 1.66 & 1.49 & -0.70 & 2.19 & & 9.73 & & 134.24 \\
\hline hept-1-yne & 0.60 & 0.86 & -1.31 & 2.17 & & 9.27 & & 124.73 \\
\hline heptan-1-ol & -4.21 & -3.65 & -5.87 & 2.22 & $12.33^{\mathrm{c}}$ & 10.59 & $124.28^{\mathrm{c}}$ & 135.63 \\
\hline heptan-2-one & -3.04 & -3.64 & -5.84 & 2.21 & $9.96^{\mathrm{d}}$ & 9.47 & $64.01^{\mathrm{b}}$ & 124.63 \\
\hline heptan-4-one & -2.92 & -3.21 & -5.42 & 2.21 & $10.88^{\mathrm{d}}$ & 9.59 & $58.05^{\mathrm{b}}$ & 127.61 \\
\hline heptanal & -2.67 & -3.64 & -5.84 & 2.20 & & 9.10 & & 115.19 \\
\hline hex-1-ene & 1.58 & 1.44 & -0.69 & 2.13 & $8.68^{c}$ & 8.79 & & 117.33 \\
\hline hex-1-yne & 0.29 & 0.79 & -1.33 & 2.12 & & 8.34 & & 107.99 \\
\hline hexa-1,5-diene & 1.01 & 0.80 & -1.31 & 2.11 & & 8.13 & & 104.36 \\
\hline hexafluoropropene & -3.76 & 0.54 & -1.51 & 2.05 & & 6.60 & $13.72^{\mathrm{b}}$ & 71.86 \\
\hline hexan-1-ol & -4.40 & -3.62 & -5.79 & 2.16 & $11.28^{\mathrm{c}}$ & 9.72 & $109.94^{\mathrm{c}}$ & 120.38 \\
\hline hexan-2-one & -3.28 & -3.71 & -5.87 & 2.15 & $8.50^{\mathrm{d}}$ & 8.55 & & 108.04 \\
\hline hexan-3-ol & -4.06 & -2.76 & -4.91 & 2.15 & $11.97^{\mathrm{c}}$ & 9.60 & $112.33^{\mathrm{c}}$ & 118.70 \\
\hline hexanal & -2.81 & -3.83 & -5.98 & 2.15 & & 8.22 & & 99.39 \\
\hline hexanoic-acid & -6.21 & -8.17 & -10.34 & 2.17 & & 10.61 & & 119.28 \\
\hline
\end{tabular}


Table SI-7. (Continued)

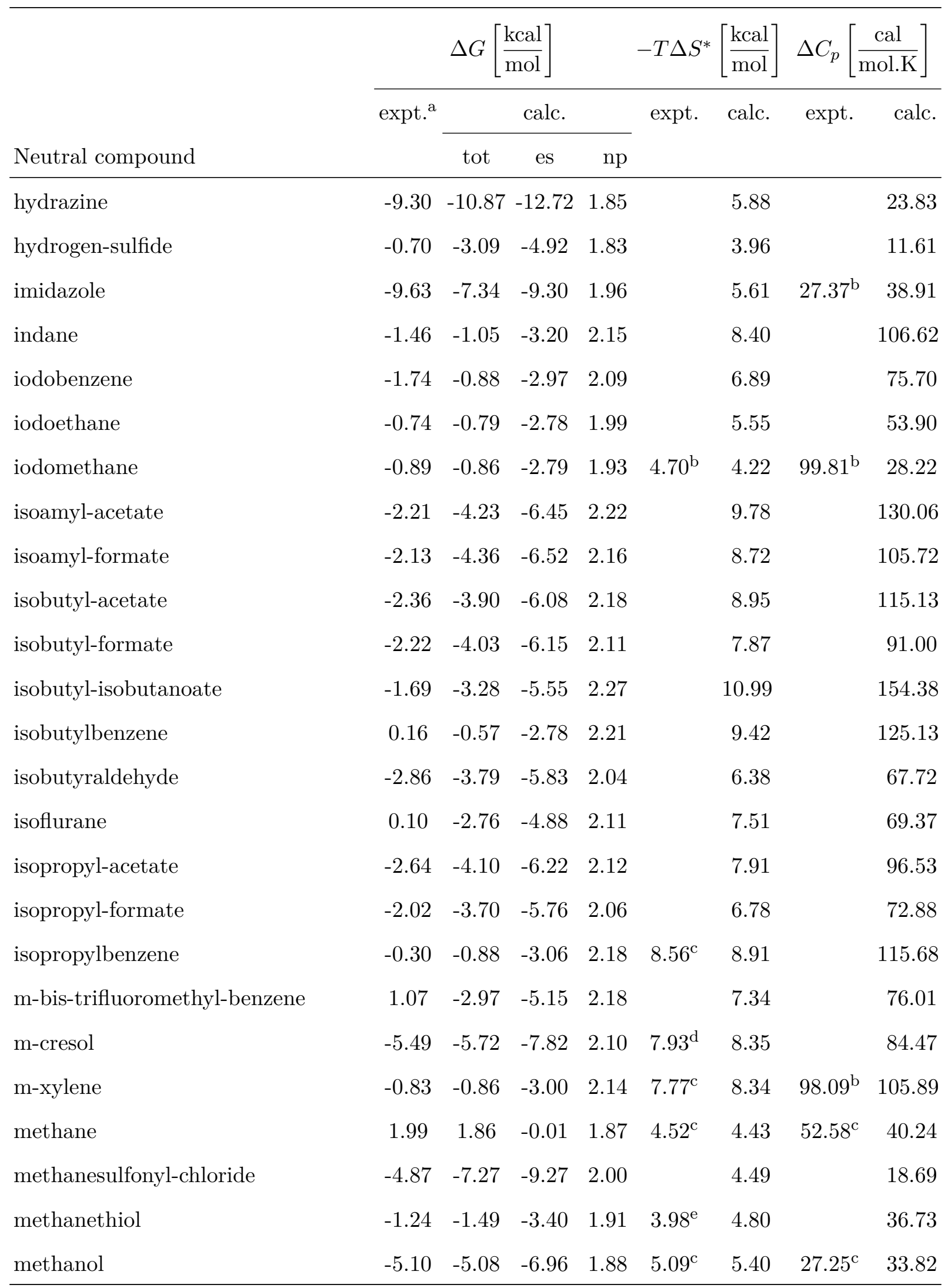


Table SI-7. (Continued)

\begin{tabular}{|c|c|c|c|c|c|c|c|c|}
\hline \multirow[b]{3}{*}{ Neutral compound } & & $\Delta G$ & \multicolumn{2}{|l|}{$\left.\frac{\mathrm{kcal}}{\mathrm{mol}}\right]$} & \multirow[t]{3}{*}{$-T \Delta S^{*}$} & \multirow{3}{*}{$\frac{\left[\frac{\mathrm{kcal}}{\mathrm{mol}}\right]}{\text { calc. }}$} & \multirow{3}{*}{$\frac{\Delta C_{p}[}{\text { expt. }}$} & $\left.\frac{\mathrm{cal}}{\mathrm{mol} \cdot \mathrm{K}}\right]$ \\
\hline & & & calc. & & & & & calc. \\
\hline & & tot & es & $\mathrm{np}$ & & & & \\
\hline methoxyflurane & -1.12 & -1.18 & -3.27 & 2.10 & & 7.03 & & 75.62 \\
\hline methyl-acetate & -3.13 & -5.04 & -7.06 & 2.02 & $6.43^{\mathrm{b}}$ & 5.77 & $49.02^{\mathrm{b}}$ & 55.04 \\
\hline methyl-benzoate & -3.92 & -5.80 & -7.96 & 2.16 & & 7.83 & & 89.49 \\
\hline methyl-butanoate & -2.83 & -4.18 & -6.31 & 2.13 & & 7.94 & & 96.34 \\
\hline methyl-chloroacetate & -4.00 & -4.78 & -6.83 & 2.05 & & 5.58 & & 46.08 \\
\hline methyl-cyanoacetate & -6.72 & -7.24 & -9.31 & 2.07 & & 5.13 & & 31.27 \\
\hline methyl-cyclohexanecarboxylate & -3.30 & -3.58 & -5.78 & 2.20 & & 9.30 & & 121.69 \\
\hline methyl-cyclohexyl-ketone & -3.90 & -3.53 & -5.71 & 2.18 & & 9.11 & & 119.18 \\
\hline methyl-cyclopropanecarboxylate & -4.10 & -4.71 & -6.81 & 2.10 & & 7.38 & & 85.74 \\
\hline methyl-cyclopropyl-ketone & -4.61 & -3.51 & -5.59 & 2.07 & & 7.18 & & 83.93 \\
\hline methyl-ethyl-ether & -2.10 & -1.25 & -3.27 & 2.01 & & 6.41 & & 72.24 \\
\hline methyl-ethyl-sulfide & -1.50 & -0.54 & -2.58 & 2.04 & & 6.73 & & 77.82 \\
\hline methyl-formate & -2.78 & -4.17 & -6.12 & 1.95 & & 4.67 & & 31.83 \\
\hline methyl-hexanoate & -2.49 & -4.16 & -6.39 & 2.23 & & 9.82 & & 130.20 \\
\hline methyl-isopropyl-ether & -2.01 & -1.08 & -3.13 & 2.05 & & 7.15 & & 85.99 \\
\hline methyl-methanesulfonate & -4.87 & -9.13 & -11.18 & 2.05 & & 5.34 & & 37.68 \\
\hline methyl-octanoate & -2.04 & -3.91 & -6.25 & 2.34 & & 11.65 & & 163.05 \\
\hline methyl-p-methoxybenzoate & -5.33 & -7.35 & -9.59 & 2.23 & & 8.42 & & 96.07 \\
\hline methyl-p-nitrobenzoate & -6.88 & -5.80 & -8.02 & 2.22 & & 8.12 & & 88.63 \\
\hline methyl-pentanoate & -2.56 & -4.27 & -6.45 & 2.18 & & 8.85 & & 112.54 \\
\hline methyl-propanoate & -2.93 & -4.54 & -6.61 & 2.07 & & 6.96 & & 78.21 \\
\hline methyl-propyl-ether & -1.66 & -1.23 & -3.30 & 2.07 & & 7.43 & & 90.79 \\
\hline methyl-t-butyl-ether & -2.21 & -0.87 & -2.96 & 2.09 & & 7.78 & & 97.60 \\
\hline methyl-tert-butyl-ether & -2.21 & -0.88 & -2.96 & 2.09 & & 7.78 & & 97.60 \\
\hline methyl-trifluoroacetate & -1.10 & -2.80 & -4.86 & 2.06 & & 5.95 & & 53.65 \\
\hline
\end{tabular}


Table SI-7. (Continued)

\begin{tabular}{|c|c|c|c|c|c|c|c|c|}
\hline \multirow[b]{3}{*}{ Neutral compound } & & $\Delta G$ & \multicolumn{2}{|l|}{$\left.\frac{\mathrm{kcal}}{\mathrm{mol}}\right]$} & \multirow{3}{*}{$\begin{array}{c}-T \Delta S^{*} \\
\text { expt. }\end{array}$} & \multirow{3}{*}{$\frac{\left[\frac{\mathrm{kcal}}{\mathrm{mol}}\right]}{\text { calc. }}$} & \multirow{3}{*}{$\frac{\Delta C_{p}\left[\frac{}{\mathrm{n}}\right.}{\text { expt. }}$} & $\left.\frac{\mathrm{cal}}{\mathrm{mol} \cdot \mathrm{K}}\right]$ \\
\hline & & & calc. & & & & & calc. \\
\hline & & tot & es & $\mathrm{np}$ & & & & \\
\hline methyl-trimethylacetate & -2.40 & -3.69 & -5.84 & 2.15 & & 8.60 & & 109.74 \\
\hline methylamine & -4.55 & -4.50 & -6.39 & 1.89 & & 5.26 & $25.07^{\mathrm{b}}$ & 36.60 \\
\hline methylcyclohexane & 1.70 & 2.07 & -0.06 & 2.13 & $12.02^{\mathrm{c}}$ & 8.91 & & 120.86 \\
\hline methylcyclopentane & 1.59 & 2.01 & -0.08 & 2.09 & & 8.28 & & 109.47 \\
\hline morpholine & -7.17 & -5.16 & -7.19 & 2.03 & $8.83^{\mathrm{b}}$ & 6.84 & $33.17^{\mathrm{b}}$ & 68.65 \\
\hline N-acetylpyrrolidine & -9.80 & -7.17 & -9.30 & 2.13 & & 7.96 & & 95.59 \\
\hline n-butane & 2.07 & 2.00 & -0.04 & 2.04 & $7.66^{\mathrm{c}}$ & 7.45 & $92.02^{\mathrm{c}}$ & 94.53 \\
\hline n-butanethiol & -0.99 & -1.37 & -3.44 & 2.08 & $7.08^{\mathrm{e}}$ & 7.75 & & 90.66 \\
\hline n-butyl-acetate & -2.64 & -4.34 & -6.53 & 2.19 & & 9.18 & & 118.71 \\
\hline n-butylacetamide & -9.31 & -9.17 & -11.34 & 2.17 & $11.53^{\mathrm{d}}$ & 9.94 & $85.44^{\mathrm{b}}$ & 115.39 \\
\hline n-butylamine & -4.24 & -3.89 & -5.95 & 2.06 & $9.27^{\mathrm{d}}$ & 8.20 & $72.54^{\mathrm{b}}$ & 92.02 \\
\hline n-butylbenzene & -0.40 & -0.85 & -3.09 & 2.24 & $10.02^{\mathrm{c}}$ & 10.06 & & 136.32 \\
\hline n-decane & 3.16 & 2.28 & -0.09 & 2.37 & & 13.05 & & 195.36 \\
\hline n-heptane & 2.67 & 2.14 & -0.06 & 2.21 & $10.46^{\mathrm{c}}$ & 10.25 & & 145.00 \\
\hline n-heptylamine & -3.79 & -3.58 & -5.81 & 2.22 & & 11.03 & & 142.49 \\
\hline n-hexane & 2.48 & 2.10 & -0.06 & 2.15 & $9.43^{\mathrm{c}}$ & 9.30 & $117.11^{\mathrm{c}}$ & 127.90 \\
\hline n-hexyl-acetate & -2.26 & -4.16 & -6.46 & 2.30 & & 11.02 & & 151.85 \\
\hline n-hexylamine & -3.95 & -3.45 & -5.62 & 2.17 & $11.14^{\mathrm{d}}$ & 10.05 & $104.95^{\mathrm{b}}$ & 126.50 \\
\hline n-hexylbenzene & -0.04 & -0.76 & -3.11 & 2.35 & $11.88^{\mathrm{c}}$ & 11.92 & & 169.80 \\
\hline N-methyl-N-2,2,2-trifluoroethyl-anilin & ne1.92 & -5.47 & -7.69 & 2.23 & & 7.48 & & 73.52 \\
\hline N-methylacetamide & -10.00 & -8.58 & -10.60 & 2.02 & $6.92^{\mathrm{f}}$ & 6.59 & $40.03^{\mathrm{b}}$ & 59.97 \\
\hline N-methylaniline & -4.69 & -5.60 & -7.71 & 2.11 & & 8.13 & & 84.43 \\
\hline N-methylmorpholine & -6.32 & -4.17 & -6.25 & 2.08 & $9.49^{\mathrm{b}}$ & 7.05 & $47.83^{\mathrm{b}}$ & 79.86 \\
\hline N-methylpiperazine & -7.77 & -5.48 & -7.57 & 2.09 & & 7.93 & $52.96^{\mathrm{b}}$ & 88.41 \\
\hline N-methylpiperidine & -3.88 & -1.64 & -3.74 & 2.10 & $11.24^{\mathrm{b}}$ & 8.11 & $96.65^{\mathrm{b}}$ & 103.73 \\
\hline
\end{tabular}


Table SI-7. (Continued)

\begin{tabular}{|c|c|c|c|c|c|c|c|c|}
\hline \multirow[b]{3}{*}{ Neutral compound } & & $\Delta G[$ & $\left.\frac{\mathrm{kcal}}{\mathrm{mol}}\right]$ & & \multirow{3}{*}{$\begin{array}{c}-T \Delta S^{*} \\
\text { expt. }\end{array}$} & \multirow{3}{*}{$\frac{\left[\frac{\mathrm{kcal}}{\mathrm{mol}}\right]}{\text { calc. }}$} & \multirow{3}{*}{$\frac{\Delta C_{p}\left[\frac{1}{\mathrm{r}}\right.}{\operatorname{expt}}$} & \multirow{3}{*}{$\begin{array}{r}\left.\frac{\mathrm{cal}}{\mathrm{mol} . \mathrm{K}}\right] \\
\text { calc. }\end{array}$} \\
\hline & & \multicolumn{3}{|c|}{ calc. } & & & & \\
\hline & & tot & es & np & & & & \\
\hline n-nonane & 3.13 & 2.23 & -0.08 & 2.31 & & 12.11 & & 178.35 \\
\hline n-octane & 2.88 & 2.19 & -0.07 & 2.26 & $11.46^{\mathrm{c}}$ & 11.18 & & 161.65 \\
\hline n-octylamine & -3.65 & -3.76 & -6.04 & 2.28 & & 11.93 & & 159.07 \\
\hline n-pentane & 2.32 & 2.05 & -0.05 & 2.10 & $8.60^{\mathrm{c}}$ & 8.38 & $105.16^{\mathrm{c}}$ & 111.19 \\
\hline n-pentyl-acetate & -2.51 & -4.33 & -6.58 & 2.25 & & 10.10 & & 135.23 \\
\hline n-pentyl-propanoate & -2.11 & -3.95 & -6.25 & 2.30 & & 11.27 & & 157.88 \\
\hline n-pentylamine & -4.09 & -3.99 & -6.10 & 2.12 & $10.16^{\mathrm{d}}$ & 9.16 & $89.44^{\mathrm{b}}$ & 109.34 \\
\hline n-pentylbenzene & -0.23 & -0.80 & -3.10 & 2.30 & $10.83^{\mathrm{c}}$ & 11.02 & & 153.48 \\
\hline n-pentylcyclopentane & 2.55 & 2.19 & -0.11 & 2.30 & & 11.83 & & 173.26 \\
\hline n-propanethiol & -1.06 & -1.47 & -3.49 & 2.03 & $5.56^{\mathrm{e}}$ & 6.88 & $78.87^{\mathrm{c}}$ & 73.08 \\
\hline n-propyl-acetate & -2.79 & -4.25 & -6.39 & 2.14 & & 8.27 & & 102.62 \\
\hline n-propyl-butyrate & -2.28 & -3.68 & -5.93 & 2.25 & & 10.38 & & 142.24 \\
\hline n-propyl-formate & -2.48 & -4.31 & -6.39 & 2.07 & & 7.13 & & 77.27 \\
\hline n-propyl-propanoate & -2.44 & -4.00 & -6.20 & 2.20 & & 9.41 & & 124.39 \\
\hline n-propylamine & -4.39 & -3.74 & -5.75 & 2.01 & $8.33^{\mathrm{d}}$ & 7.31 & $55.26^{\mathrm{b}}$ & 75.95 \\
\hline n-propylbenzene & -0.53 & -0.86 & -3.05 & 2.19 & $9.36^{\mathrm{c}}$ & 9.16 & $107.55^{\mathrm{c}}$ & 120.26 \\
\hline n-propylcyclopentane & 2.13 & 2.10 & -0.09 & 2.19 & & 9.98 & & 139.96 \\
\hline naphthalene & -2.40 & -3.05 & -5.20 & 2.15 & $8.20^{\mathrm{b}}$ & 7.52 & $82.10^{\mathrm{b}}$ & 85.35 \\
\hline nitrobenzene & -4.12 & -2.38 & -4.47 & 2.09 & & 6.44 & & 64.44 \\
\hline nitroethane & -3.71 & -1.29 & -3.28 & 2.00 & & 5.57 & & 53.91 \\
\hline nitromethane & -4.02 & -1.50 & -3.44 & 1.94 & $3.92^{\mathrm{b}}$ & 4.16 & & 26.13 \\
\hline N,N-dimethyl-p-methylbenzamide & -9.76 & -8.56 & -10.82 & 2.27 & & 9.62 & & 120.79 \\
\hline N,N-dimethyl-p-nitrobenzamide & -11.95 & -9.20 & -11.47 & 2.27 & & 8.66 & & 95.39 \\
\hline N,N-dimethylaniline & -3.45 & -4.15 & -6.31 & 2.16 & & 7.78 & & 90.36 \\
\hline N,N-dimethylbenzamide & -9.29 & -8.75 & -10.96 & 2.21 & & 8.57 & & 101.15 \\
\hline
\end{tabular}


Table SI-7. (Continued)

\begin{tabular}{|c|c|c|c|c|c|c|c|c|}
\hline \multirow[b]{3}{*}{ Neutral compound } & & \multicolumn{2}{|c|}{$\Delta G\left[\frac{\mathrm{kcal}}{\mathrm{mol}}\right]$} & \multicolumn{2}{|r|}{$-T \Delta S^{*}$} & {$\left[\frac{\mathrm{kcal}}{\mathrm{mol}}\right]$} & $\Delta C_{p}[$ & $\left.\frac{\mathrm{cal}}{\mathrm{mol} . \mathrm{K}}\right]$ \\
\hline & & & calc. & & expt. & calc. & expt. & calc. \\
\hline & & tot & es & $\mathrm{np}$ & & & & \\
\hline N,N-dimethylformamide & -7.81 & -6.81 & -8.83 & 2.01 & $6.70^{\mathrm{f}}$ & 5.55 & $32.55^{\mathrm{b}}$ & 48.31 \\
\hline non-1-ene & 2.06 & 1.58 & -0.72 & 2.30 & & 11.61 & & 168.10 \\
\hline nonan-1-ol & -3.88 & -4.42 & -6.75 & 2.33 & & 13.03 & & 172.04 \\
\hline nonan-2-one & -2.49 & -3.50 & -5.82 & 2.31 & $11.81^{\mathrm{d}}$ & 11.32 & & 157.82 \\
\hline nonan-5-one & -2.64 & -3.10 & -5.42 & 2.32 & $12.80^{\mathrm{d}}$ & 11.44 & & 160.85 \\
\hline nonanal & -2.07 & -3.68 & -5.99 & 2.31 & & 11.02 & & 149.79 \\
\hline o-cresol & -5.87 & -5.54 & -7.64 & 2.10 & $8.51^{\mathrm{d}}$ & 8.14 & & 80.59 \\
\hline o-toluidine & -5.53 & -5.55 & -7.65 & 2.10 & & 8.34 & & 84.80 \\
\hline o-xylene & -0.90 & -0.90 & -3.03 & 2.13 & $7.25^{\mathrm{c}}$ & 8.05 & & 100.51 \\
\hline oct-1-ene & 1.92 & 1.55 & -0.69 & 2.24 & $10.14^{\mathrm{c}}$ & 10.66 & & 151.07 \\
\hline oct-1-yne & 0.71 & 0.90 & -1.33 & 2.23 & & 10.20 & & 141.40 \\
\hline octan-1-ol & -4.09 & -5.07 & -7.34 & 2.27 & $13.09^{\mathrm{c}}$ & 12.61 & & 158.24 \\
\hline octan-2-one & -2.88 & -3.56 & -5.82 & 2.26 & & 10.38 & & 140.92 \\
\hline octanal & -2.29 & -3.79 & -6.05 & 2.26 & & 10.04 & & 131.99 \\
\hline p-cresol & -6.13 & -6.00 & -8.10 & 2.10 & $8.00^{\mathrm{d}}$ & 8.24 & $62.02^{\mathrm{b}}$ & 81.03 \\
\hline p-dibromobenzene & -2.30 & -0.28 & -2.40 & 2.12 & & 7.45 & & 85.59 \\
\hline p-toluidine & -5.57 & -6.14 & -8.25 & 2.11 & & 8.72 & & 88.50 \\
\hline p-xylene & -0.80 & -0.88 & -3.02 & 2.14 & $7.83^{c}$ & 8.34 & $80.09^{\mathrm{b}}$ & 105.77 \\
\hline pent-1-ene & 1.68 & 1.40 & -0.68 & 2.08 & & 7.86 & & 100.68 \\
\hline pent-1-yne & 0.01 & 0.75 & -1.32 & 2.07 & & 7.42 & & 91.42 \\
\hline penta-1,4-diene & 0.93 & 0.60 & -1.46 & 2.06 & & 7.25 & & 88.10 \\
\hline pentachloroethane & -1.39 & 0.85 & -1.24 & 2.09 & & 7.71 & & 91.90 \\
\hline pentan-1-ol & -4.57 & -3.69 & -5.80 & 2.11 & $10.37^{\mathrm{c}}$ & 8.89 & $96.08^{c}$ & 104.71 \\
\hline pentan-2-ol & -4.39 & -3.58 & -5.69 & 2.11 & & 9.10 & & 105.05 \\
\hline pentan-2-one & -3.52 & -3.76 & -5.86 & 2.10 & $7.52^{\mathrm{d}}$ & 7.63 & & 91.50 \\
\hline
\end{tabular}


Table SI-7. (Continued)

\begin{tabular}{|c|c|c|c|c|c|c|c|c|}
\hline \multirow[b]{3}{*}{ Neutral compound } & \multicolumn{4}{|c|}{$\Delta G\left[\frac{\mathrm{kcal}}{\mathrm{mol}}\right]$} & \multirow{3}{*}{$\frac{-T \Delta S^{*}}{\text { expt. }}$} & \multirow{3}{*}{$\frac{\left[\frac{\mathrm{kcal}}{\mathrm{mol}}\right]}{\text { calc. }}$} & \multirow{3}{*}{$\frac{\Delta C_{p}\left[\frac{}{\mathrm{n}}\right.}{\text { expt. }}$} & \multirow{3}{*}{$\begin{array}{r}\left.\frac{\mathrm{cal}}{\mathrm{mol} . \mathrm{K}}\right] \\
\text { calc. }\end{array}$} \\
\hline & \multirow[t]{2}{*}{ expt. $^{\mathrm{a}}$} & \multicolumn{3}{|c|}{ calc. } & & & & \\
\hline & & tot & es & $\mathrm{np}$ & & & & \\
\hline pentan-3-ol & -4.35 & -3.22 & -5.33 & 2.10 & $11.02^{\mathrm{c}}$ & 8.90 & $97.99^{\mathrm{c}}$ & 104.95 \\
\hline pentan-3-one & -3.41 & -3.42 & -5.52 & 2.10 & $7.81^{\mathrm{d}}$ & 7.67 & $71.99^{\mathrm{b}}$ & 92.76 \\
\hline pentanal & -3.03 & -3.81 & -5.91 & 2.10 & & 7.27 & & 82.50 \\
\hline pentanenitrile & -3.52 & -2.26 & -4.36 & 2.10 & & 7.59 & & 91.43 \\
\hline pentanoic-acid & -6.16 & -8.48 & -10.59 & 2.11 & & 9.73 & $70.08^{\mathrm{b}}$ & 101.32 \\
\hline phenanthrene & -3.88 & -4.55 & -6.80 & 2.25 & $8.52^{\mathrm{b}}$ & 8.60 & $263.07^{\mathrm{b}}$ & 100.50 \\
\hline phenol & -6.61 & -6.20 & -8.25 & 2.05 & $6.40^{\mathrm{d}}$ & 7.20 & $50.53^{\mathrm{b}}$ & 61.51 \\
\hline phenyl-formate & -3.82 & -6.29 & -8.40 & 2.11 & & 6.85 & & 64.16 \\
\hline phenyl-methyl-sulfide & -2.73 & -1.88 & -4.01 & 2.13 & & 7.61 & & 88.99 \\
\hline phenyl-trifluoroethyl-ether & -1.29 & -4.79 & -6.99 & 2.21 & & 7.61 & & 72.11 \\
\hline piperazine & -7.40 & -6.35 & -8.38 & 2.03 & & 7.59 & $42.40^{\mathrm{b}}$ & 74.84 \\
\hline piperidine & -5.11 & -2.42 & -4.48 & 2.06 & $9.92^{\mathrm{b}}$ & 7.94 & $76.12^{\mathrm{b}}$ & 92.24 \\
\hline prop-2-en-1-ol & -5.03 & -4.32 & -6.30 & 1.98 & $7.37^{\mathrm{c}}$ & 6.63 & $62.14^{\mathrm{c}}$ & 59.82 \\
\hline propan-1-ol & -4.85 & -3.76 & -5.76 & 2.00 & $8.33^{\mathrm{c}}$ & 7.02 & $64.05^{\mathrm{c}}$ & 71.20 \\
\hline propan-2-ol & -4.74 & -3.78 & -5.79 & 2.00 & $8.64^{\mathrm{c}}$ & 6.92 & $65.01^{\mathrm{c}}$ & 68.73 \\
\hline propane & 1.96 & 1.96 & -0.03 & 1.99 & $6.83^{\mathrm{c}}$ & 6.52 & $78.87^{\mathrm{c}}$ & 77.81 \\
\hline propanenitrile & -3.84 & -2.46 & -4.46 & 1.99 & & 5.64 & & 55.75 \\
\hline propanoic-acid & -6.46 & -9.23 & -11.23 & 2.01 & $6.44^{\mathrm{d}}$ & 8.10 & $38.29^{\mathrm{b}}$ & 67.18 \\
\hline propanone & -3.80 & -4.15 & -6.14 & 1.99 & $5.37^{\mathrm{b}}$ & 5.67 & $39.77^{\mathrm{b}}$ & 55.59 \\
\hline propene & 1.32 & 1.22 & -0.75 & 1.97 & $5.88^{\mathrm{c}}$ & 5.92 & $66.92^{\mathrm{c}}$ & 65.69 \\
\hline propionaldehyde & -3.43 & -3.96 & -5.95 & 1.99 & & 5.40 & & 48.67 \\
\hline propyne & -0.48 & 0.50 & -1.45 & 1.95 & $3.75^{\mathrm{c}}$ & 5.36 & $79.54^{\mathrm{b}}$ & 53.73 \\
\hline pyrene & -4.52 & -5.39 & -7.67 & 2.28 & $10.08^{\mathrm{b}}$ & 8.70 & $129.97^{\mathrm{b}}$ & 100.25 \\
\hline pyridine & -4.69 & -3.70 & -5.72 & 2.02 & $6.62^{\mathrm{d}}$ & 5.75 & $54.40^{\mathrm{b}}$ & 55.35 \\
\hline pyrrole & -4.78 & -4.23 & -6.21 & 1.98 & & 6.18 & & 52.29 \\
\hline
\end{tabular}


Table SI-7. (Continued)

\begin{tabular}{|c|c|c|c|c|c|c|c|c|}
\hline \multirow[b]{3}{*}{ Neutral compound } & \multicolumn{2}{|r|}{$\Delta G$} & \multicolumn{2}{|l|}{$\left.\frac{\mathrm{kcal}}{\mathrm{mol}}\right]$} & $-T \Delta S^{*}$ & {$\left[\frac{\mathrm{kcal}}{\mathrm{mol}}\right]$} & $\Delta C_{p}$ & $\left.\frac{\mathrm{cal}}{\mathrm{mol} . \mathrm{K}}\right]$ \\
\hline & expt. $^{a}$ & & calc. & & expt. & calc. & expt. & calc. \\
\hline & & tot & es & $\mathrm{np}$ & & & & \\
\hline pyrrolidine & -5.48 & -3.12 & -5.14 & 2.02 & $9.11^{\mathrm{b}}$ & 7.16 & $60.33^{\mathrm{b}}$ & 78.30 \\
\hline quinoline & -5.72 & -4.52 & -6.66 & 2.13 & & 7.33 & $68.36^{\mathrm{b}}$ & 80.95 \\
\hline sec-butylbenzene & -0.45 & -0.70 & -2.92 & 2.22 & & 9.64 & & 128.92 \\
\hline styrene & -1.24 & -1.78 & -3.90 & 2.12 & & 7.46 & & 87.14 \\
\hline teflurane & 0.50 & -0.25 & -2.28 & 2.03 & & 6.27 & & 61.00 \\
\hline tert-butylbenzene & -0.44 & -0.86 & -3.06 & 2.20 & & 9.39 & & 124.49 \\
\hline tetrachloroethene & 0.10 & 1.95 & -0.10 & 2.06 & & 7.58 & & 96.64 \\
\hline tetrachloromethane & 0.08 & 1.82 & -0.20 & 2.02 & & 6.93 & & 84.53 \\
\hline tetrafluoromethane & 3.12 & 1.25 & -0.69 & 1.94 & $6.12^{\mathrm{b}}$ & 5.13 & $90.75^{\mathrm{b}}$ & 49.62 \\
\hline tetrahydrofuran & -3.47 & -1.83 & -3.84 & 2.02 & $7.23^{\mathrm{b}}$ & 6.51 & $50.29^{\mathrm{b}}$ & 74.18 \\
\hline tetrahydropyran & -3.12 & -1.13 & -3.19 & 2.06 & $7.96^{\mathrm{b}}$ & 7.27 & $63.60^{\mathrm{b}}$ & 88.34 \\
\hline thiophene & -1.42 & -0.61 & -2.61 & 2.00 & & 5.68 & & 55.81 \\
\hline thiophenol & -2.55 & -2.59 & -4.67 & 2.08 & & 6.82 & & 68.00 \\
\hline toluene & -0.89 & -1.06 & -3.15 & 2.09 & $7.19^{\mathrm{c}}$ & 7.32 & $85.80^{\mathrm{g}}$ & 86.61 \\
\hline trans-1,4-dimethylcyclohexane & 2.11 & 2.11 & -0.06 & 2.17 & & 9.66 & & 134.31 \\
\hline triacetyl-glycerol & -8.84 & -14.75 & -17.02 & 2.27 & & 9.28 & & 85.26 \\
\hline tribromomethane & -2.13 & 1.14 & -0.87 & 2.01 & & 6.52 & & 72.81 \\
\hline trichloroethene & -0.44 & 1.04 & -0.98 & 2.02 & & 6.48 & & 72.19 \\
\hline trichloromethane & -1.08 & 0.50 & -1.49 & 1.98 & & 5.85 & & 57.27 \\
\hline triethyl-phosphate & -7.54 & -11.11 & -13.43 & 2.32 & & 10.65 & & 139.65 \\
\hline triethylamine & -3.22 & -0.88 & -3.04 & 2.15 & & 8.98 & & 119.38 \\
\hline trimethoxy-methane & -4.42 & -5.04 & -7.13 & 2.10 & & 6.94 & & 74.67 \\
\hline trimethoxymethylbenzene & -4.04 & -6.07 & -8.33 & 2.27 & & 9.64 & & 122.57 \\
\hline trimethyl-phosphate & -8.70 & -11.87 & -14.00 & 2.13 & & 6.47 & & 57.71 \\
\hline trimethylamine & -3.20 & -2.16 & -4.16 & 2.00 & & 6.28 & & 69.71 \\
\hline
\end{tabular}


Table SI-7. (Continued)

\begin{tabular}{|c|c|c|c|c|c|c|c|c|}
\hline \multirow[b]{3}{*}{ Neutral compound } & \multicolumn{3}{|c|}{$\Delta G\left[\frac{\mathrm{kcal}}{\mathrm{mol}}\right]$} & \multirow{3}{*}{\multicolumn{2}{|c|}{$\begin{array}{c}-T \Delta S^{*} \\
\text { expt. }\end{array}$}} & \multirow{3}{*}{$\frac{\left[\frac{\mathrm{kcal}}{\mathrm{mol}}\right]}{\text { calc. }}$} & \multirow{3}{*}{$\frac{\Delta C_{p}\left[\frac{1}{1}\right.}{\text { expt. }}$} & \multirow{3}{*}{$\frac{\left.\frac{\mathrm{cal}}{\mathrm{mol} . \mathrm{K}}\right]}{\text { calc. }}$} \\
\hline & \multirow{2}{*}{ expt. $^{a}$} & \multicolumn{2}{|r|}{ calc. } & & & & & \\
\hline & & tot & es & & & & & \\
\hline undecan-2-one & -2.15 & -3.63 & -6.06 & 2.42 & & 13.25 & & 192.76 \\
\hline Z-1,2-dichloroethene & -1.17 & -0.11 & -2.10 & 1.98 & & 5.21 & & 45.66 \\
\hline Z-pent-2-ene & 1.31 & 1.36 & -0.71 & 2.07 & & 7.69 & & 97.71 \\
\hline RMSE & & 1.25 & & & & 1.22 & & 24.42 \\
\hline MAE & & 0.95 & & & & 0.89 & & 18.52 \\
\hline 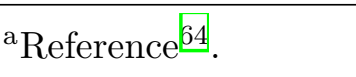 & & & & ${ }^{\mathrm{e}} \mathrm{Refe}$ & rence $\sqrt{15}$. & & & \\
\hline beference ${ }^{3}$. & & & & ${ }^{\mathrm{f}}$ Refe & erence ${ }^{1}$. & & & \\
\hline${ }^{\mathrm{c}}$ Reference 14 . & & & & ${ }^{g}$ Refe & erence ${ }^{9}$. & & & \\
\hline${ }^{\mathrm{d}}$ Reference 10. & & & & & & & & \\
\hline
\end{tabular}


TABLE SI-8: SLIC/CDC predictions of the total, electrostatic, hydrogen bonding, dispersion, cavity, and combinatorial components of hydration Gibbs energies and the predicted hydration entropies for 12 small molecules. Experimental data are also presented for the solutes with experimental measurements available.

\begin{tabular}{|c|c|c|c|c|c|c|c|c|c|}
\hline \multirow[b]{3}{*}{ Neutral compound } & \multicolumn{7}{|c|}{$\Delta G\left[\frac{\mathrm{kcal}}{\mathrm{mol}}\right]$} & \multirow{3}{*}{$\frac{-T \Delta S}{\text { expt. }}$} & \multirow{3}{*}{$\frac{\left[\frac{\mathrm{kcal}}{\mathrm{mol}}\right]}{\text { calc. }}$} \\
\hline & \multirow[t]{2}{*}{ expt. $^{a}$} & \multicolumn{6}{|c|}{ calc. } & & \\
\hline & & tot & es & $\mathrm{hb}$ & disp & comb & cav & & \\
\hline 1-bromo-2-chloroethane & -1.95 & -1.41 & -1.93 & 0.00 & -9.14 & 0.97 & 8.70 & & 4.75 \\
\hline 1-bromo-2-methylpropane & -0.03 & -1.59 & -1.30 & 0.00 & -12.59 & 1.57 & 10.73 & & 5.06 \\
\hline 1-bromobutane & -0.40 & -0.41 & -1.35 & 0.00 & -12.68 & 1.61 & 12.02 & & 6.27 \\
\hline 1-bromoheptane & 0.34 & 0.07 & -1.35 & 0.00 & -19.35 & 3.07 & 17.70 & & 9.42 \\
\hline 1-bromohexane & 0.18 & 0.12 & -1.33 & 0.00 & -17.03 & 2.57 & 15.91 & & 8.50 \\
\hline 1-bromooctane & 0.52 & 0.17 & -1.34 & 0.00 & -21.67 & 3.57 & 19.61 & & 10.46 \\
\hline 1-bromopentane & -0.10 & -0.02 & -1.33 & 0.00 & -14.80 & 2.08 & 14.03 & & 7.46 \\
\hline 1-bromopropane & -0.56 & -0.58 & -1.35 & 0.00 & -10.46 & 1.15 & 10.08 & & 5.20 \\
\hline 1-chloro-2,2,2-trifluoroethane & 0.06 & -0.07 & -2.73 & -0.37 & -6.20 & 1.00 & 8.23 & & 6.07 \\
\hline 1-chlorobutane & -0.16 & 0.25 & -1.50 & 0.00 & -11.78 & 1.53 & 12.00 & & 6.63 \\
\hline 1-chloroheptane & 0.29 & 0.59 & -1.50 & 0.00 & -18.61 & 2.99 & 17.71 & & 9.74 \\
\hline 1-chlorohexane & 0.00 & -0.06 & -1.54 & 0.00 & -16.44 & 2.48 & 15.44 & & 8.28 \\
\hline 1-chloropentane & -0.07 & 0.05 & -1.55 & 0.00 & -14.13 & 1.99 & 13.74 & & 7.44 \\
\hline 1-chloropropane & -0.33 & -0.42 & -1.44 & 0.00 & -9.80 & 1.07 & 9.75 & & 5.15 \\
\hline 1-ethylnaphthalene & -2.40 & -3.66 & -4.58 & 0.00 & -22.96 & 3.26 & 20.62 & & 11.53 \\
\hline 1-iodobutane & -0.25 & -0.68 & -2.46 & 0.00 & -11.66 & 1.75 & 11.70 & & 6.66 \\
\hline 1-iodoheptane & 0.27 & 0.08 & -2.42 & 0.00 & -18.21 & 3.22 & 17.50 & & 10.00 \\
\hline 1-iodohexane & 0.08 & -0.09 & -2.41 & 0.00 & -15.97 & 2.72 & 15.58 & & 8.92 \\
\hline 1-iodopentane & -0.14 & -0.38 & -2.43 & 0.00 & -13.94 & 2.23 & 13.76 & & 7.84 \\
\hline 1-iodopropane & -0.53 & -0.97 & -2.47 & 0.00 & -9.51 & 1.29 & 9.72 & & 5.53 \\
\hline 1-methyl-imidazole & -8.41 & -5.91 & -7.65 & -0.10 & -12.51 & 1.10 & 13.24 & & 7.43 \\
\hline
\end{tabular}


Table SI-8. (Continued)

\begin{tabular}{|c|c|c|c|c|c|c|c|c|c|}
\hline \multirow[b]{3}{*}{ Neutral compound } & \multicolumn{3}{|c|}{$\Delta G$} & $G\left[\frac{\mathrm{kca}}{\mathrm{mo}}\right.$ & & & & \multirow{3}{*}{$\frac{-T \Delta S^{*}}{\text { expt. }}$} & \multirow{3}{*}{$\frac{*\left[\frac{\mathrm{kcal}}{\mathrm{mol}}\right]}{\text { calc. }}$} \\
\hline & \multirow[t]{2}{*}{ expt. $^{a}$} & \multicolumn{6}{|c|}{ calc. } & & \\
\hline & & tot & es & $\mathrm{hb}$ & disp & comb & cav & & \\
\hline 1-methyl-pyrrole & -2.89 & -0.44 & -4.22 & 0.00 & -11.60 & 1.23 & 14.15 & & 8.88 \\
\hline 1-methylcyclohexene & 0.67 & 0.31 & -0.75 & 0.00 & -16.37 & 2.10 & 15.32 & & 7.84 \\
\hline 1-methylnaphthalene & -2.44 & -3.65 & -4.67 & 0.00 & -20.88 & 2.75 & 19.15 & & 10.81 \\
\hline 1-naphthol & -7.67 & -8.77 & -8.74 & -2.11 & -19.12 & 2.43 & 18.77 & & 12.36 \\
\hline 1-naphthylamine & -7.28 & -8.88 & -8.37 & -3.40 & -19.02 & 2.49 & 19.42 & & 13.15 \\
\hline 1-nitrobutane & -3.09 & -2.81 & -2.97 & -0.96 & -15.07 & 1.74 & 14.44 & & 8.03 \\
\hline 1-nitropentane & -2.82 & -3.16 & -2.93 & -1.24 & -17.47 & 2.22 & 16.25 & & 9.02 \\
\hline 1-nitropropane & -3.34 & -2.86 & -3.01 & -0.96 & -12.75 & 1.28 & 12.58 & & 7.07 \\
\hline 1,1-diacetoxyethane & -4.97 & -6.41 & -11.45 & -0.27 & -15.52 & 2.60 & 18.23 & & 11.87 \\
\hline 1,1-dichloroethane & -0.84 & -1.37 & -2.05 & 0.00 & -8.20 & 0.94 & 7.94 & & 4.46 \\
\hline 1,1-dichloroethene & 0.25 & 0.02 & -1.11 & 0.00 & -6.79 & 0.79 & 7.12 & & 4.56 \\
\hline 1,1-diethoxyethane & -3.28 & -1.83 & -5.52 & -0.16 & -17.41 & 2.52 & 18.74 & & 10.89 \\
\hline 1,1-difluoroethane & -0.11 & -0.75 & -2.86 & -0.25 & -6.13 & 0.61 & 7.88 & & 4.99 \\
\hline 1,1,1-trichloroethane & -0.19 & 0.43 & -1.34 & 0.00 & -7.26 & 1.27 & 7.75 & & 5.26 \\
\hline 1,1,1-trifluoro-2,2,2-trimethoxyethane & e -0.80 & -1.53 & -5.66 & -0.61 & -12.56 & 2.47 & 14.83 & & 10.26 \\
\hline 1,1,1-trifluoropropan-2-ol & -4.16 & -6.05 & -7.94 & -2.48 & -7.51 & 1.27 & 10.61 & $8.04^{\mathrm{b}}$ & 8.79 \\
\hline 1,1,1-trimethoxyethane & -4.42 & -3.71 & -6.59 & -0.24 & -14.24 & 2.13 & 15.23 & & 9.00 \\
\hline 1,1,1,2-tetrachloroethane & -1.28 & -0.06 & -1.74 & 0.00 & -8.23 & 1.54 & 8.37 & & 5.86 \\
\hline 1,1,2-trichloro-1,2,2-trifluoroethane & 1.77 & 3.04 & -0.55 & -0.37 & -5.64 & 1.64 & 7.96 & & 7.12 \\
\hline 1,1,2-trichloroethane & -1.99 & -2.89 & -3.25 & 0.00 & -8.48 & 1.75 & 7.09 & & 4.44 \\
\hline 1,1,2,2-tetrachloroethane & -2.47 & -1.93 & -2.55 & 0.00 & -8.88 & 2.08 & 7.42 & & 5.09 \\
\hline 1,2-diacetoxyethane & -6.34 & -7.47 & -12.97 & -0.27 & -16.40 & 2.54 & 19.63 & $10.25^{\mathrm{b}}$ & 12.72 \\
\hline 1,2-dibromoethane & -2.33 & -2.06 & -1.85 & 0.00 & -9.98 & 1.04 & 8.73 & & 4.42 \\
\hline
\end{tabular}


Table SI-8. (Continued)

\begin{tabular}{|c|c|c|c|c|c|c|c|c|}
\hline \multirow[b]{3}{*}{ Neutral compound } & \multicolumn{3}{|c|}{$\Delta G$} & $G\left[\frac{\mathrm{kca}}{\mathrm{mo}}\right.$ & & & \multirow{3}{*}{$\frac{-T \Delta S}{\text { expt. }}$} & \multirow{3}{*}{$\frac{\text { * }\left[\frac{\mathrm{kcal}}{\mathrm{mol}}\right]}{\text { calc. }}$} \\
\hline & \multirow[t]{2}{*}{ expt. ${ }^{a}$} & \multicolumn{5}{|c|}{ calc. } & & \\
\hline & & tot & es & $\mathrm{hb}$ & disp comb & cav & & \\
\hline 1,2-dichlorobenzene & -1.36 & -1.56 & -2.37 & 0.00 & -14.011 .83 & 13.00 & & 7.79 \\
\hline 1,2-dichloroethane & -1.79 & -2.20 & -3.06 & 0.00 & $-8.59 \quad 0.89$ & 8.55 & & 4.80 \\
\hline 1,2-dichloropropane & -1.27 & -2.13 & -2.92 & 0.00 & -10.561 .35 & 10.01 & & 5.52 \\
\hline 1,2-diethoxyethane & -3.54 & -2.18 & -6.36 & -0.16 & -18.232 .47 & 20.11 & & 11.71 \\
\hline 1,2-dimethoxyethane & -4.84 & -3.21 & -7.26 & -0.16 & -13.341 .45 & 16.10 & $8.74^{\mathrm{b}}$ & 9.63 \\
\hline 1,2-ethanediol & -9.30 & -11.12 & -11.84 & -4.22 & $\begin{array}{ll}-7.45 & 0.57\end{array}$ & 11.82 & $7.38^{\mathrm{b}}$ & 10.10 \\
\hline 1,2,3-trichlorobenzene & -1.24 & -1.83 & -1.95 & 0.00 & -15.062 .14 & 13.04 & & 7.80 \\
\hline 1,2,3-trimethylbenzene & -1.21 & -2.09 & -2.68 & -0.01 & -18.872 .56 & 16.91 & $7.15^{\mathrm{c}}$ & 8.98 \\
\hline 1,2,3,4-tetrachlorobenzene & -1.34 & -2.00 & -1.42 & 0.00 & -16.142 .47 & 13.09 & & 7.82 \\
\hline 1,2,3,5-tetrachlorobenzene & -1.62 & -1.37 & -1.14 & 0.00 & -16.062 .47 & 13.36 & & 8.13 \\
\hline 1,2,4-trichlorobenzene & -1.12 & -1.35 & -1.76 & 0.00 & -15.032 .15 & 13.29 & & 8.07 \\
\hline 1,2,4-trimethylbenzene & -0.86 & -1.65 & -2.66 & 0.00 & -19.112 .61 & 17.51 & $8.08^{\mathrm{c}}$ & 9.43 \\
\hline 1,2,4,5-tetrachlorobenzene & -1.34 & -1.43 & -1.19 & 0.00 & -16.052 .47 & 13.35 & & 8.12 \\
\hline 1,3-dichlorobenzene & -0.98 & -0.96 & -2.14 & 0.00 & -13.991 .83 & 13.33 & & 8.12 \\
\hline 1,3-dichloropropane & -1.89 & -2.00 & -2.75 & 0.00 & -10.911 .33 & 10.34 & & 5.65 \\
\hline 1,3-dimethylnaphthalene & -2.47 & -3.64 & -4.45 & 0.00 & -23.343 .25 & 20.90 & & 11.57 \\
\hline 1,3,5-trichlorobenzene & -0.78 & -0.71 & -1.43 & 0.00 & -14.992 .15 & 13.57 & & 8.36 \\
\hline 1,3,5-trimethylbenzene & -0.90 & -0.29 & -2.61 & 0.00 & -18.782 .63 & 18.46 & $8.30^{\mathrm{c}}$ & 10.47 \\
\hline 1,4-dichlorobenzene & -1.01 & -1.02 & -2.21 & 0.00 & -14.031 .83 & 13.38 & & 8.15 \\
\hline 1,4-dichlorobutane & -2.32 & -2.21 & -3.04 & 0.00 & -13.141 .78 & 12.19 & & 6.63 \\
\hline 1,4-dimethyl-piperazine & -7.58 & -3.62 & -6.40 & -1.81 & -16.652 .20 & 19.05 & & 12.14 \\
\hline 1,4-dimethylnaphthalene & -2.82 & -4.11 & -4.48 & 0.00 & -23.223 .21 & 20.39 & & 11.12 \\
\hline 1,4-dioxane & -5.06 & -4.34 & -5.97 & -0.16 & -13.111 .16 & 13.74 & $5.81^{\mathrm{b}}$ & 7.38 \\
\hline
\end{tabular}


Table SI-8. (Continued)

\begin{tabular}{|c|c|c|c|c|c|c|c|c|}
\hline \multirow[b]{3}{*}{ Neutral compound } & \multicolumn{6}{|c|}{$\Delta G\left[\frac{\mathrm{kcal}}{\mathrm{mol}}\right]$} & \multirow{3}{*}{$\frac{-T \Delta S^{*}}{\text { expt. }}$} & \multirow{3}{*}{$\frac{\left[\frac{\mathrm{kcal}}{\mathrm{mol}}\right]}{\text { calc. }}$} \\
\hline & \multirow[t]{2}{*}{ expt. $^{a}$} & \multicolumn{5}{|c|}{ calc. } & & \\
\hline & & tot & es & $\mathrm{hb}$ & disp comb & cav & & \\
\hline 2-bromo-2-methylpropane & 0.84 & 0.17 & -1.66 & 0.00 & -10.511 .64 & 10.71 & & 6.09 \\
\hline 2-bromopropane & -0.48 & -1.03 & -1.58 & 0.00 & -10.171 .17 & 9.55 & & 4.85 \\
\hline 2-butoxyethanol & -6.25 & -4.14 & -6.60 & -2.19 & -17.282 .43 & 19.49 & $10.75^{\mathrm{b}}$ & 12.70 \\
\hline 2-chloro-1,1,1-trimethoxyethane & -4.59 & -5.23 & -8.02 & -0.24 & -15.372 .41 & 15.99 & & 9.71 \\
\hline 2-chloro-2-methylpropane & 1.09 & 0.68 & -1.71 & 0.00 & $-9.84 \quad 1.56$ & 10.67 & & 6.34 \\
\hline 2-chloroaniline & -4.91 & -6.60 & -6.33 & -3.40 & -13.421 .70 & 14.84 & & 10.79 \\
\hline 2-chlorobutane & 0.00 & -0.41 & -1.59 & 0.00 & -11.661 .54 & 11.31 & & 6.03 \\
\hline 2-chlorophenol & -4.55 & -5.03 & -5.22 & -2.11 & -13.521 .64 & 14.17 & & 9.98 \\
\hline 2-chloropropane & -0.25 & -0.40 & -1.69 & 0.00 & $-9.44 \quad 1.09$ & 9.62 & & 5.23 \\
\hline 2-chloropyridine & -4.39 & -5.78 & -5.60 & -0.10 & -13.601 .40 & 12.13 & $6.83^{\mathrm{b}}$ & 6.55 \\
\hline 2-chlorotoluene & -1.14 & -1.41 & -2.56 & 0.00 & -15.221 .98 & 14.39 & & 8.30 \\
\hline 2-ethoxyethanol & -6.69 & -8.27 & -10.63 & -2.19 & -12.671 .47 & 15.75 & $8.57^{\mathrm{b}}$ & 10.74 \\
\hline 2-ethylpyrazine & -5.45 & -8.69 & -7.72 & -0.19 & -17.961 .89 & 15.29 & & 7.36 \\
\hline 2-ethylpyridine & -4.33 & -4.22 & -5.16 & -0.10 & -16.972 .03 & 15.98 & $7.85^{\mathrm{d}}$ & 8.65 \\
\hline 2-ethyltoluene & -1.04 & -1.77 & -2.74 & 0.00 & -18.522 .59 & 16.90 & & 9.19 \\
\hline 2-fluorophenol & -5.29 & -4.54 & -5.50 & -2.23 & -12.571 .47 & 14.28 & & 10.35 \\
\hline 2-iodophenol & -6.20 & -4.63 & -4.82 & -2.11 & -13.401 .86 & 13.84 & & 9.96 \\
\hline 2-iodopropane & -0.46 & -1.45 & -2.61 & 0.00 & $-9.37 \quad 1.31$ & 9.22 & & 5.13 \\
\hline 2-isobutylpyrazine & -5.04 & -9.55 & -7.21 & -0.19 & -21.672 .80 & 16.72 & & 7.55 \\
\hline 2-methoxy-1,1,1-trimethoxyethane & -5.73 & -5.69 & -10.77 & -0.24 & -17.132 .74 & 19.72 & & 12.36 \\
\hline 2-methoxyaniline & -6.12 & -6.94 & -8.38 & -3.48 & -15.672 .01 & 18.57 & & 13.25 \\
\hline 2-methoxyethanamine & -6.55 & -5.46 & -8.26 & -3.48 & $-9.82 \quad 1.05$ & 15.04 & & 11.29 \\
\hline 2-methoxyphenol & -5.57 & -5.42 & -7.35 & -2.19 & -15.861 .96 & 18.02 & & 12.52 \\
\hline
\end{tabular}


Table SI-8. (Continued)

\begin{tabular}{|c|c|c|c|c|c|c|c|c|}
\hline \multirow[b]{3}{*}{ Neutral compound } & \multicolumn{6}{|c|}{$\Delta G\left[\frac{\mathrm{kcal}}{\mathrm{mol}}\right]$} & \multirow{3}{*}{$\frac{-T \Delta S^{*}}{\text { expt. }}$} & \multirow{3}{*}{$\frac{P^{*}\left[\frac{\mathrm{kcal}}{\mathrm{mol}}\right]}{\text { calc. }}$} \\
\hline & \multirow[t]{2}{*}{ expt. $^{\mathrm{a}}$} & \multicolumn{5}{|c|}{ calc. } & & \\
\hline & & tot & es & $\mathrm{hb}$ & disp comb & cav & & \\
\hline 2-methyl-but-2-ene & 1.31 & 0.96 & -0.74 & 0.00 & -12.201 .49 & 12.41 & $7.78^{c}$ & 6.71 \\
\hline 2-methylbut-2-ene & 1.31 & 0.96 & -0.74 & 0.00 & -12.201 .49 & 12.41 & & 6.71 \\
\hline 2-methylbuta-1,3-diene & 0.68 & 1.07 & -1.45 & 0.00 & -10.531 .30 & 11.76 & $5.51^{\mathrm{c}}$ & 7.12 \\
\hline 2-methylbutan-1-ol & -4.42 & -4.70 & -5.24 & -2.11 & -13.071 .78 & 13.94 & & 8.96 \\
\hline 2-methylbutan-2-ol & -4.43 & -3.15 & -4.55 & -2.11 & -11.491 .83 & 13.16 & $11.34^{\mathrm{c}}$ & 9.02 \\
\hline 2-methylbutane & 2.38 & 0.34 & -0.04 & 0.00 & -13.031 .67 & 11.74 & $7.78^{c}$ & 5.58 \\
\hline 2-methylhexane & 2.93 & 0.92 & -0.05 & 0.00 & -17.202 .63 & 15.54 & & 7.81 \\
\hline 2-methylpent-1-ene & 1.47 & 1.46 & -0.65 & 0.00 & -13.901 .97 & 14.03 & & 7.77 \\
\hline 2-methylpentan-2-ol & -3.92 & -3.23 & -4.94 & -2.11 & -13.472 .31 & 14.99 & & 10.10 \\
\hline 2-methylpentan-3-ol & -3.88 & -3.54 & -4.12 & -2.11 & -14.902 .28 & 15.31 & & 9.70 \\
\hline 2-methylpentane & 2.51 & 1.39 & -0.05 & 0.00 & -14.882 .17 & 14.14 & $9.70^{\mathrm{c}}$ & 7.28 \\
\hline 2-methylpropan-1-ol & -4.50 & -4.34 & -5.24 & -2.11 & -10.921 .34 & 12.59 & $9.29^{\mathrm{c}}$ & 8.41 \\
\hline 2-methylpropan-2-ol & -4.47 & -3.09 & -5.15 & -2.11 & $-9.23 \quad 1.38$ & 12.02 & $10.25^{\mathrm{c}}$ & 8.73 \\
\hline 2-methylpropane & 2.32 & 1.31 & -0.03 & 0.00 & -10.741 .26 & 10.82 & $7.50^{\mathrm{c}}$ & 5.53 \\
\hline 2-methylpropene & 1.16 & 1.50 & -0.70 & 0.00 & $-9.53 \quad 1.06$ & 10.67 & & 6.10 \\
\hline 2-methylpyrazine & -5.51 & -9.37 & -7.97 & -0.19 & -15.741 .42 & 13.12 & & 6.08 \\
\hline 2-methylpyridine & -4.63 & -4.84 & -5.39 & -0.11 & -14.821 .55 & 13.93 & $7.82^{\mathrm{d}}$ & 7.44 \\
\hline 2-methyltetrahydrofuran & -3.30 & -2.41 & -3.39 & -0.08 & -14.161 .52 & 13.69 & & 6.91 \\
\hline 2-methylthiophene & -1.38 & -1.83 & -2.37 & 0.00 & -13.301 .41 & 12.43 & & 6.65 \\
\hline 2-naphthol & -8.11 & -8.68 & -8.97 & -2.11 & -19.222 .44 & 19.18 & & 12.71 \\
\hline 2-naphthylamine & -7.47 & -8.79 & -8.63 & -3.40 & -19.062 .50 & 19.80 & & 13.50 \\
\hline 2-nitroaniline & -7.37 & -9.79 & -6.97 & -4.36 & -16.681 .88 & 16.34 & & 11.28 \\
\hline 2-nitrophenol & -4.58 & -11.39 & -8.89 & -3.07 & -16.871 .83 & 15.61 & & 10.38 \\
\hline
\end{tabular}


Table SI-8. (Continued)

\begin{tabular}{|c|c|c|c|c|c|c|c|c|}
\hline \multirow[b]{3}{*}{ Neutral compound } & \multicolumn{6}{|c|}{$\Delta G\left[\frac{\mathrm{kcal}}{\mathrm{mol}}\right]$} & \multirow{3}{*}{$\frac{-T \Delta S^{*}}{\text { expt. }}$} & \multirow{3}{*}{$\frac{P^{*}\left[\frac{\mathrm{kcal}}{\mathrm{mol}}\right]}{\text { calc. }}$} \\
\hline & \multirow[t]{2}{*}{ expt. $^{\mathrm{a}}$} & \multicolumn{5}{|c|}{ calc. } & & \\
\hline & & tot & es & $\mathrm{hb}$ & disp comb & cav & & \\
\hline 2-nitropropane & -3.13 & -3.33 & -3.06 & -0.96 & -12.141 .28 & 11.55 & & 6.40 \\
\hline 2-nitrotoluene & -3.58 & -5.42 & -3.85 & -0.96 & -18.622 .13 & 15.88 & & 8.71 \\
\hline 2-phenylethanol & -6.79 & -5.86 & -8.06 & -2.11 & -16.682 .24 & 18.74 & & 12.87 \\
\hline 2-propoxyethanol & -6.40 & -8.39 & -10.82 & -2.19 & -15.001 .94 & 17.68 & $9.72^{\mathrm{b}}$ & 11.76 \\
\hline 2,2-dimethylbutane & 2.51 & 1.63 & -0.04 & 0.00 & -13.182 .13 & 12.71 & & 6.75 \\
\hline 2,2-dimethylpentane & 2.88 & 1.88 & -0.04 & 0.00 & -15.282 .63 & 14.58 & & 7.83 \\
\hline 2,2-dimethylpropane & 2.51 & 2.31 & -0.03 & 0.00 & -11.001 .71 & 11.64 & $7.91^{\mathrm{c}}$ & 6.49 \\
\hline 2,2,2-trifluoroethanol & -4.31 & -4.83 & -7.01 & -2.48 & $-5.62 \quad 0.83$ & 9.45 & $7.06^{\mathrm{b}}$ & 8.33 \\
\hline 2,2,4-trimethylpentane & 2.89 & 0.76 & -0.04 & 0.00 & -17.343 .00 & 15.15 & & 7.64 \\
\hline 2,2,5-trimethylhexane & 2.93 & 1.25 & -0.05 & 0.00 & -19.223 .55 & 16.97 & & 8.85 \\
\hline 2,3-dimethylbuta-1,3-diene & 0.40 & 0.21 & -1.48 & 0.00 & -12.771 .74 & 12.72 & & 7.20 \\
\hline 2,3-dimethylbutane & 2.34 & 0.23 & -0.04 & 0.00 & -14.652 .14 & 12.78 & $8.72^{\mathrm{c}}$ & 6.11 \\
\hline 2,3-dimethylnaphthalene & -2.78 & -3.74 & -4.46 & 0.00 & -23.203 .26 & 20.67 & & 11.43 \\
\hline 2,3-dimethylpentane & 2.52 & 0.34 & -0.04 & 0.00 & -16.382 .60 & 14.16 & & 6.90 \\
\hline 2,3-dimethylphenol & -6.16 & -6.42 & -6.60 & -2.11 & -17.062 .22 & 17.13 & & 11.08 \\
\hline 2,3-dimethylpyridine & -4.82 & -5.16 & -5.20 & -0.10 & -17.161 .97 & 15.33 & $8.37^{\mathrm{d}}$ & 7.87 \\
\hline 2,3,4-trimethylpentane & 2.56 & 0.84 & -0.05 & 0.00 & -17.113 .07 & 14.93 & & 7.60 \\
\hline 2,4-dimethylpentan-3-one & -2.74 & -1.39 & -5.38 & -0.05 & -14.842 .67 & 16.22 & $9.33^{\mathrm{b}}$ & 9.73 \\
\hline 2,4-dimethylpentane & 2.83 & -0.04 & -0.05 & 0.00 & -17.132 .53 & 14.61 & & 6.89 \\
\hline 2,4-dimethylphenol & -6.01 & -5.84 & -6.57 & -2.11 & -17.022 .27 & 17.58 & & 11.54 \\
\hline 2,4-dimethylpyridine & -4.86 & -4.73 & -5.26 & -0.10 & -17.192 .02 & 15.80 & $9.05^{\mathrm{d}}$ & 8.31 \\
\hline 2,5-dimethylphenol & -5.91 & -5.08 & -5.63 & -2.11 & -17.152 .27 & 17.54 & & 11.45 \\
\hline 2,5-dimethylpyridine & -4.72 & -4.76 & -5.16 & -0.10 & -17.302 .03 & 15.77 & $9.22^{\mathrm{d}}$ & 8.24 \\
\hline
\end{tabular}


Table SI-8. (Continued)

\begin{tabular}{|c|c|c|c|c|c|c|c|c|}
\hline \multirow[b]{3}{*}{ Neutral compound } & \multicolumn{6}{|c|}{$\Delta G\left[\frac{\mathrm{kcal}}{\mathrm{mol}}\right]$} & \multirow{3}{*}{$\frac{-T \Delta S^{*}}{\text { expt. }}$} & \multirow{3}{*}{$\frac{\left[\frac{\mathrm{kcal}}{\mathrm{mol}}\right]}{\text { calc. }}$} \\
\hline & \multirow[t]{2}{*}{ expt. $^{a}$} & \multicolumn{5}{|c|}{ calc. } & & \\
\hline & & tot & es & $\mathrm{hb}$ & disp comb & cav & & \\
\hline 2,5-dimethyltetrahydrofuran & -2.92 & -1.10 & -3.15 & -0.08 & -15.982 .03 & 16.07 & & 8.60 \\
\hline 2,6-dimethylaniline & -5.21 & -6.20 & -6.07 & -3.40 & -16.882 .31 & 17.84 & & 11.98 \\
\hline 2,6-dimethylnaphthalene & -2.63 & -3.09 & -4.46 & 0.00 & -23.453 .30 & 21.52 & & 12.13 \\
\hline 2,6-dimethylphenol & -5.26 & -5.26 & -5.67 & -2.11 & -16.992 .26 & 17.24 & & 11.24 \\
\hline 2,6-dimethylpyridine & -4.59 & -4.29 & -4.99 & -0.10 & -17.052 .03 & 15.81 & $9.62^{\mathrm{d}}$ & 8.41 \\
\hline 3-acetylpyridine & -8.26 & -9.22 & -9.86 & -0.15 & -16.581 .98 & 15.38 & & 8.49 \\
\hline 3-chloroaniline & -5.82 & -5.93 & -6.13 & -3.40 & -13.281 .70 & 15.18 & & 11.16 \\
\hline 3-chlorophenol & -6.62 & -6.04 & -6.48 & -2.11 & -13.521 .64 & 14.43 & $4.81^{\mathrm{b}}$ & 10.22 \\
\hline 3-chloroprop-1-ene & -0.57 & 0.10 & -2.10 & 0.00 & $\begin{array}{lll}-8.37 & 0.88\end{array}$ & 9.69 & & 5.98 \\
\hline 3-chloropyridine & -4.01 & -4.95 & -4.77 & -0.10 & -13.701 .38 & 12.22 & $6.44^{\mathrm{b}}$ & 6.57 \\
\hline 3-cyanophenol & -9.65 & -9.62 & -9.08 & -2.20 & -16.011 .77 & 15.91 & & 10.60 \\
\hline 3-cyanopyridine & -6.75 & -8.25 & -7.31 & -0.10 & -16.141 .51 & 13.78 & & 7.01 \\
\hline 3-ethylphenol & -6.25 & -5.43 & -6.87 & -2.11 & -16.872 .28 & 18.14 & & 12.20 \\
\hline 3-ethylpyridine & -4.59 & -4.40 & -5.32 & -0.10 & -17.072 .02 & 16.07 & & 8.66 \\
\hline 3-formylpyridine & -7.10 & -9.06 & -10.19 & -0.15 & -14.381 .51 & 14.14 & & 8.12 \\
\hline 3-hydroxybenzaldehyde & -9.50 & -9.42 & -11.18 & -2.16 & -14.141 .77 & 16.29 & & 11.75 \\
\hline 3-methoxyaniline & -7.29 & -8.43 & -8.80 & -3.48 & -16.001 .97 & 17.89 & & 12.44 \\
\hline 3-methoxyphenol & -7.66 & -8.36 & -9.10 & -2.19 & -16.191 .91 & 17.21 & & 11.59 \\
\hline 3-methyl-1h-indole & -5.88 & -7.15 & -7.49 & -2.50 & -18.332 .33 & 18.84 & & 12.06 \\
\hline 3-methyl-but-1-ene & 1.83 & 2.60 & -0.57 & 0.00 & -11.141 .51 & 12.80 & & 7.66 \\
\hline 3-methylbut-1-ene & 1.82 & 2.60 & -0.57 & 0.00 & -11.141 .51 & 12.80 & & 7.66 \\
\hline 3-methylbutan-1-ol & -4.42 & -6.16 & -5.95 & -2.11 & -13.311 .77 & 13.44 & & 8.37 \\
\hline 3-methylbutan-2-one & -3.24 & -2.95 & -5.85 & -0.05 & -11.731 .71 & 12.98 & $7.49^{\mathrm{d}}$ & 7.61 \\
\hline
\end{tabular}


Table SI-8. (Continued)

\begin{tabular}{|c|c|c|c|c|c|c|c|c|}
\hline \multirow[b]{3}{*}{ Neutral compound } & \multicolumn{3}{|c|}{$\Delta G$} & \multicolumn{3}{|c|}{$\left[\frac{\mathrm{kcal}}{\mathrm{mol}}\right]$} & \multirow{3}{*}{$\frac{-T \Delta S^{*}}{\text { expt. }}$} & \multirow{3}{*}{$\frac{\left[\frac{\mathrm{kcal}}{\mathrm{mol}}\right]}{\text { calc. }}$} \\
\hline & \multirow[t]{2}{*}{ expt. $^{a}$} & \multicolumn{5}{|c|}{ calc. } & & \\
\hline & & tot & es & $\mathrm{hb}$ & disp comb & cav & & \\
\hline 3-methylbutanoic-acid & -6.09 & -7.68 & -9.09 & -2.16 & -12.161 .82 & 13.92 & & 9.66 \\
\hline 3-methylheptane & 2.97 & 1.33 & -0.06 & 0.00 & -19.163 .13 & 17.41 & & 8.97 \\
\hline 3-methylhexane & 2.71 & 0.16 & -0.05 & 0.00 & -17.302 .64 & 14.87 & & 7.14 \\
\hline 3-methylpentane & 2.51 & 0.80 & -0.04 & 0.00 & -14.992 .16 & 13.66 & & 6.78 \\
\hline 3-methylpyridine & -4.77 & -4.92 & -5.39 & -0.10 & -14.921 .54 & 13.94 & $7.90^{\mathrm{d}}$ & 7.39 \\
\hline 3-nitroaniline & -8.84 & -10.72 & -8.06 & -4.36 & -16.861 .90 & 16.66 & & 11.53 \\
\hline 3-nitrophenol & -9.62 & -10.04 & -7.78 & -3.07 & -17.011 .84 & 15.98 & $5.96^{\mathrm{b}}$ & 10.70 \\
\hline 3-nitrotoluene & -3.45 & -5.26 & -4.05 & -0.96 & -18.812 .19 & 16.36 & & 9.13 \\
\hline 3-phenylpropanol & -6.92 & -5.91 & -8.04 & -2.11 & -18.922 .73 & 20.42 & & 13.74 \\
\hline 3,3-dimethylbutan-2-one & -3.11 & -2.52 & -5.65 & -0.05 & -12.182 .14 & 13.22 & $8.22^{\mathrm{d}}$ & 7.93 \\
\hline 3,3-dimethylpentane & 2.56 & 0.49 & -0.04 & 0.00 & -15.382 .60 & 13.30 & & 6.58 \\
\hline 3,3,3-trimethoxypropionitrile & -6.40 & -7.77 & -9.69 & -0.34 & -17.102 .58 & 16.78 & & 9.76 \\
\hline 3,4-dimethylphenol & -6.50 & -7.00 & -6.78 & -2.11 & -17.112 .25 & 16.74 & & 10.73 \\
\hline 3,4-dimethylpyridine & -5.22 & -6.02 & -5.32 & -0.10 & -17.311 .99 & 14.71 & $7.72^{\mathrm{d}}$ & 7.24 \\
\hline 3,5-dimethylphenol & -6.27 & -6.01 & -7.00 & -2.11 & -17.082 .28 & 17.90 & & 11.82 \\
\hline 3,5-dimethylpyridine & -4.84 & -4.89 & -5.26 & -0.10 & -17.402 .01 & 15.85 & $9.02^{\mathrm{d}}$ & 8.25 \\
\hline 4-acetylpyridine & -7.62 & -9.44 & -10.00 & -0.15 & -16.561 .98 & 15.30 & & 8.42 \\
\hline 4-bromophenol & -7.13 & -7.28 & -6.93 & -2.11 & -14.391 .72 & 14.42 & $8.54^{\mathrm{b}}$ & 9.85 \\
\hline 4-bromotoluene & -1.39 & -1.62 & -2.63 & 0.00 & -16.082 .07 & 15.02 & & 8.53 \\
\hline 4-chloro-3-methylphenol & -6.79 & -6.78 & -6.51 & -2.11 & -15.892 .11 & 15.62 & & 10.48 \\
\hline 4-chloroaniline & -5.90 & -6.65 & -6.69 & -3.40 & -13.431 .70 & 15.18 & & 11.10 \\
\hline 4-chlorophenol & -7.03 & -6.53 & -6.90 & -2.11 & -13.591 .64 & 14.43 & & 10.19 \\
\hline 4-cyanophenol & -10.17 & -9.85 & -9.28 & -2.20 & -16.041 .77 & 15.91 & & 10.58 \\
\hline
\end{tabular}


Table SI-8. (Continued)

\begin{tabular}{|c|c|c|c|c|c|c|c|c|}
\hline \multirow[b]{3}{*}{ Neutral compound } & \multicolumn{6}{|c|}{$\Delta G\left[\frac{\mathrm{kcal}}{\mathrm{mol}}\right]$} & \multirow{3}{*}{$\frac{-T \Delta S}{\text { expt. }}$} & \multirow{3}{*}{$\frac{\text { * }\left[\frac{\mathrm{kcal}}{\mathrm{mol}}\right]}{\text { calc. }}$} \\
\hline & \multirow[t]{2}{*}{ expt. $^{a}$} & \multicolumn{5}{|c|}{ calc. } & & \\
\hline & & tot & es & $\mathrm{hb}$ & disp comb & cav & & \\
\hline 4-cyanopyridine & -6.02 & -8.35 & -7.37 & -0.10 & -16.101 .51 & 13.71 & & 6.96 \\
\hline 4-ethylphenol & -6.13 & -5.76 & -7.09 & -2.11 & -17.042 .28 & 18.20 & & 12.18 \\
\hline 4-ethylpyridine & -4.73 & -4.66 & -5.47 & -0.10 & -17.052 .01 & 15.94 & & 8.55 \\
\hline 4-ethyltoluene & -0.95 & -0.09 & -2.73 & 0.00 & -18.722 .64 & 18.71 & & 10.80 \\
\hline 4-fluorophenol & -6.19 & -5.89 & -6.94 & -2.23 & -12.611 .47 & 14.43 & & 10.47 \\
\hline 4-formylpyridine & -7.00 & -8.83 & -9.94 & -0.15 & -14.321 .51 & 14.07 & & 8.08 \\
\hline 4-hydroxybenzaldehyde & -8.83 & -10.48 & -12.14 & -2.16 & -14.241 .77 & 16.29 & & 11.71 \\
\hline 4-isopropyltoluene & -0.68 & -0.35 & -2.45 & 0.00 & -20.113 .11 & 19.10 & & 10.80 \\
\hline 4-methoxyacetophenone & -4.40 & -8.00 & -9.86 & -0.13 & -19.762 .72 & 19.03 & & 11.12 \\
\hline 4-methoxyaniline & -7.48 & -8.68 & -9.00 & -3.48 & -16.131 .97 & 17.96 & & 12.46 \\
\hline 4-methyl-1h-imidazole & -10.27 & -9.65 & -9.04 & -2.59 & -12.091 .11 & 12.96 & & 8.14 \\
\hline 4-methylacetophenone & -4.70 & -5.47 & -7.80 & -0.05 & -18.262 .60 & 18.04 & & 10.64 \\
\hline 4-methylbenzaldehyde & -4.27 & -4.85 & -7.82 & -0.05 & -15.912 .12 & 16.81 & & 10.33 \\
\hline 4-methylpentan-2-ol & -3.73 & -4.38 & -3.96 & -2.11 & -15.332 .24 & 14.77 & & 8.95 \\
\hline 4-methylpentan-2-one & -3.05 & -3.00 & -5.67 & -0.05 & -13.952 .18 & 14.49 & $7.77^{\mathrm{d}}$ & 8.30 \\
\hline 4-methylpyridine & -4.93 & -5.02 & -5.55 & -0.10 & -14.871 .53 & 13.96 & $7.78^{\mathrm{d}}$ & 7.42 \\
\hline 4-n-propylphenol & -5.90 & -5.61 & -7.06 & -2.11 & -19.182 .77 & 19.97 & & 13.16 \\
\hline 4-nitroaniline & -10.27 & -11.53 & -8.84 & -4.36 & -16.931 .90 & 16.69 & & 11.54 \\
\hline 4-nitrophenol & -10.64 & -10.40 & -8.11 & -3.07 & -17.021 .84 & 15.96 & $5.16^{\mathrm{b}}$ & 10.67 \\
\hline 4-tert-butylphenol & -5.91 & -6.64 & -7.52 & -2.11 & -18.833 .17 & 18.64 & & 12.35 \\
\hline acenaphthene & -3.15 & -3.76 & -4.92 & 0.00 & -22.852 .94 & 21.07 & $8.11^{\mathrm{b}}$ & 11.76 \\
\hline acetaldehyde & -3.50 & -3.50 & -6.31 & -0.05 & $\begin{array}{ll}-5.34 & 0.42\end{array}$ & 7.78 & & 5.04 \\
\hline acetic-acid & -6.69 & -8.15 & -9.83 & -2.16 & $\begin{array}{ll}-5.90 & 0.53\end{array}$ & 9.22 & $5.33^{\mathrm{d}}$ & 7.42 \\
\hline
\end{tabular}


Table SI-8. (Continued)

\begin{tabular}{|c|c|c|c|c|c|c|c|c|c|}
\hline \multirow[b]{3}{*}{ Neutral compound } & \multicolumn{7}{|c|}{$\Delta G\left[\frac{\mathrm{kcal}}{\mathrm{mol}}\right]$} & \multirow{3}{*}{$\frac{-T \Delta S^{*}}{\text { expt. }}$} & \multirow{3}{*}{$\frac{\left[\frac{\mathrm{kcal}}{\mathrm{mol}}\right.}{\text { calc. }}$} \\
\hline & \multirow[t]{2}{*}{ expt. $^{a}$} & \multicolumn{6}{|c|}{ calc. } & & \\
\hline & & tot & es & $\mathrm{hb}$ & disp & comb & cav & & \\
\hline acetonitrile & -3.88 & -4.61 & -4.55 & -0.11 & -7.22 & 0.41 & 6.86 & & 3.39 \\
\hline acetophenone & -4.58 & -5.52 & -7.90 & -0.05 & -15.87 & 2.12 & 16.19 & & 9.77 \\
\hline alpha-methylstyrene & -1.24 & -1.72 & -3.57 & 0.00 & -17.38 & 2.38 & 16.85 & & 9.85 \\
\hline aniline & -5.49 & -6.33 & -7.18 & -3.40 & -12.31 & 1.39 & 15.17 & & 11.14 \\
\hline anisole & -2.45 & -2.96 & -4.96 & -0.08 & -15.55 & 1.78 & 15.84 & & 9.29 \\
\hline anthracene & -3.95 & -5.39 & -6.23 & 0.00 & -25.29 & 3.46 & 22.68 & $9.45^{\mathrm{b}}$ & 13.03 \\
\hline azetidine & -5.56 & -5.71 & -5.32 & -3.40 & -9.52 & 0.73 & 11.80 & & 8.00 \\
\hline benzaldehyde & -4.02 & -4.84 & -7.87 & -0.05 & -13.57 & 1.64 & 15.01 & & 9.48 \\
\hline benzamide & -11.00 & -12.74 & -12.69 & -2.60 & -15.86 & 1.82 & 16.59 & & 10.72 \\
\hline benzene & -0.86 & -0.66 & -3.04 & 0.00 & -11.83 & 1.21 & 12.99 & $6.12^{\mathrm{c}}$ & 7.88 \\
\hline benzonitrile & -4.21 & -4.30 & -5.20 & -0.10 & -15.30 & 1.64 & 14.65 & & 8.41 \\
\hline benzotrifluoride & -0.25 & 0.03 & -3.73 & -0.37 & -12.67 & 2.05 & 14.76 & & 10.29 \\
\hline benzyl-alcohol & -6.62 & -5.50 & -7.40 & -2.11 & -14.41 & 1.76 & 16.65 & & 11.65 \\
\hline benzyl-bromide & -2.38 & -2.08 & -3.86 & 0.00 & -15.84 & 2.02 & 15.59 & & 9.19 \\
\hline benzyl-chloride & -1.93 & -1.59 & -4.03 & 0.00 & -15.09 & 1.95 & 15.57 & & 9.48 \\
\hline biphenyl & -2.66 & -0.16 & -4.82 & 0.00 & -20.66 & 3.09 & 22.23 & & 14.27 \\
\hline bromobenzene & -1.46 & -1.75 & -2.76 & 0.00 & -13.72 & 1.59 & 13.13 & & 7.62 \\
\hline bromoethane & -0.74 & -0.99 & -1.43 & 0.00 & -8.25 & 0.72 & 7.97 & & 4.00 \\
\hline bromomethane & -0.82 & -1.06 & -1.36 & 0.00 & -5.81 & 0.32 & 5.79 & $4.68^{\mathrm{b}}$ & 2.89 \\
\hline bromotrifluoromethane & 1.79 & 1.28 & -0.66 & -0.37 & -4.15 & 0.69 & 5.77 & & 4.57 \\
\hline but-1-ene & 1.38 & 2.10 & -0.62 & 0.00 & -9.58 & 1.07 & 11.23 & $6.73^{\mathrm{c}}$ & 6.65 \\
\hline but-1-yne & -0.16 & 0.04 & -1.27 & 0.00 & -9.95 & 0.91 & 10.35 & $3.06^{\mathrm{c}}$ & 5.57 \\
\hline buta-1,3-diene & 0.61 & 1.85 & -1.44 & 0.00 & -8.27 & 0.86 & 10.69 & $6.46^{\mathrm{c}}$ & 6.97 \\
\hline
\end{tabular}


Table SI-8. (Continued)

\begin{tabular}{|c|c|c|c|c|c|c|c|c|c|}
\hline \multirow[b]{3}{*}{ Neutral compound } & \multicolumn{7}{|c|}{$\Delta G\left[\frac{\mathrm{kcal}}{\mathrm{mol}}\right]$} & \multirow{3}{*}{$\frac{-T \Delta S^{*}}{\text { expt. }}$} & \multirow{3}{*}{$\frac{\left[\frac{\mathrm{kcal}}{\mathrm{mol}}\right.}{\text { calc. }}$} \\
\hline & \multirow[t]{2}{*}{ expt. $^{\mathrm{a}}$} & \multicolumn{6}{|c|}{ calc. } & & \\
\hline & & tot & es & $\mathrm{hb}$ & disp & comb & cav & & \\
\hline butan-1-ol & -4.72 & -4.41 & -5.61 & -2.11 & -11.34 & 1.35 & 13.30 & $9.43^{\mathrm{c}}$ & 8.90 \\
\hline butan-2-ol & -4.62 & -3.87 & -4.81 & -2.11 & -11.02 & 1.36 & 12.70 & $9.79^{\mathrm{c}}$ & 8.48 \\
\hline butanenitrile & -3.64 & -3.73 & -4.17 & -0.10 & -11.77 & 1.24 & 11.07 & & 5.67 \\
\hline butanoic-acid & -6.35 & -7.42 & -9.24 & -2.16 & -10.40 & 1.38 & 13.00 & $7.27^{\mathrm{d}}$ & 9.35 \\
\hline butanone & -3.71 & -3.19 & -6.12 & -0.05 & -9.98 & 1.25 & 11.71 & $6.61^{\mathrm{b}}$ & 7.02 \\
\hline butyraldehyde & -3.18 & -3.19 & -6.12 & -0.05 & -9.98 & 1.25 & 11.71 & & 7.02 \\
\hline chlorobenzene & -1.12 & -0.94 & -2.67 & 0.00 & -12.94 & 1.52 & 13.15 & & 7.97 \\
\hline chlorodifluoromethane & -0.50 & -2.17 & -2.84 & -0.25 & -3.85 & 0.96 & 3.80 & $6.93^{\mathrm{b}}$ & 2.89 \\
\hline chloroethane & -0.63 & -0.36 & -1.63 & 0.00 & -7.36 & 0.66 & 7.97 & & 4.39 \\
\hline chloroethylene & -0.59 & 0.15 & -1.47 & 0.00 & -5.85 & 0.50 & 6.97 & $5.15^{\mathrm{b}}$ & 4.41 \\
\hline chlorofluoromethane & -0.77 & -1.61 & -2.86 & -0.12 & -4.96 & 0.36 & 5.97 & $3.82^{\mathrm{b}}$ & 3.71 \\
\hline chloromethane & -0.55 & -0.46 & -1.58 & 0.00 & -4.93 & 0.27 & 5.78 & $4.38^{\mathrm{b}}$ & 3.28 \\
\hline cis-1,2-dimethylcyclohexane & 1.58 & -0.95 & -0.05 & 0.00 & -18.65 & 2.73 & 15.02 & & 6.69 \\
\hline cyanobenzene & -4.10 & -4.30 & -5.20 & -0.10 & -15.30 & 1.64 & 14.65 & & 8.41 \\
\hline cyclohepta-1,3,5-triene & -0.99 & -0.79 & -2.82 & 0.00 & -14.16 & 1.65 & 14.54 & $6.18^{\mathrm{c}}$ & 8.51 \\
\hline cycloheptanol & -5.48 & -7.46 & -5.36 & -2.11 & -17.75 & 2.37 & 15.39 & $11.77^{\mathrm{c}}$ & 8.48 \\
\hline cyclohexane & 1.23 & 0.21 & -0.04 & 0.00 & -15.33 & 1.83 & 13.76 & $8.54^{\mathrm{c}}$ & 6.46 \\
\hline cyclohexanol & -5.46 & -5.63 & -5.43 & -2.11 & -15.29 & 1.94 & 15.26 & $10.84^{\mathrm{c}}$ & 9.22 \\
\hline cyclohexanone & -4.91 & -4.33 & -6.00 & -0.07 & -14.30 & 1.83 & 14.22 & & 7.63 \\
\hline cyclohexene & 0.37 & 0.69 & -0.75 & 0.00 & -13.98 & 1.63 & 13.79 & $7.42^{\mathrm{c}}$ & 7.29 \\
\hline cyclohexylamine & -4.59 & -5.17 & -3.88 & -3.40 & -15.25 & 1.99 & 15.36 & & 9.45 \\
\hline cyclopentane & 1.20 & 0.70 & -0.07 & 0.00 & -13.38 & 1.39 & 12.76 & $7.05^{\mathrm{c}}$ & 6.15 \\
\hline cyclopentanol & -5.49 & -5.32 & -5.22 & -2.11 & -13.48 & 1.49 & 14.00 & $10.11^{\mathrm{c}}$ & 8.59 \\
\hline
\end{tabular}


Table SI-8. (Continued)

\begin{tabular}{|c|c|c|c|c|c|c|c|c|}
\hline \multirow[b]{3}{*}{ Neutral compound } & \multicolumn{3}{|c|}{$\Delta G$} & $G\left[\frac{\mathrm{kca}}{\mathrm{mo}}\right.$ & & & \multirow{3}{*}{$\frac{-T \Delta S^{*}}{\text { expt. }}$} & \multirow{3}{*}{$\frac{*\left[\frac{\mathrm{kcal}}{\mathrm{mol}}\right]}{\text { calc. }}$} \\
\hline & \multirow[t]{2}{*}{ expt. ${ }^{a}$} & \multicolumn{5}{|c|}{ calc. } & & \\
\hline & & tot & es & $\mathrm{hb}$ & disp comb & cav & & \\
\hline cyclopentanone & -4.70 & -3.70 & -5.84 & -0.07 & -12.421 .38 & 13.24 & & 7.32 \\
\hline cyclopentene & 0.56 & 0.60 & -0.87 & 0.00 & -11.891 .20 & 12.16 & $6.10^{\mathrm{c}}$ & 6.47 \\
\hline cyclopropane & 0.75 & 0.43 & -0.20 & 0.00 & $-9.12 \quad 0.61$ & 9.14 & $5.72^{\mathrm{c}}$ & 4.30 \\
\hline decan-1-ol & -3.64 & -3.97 & -5.61 & -2.11 & -24.864 .31 & 24.30 & & 14.80 \\
\hline decan-2-one & -2.34 & -2.22 & -5.79 & -0.05 & -23.354 .20 & 22.77 & & 13.00 \\
\hline di-isopropyl-sulfide & -1.21 & -2.71 & -2.76 & 0.00 & -17.192 .55 & 14.70 & & 7.13 \\
\hline di-n-butyl-ether & -0.83 & 0.70 & -2.60 & -0.08 & -21.493 .34 & 21.52 & & 11.99 \\
\hline di-n-propyl-ether & -1.16 & 0.85 & -2.62 & -0.08 & -16.712 .34 & 17.92 & & 10.19 \\
\hline di-n-propyl-sulfide & -1.28 & -0.46 & -2.39 & 0.00 & -18.142 .60 & 17.47 & $9.51^{\mathrm{e}}$ & 9.31 \\
\hline di-n-propylamine & -3.65 & -2.71 & -3.88 & -3.40 & -16.442 .40 & 18.60 & $13.01^{\mathrm{d}}$ & 12.15 \\
\hline dibromomethane & -1.96 & -2.58 & -1.51 & 0.00 & $\begin{array}{ll}-7.84 & 0.63\end{array}$ & 6.13 & & 2.74 \\
\hline dichloromethane & -1.31 & -1.56 & -2.04 & 0.00 & $-6.10 \quad 0.50$ & 6.07 & & 3.44 \\
\hline diethoxymethoxybenzene & -5.23 & -3.07 & -7.15 & -0.24 & -26.004 .19 & 26.13 & & 15.87 \\
\hline diethyl-disulfide & -1.64 & -2.55 & -2.89 & 0.00 & -16.382 .10 & 14.62 & $7.55^{\mathrm{e}}$ & 7.31 \\
\hline diethyl-ether & -1.59 & 0.05 & -2.92 & -0.08 & -12.191 .39 & 13.85 & & 7.89 \\
\hline diethyl-malonate & -6.00 & -6.74 & -12.04 & -0.27 & -18.863 .05 & 21.39 & & 13.54 \\
\hline diethyl-succinate & -5.71 & -5.25 & -11.19 & -0.27 & -20.863 .55 & 23.52 & & 14.95 \\
\hline diethyl-sulfide & -1.46 & -0.92 & -2.51 & 0.00 & -13.731 .63 & 13.69 & $7.55^{\mathrm{e}}$ & 7.20 \\
\hline diethylamine & -4.07 & -2.91 & -4.01 & -3.40 & -11.781 .44 & 14.84 & $10.87^{\mathrm{d}}$ & 10.19 \\
\hline diiodomethane & -2.49 & -2.51 & -3.18 & 0.00 & $-6.02 \quad 0.86$ & 5.83 & & 3.68 \\
\hline diisopropyl-ether & -0.53 & 0.50 & -2.29 & -0.08 & -15.382 .36 & 15.89 & & 8.96 \\
\hline diisopropylamine & -3.22 & -4.28 & -3.54 & -3.40 & -15.612 .35 & 15.91 & & 10.01 \\
\hline dimethoxymethane & -2.93 & -1.82 & -4.71 & -0.16 & -11.021 .02 & 13.05 & & 7.64 \\
\hline
\end{tabular}


Table SI-8. (Continued)

\begin{tabular}{|c|c|c|c|c|c|c|c|c|c|}
\hline \multirow[b]{3}{*}{ Neutral compound } & \multicolumn{7}{|c|}{$\Delta G\left[\frac{\mathrm{kcal}}{\mathrm{mol}}\right]$} & \multirow{3}{*}{$\frac{-T \Delta S^{*}}{\text { expt. }}$} & \multirow{3}{*}{$\frac{\left[\frac{\mathrm{kcal}}{\mathrm{mol}}\right]}{\text { calc. }}$} \\
\hline & \multirow[t]{2}{*}{ expt. $^{a}$} & \multicolumn{6}{|c|}{ calc. } & & \\
\hline & & tot & es & $\mathrm{hb}$ & disp & comb & cav & & \\
\hline dimethyl-ether & -1.91 & -3.02 & -3.49 & -0.08 & -9.55 & 0.49 & 9.61 & & 4.62 \\
\hline dimethyl-sulfate & -5.10 & -6.10 & -11.26 & -0.27 & -10.04 & 1.41 & 14.06 & & 9.72 \\
\hline dimethyl-sulfide & -1.61 & -1.27 & -2.25 & 0.00 & -9.18 & 0.70 & 9.47 & $5.31^{\mathrm{e}}$ & 4.82 \\
\hline dimethyl-sulfone & -10.08 & -8.78 & -13.28 & -0.11 & -8.21 & 0.98 & 11.83 & & 7.88 \\
\hline dimethyl-sulfoxide & -8.71 & -8.24 & -10.52 & -0.05 & -8.91 & 0.84 & 10.41 & $7.88^{\mathrm{d}}$ & 6.04 \\
\hline dimethylamine & -4.29 & -4.25 & -5.15 & -3.40 & -7.00 & 0.53 & 10.77 & & 8.11 \\
\hline E-1,2-dichloroethene & -0.78 & -0.22 & -1.34 & 0.00 & -7.15 & 0.76 & 7.51 & & 4.74 \\
\hline E-but-2-enal & -4.22 & -3.72 & -7.15 & -0.05 & -9.07 & 1.05 & 11.51 & & 7.42 \\
\hline E-hept-2-ene & 1.68 & 2.27 & -0.65 & 0.00 & -16.63 & 2.48 & 17.07 & & 9.67 \\
\hline E-hex-2-enal & -3.68 & -2.86 & -6.73 & -0.05 & -13.54 & 1.97 & 15.49 & & 9.62 \\
\hline E-oct-2-enal & -3.43 & -2.58 & -6.61 & -0.05 & -18.11 & 2.95 & 19.25 & & 11.65 \\
\hline ethanamide & -9.71 & -10.95 & -11.51 & -2.60 & -7.67 & 0.57 & 10.26 & $6.56^{\mathrm{f}}$ & 7.06 \\
\hline ethane & 1.83 & 1.67 & -0.02 & 0.00 & -6.13 & 0.43 & 7.39 & $5.87^{\mathrm{c}}$ & 3.99 \\
\hline ethanethiol & -1.14 & -1.86 & -3.20 & -0.01 & -8.77 & 0.69 & 9.43 & $5.16^{\mathrm{e}}$ & 5.00 \\
\hline ethanol & -5.00 & -4.56 & -5.76 & -2.11 & -6.72 & 0.50 & 9.53 & $6.97^{\mathrm{c}}$ & 7.01 \\
\hline ethene & 1.28 & 2.02 & -0.64 & 0.00 & -4.43 & 0.27 & 6.82 & $4.62^{\mathrm{c}}$ & 4.54 \\
\hline ethyl-acetate & -2.94 & -2.66 & -6.31 & -0.13 & -11.33 & 1.42 & 13.70 & $7.36^{\mathrm{b}}$ & 8.44 \\
\hline ethyl-benzoate & -3.64 & -3.83 & -7.59 & -0.13 & -19.37 & 2.79 & 20.48 & & 12.69 \\
\hline ethyl-butanoate & -2.49 & -2.30 & -6.08 & -0.13 & -15.93 & 2.38 & 17.47 & & 10.42 \\
\hline ethyl-formate & -2.56 & -2.57 & -6.14 & -0.13 & -8.92 & 0.95 & 11.69 & & 7.48 \\
\hline ethyl-hexanoate & -2.23 & -2.18 & -6.12 & -0.13 & -20.33 & 3.38 & 21.03 & & 12.36 \\
\hline ethyl-pentanoate & -2.49 & -2.12 & -6.25 & -0.13 & -17.93 & 2.87 & 19.33 & & 11.55 \\
\hline ethyl-phenyl-ether & -2.22 & -2.02 & -4.61 & -0.08 & -17.69 & 2.31 & 18.05 & & 10.68 \\
\hline
\end{tabular}


Table SI-8. (Continued)

\begin{tabular}{|c|c|c|c|c|c|c|c|c|c|}
\hline \multirow[b]{3}{*}{ Neutral compound } & \multicolumn{7}{|c|}{$\Delta G\left[\frac{\mathrm{kcal}}{\mathrm{mol}}\right]$} & \multirow{3}{*}{$\frac{-T \Delta S^{*}}{\text { expt. }}$} & \multirow{3}{*}{$\frac{P^{*}\left[\frac{\mathrm{kcal}}{\mathrm{mol}}\right]}{\text { calc. }}$} \\
\hline & \multirow[t]{2}{*}{ expt. $^{a}$} & \multicolumn{6}{|c|}{ calc. } & & \\
\hline & & tot & es & $\mathrm{hb}$ & disp & comb & cav & & \\
\hline ethyl-propanoate & -2.68 & -2.69 & -6.35 & -0.13 & -13.76 & 1.89 & 15.66 & & 9.42 \\
\hline ethylamine & -4.50 & -4.29 & -5.54 & -3.40 & -6.59 & 0.55 & 10.69 & $7.81^{\mathrm{d}}$ & 8.28 \\
\hline ethylbenzene & -0.79 & -0.15 & -2.86 & 0.00 & -16.31 & 2.15 & 16.87 & $8.22^{\mathrm{c}}$ & 9.94 \\
\hline fluorene & -3.35 & -4.13 & -5.63 & 0.00 & -23.94 & 3.24 & 22.19 & $8.75^{\mathrm{b}}$ & 12.80 \\
\hline fluorobenzene & -0.80 & -0.31 & -2.68 & -0.12 & -11.98 & 1.34 & 13.13 & & 8.22 \\
\hline fluoromethane & -0.22 & 0.13 & -2.03 & -0.12 & -3.71 & 0.15 & 5.84 & $3.51^{\mathrm{b}}$ & 3.76 \\
\hline formaldehyde & -2.75 & -3.28 & -6.27 & 0.00 & -2.56 & 0.10 & 5.45 & & 4.04 \\
\hline halothane & -0.11 & -0.06 & -1.86 & -0.37 & -6.84 & 1.93 & 7.09 & & 5.68 \\
\hline hept-1-ene & 1.66 & 2.39 & -0.64 & 0.00 & -16.19 & 2.48 & 16.74 & & 9.63 \\
\hline hept-1-yne & 0.60 & 0.51 & -1.22 & 0.00 & -16.52 & 2.30 & 15.96 & & 8.64 \\
\hline heptan-1-ol & -4.21 & -3.87 & -5.53 & -2.11 & -17.89 & 2.78 & 18.88 & $12.33^{\mathrm{c}}$ & 11.98 \\
\hline heptan-2-one & -3.04 & -2.56 & -5.88 & -0.05 & -16.64 & 2.69 & 17.33 & $9.96^{\mathrm{d}}$ & 10.04 \\
\hline heptan-4-one & -2.92 & -2.50 & -5.50 & -0.05 & -16.93 & 2.69 & 17.30 & $10.88^{\mathrm{d}}$ & 9.85 \\
\hline heptanal & -2.67 & -2.86 & -5.91 & -0.05 & -16.81 & 2.67 & 17.25 & & 9.93 \\
\hline hex-1-ene & 1.58 & 2.28 & -0.63 & 0.00 & -13.97 & 1.99 & 14.89 & $8.68^{\mathrm{c}}$ & 8.61 \\
\hline hex-1-yne & 0.29 & 0.14 & -1.24 & 0.00 & -14.47 & 1.82 & 14.03 & & 7.48 \\
\hline hexa-1,5-diene & 1.01 & 2.74 & -1.18 & 0.00 & -12.52 & 1.78 & 14.67 & & 9.24 \\
\hline hexafluoropropene & -3.76 & 2.41 & -1.51 & -0.75 & -5.82 & 1.38 & 9.12 & & 7.93 \\
\hline hexan-1-ol & -4.40 & -3.96 & -5.50 & -2.11 & -15.72 & 2.29 & 17.07 & $11.28^{\mathrm{c}}$ & 10.99 \\
\hline hexan-2-one & -3.28 & -2.88 & -5.91 & -0.05 & -14.49 & 2.20 & 15.37 & $8.50^{\mathrm{d}}$ & 8.89 \\
\hline hexan-3-ol & -4.06 & -3.83 & -4.61 & -2.11 & -15.30 & 2.29 & 15.89 & $11.97^{\mathrm{c}}$ & 10.06 \\
\hline hexanal & -2.81 & -2.57 & -6.05 & -0.05 & -14.27 & 2.18 & 15.62 & & 9.28 \\
\hline hexanoic-acid & -6.21 & -6.68 & -9.16 & -2.16 & -14.53 & 2.33 & 16.84 & & 11.63 \\
\hline
\end{tabular}


Table SI-8. (Continued)

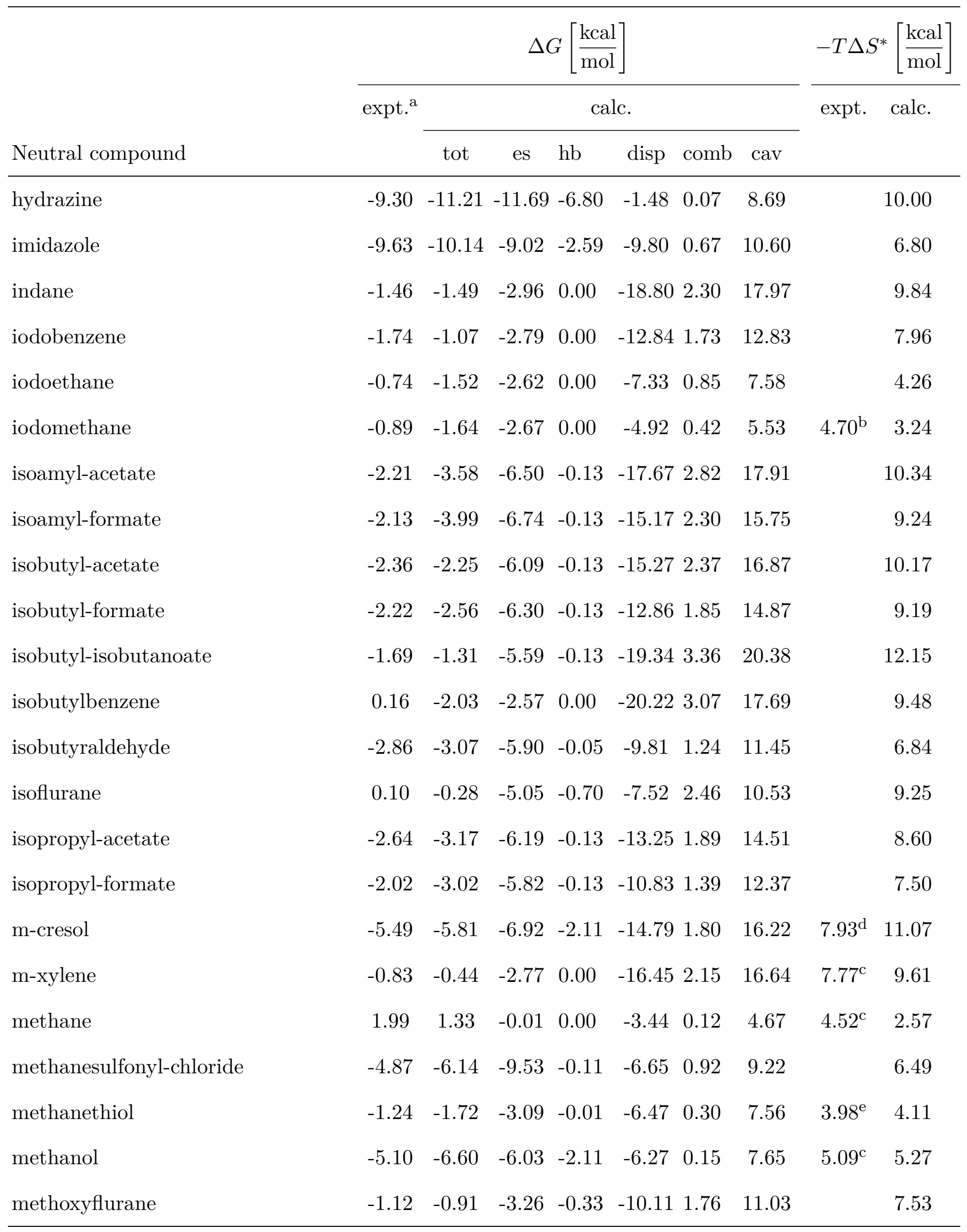


Table SI-8. (Continued)

\begin{tabular}{|c|c|c|c|c|c|c|c|c|}
\hline \multirow[b]{3}{*}{ Neutral compound } & \multicolumn{6}{|c|}{$\Delta G\left[\frac{\mathrm{kcal}}{\mathrm{mol}}\right]$} & \multirow{3}{*}{$\frac{-T \Delta S^{*}}{\text { expt. }}$} & \multirow{3}{*}{$\frac{\left[\frac{\mathrm{kcal}}{\mathrm{mol}}\right]}{\text { calc. }}$} \\
\hline & \multirow[t]{2}{*}{ expt. $^{a}$} & \multicolumn{5}{|c|}{ calc. } & & \\
\hline & & tot & es & $\mathrm{hb}$ & disp comb & cav & & \\
\hline methyl-acetate & -3.13 & -3.97 & -7.13 & -0.13 & $-9.05 \quad 0.95$ & 11.39 & $6.43^{\mathrm{b}}$ & 7.07 \\
\hline methyl-benzoate & -3.92 & -4.88 & -7.94 & -0.13 & -17.182 .27 & 18.10 & & 11.17 \\
\hline methyl-butanoate & -2.83 & -3.22 & -6.36 & -0.13 & -13.631 .86 & 15.05 & & 8.91 \\
\hline methyl-chloroacetate & -4.00 & -4.32 & -6.87 & -0.13 & -10.311 .20 & 11.79 & & 7.32 \\
\hline methyl-cyanoacetate & -6.72 & -7.53 & -9.33 & -0.23 & -12.441 .37 & 13.10 & & 7.74 \\
\hline methyl-cyclohexanecarboxylate & -3.30 & -5.08 & -5.80 & -0.13 & -19.852 .91 & 17.80 & & 9.18 \\
\hline methyl-cyclohexyl-ketone & -3.90 & -3.96 & -5.73 & -0.05 & -17.942 .77 & 16.99 & & 9.12 \\
\hline methyl-cyclopropanecarboxylate & -4.10 & -4.28 & -6.87 & -0.13 & -14.021 .62 & 15.13 & & 8.61 \\
\hline methyl-cyclopropyl-ketone & -4.61 & -4.00 & -5.60 & -0.05 & -12.831 .47 & 13.01 & & 6.95 \\
\hline methyl-ethyl-ether & -2.10 & -0.38 & -3.20 & -0.08 & $-9.78 \quad 0.92$ & 11.76 & & 6.79 \\
\hline methyl-ethyl-sulfide & -1.50 & -1.14 & -2.40 & 0.00 & -11.421 .15 & 11.54 & & 5.97 \\
\hline methyl-formate & -2.78 & -2.94 & -6.24 & -0.13 & $-6.52 \quad 0.52$ & 9.44 & & 6.25 \\
\hline methyl-hexanoate & -2.49 & -2.96 & -6.43 & -0.13 & -18.052 .84 & 18.81 & & 11.02 \\
\hline methyl-isopropyl-ether & -2.01 & -1.11 & -3.07 & -0.08 & -11.711 .35 & 12.40 & & 6.76 \\
\hline methyl-methanesulfonate & -4.87 & -6.34 & -11.46 & -0.11 & $-9.04 \quad 1.19$ & 13.07 & & 8.91 \\
\hline methyl-octanoate & -2.04 & -2.64 & -6.27 & -0.13 & -22.693 .85 & 22.61 & & 13.07 \\
\hline methyl-p-methoxybenzoate & -5.33 & -6.69 & -9.53 & -0.13 & -20.922 .88 & 21.01 & & 12.63 \\
\hline methyl-p-nitrobenzoate & -6.88 & -9.93 & -8.03 & -1.52 & -23.102 .81 & 19.89 & & 11.47 \\
\hline methyl-pentanoate & -2.56 & -2.73 & -6.53 & -0.13 & -15.602 .34 & 17.19 & & 10.31 \\
\hline methyl-propanoate & -2.93 & -3.41 & -6.68 & -0.13 & -11.381 .40 & 13.39 & & 8.11 \\
\hline methyl-propyl-ether & -1.66 & -0.33 & -3.28 & -0.08 & -12.081 .36 & 13.75 & & 7.84 \\
\hline methyl-t-butyl-ether & -2.21 & -0.39 & -2.90 & -0.08 & -12.281 .79 & 13.09 & & 7.44 \\
\hline methyl-tert-butyl-ether & -2.21 & -0.39 & -2.90 & -0.08 & -12.281 .79 & 13.09 & & 7.44 \\
\hline
\end{tabular}


Table SI-8. (Continued)

\begin{tabular}{|c|c|c|c|c|c|c|c|c|}
\hline \multirow[b]{3}{*}{ Neutral compound } & \multicolumn{6}{|c|}{$\Delta G\left[\frac{\mathrm{kcal}}{\mathrm{mol}}\right]$} & \multirow{3}{*}{$\frac{-T \Delta S^{*}}{\text { expt. }}$} & \multirow{3}{*}{$\frac{*\left[\frac{\mathrm{kcal}}{\mathrm{mol}}\right]}{\text { calc. }}$} \\
\hline & \multirow[t]{2}{*}{ expt. $^{a}$} & \multicolumn{5}{|c|}{ calc. } & & \\
\hline & & tot & es & $\mathrm{hb}$ & disp comb & cav & & \\
\hline methyl-trifluoroacetate & -1.10 & 0.20 & -4.86 & -0.51 & $-7.32 \quad 1.31$ & 11.57 & & 8.95 \\
\hline methyl-trimethylacetate & -2.40 & -1.80 & -5.87 & -0.13 & -13.382 .31 & 15.28 & & 9.50 \\
\hline methylamine & -4.55 & -1.63 & -5.91 & -0.90 & $-4.02 \quad 0.18$ & 9.02 & & 7.02 \\
\hline methylcyclohexane & 1.70 & 0.28 & -0.05 & 0.00 & -16.882 .29 & 14.92 & $12.02^{\mathrm{c}}$ & 7.13 \\
\hline methylcyclopentane & 1.59 & 0.77 & -0.07 & 0.00 & -15.261 .85 & 14.25 & & 6.96 \\
\hline morpholine & -7.17 & -7.06 & -6.91 & -3.48 & -12.671 .21 & 14.79 & $8.83^{\mathrm{b}}$ & 9.76 \\
\hline N-acetylpyrrolidine & -9.80 & -7.42 & -9.52 & -0.05 & -16.462 .09 & 16.53 & & 8.95 \\
\hline n-butane & 2.07 & 1.60 & -0.04 & -0.01 & -10.851 .27 & 11.23 & $7.66^{\mathrm{c}}$ & 5.87 \\
\hline n-butanethiol & -0.99 & -1.91 & -3.13 & -0.01 & -13.361 .56 & 13.02 & $7.08^{\mathrm{e}}$ & 6.74 \\
\hline n-butyl-acetate & -2.64 & -2.64 & -6.56 & -0.13 & -15.882 .38 & 17.56 & & 10.55 \\
\hline n-butylacetamide & -9.31 & -10.07 & -10.97 & -2.60 & -16.432 .38 & 17.55 & $11.53^{\mathrm{d}}$ & 10.92 \\
\hline n-butylamine & -4.24 & -4.48 & -5.63 & -3.40 & -11.031 .40 & 14.18 & $9.27^{\mathrm{d}}$ & 10.00 \\
\hline n-butylbenzene & -0.40 & 0.05 & -2.87 & 0.00 & -20.603 .14 & 20.38 & $10.02^{\mathrm{C}}$ & 11.89 \\
\hline n-decane & 3.16 & 2.10 & -0.08 & 0.00 & -24.654 .22 & 22.61 & & 11.98 \\
\hline n-heptane & 2.67 & 2.42 & -0.06 & 0.00 & -17.292 .69 & 17.07 & $10.46^{\mathrm{c}}$ & 9.24 \\
\hline n-heptylamine & -3.79 & -4.38 & -5.40 & -3.40 & -18.062 .85 & 19.63 & & 12.74 \\
\hline n-hexane & 2.48 & 1.93 & -0.05 & 0.00 & -15.282 .20 & 15.06 & $9.43^{\mathrm{c}}$ & 7.97 \\
\hline n-hexyl-acetate & -2.26 & -2.24 & -6.48 & -0.13 & -20.313 .38 & 21.30 & & 12.64 \\
\hline n-hexylamine & -3.95 & -4.14 & -5.39 & -3.40 & -15.572 .35 & 17.87 & $11.14^{\mathrm{d}}$ & 11.93 \\
\hline n-hexylbenzene & -0.04 & 0.19 & -2.89 & 0.00 & -25.144 .15 & 24.06 & $11.88^{\mathrm{c}}$ & 13.90 \\
\hline N-methylacetamide & -10.00 & -9.29 & -10.45 & -2.55 & $-9.95 \quad 1.00$ & 12.66 & $6.92^{\mathrm{f}}$ & 8.44 \\
\hline N-methylaniline & -4.69 & -6.57 & -6.79 & -3.40 & -15.041 .85 & 16.82 & & 11.62 \\
\hline N-methylmorpholine & -6.32 & -4.31 & -6.28 & -0.98 & -15.061 .67 & 16.34 & $9.49^{\mathrm{b}}$ & 9.62 \\
\hline
\end{tabular}


Table SI-8. (Continued)

\begin{tabular}{|c|c|c|c|c|c|c|c|c|}
\hline \multirow[b]{3}{*}{ Neutral compound } & \multicolumn{6}{|c|}{$\Delta G\left[\frac{\mathrm{kcal}}{\mathrm{mol}}\right]$} & \multirow[t]{3}{*}{$-T \Delta S$} & \multirow{3}{*}{$\frac{\text { * }\left[\frac{\mathrm{kcal}}{\mathrm{mol}}\right]}{\text { calc. }}$} \\
\hline & \multirow[t]{2}{*}{ expt. $^{a}$} & \multicolumn{5}{|c|}{ calc. } & & \\
\hline & & tot & es & $\mathrm{hb}$ & disp comb & cav & & \\
\hline N-methylpiperazine & -7.77 & -7.07 & -7.38 & -4.30 & -14.371 .72 & 17.26 & & 11.99 \\
\hline N-methylpiperidine & -3.88 & -3.94 & -3.85 & -0.90 & -16.341 .99 & 15.17 & $11.24^{\mathrm{b}}$ & 7.97 \\
\hline n-nonane & 3.13 & 2.03 & -0.07 & 0.00 & -22.323 .70 & 20.72 & & 10.96 \\
\hline n-octane & 2.88 & 2.16 & -0.06 & 0.00 & -19.883 .19 & 18.91 & $11.46^{\mathrm{c}}$ & 10.07 \\
\hline n-octylamine & -3.65 & -4.33 & -5.71 & -3.40 & -20.063 .35 & 21.48 & & 13.88 \\
\hline n-pentane & 2.32 & 1.84 & -0.04 & 0.00 & -13.041 .72 & 13.21 & $8.60^{\mathrm{c}}$ & 6.97 \\
\hline n-pentyl-acetate & -2.51 & -2.48 & -6.63 & -0.13 & -17.972 .87 & 19.39 & & 11.61 \\
\hline n-pentyl-propanoate & -2.11 & -2.17 & -6.32 & -0.13 & -20.423 .37 & 21.32 & & 12.58 \\
\hline n-pentylamine & -4.09 & -4.91 & -5.84 & -3.40 & -13.401 .87 & 15.87 & $10.16^{\mathrm{d}}$ & 10.76 \\
\hline n-pentylbenzene & -0.23 & -0.03 & -2.88 & 0.00 & -23.103 .65 & 22.31 & $10.83^{\mathrm{c}}$ & 12.88 \\
\hline n-pentylcyclopentane & 2.55 & 0.83 & -0.09 & 0.00 & -23.913 .81 & 21.03 & & 10.55 \\
\hline n-propanethiol & -1.06 & -1.54 & -3.04 & -0.01 & -11.041 .12 & 11.44 & $5.56^{\mathrm{e}}$ & 6.07 \\
\hline n-propyl-acetate & -2.79 & -2.51 & -6.42 & -0.13 & -13.571 .89 & 15.72 & & 9.59 \\
\hline n-propyl-butyrate & -2.28 & -2.08 & -5.97 & -0.13 & -18.272 .88 & 19.42 & & 11.48 \\
\hline n-propyl-formate & -2.48 & -2.72 & -6.56 & -0.13 & -11.121 .40 & 13.69 & & 8.61 \\
\hline n-propyl-propanoate & -2.44 & -2.40 & -6.25 & -0.13 & -16.012 .38 & 17.61 & & 10.52 \\
\hline n-propylamine & -4.39 & -4.25 & -5.40 & -3.40 & $-8.83 \quad 0.96$ & 12.42 & $8.33^{\mathrm{d}}$ & 9.10 \\
\hline n-propylbenzene & -0.53 & -0.10 & -2.83 & 0.00 & -18.512 .64 & 18.61 & $9.36^{\mathrm{c}}$ & 10.87 \\
\hline n-propylcyclopentane & 2.13 & 0.76 & -0.08 & 0.00 & -19.322 .80 & 17.35 & & 8.59 \\
\hline naphthalene & -2.40 & -3.15 & -4.83 & 0.00 & -18.572 .30 & 17.95 & $8.20^{\mathrm{b}}$ & 10.53 \\
\hline nitrobenzene & -4.12 & -5.28 & -4.28 & -1.25 & -16.231 .71 & 14.77 & & 8.69 \\
\hline nitroethane & -3.71 & -3.24 & -3.10 & -0.96 & -10.610 .84 & 10.59 & & 5.94 \\
\hline nitromethane & -4.02 & -3.52 & -3.29 & -0.96 & $\begin{array}{ll}-8.31 & 0.42\end{array}$ & 8.62 & $3.92^{\mathrm{b}}$ & 4.94 \\
\hline
\end{tabular}


Table SI-8. (Continued)

\begin{tabular}{|c|c|c|c|c|c|c|c|c|}
\hline \multirow[b]{3}{*}{ Neutral compound } & \multicolumn{6}{|c|}{$\Delta G\left[\frac{\mathrm{kcal}}{\mathrm{mol}}\right]$} & \multirow{3}{*}{$\frac{-T \Delta S^{*}}{\text { expt. }}$} & \multirow{3}{*}{$\frac{\left[\frac{\mathrm{kcal}}{\mathrm{mol}}\right]}{\text { calc. }}$} \\
\hline & \multirow[t]{2}{*}{ expt. $^{a}$} & \multicolumn{5}{|c|}{ calc. } & & \\
\hline & & tot & es & $\mathrm{hb}$ & disp comb & cav & & \\
\hline N,N-dimethyl-p-methylbenzamide & -9.76 & -5.97 & -10.88 & -0.05 & -21.213 .34 & 22.83 & & 14.14 \\
\hline N,N-dimethyl-p-nitrobenzamide & -11.95 & -11.42 & -11.58 & -1.06 & -24.973 .39 & 22.82 & & 13.32 \\
\hline N,N-dimethylaniline & -3.45 & -3.56 & -5.98 & -0.90 & -17.252 .32 & 18.25 & & 11.44 \\
\hline N,N-dimethylbenzamide & -9.29 & -6.02 & -11.08 & -0.05 & -18.922 .82 & 21.21 & & 13.44 \\
\hline N,N-dimethylformamide & -7.81 & -4.99 & -9.02 & -0.05 & $-9.54 \quad 0.97$ & 12.65 & $6.70^{\mathrm{f}}$ & 7.92 \\
\hline non-1-ene & 2.06 & 2.68 & -0.65 & 0.00 & -20.683 .48 & 20.53 & & 11.74 \\
\hline nonan-1-ol & -3.88 & -2.06 & -5.89 & 0.00 & -22.513 .80 & 22.54 & & 12.84 \\
\hline nonan-2-one & -2.49 & -2.46 & -5.84 & -0.05 & -21.273 .69 & 21.01 & $11.81^{\mathrm{d}}$ & 11.98 \\
\hline nonan-5-one & -2.64 & -1.87 & -5.46 & -0.05 & -21.093 .70 & 21.04 & $12.80^{\mathrm{d}}$ & 12.08 \\
\hline nonanal & -2.07 & -2.33 & -6.05 & -0.05 & -21.003 .68 & 21.10 & & 12.25 \\
\hline o-cresol & -5.87 & -5.97 & -6.73 & -2.11 & -14.681 .80 & 15.76 & $8.51^{\mathrm{d}}$ & 10.69 \\
\hline o-toluidine & -5.53 & -6.35 & -6.70 & -3.40 & -14.571 .85 & 16.48 & & 11.55 \\
\hline o-xylene & -0.90 & -1.66 & -2.80 & 0.00 & -16.452 .12 & 15.47 & $7.25^{\mathrm{c}}$ & 8.52 \\
\hline oct-1-ene & 1.92 & 2.43 & -0.63 & 0.00 & -18.592 .97 & 18.68 & $10.14^{\mathrm{c}}$ & 10.64 \\
\hline oct-1-yne & 0.71 & 0.48 & -1.24 & 0.00 & $-18.82 \quad 2.79$ & 17.75 & & 9.56 \\
\hline octan-1-ol & -4.09 & -4.80 & -6.05 & -2.11 & -20.643 .28 & 20.71 & $13.09^{\mathrm{c}}$ & 12.73 \\
\hline octan-2-one & -2.88 & -2.78 & -5.85 & -0.05 & -19.133 .19 & 19.06 & & 10.83 \\
\hline octanal & -2.29 & -2.55 & -6.13 & -0.05 & -18.783 .17 & 19.25 & & 11.21 \\
\hline p-cresol & -6.13 & -6.16 & -7.17 & -2.11 & $-14.81 \quad 1.80$ & 16.13 & $8.00^{\mathrm{d}}$ & 10.98 \\
\hline p-dibromobenzene & -2.30 & -2.55 & -2.29 & 0.00 & -15.651 .99 & 13.40 & & 7.48 \\
\hline p-toluidine & -5.57 & -6.24 & -6.99 & -3.40 & -14.621 .86 & 16.92 & & 11.94 \\
\hline p-xylene & -0.80 & -0.44 & -2.79 & 0.00 & -16.462 .15 & 16.67 & $7.83^{\mathrm{c}}$ & 9.63 \\
\hline pent-1-ene & 1.68 & 2.20 & -0.62 & 0.00 & -11.731 .51 & 13.03 & & 7.61 \\
\hline
\end{tabular}


Table SI-8. (Continued)

\begin{tabular}{|c|c|c|c|c|c|c|c|c|c|}
\hline \multirow[b]{3}{*}{ Neutral compound } & \multicolumn{7}{|c|}{$\Delta G\left[\frac{\mathrm{kcal}}{\mathrm{mol}}\right]$} & \multirow{3}{*}{$\frac{-T \Delta S^{*}}{\text { expt. }}$} & \multirow{3}{*}{$\frac{*\left[\frac{\mathrm{kcal}}{\mathrm{mol}}\right]}{\text { calc. }}$} \\
\hline & \multirow[t]{2}{*}{ expt. $^{a}$} & \multicolumn{6}{|c|}{ calc. } & & \\
\hline & & tot & es & $\mathrm{hb}$ & disp & comb & cav & & \\
\hline pent-1-yne & 0.01 & 0.08 & -1.23 & 0.00 & -12.32 & 1.35 & 12.27 & & 6.54 \\
\hline penta-1,4-diene & 0.93 & 2.30 & -1.33 & 0.00 & -10.53 & 1.31 & 12.85 & & 8.20 \\
\hline pentachloroethane & -1.39 & 0.86 & -1.29 & 0.00 & -7.80 & 2.45 & 7.50 & & 6.24 \\
\hline pentan-1-ol & -4.57 & -3.95 & -5.43 & -2.11 & -13.37 & 1.81 & 15.14 & $10.37^{\mathrm{c}}$ & 9.96 \\
\hline pentan-2-ol & -4.39 & -3.95 & -4.90 & -2.11 & -13.29 & 1.83 & 14.52 & & 9.41 \\
\hline pentan-2-one & -3.52 & -3.08 & -5.91 & -0.05 & -12.39 & 1.72 & 13.56 & $7.52^{\mathrm{d}}$ & 7.86 \\
\hline pentan-3-ol & -4.35 & -3.86 & -4.84 & -2.11 & -13.11 & 1.83 & 14.37 & $11.02^{\mathrm{c}}$ & 9.35 \\
\hline pentan-3-one & -3.41 & -2.90 & -5.54 & -0.05 & -12.61 & 1.72 & 13.59 & $7.81^{\mathrm{d}}$ & 7.77 \\
\hline pentanal & -3.03 & -2.76 & -5.98 & 0.00 & -12.05 & 1.70 & 13.58 & & 8.07 \\
\hline pentanenitrile & -3.52 & -3.51 & -4.17 & -0.10 & -14.01 & 1.70 & 13.08 & & 6.79 \\
\hline pentanoic-acid & -6.16 & -7.28 & -9.31 & -2.16 & -12.61 & 1.84 & 14.95 & & 10.45 \\
\hline phenanthrene & -3.88 & -5.98 & -6.29 & 0.00 & -25.40 & 3.43 & 22.29 & $8.52^{\mathrm{b}}$ & 12.60 \\
\hline phenol & -6.61 & -6.16 & -7.32 & -2.11 & -12.47 & 1.33 & 14.40 & $6.40^{\mathrm{d}}$ & 10.22 \\
\hline phenyl-formate & -3.82 & -4.37 & -8.39 & -0.13 & -14.29 & 1.86 & 16.59 & & 10.93 \\
\hline phenyl-methyl-sulfide & -2.73 & -2.35 & -3.72 & 0.00 & -16.73 & 2.07 & 16.04 & & 9.09 \\
\hline phenyl-trifluoroethyl-ether & -1.29 & -2.48 & -6.92 & -0.33 & -16.25 & 3.29 & 17.73 & & 12.40 \\
\hline piperazine & -7.40 & -9.77 & -7.87 & -6.80 & -12.13 & 1.26 & 15.76 & & 12.11 \\
\hline piperidine & -5.11 & -4.98 & -4.19 & -3.40 & -13.64 & 1.54 & 14.71 & $9.92^{\mathrm{b}}$ & 9.27 \\
\hline prop-2-en-1-ol & -5.03 & -3.63 & -5.67 & -2.11 & -7.72 & 0.72 & 11.15 & $7.37^{\mathrm{c}}$ & 8.51 \\
\hline propan-1-ol & -4.85 & -4.36 & -5.60 & -2.11 & -9.05 & 0.91 & 11.49 & $8.33^{\mathrm{c}}$ & 8.00 \\
\hline propan-2-ol & -4.74 & -4.33 & -5.34 & -2.11 & -8.87 & 0.93 & 11.07 & $8.64^{\mathrm{c}}$ & 7.69 \\
\hline propane & 1.96 & 1.63 & -0.03 & 0.00 & -8.57 & 0.83 & 9.40 & $6.83^{\mathrm{c}}$ & 4.95 \\
\hline propanenitrile & -3.84 & -3.97 & -4.26 & -0.11 & -9.53 & 0.81 & 9.13 & & 4.63 \\
\hline
\end{tabular}


Table SI-8. (Continued)

\begin{tabular}{|c|c|c|c|c|c|c|c|c|c|}
\hline \multirow[b]{3}{*}{ Neutral compound } & \multicolumn{3}{|c|}{$\Delta G$} & $G\left[\frac{\mathrm{kca}}{\mathrm{mc}}\right.$ & & & & \multirow{3}{*}{$\frac{-T \Delta S^{*}}{\text { expt. }}$} & \multirow{3}{*}{$\frac{\left[\frac{\mathrm{kcal}}{\mathrm{mol}}\right]}{\text { calc. }}$} \\
\hline & \multirow[t]{2}{*}{ expt. $^{a}$} & \multicolumn{6}{|c|}{ calc. } & & \\
\hline & & tot & es & $\mathrm{hb}$ & disp & comb & cav & & \\
\hline propanoic-acid & -6.46 & -8.12 & -9.76 & -2.16 & -8.29 & 0.93 & 11.16 & $6.44^{\mathrm{d}}$ & 8.34 \\
\hline propanone & -3.80 & -3.49 & -6.16 & -0.05 & -7.79 & 0.83 & 9.69 & $5.37^{\mathrm{b}}$ & 5.85 \\
\hline propene & 1.32 & 1.71 & -0.68 & 0.00 & -7.25 & 0.64 & 9.00 & $5.88^{\mathrm{c}}$ & 5.42 \\
\hline propionaldehyde & -3.43 & -3.16 & -6.00 & -0.05 & -7.76 & 0.81 & 9.84 & & 6.04 \\
\hline propyne & -0.48 & -0.39 & -1.36 & 0.00 & -7.61 & 0.51 & 8.08 & $3.75^{\mathrm{c}}$ & 4.31 \\
\hline pyrene & -4.52 & -7.64 & -7.09 & 0.00 & -28.39 & 3.83 & 24.01 & $10.08^{\mathrm{b}}$ & 13.27 \\
\hline pyridine & -4.69 & -5.24 & -5.69 & -0.10 & -12.53 & 1.09 & 12.00 & $6.62^{\mathrm{d}}$ & 6.45 \\
\hline pyrrole & -4.78 & -4.75 & -5.63 & -2.50 & -8.99 & 0.79 & 11.58 & & 8.24 \\
\hline pyrrolidine & -5.48 & -5.48 & -4.97 & -3.40 & -11.65 & 1.11 & 13.42 & $9.11^{\mathrm{b}}$ & 8.74 \\
\hline quinoline & -5.72 & -6.58 & -6.53 & -0.10 & -19.23 & 2.17 & 17.10 & & 9.25 \\
\hline sec-butylbenzene & -0.45 & -0.12 & -2.71 & 0.00 & -19.28 & 3.08 & 18.79 & & 10.93 \\
\hline styrene & -1.24 & -1.17 & -3.63 & 0.00 & -15.26 & 1.92 & 15.80 & & 9.62 \\
\hline teflurane & 0.50 & 0.07 & -2.39 & -0.50 & -5.62 & 1.75 & 6.84 & & 5.82 \\
\hline tert-butylbenzene & -0.44 & -0.49 & -2.83 & 0.00 & -18.12 & 3.04 & 17.42 & & 10.21 \\
\hline tetrachloroethene & 0.10 & -0.20 & -0.09 & 0.00 & -9.11 & 1.37 & 7.63 & & 4.85 \\
\hline tetrachloromethane & 0.08 & 1.05 & -0.18 & 0.00 & -6.05 & 1.12 & 6.15 & & 4.56 \\
\hline tetrafluoromethane & 3.12 & 1.77 & -0.67 & -0.50 & -3.11 & 0.48 & 5.58 & $6.12^{\mathrm{b}}$ & 4.66 \\
\hline tetrahydrofuran & -3.47 & -2.24 & -3.81 & -0.08 & -12.10 & 1.07 & 12.68 & $7.23^{\mathrm{b}}$ & 6.64 \\
\hline tetrahydropyran & -3.12 & -2.09 & -3.14 & -0.08 & -14.21 & 1.49 & 13.85 & $7.96^{\mathrm{b}}$ & 7.01 \\
\hline thiophene & -1.42 & -2.35 & -2.51 & 0.00 & -11.05 & 0.95 & 10.26 & & 5.44 \\
\hline thiophenol & -2.55 & -2.74 & -4.25 & -0.01 & -14.34 & 1.56 & 14.31 & & 8.31 \\
\hline toluene & -0.89 & -0.55 & -2.92 & -0.01 & -14.10 & 1.67 & 14.81 & $7.19^{\mathrm{c}}$ & 8.76 \\
\hline trans-1,4-dimethylcyclohexane & 2.11 & 0.73 & -0.06 & 0.00 & -18.24 & 2.76 & 16.27 & & 8.07 \\
\hline
\end{tabular}


Table SI-8. (Continued)

\begin{tabular}{|c|c|c|c|c|c|c|c|c|c|}
\hline \multirow[b]{3}{*}{ Neutral compound } & \multicolumn{7}{|c|}{$\Delta G\left[\frac{\mathrm{kcal}}{\mathrm{mol}}\right]$} & \multirow{3}{*}{$\begin{array}{l}-T \Delta S^{*} \\
\text { expt. }\end{array}$} & \multirow{3}{*}{$\frac{*\left[\frac{\mathrm{kcal}}{\mathrm{mol}}\right]}{\text { calc. }}$} \\
\hline & \multirow[t]{2}{*}{ expt. ${ }^{a}$} & \multicolumn{6}{|c|}{ calc. } & & \\
\hline & & tot & es & $\mathrm{hb}$ & disp & comb & cav & & \\
\hline triacetyl-glycerol & -8.84 & -10.65 & -16.72 & -4.37 & -14.96 & 3.97 & 21.44 & & 18.59 \\
\hline tribromomethane & -2.13 & -2.70 & -0.91 & 0.00 & -9.18 & 1.01 & 6.38 & & 2.88 \\
\hline trichloroethene & -0.44 & -0.56 & -1.00 & 0.00 & -8.12 & 1.06 & 7.51 & & 4.73 \\
\hline trichloromethane & -1.08 & -1.79 & -1.54 & 0.00 & -6.07 & 1.31 & 4.51 & & 2.90 \\
\hline triethyl-phosphate & -7.54 & -8.69 & -13.85 & -0.29 & -19.30 & 3.52 & 21.23 & & 13.37 \\
\hline triethylamine & -3.22 & -1.73 & -3.04 & -0.90 & -16.32 & 2.31 & 16.23 & & 9.17 \\
\hline trimethoxy-methane & -4.42 & -3.45 & -7.02 & -0.24 & -13.79 & 1.64 & 15.96 & & 9.58 \\
\hline trimethoxymethylbenzene & -4.04 & -2.42 & -8.26 & -0.24 & -19.88 & 3.56 & 22.40 & & 14.71 \\
\hline trimethyl-phosphate & -8.70 & -9.92 & -14.45 & -0.29 & -12.40 & 1.95 & 15.28 & & 10.07 \\
\hline trimethylamine & -3.20 & -1.43 & -4.28 & -0.90 & -9.67 & 0.94 & 12.48 & & 7.94 \\
\hline undecan-2-one & -2.15 & -2.09 & -6.12 & -0.05 & -25.45 & 4.73 & 24.80 & & 14.28 \\
\hline Z-1,2-dichloroethene & -1.17 & -1.45 & -2.08 & 0.00 & -7.30 & 0.75 & 7.17 & & 4.36 \\
\hline Z-pent-2-ene & 1.31 & 1.15 & -0.64 & 0.00 & -12.11 & 1.49 & 12.42 & & 6.81 \\
\hline RMSE & & 0.98 & & & & & & & 1.76 \\
\hline MAE & & 0.69 & & & & & & & 1.35 \\
\hline${ }^{\text {a Reference }{ }^{64} \text {. }}$ & & & & ${ }^{\mathrm{d}} \operatorname{Ref}$ & rence $\sqrt{10}$ & & & & \\
\hline${ }^{\mathrm{b}}$ Reference ${ }^{3}$. & & & & ${ }^{\mathrm{e}} \operatorname{Refe}$ & rence $\frac{15}{15}$. & & & & \\
\hline${ }^{\mathrm{c}}$ Reference ${ }^{14}$. & & & & ${ }^{\mathrm{f}} \mathrm{Refe}$ & ence ${ }^{1}$. & & & & \\
\hline
\end{tabular}


Table SI-8. (Continued)

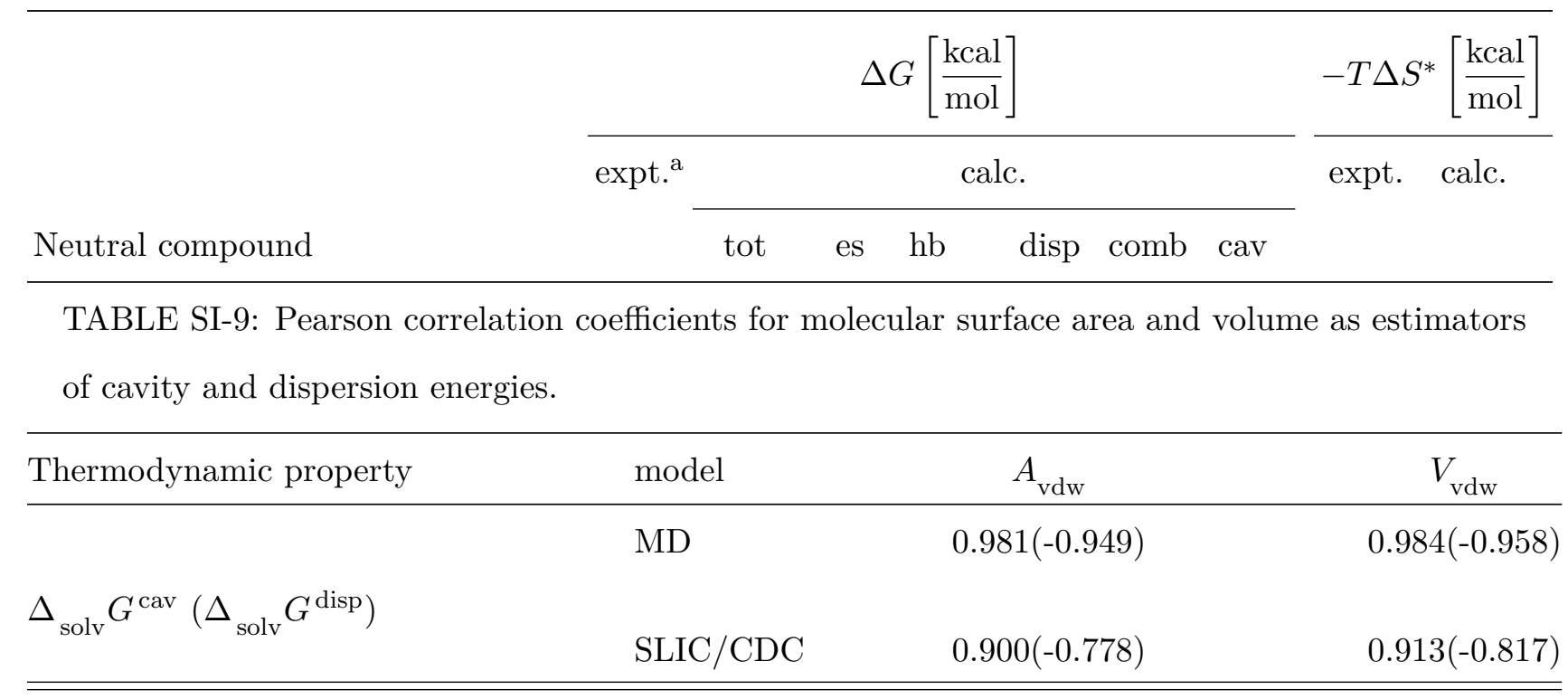

TABLE SI-10: Solvation Gibbs energies (in $\frac{\text { kcal }}{\text { mol }}$ ) for 12 amino-acid sidechain analogues in $[\mathrm{BMIM}][\mathrm{Tf} 2 \mathrm{~N}]$ as calculated using SLIC/SASA (SS), compared to MD obtained values of Paluch et al. .74 and Latif et al. $\underline{54}$ The dielectric constant that is used to parameterize SLIC/SASA is shown for each calculation.

\begin{tabular}{|c|c|c|c|c|c|c|}
\hline \multirow{2}{*}{$\begin{array}{l}\text { Solute } \\
\text { Dielectric constant }\end{array}$} & \multirow[t]{2}{*}{$\Delta G_{\mathrm{MD}, \text { Paluch }}$} & \multicolumn{2}{|c|}{$\Delta G_{\mathrm{SS}, \text { Paluch }}^{\text {solv }}$} & \multirow[t]{2}{*}{$\Delta G_{\mathrm{MD}, \text { Latif }}^{\text {solv }}$} & \multicolumn{2}{|c|}{$\Delta G_{\mathrm{SS}, \text { Latif }}^{\text {solv }}$} \\
\hline & & 9311.6 & $78_{13.85}$ & & 9311.6 & 7813.85 \\
\hline methane & 0.97 & 0.58 & 0.56 & 1.52 & 1.04 & 1.07 \\
\hline propane & -0.03 & -0.56 & -0.57 & 0.09 & -0.30 & -0.27 \\
\hline n-butane & -0.53 & -1.07 & -1.08 & -0.54 & -0.89 & -0.87 \\
\hline 2-methylpropane & -0.57 & -0.98 & -0.98 & -0.50 & -0.78 & -0.76 \\
\hline toluene & -4.26 & -3.79 & -3.75 & -4.61 & -3.57 & -3.57 \\
\hline methanol & -3.75 & -4.20 & -4.20 & -3.89 & -4.11 & -4.10 \\
\hline ethanol & -4.13 & -4.62 & -4.62 & -3.95 & -4.51 & -4.52 \\
\hline p-cresol & -7.83 & -7.61 & -7.59 & -8.97 & -8.91 & -8.87 \\
\hline methanethiol & -2.68 & -2.46 & -2.48 & -1.80 & -2.63 & -2.62 \\
\hline methyl-ethyl-sulfide & -3.75 & -2.95 & -2.92 & -3.00 & -2.67 & -2.66 \\
\hline
\end{tabular}


TABLE SI-10: Solvation Gibbs energies (in $\frac{\mathrm{kcal}}{\mathrm{mol}}$ ) for 12 amino-acid sidechain analogues in $[\mathrm{BMIM}][\mathrm{Tf} 2 \mathrm{~N}]$ as calculated using SLIC/SASA (SS), compared to MD obtained values of Paluch et al. .74 and Latif et al. $\underline{54}$ The dielectric constant that is used to parameterize SLIC/SASA is shown for each calculation.

\begin{tabular}{|c|c|c|c|c|c|c|}
\hline \multirow{2}{*}{$\begin{array}{l}\text { Solute } \\
\text { Dielectric constant }\end{array}$} & \multirow[t]{2}{*}{$\Delta G_{\mathrm{MD}, \text { Paluch }}$} & \multicolumn{2}{|c|}{$\Delta G_{\mathrm{SS}, \text { Paluch }}^{\text {solv }}$} & \multirow{2}{*}{$\Delta G_{\mathrm{MD}, \text { Latif }}^{\text {solv }}$} & \multicolumn{2}{|c|}{$\Delta G_{\mathrm{SS}, \text { Latif }}^{\text {solv }}$} \\
\hline & & 9311.6 & 7813.85 & & 9311.6 & 7813.85 \\
\hline ethanamide & -8.46 & -9.31 & -9.29 & -9.83 & -10.41 & -10.43 \\
\hline 3-methyl-1h-indole & -8.98 & -8.21 & -8.18 & -10.40 & -9.44 & -9.44 \\
\hline RMSE & & 0.55 & 0.56 & & 0.58 & 0.58 \\
\hline
\end{tabular}




\section{FIGURES}

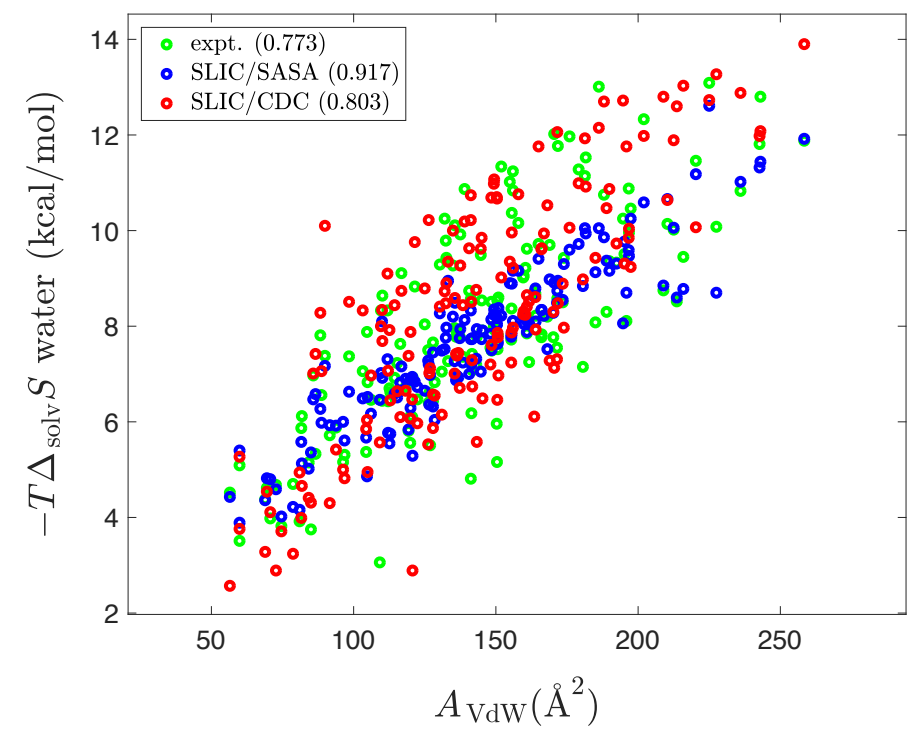

FIG. SI-1. SLIC/SASA, SLIC/CDC, and experimental solvation entropies (vertical axis) for the entropy-set plotted against van der Waals surface areas (horizontal axis). The numbers in parentheses are the Pearson correlation coefficients. 


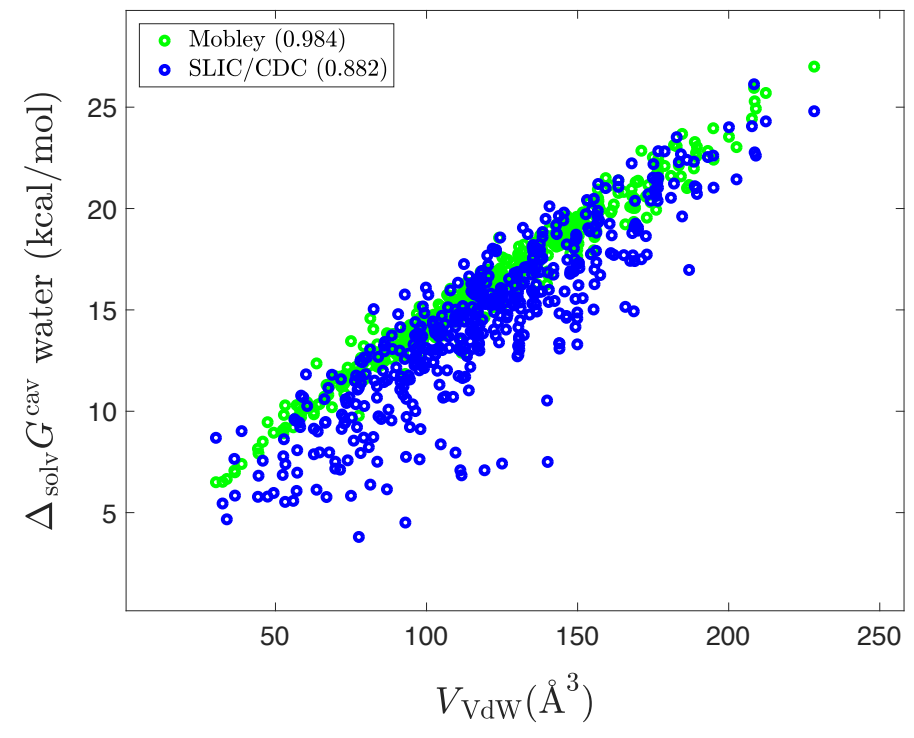

FIG. SI-2. Dependence of the cavity-formation part of the hydration Gibbs energy on the van der Waals volume for SLIC/CDC and Mobley calculations.

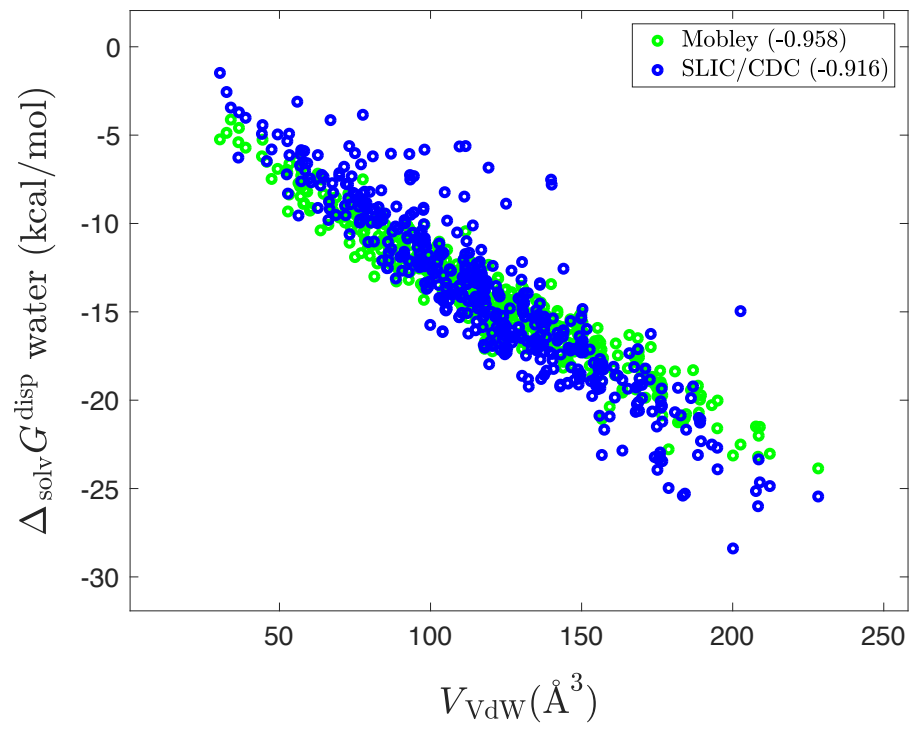

FIG. SI-3. Dependence of the dispersion component of the hydration Gibbs energy on the van der Waals volume for SLIC/CDC and Mobley calculations. 


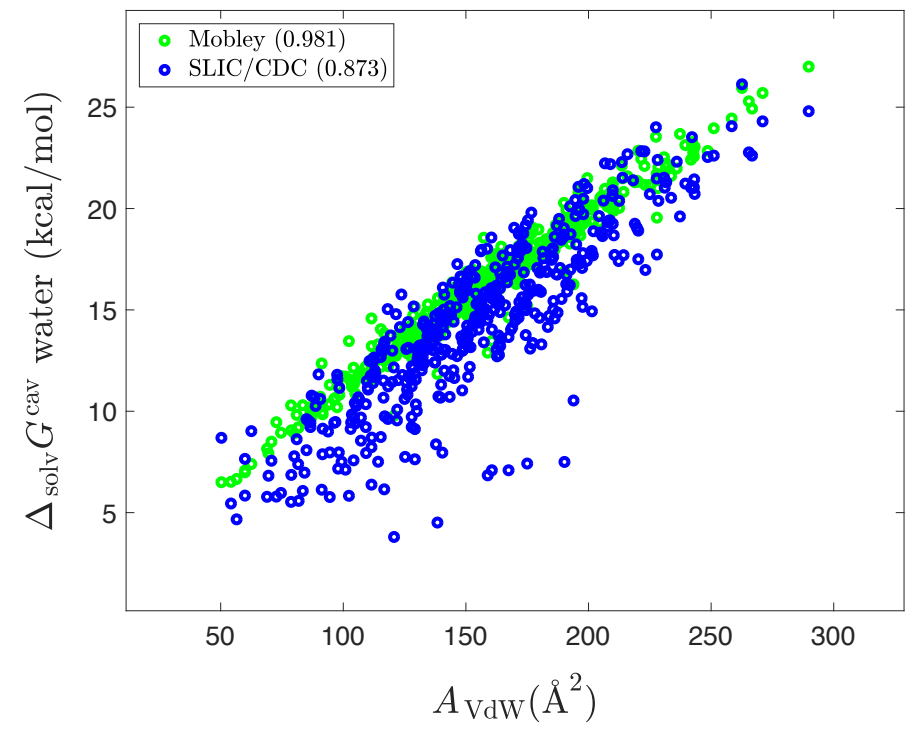

FIG. SI-4. Dependence of the cavity-formation part of the hydration Gibbs energy on the van der Waals area for SLIC/CDC and Mobley calculations.

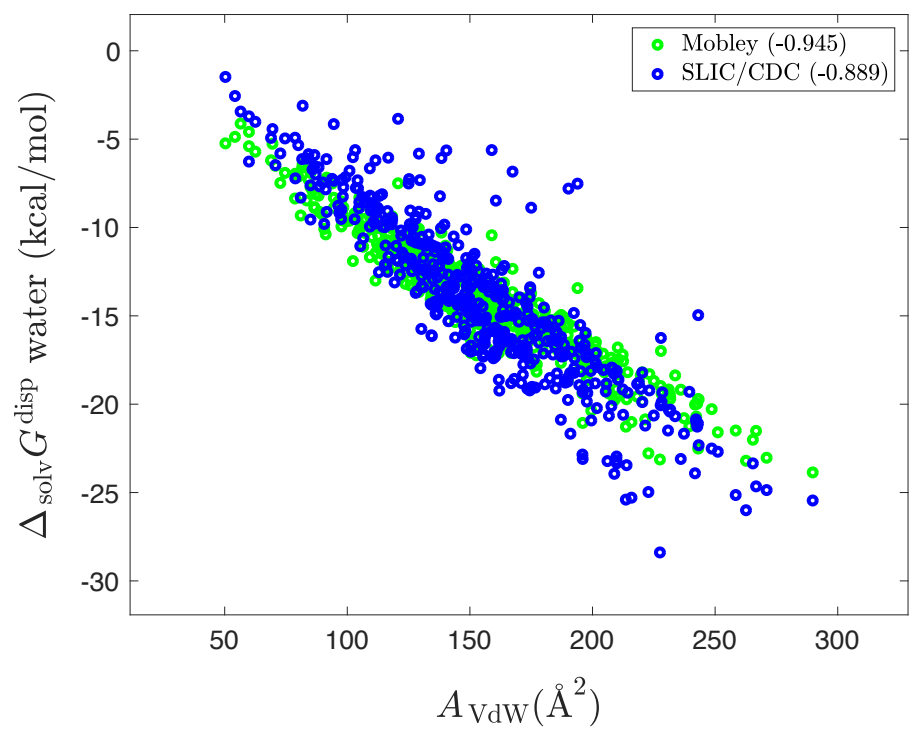

FIG. SI-5. Dependence of the dispersion component of the hydration Gibbs energy on the van der Waals area for SLIC/CDC and Mobley calculations. 


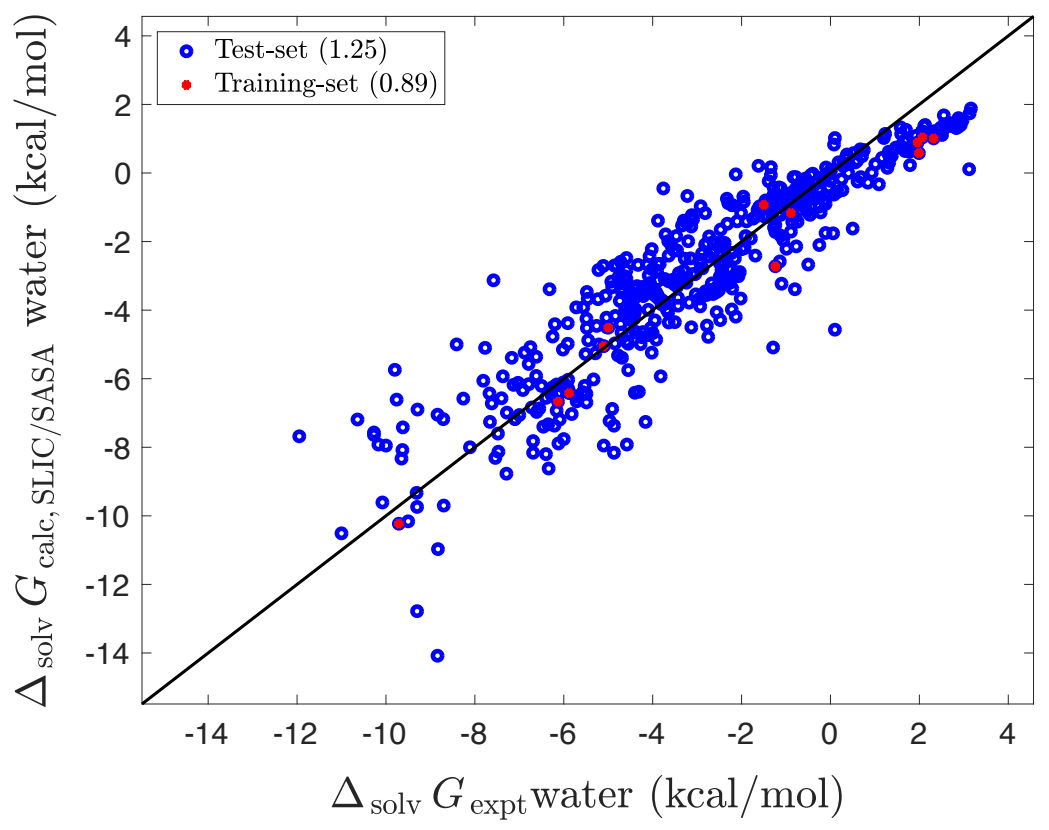

FIG. SI-6. SLIC/SASA predictions of hydration Gibbs energies (vertical axis) of 7 small molecules compared with experiments (horizontal axis). Blue and red circles denote test-set and training-set predictions, respectively. The optimization process was carried out in two steps where the electrostatic parameters were obtained by optimizing the SLIC electrostatic model against electrostatic component of hydration Gibbs energies from explicit-solvent MD. Next, the SLIC/SASA model was optimized against experimental data where the electrostatic parameters were held at their optimal values from the previous step. 


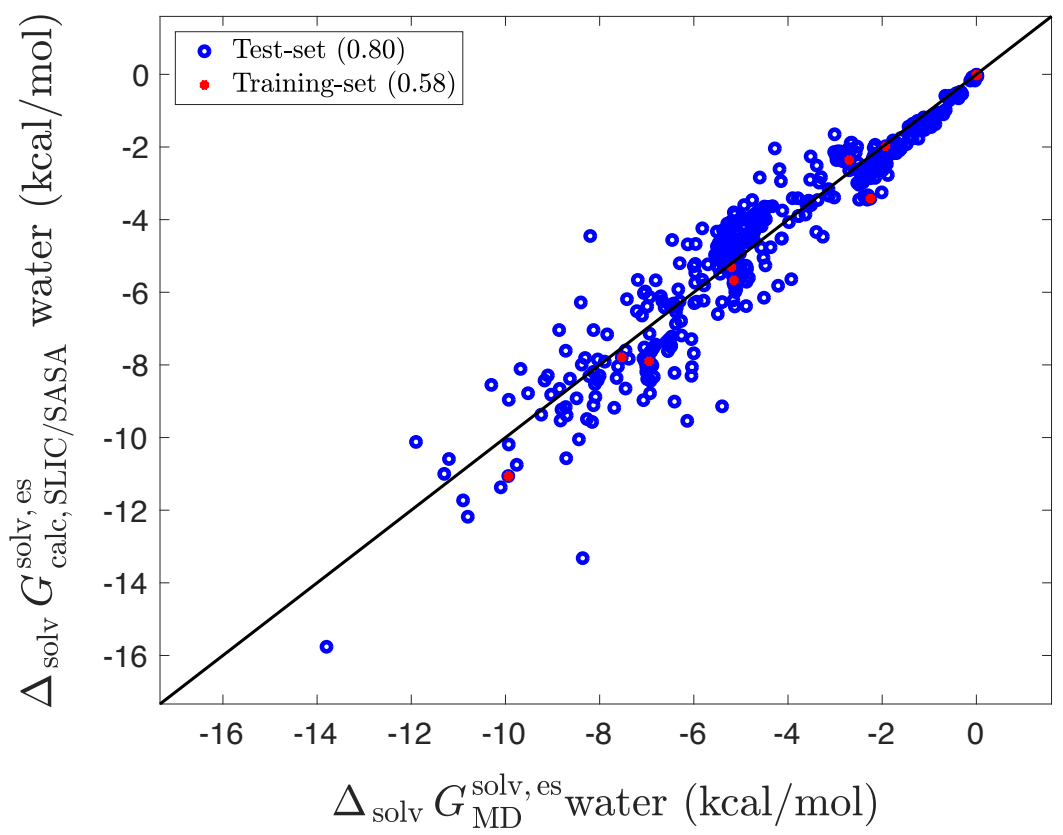

FIG. SI-7. SLIC/SASA predictions of the electrostatic component of hydration Gibbs energies (vertical axis) of 38 small molecules compared with experiments (horizontal axis). Blue and red circles denote test-set and training-set predictions, respectively. The optimization process was carried out in two steps where the electrostatic parameters were obtained by optimizing the SLIC electrostatic model against electrostatic component of hydration Gibbs energies from explicit-solvent MD. Next, the SLIC/SASA model was optimized against experimental data where the electrostatic parameters were held at their optimal values from the previous step. 


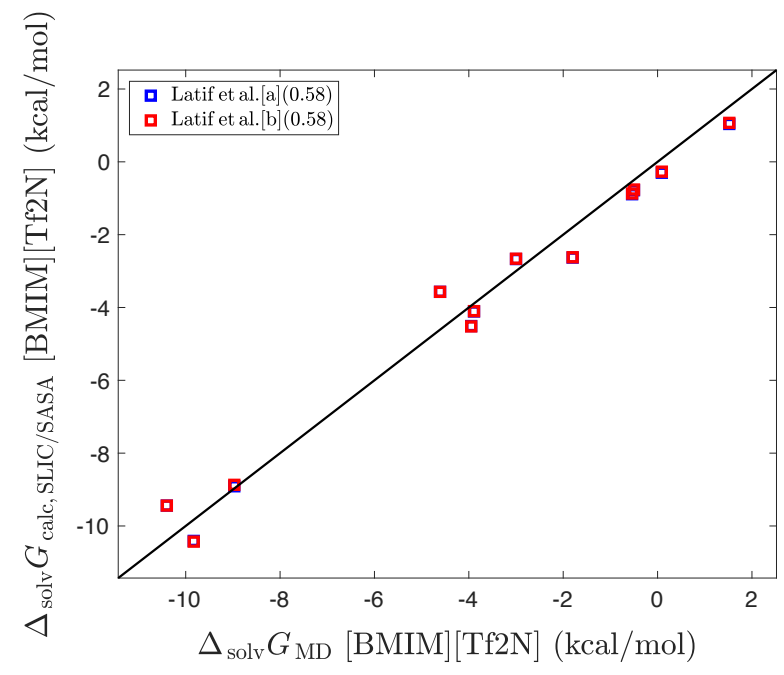

FIG. SI-8. Solvation Gibbs energies for 12 amino acid side chain analogues in [BMIM][TfO] calculated using SLIC (vertical axis), compared to MD (horizontal axis). SLIC was parameterized using the explicit-solvent MD results of Latif et al. $\underline{54}$ as reference. The letters in brackets denote the dielectric constant that was used; a:Reference $\frac{93}{3}$ and b:Reference $\underline{78}$. The numbers in parentheses are the RMS errors in $\mathrm{kcal} / \mathrm{mol}$.

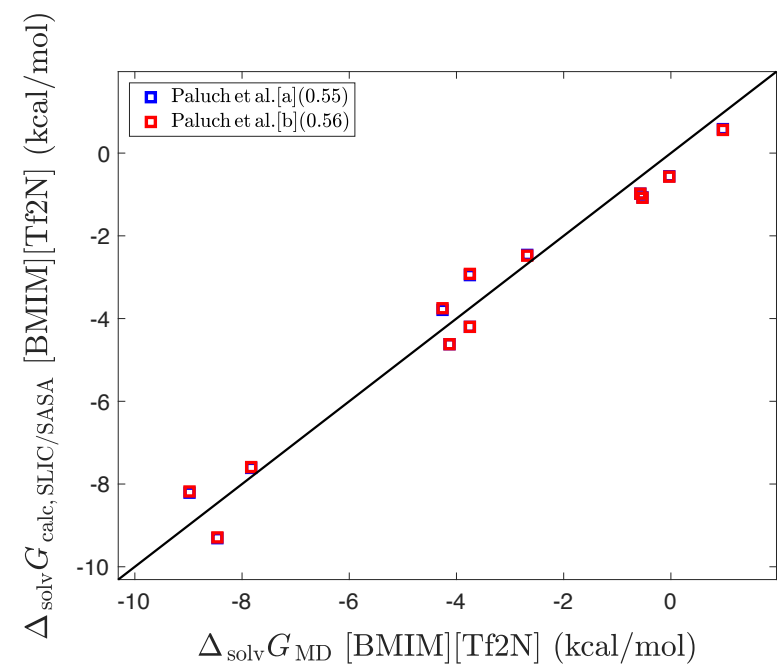

FIG. SI-9. Solvation Gibbs energies for 12 amino acid side chain analogues in [BMIM][Tf2N] calculated using SLIC (vertical axis), compared to MD (horizontal axis). SLIC was parameterized using the explicit-solvent MD results of Paluch et al. 74 as reference. The letters in brackets denote the dielectric constant that was used; a:Reference $\frac{93}{93}$ and b:Reference $\underline{78}$. The numbers in parentheses are the RMS errors in $\mathrm{kcal} / \mathrm{mol}$. 


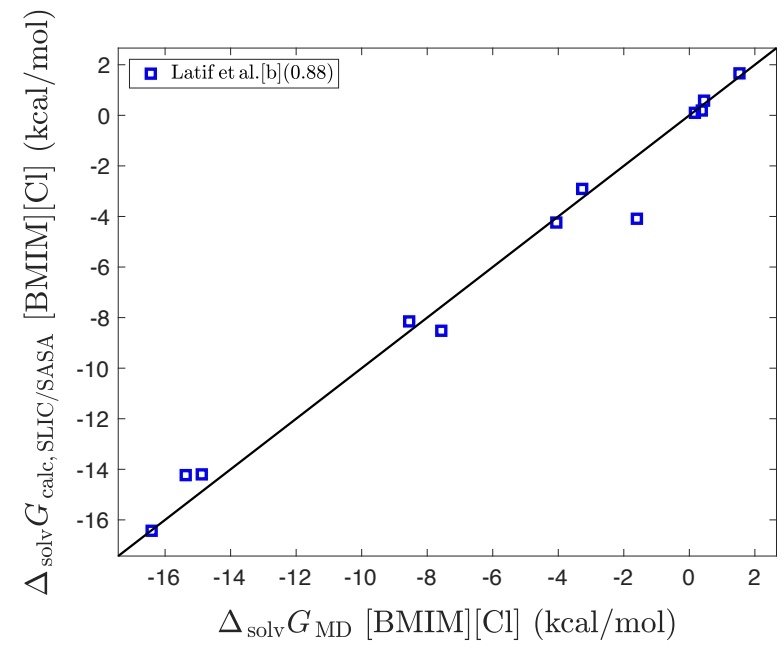

FIG. SI-10. Solvation Gibbs energies for 12 amino-acid sidechain analogues in [BMIM][Cl] calculated using SLIC (vertical axis), compared to MD (horizontal axis). SLIC/SASA was parameterized using the explicit-solvent MD results of Latif 54 et al. as reference. The letters in brackets denote the dielectric constant that was used; b:Reference 78 . The number in parentheses is the RMS error in $\mathrm{kcal} / \mathrm{mol}$.

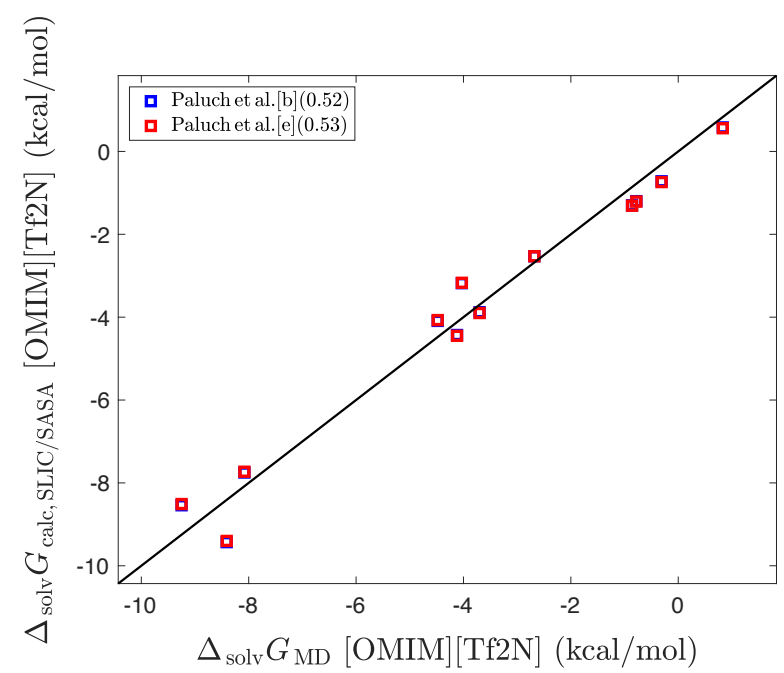

FIG. SI-11. Solvation Gibbs energies for 12 amino acid side chain analogues in [OMIM][Tf2N] calculated using SLIC (vertical axis), compared to MD (horizontal axis). SLIC/SASA was parameterized using the explicit-solvent MD results of Paluch et al. .74 as reference. The letters in brackets denote the dielectric constant that was used; b:Reference $\frac{78}{8}$ and e:Reference 12 . The numbers in parentheses are the RMS errors in $\mathrm{kcal} / \mathrm{mol}$. 


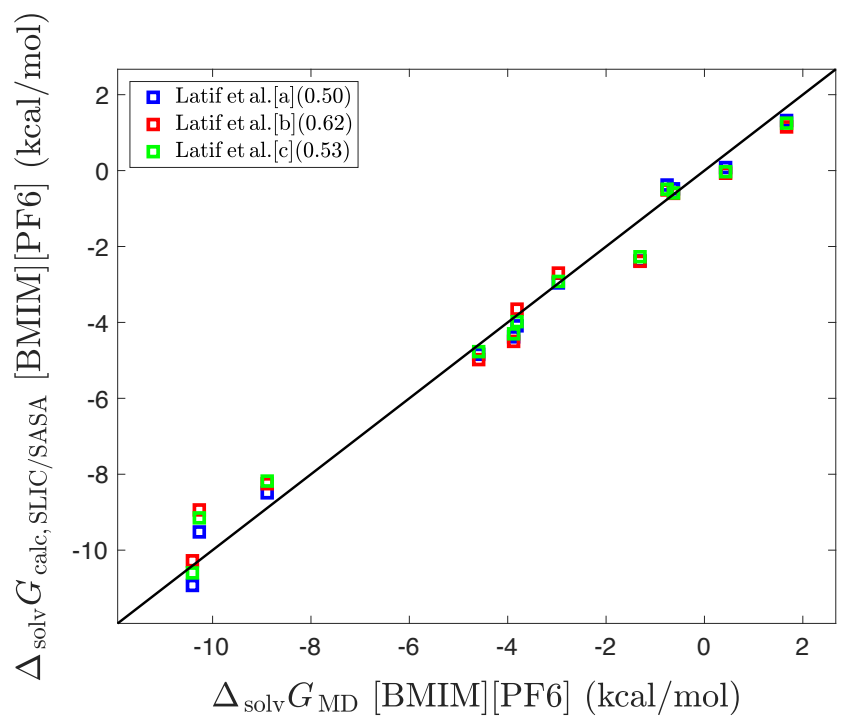

FIG. SI-12. Solvation Gibbs energies for 12 amino acid side chain analogues in [BMIM][PF6] calculated using SLIC (vertical axis), compared to MD (horizontal axis). SLIC/SASA was parameterized using the explicit-solvent MD results of Latif et al. 54 as reference. The letters in brackets denote the dielectric constant that was used; a:Reference $\underline{93}$, b:Reference $\frac{78}{6}$ and c:Reference $\underline{43}$. The numbers in parentheses are the RMS errors in $\mathrm{kcal} / \mathrm{mol}$.

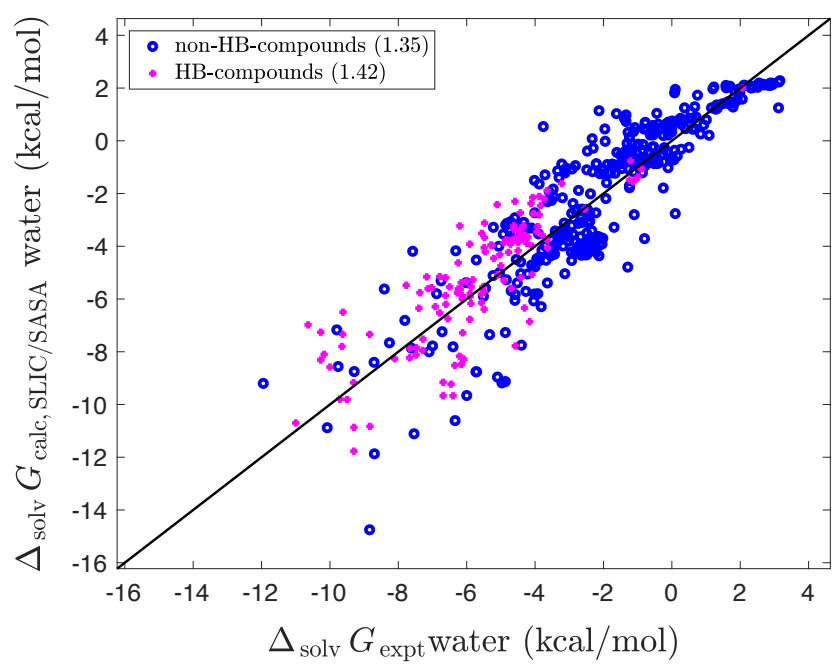

FIG. SI-13. Performance of SLIC/SASA in predicting hydration Gibbs energies for hydrogenbonding and non-hydrogen-bonding small molecules. 


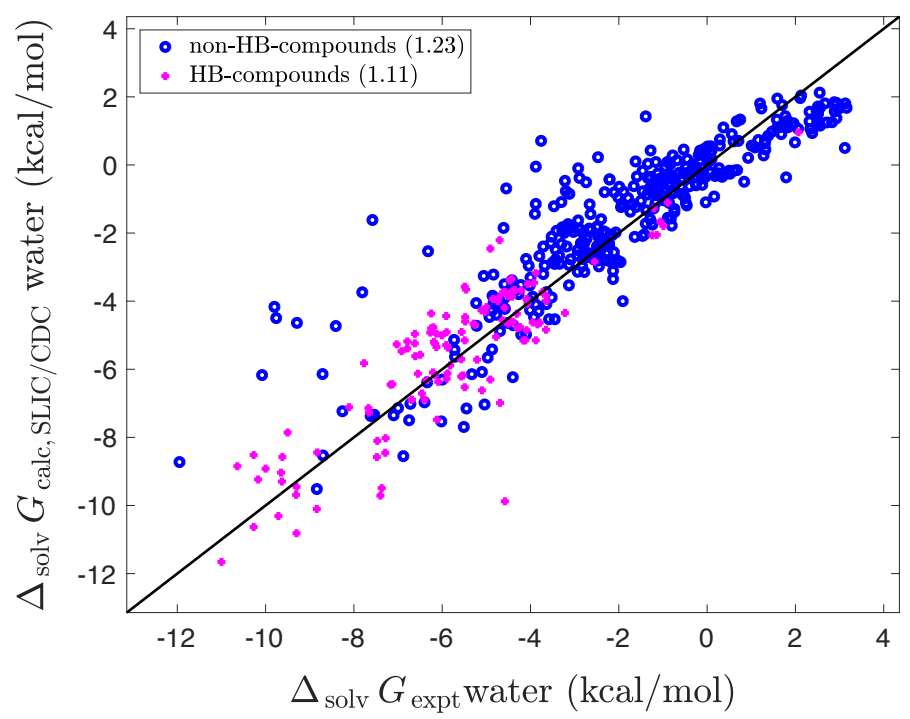

FIG. SI-14. Performance of SLIC/CDC in predicting hydration Gibbs energies for hydrogenbonding and non-hydrogen-bonding small molecules.

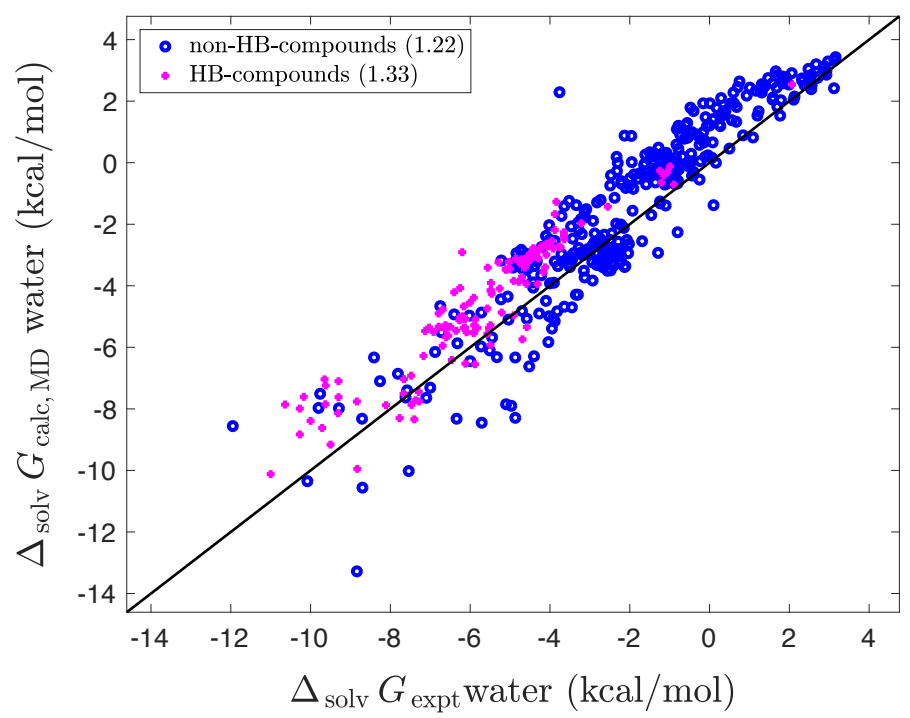

FIG. SI-15. Explicit-solvent MD simulation results of hydration Gibbs energy calculations shown for hydrogen-bonding and non-hydrogen-bonding small molecules $\underline{64}$. 


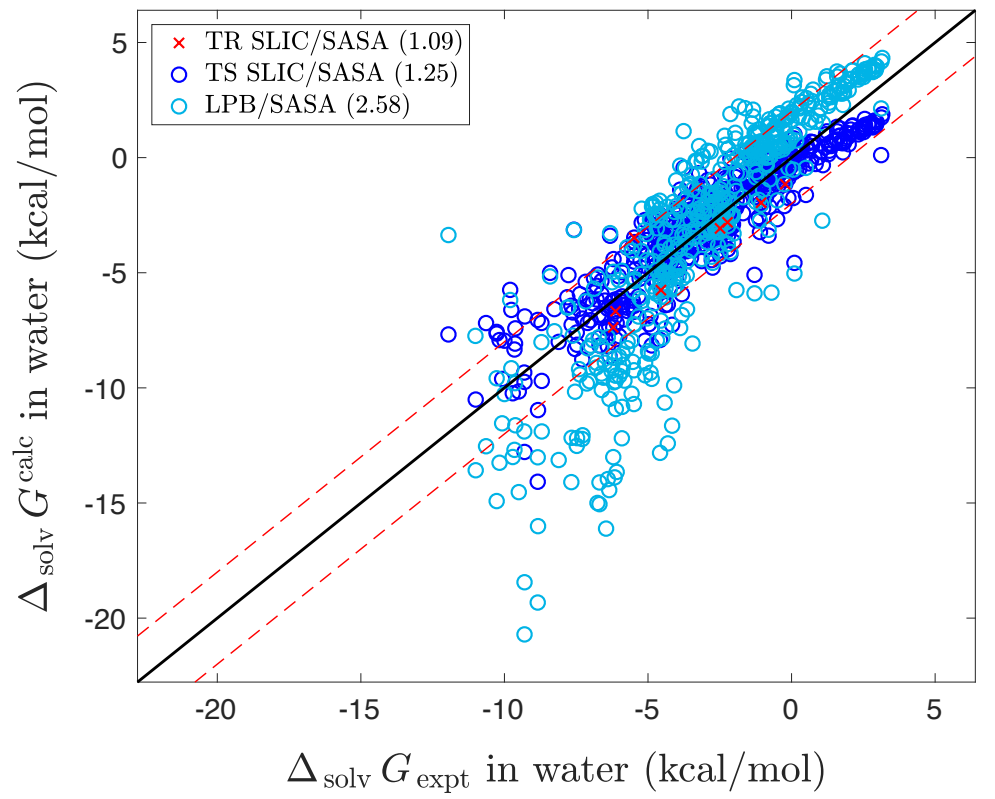

FIG. SI-16. SLIC/SASA and LPB/SASA predictions of solvation Gibbs energies for 9 small molecules in trimethylbenzene.

\section{SI REFERENCES}

1 G. Barone and C. Giancola. Peptide-peptide interactions in water and concentrated urea solutions. Pure Appl. Chem., 62(1):57-68, 1990.

2 A. Ben-Naim and Y. Marcus. Solvation thermodynamics of nonionic solutes. J. Chem. Phys., 81(4):2016-2027, 1984.

3 S. Cabani, P. Gianni, V. Mollica, and L. Lepori. Group contributions to the thermodynamic properties of non-ionic organic solutes in dilute aqueous solution. J. Solution Chem., 10:563-595, 1981.

4 J. Florián and A. Warshel. Calculations of hydration entropies of hydrophobic, polar, and ionic solutes in the framework of the Langevin dipoles solvation model. J. Phys. Chem. B, 103:10282-10288, 1999.

5 E. Gallicchio, M. M. Kubo, and R. M. Levy. Enthalpy-entropy and cavity decomposition of alkane hydration free energies: numerical results and implications for theories of hydrophobic solvation. J. Phys. Chem. B, 104(26):6271-6285, 2000. 
6 B. Hess and N. F. A. van der Vegt. Hydration thermodynamic properties of amino acid analogues: a systematic comparison of biomolecular force fields and water models. J. Phys. Chem. $B, 110: 17616-17626,2006$.

7 J. Hunger, A. Stoppa, S. Schrödle, G. Hefter, R., and Buchner. Temperature dependence of the dielectric properties and dynamics of ionic liquids. ChemPhysChem, 10(4):723-733, 2011.

8 M. A. M. Latif, N. Micaêlo, and M. B. A. Rahman. Solvation free energies in [bmim]-based ionic liquids: anion effect toward solvation of amino acid side chain analogues. Chem. Phys. Lett., 615:69-74, 2014.

9 G. I. Makhatadze and P. L. Privalov. Partial specific heat capacity of benzene and of toluene in aqueous solution determined calorimetrically for a broad temperature range. J. Chem. Thermodyn, 20(4):405-412, 1988.

10 G. I. Makhatadze and P. L. Privalov. Heat capacity of proteins: I. partial molar heat capacity of individual amino acid residues in aqueous solution: hydration effect. J. Mol. Biol., 213(2):375$384,1990$.

11 D. L. Mobley, C. I. Bayly, M. D. Cooper, M. R. Shirts, and K. A. Dill. Small molecule hydration free energies in explicit solvent: an extensive test of fixed-charge atomistic simulations. J. Chem. Theory Comput., 5(2):350-358, 2009.

12 K. Nakamura and T. Shikata. Systematic dielectric and nmr study of the ionic liquid 1-alkyl3-methyl imidazolium. ChemPhysChem, 11(1):285-294, 2010.

13 A. S. Paluch, C. A. Vitter, J. K. Shah, and E. J. Maginn. A comparison of the solvation thermodynamics of amino acid analogues in water, 1-octanol and 1-n-alkyl-3-methylimidazolium bis(trifluormethylsulfonyl)imide ionic liquids by molecular simulation. J. Chem. Phys., 137(18):184504, 2012.

14 A. V. Plyasunov and E. L. Shock. Thermodynamic functions of hydration of hydrocarbons at $298.15 \mathrm{k}$ and $0.1 \mathrm{mpa}$. Geochim. Cosmochim. Acta, 64(3):439-468, 2000.

15 N. V. Plyasunova, A. V. Plyasunov, and E. L. Shock. Group contribution values for the thermodynamic functions of hydration at $298.15 \mathrm{k}, 0.1 \mathrm{mpa} .2$. aliphatic thiols, alkyl sulfides, and polysulfides. J. Chem. Eng. Data, 50(1):246-253, 2005.

16 A. Rybinska-Fryca, A. Sosnowska, and T. Puzyn. Prediction of dielectric constant of ionic liquids. J. Mol. Liq, 260:57-64, 2018. 
17 C. Wakai, A. Oleinikova, M. Ott, and H. Weingärtner. How polar are ionic liquids? determination of the static dielectric constant of an imidazolium-based ionic liquid by microwave dielectric spectroscopy. J. Phys. Chem. B, 109:17028-17030, 2005. 